DANIEL TOURINHO SENTONE

DESENVOLVIMENTO DE MÉTODO PARA MEDIDA DE PERMEABILIDADE SUPERFICIAL DE REVESTIMENTOS DE ARGAMASSA

Dissertação apresentada à Escola

Politécnica da Universidade de São

Paulo para obtenção do título de Mestre em Engenharia 
DANIEL TOURINHO SENTONE

\section{DESENVOLVIMENTO DE MÉTODO PARA MEDIDA DE PERMEABILIDADE SUPERFICIAL DE REVESTIMENTOS DE ARGAMASSA}

Dissertação apresentada à Escola Politécnica da Universidade de São Paulo para obtenção do título de Mestre em Engenharia

Área de Concentração:

Engenharia de Construção Civil e Urbana

Orientador:

Prof. Dr. Rafael Giuliano Pileggi 
Este exemplar foi revisado e alterado em relação a versão original, sob responsabilidade única do autor e com a anuência de seu orientador.

São Paulo, de de 2011.

Assinatura do autor

Assinatura do orientador

\section{FICHA CATALOGRÁFICA}

\section{Sentone, Daniel Tourinho}

Desenvolvimento de método para medida de permeabilidade superficial de revestimento de argamassa / D.T. Sentone. -- São Paulo, 2011.

$139 \mathrm{p}$.

Dissertação (Mestrado) - Escola Politécnica da Universidade de São Paulo. Departamento de Engenharia de Construção Civil.

1. Argamassa (Permeabilidade; Revestimentos) 2. Microes trutura 3. Vaccum-Decay I. Universidade de São Paulo. Escola Politécnica. Departamento de Engenharia de Construção Civil II. t. 


\section{AGRADECIMENTOS}

Ao Departamento de Construção Civil da Escola Politécnica da USP, em especial ao meu orientador Rafael Giuliano Pileggi pelas palavras de reflexão e pelos puxões de orelha, nos momentos mais difíceis e complicados dessa jornada. Ao amigo Fábio Alonso Cardoso pelas inúmeras revisões e complementações ofertadas tanto ao plano experimental quanto ao texto deste e de outros trabalhos. Ao professor Vanderley John pelas contribuições realizadas durante todo o processo de desenvolvimento e também no momento da Qualificação desta dissertação. A professora Maria Alba pela sinceridade nas palavras, tanto na hora de elogiar quanto nos momentos de críticas construtivas.

Além desses, agradeço também aos professores Dr. Antonio Figueiredo, Dr. Racine Prado, Dr. Orestes Gonçalves, Dr. Alex Abiko, Dr. Vahan Agopyan, Dr. Francisco Cardoso, Dr. Silvio Melhado, Dr. Ubiraci Souza, Dr. Túlio Bittencourt, Dr. Douglas Gouvêa e Dr. Faiçal Massad, que estiveram presentes direta e indiretamente no desenvolvimento dessa dissertação, através do processo de aprendizagem dos mais variados tipos de conhecimentos, seja durante o decorrer das disciplinas ou dos bate papos informais de corredores.

A toda a equipe de suporte da Engenharia Civil da Escola Politécnica da USP, em especial os colaboradores e companheiros: Engracia e Paulinho (PCC); Edson, Patrícia e Rogério (Informática); Adilson, Reginaldo e Renata (PCC); Antônio e Joaquim (PEF); Wandréa e Fátima Domingues (PPGEC e SPG). Agradecimento especial ao amigo Mário Takeashi que, além dar todo o apoio técnico e logístico, foi ouvinte de inúmeras histórias, lamentações e comemorações ao longo do mestrado.

A Associação Brasileiro de Concreto Portland (ABCP), na figura do Eng. Claudio Oliveira e Eng. Mariana Marchioni, pelo incentivo e empréstimo do equipamento para o desenvolvimento dessa dissertação.

A todos do Laboratório de Microestrutura que sempre deram todo o operacional necessário para realizar todo e qualquer tipo operação. Especial agradecimento aos estagiários: Márcia Takahashi (amiga de dentro e fora do laboratório), Dayse, Marina e Caio. Aos meus grandes amigos Brunoro, Eliane e Cléber que, além de serem companheiros de pós-graduação, foram também os simpáticos moradores da 
famigerada "república" da San Remo. Aos amigos pessoais ainda da época de iniciação científica, Flavio Maranhão e Cris. Aos amigos Waleska, dos tempos de graduação, Jorge Lyra, Carlos Carbone e Engler Medina.

Aos grandes amigos de ontem, hoje e sempre: Luiz Carlos Geremias, Guilhermo Lucca Teixeira, Ricardo Sbalqueiro, André Cortez, Diogo Pereira, Giovani e Humberto Paulini, Fernando Starepravo, Leoncio, entre tantos outros que esqueço de mencionar nesse momento.

Aos meus pais, Flavio e Katia (em memória), e aos meus irmãos Flavio e Nicolas por todo o apoio, carinho e motivação, essenciais no desenvolvimento desta e de todas as outras fases de minha vida.

Ao meu avô Plinio e minha tia Lucia, por todo o suporte emocional e espiritual dado, seja em questões profissionais ou pessoais, em todos os momentos desta jornada.

A toda minha grande família: avós, primos e tios. Também, a todos os Lopes (sogros, cunhados, sobrinhos agregados, etc) que me receberam como integrante da família e sempre me assistiram e apoiaram em mais essa etapa.

A minha amada esposa Joany, por ser essa pessoa especial, referência de esforço, profissionalismo e seriedade em tudo aquilo que se propõe a fazer. Sem você nada disso teria sido possível. Muito obrigado por fazer parte da minha vida ontem, hoje e sempre. 


\section{RESUMO}

O fenômeno de permeabilidade refere-se à capacidade com que um fluido é transportado através de um meio poroso, impulsionado por gradiente de pressão entre material e meio externo. Agentes de degradação são conduzidos ao interior de argamassas e concretos impelidos através desse tipo de fenômeno. Por isso, considera-se a permeabilidade como um dos principais parâmetros referentes à durabilidade e vida útil de materiais cimentíceos. Além disso, como esse tipo de avaliação está relacionada às condições estruturais dos vazios capilares de meios porosos, esse tipo de medida pode prover um indicativo das condições da estrutura porosa das argamassas no momento do ensaio, servindo ainda como método de controle de qualidade e avaliação dos processos de produção.

Portanto, um novo procedimento de medida de permeabilidade ao ar, em regime de escoamento transiente, foi desenvolvido para avaliação de argamassas de revestimento através do método de vaccum-decay. O potencial do processo não se restringe apenas na determinação dos parâmetros clássicos de permeabilidade propostos por Henry Darcy, mas na avaliação das curvas de recuperação de pressão que fornecem um indicativo das condições microestruturais de diferentes estados da estrutura de meios porosos. Além disso, trata-se de um ensaio portátil, não destrutivo e de baixo custo de implementação para avaliação de argamassas de revestimento in situ.

Para isto, neste trabalho foram avaliadas diferentes formulações de argamassas de revestimento tanto em ambiente laboratorial quanto in situ, em comparação ao método de Cembureau (referência), e se existe relação entre as duas diferentes condições apresentadas. A profundidade alcançada por esse tipo de ensaio superficial é uma dúvida recorrente deste e outros ensaios da mesma natureza, e por isso foi considerado no desenvolvimento do plano experimental. Ainda, as diferentes direções do fluxo de ar durante a medida podem influenciar as determinações das permeabilidades para diferentes configurações de experimentos realizados, e também foram considerados no desenvolvimento do método.

Palavras-Chave: Argamassas. Microestrutura. Permeabilidade. Vaccum-Decay. 


\begin{abstract}
The phenomenon of permeability refers to the ability with which a fluid is transported through a porous medium, driven by pressure gradient between the material and the external environment. Degradation agents are conducted to the interior of mortar and concrete driven through such a phenomenon. Therefore, it is the permeability as a key parameters for durability and shelf life of cementitious materials. Moreover, as this type of evaluation is related to structural conditions of the empty capillary porous media, this type of measurement can provide an indication of the conditions of the porous structure of mortar at the time of trial, still serving as a method of quality control and evaluation production processes.
\end{abstract}

Therefore, a new procedure for measuring air permeability in transient flow regime was developed for evaluation of mortar coating by the method of vacuum-decay. The potential of the process is not restricted only to the determination of the classical parameters of permeability proposed by Henry Darcy, but in assessing the recovery curve of pressure that provide a clear picture of states in different microstructural conditions of the structure of porous media. Moreover, it is a portable test, nondestructive and low cost of implementation for evaluation of mortar coating in situ.

For this reason, this study evaluated different formulations of mortar coating in laboratory environment and in situ, compared to the Cembureau method (reference), and if there is a relationship between two different conditions presented. The depth reached by this type of test surface is a recurring question of this and other tests of the same nature, and so was considered in developing of this experimental plan. Still, the different directions of air flow during the measurement can influence the determination of permeability for different configurations of the experiments, and were also considered in developing the method.

Keywords: Mortars. Microstructure. Permeability. Vacuum-Decay. 


\section{SUMÁRIO}

FICHA CATALOGRÁFICA

1 INTRODUÇÃO

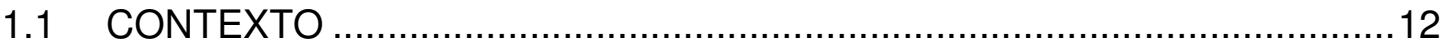

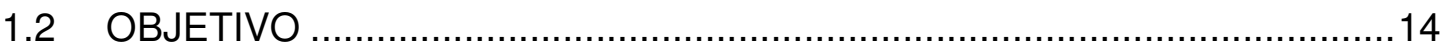

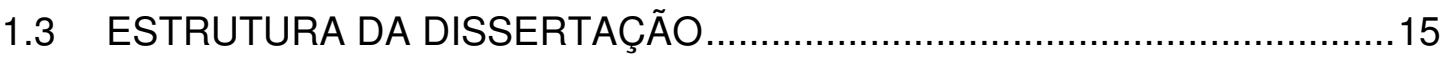

2 PERMEABILIDADE AO AR EM MATERIAIS CIMENTÍCEOS...............................17

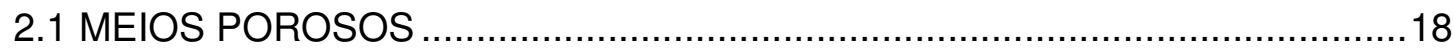

2.2 FLUIDO

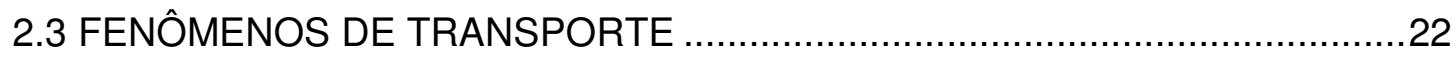

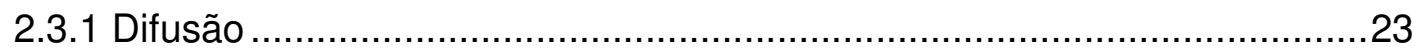

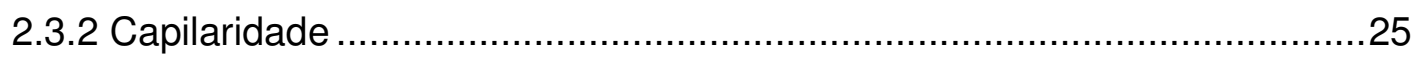

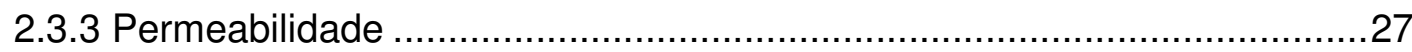

2.4 MÉTODOS DE MEDIÇÃO DE PERMEABILIDADE AO AR............................30

2.4.1 Métodos de ensaio em laboratório ……………....................................31

2.4.1.1 Método Cembureau ........................................................................

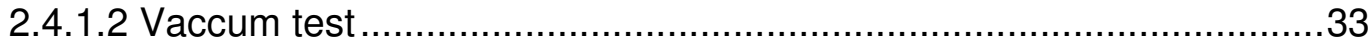

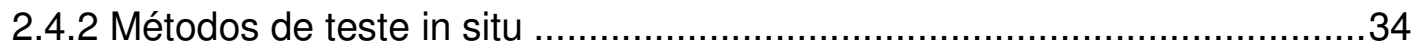

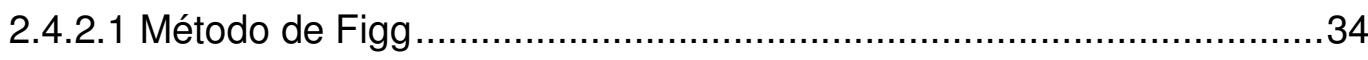

2.4.2.2 Método de Paulmann.......................................................................36 
2.4.2.3 Método de Germann (GGT)

2.4.2.4 Método de Hong-Parrot

37

2.4.2.5 Método de Torrent 38

2.5 VARIÁVEIS DO MATERIAL QUE INFLUENCIAM A MEDIDA DE

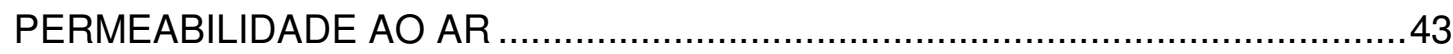

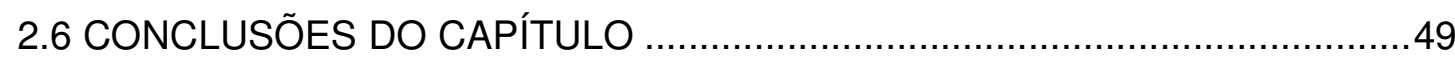

\section{DESENVOLVIMENTO DO MÉTODO DE VACCUM-DECAY PARA}

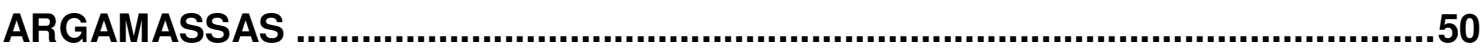

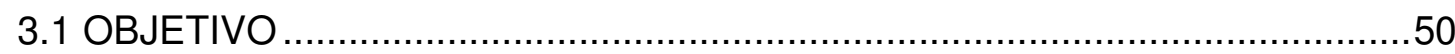

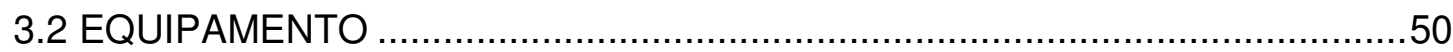

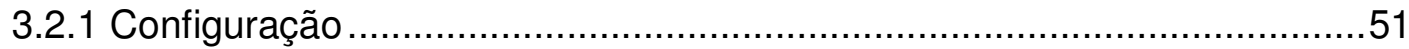

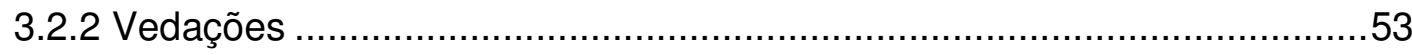

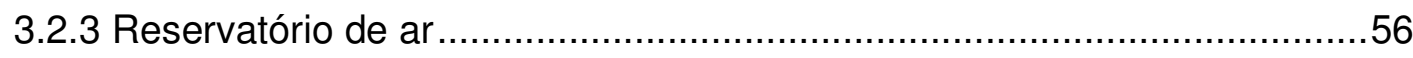

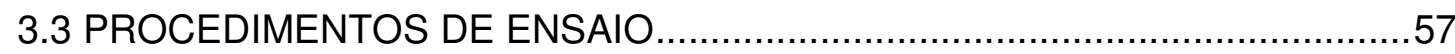

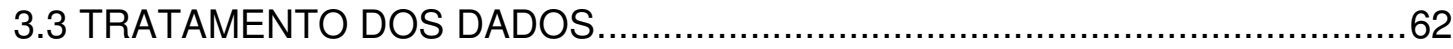

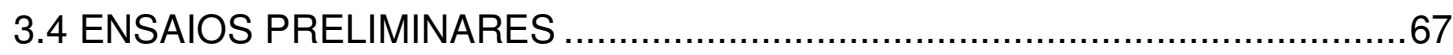

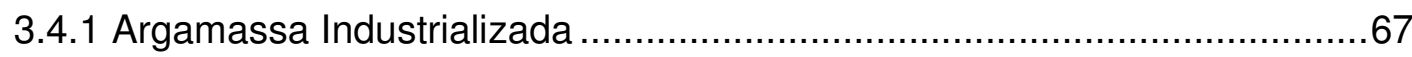

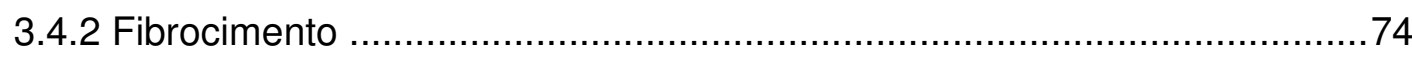

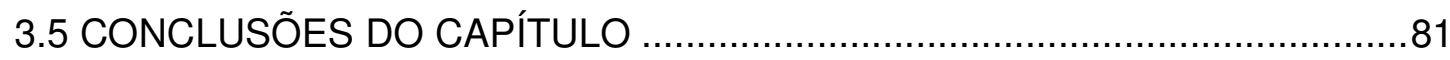




\section{AVALIAÇÃO DA INFLUÊNCIA DA ESPESSURA DO CORPO-DE-PROVA E}

TRAJETO DE PERCOLAÇÃO NO MÉTODO EM DESENVOLVIMENTO

4.1 OBJETIVO .85

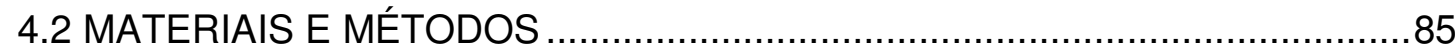

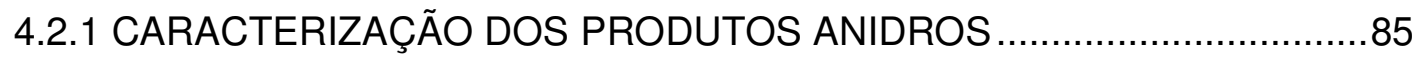

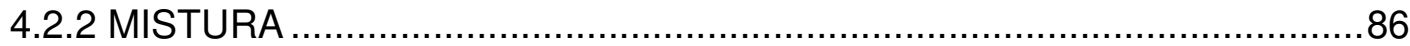

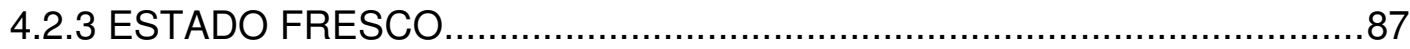

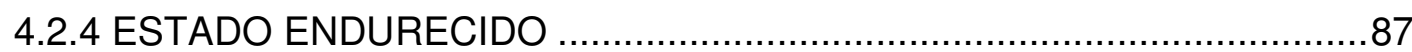

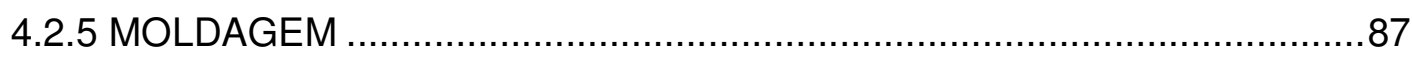

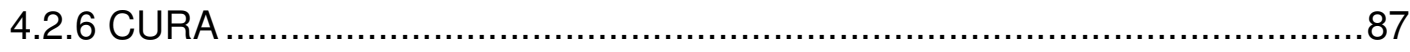

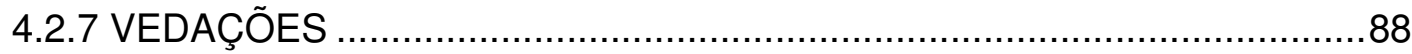

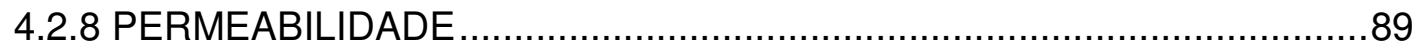

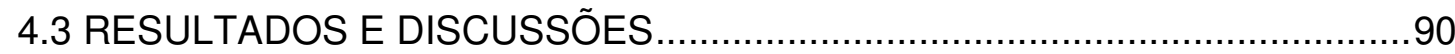

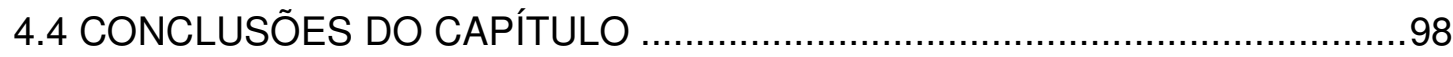

5 ENSAIO DE PERMEABILIDADE AO AR EM PAREDES REVESTIDAS COM

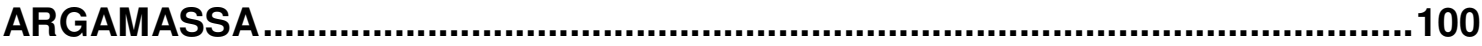

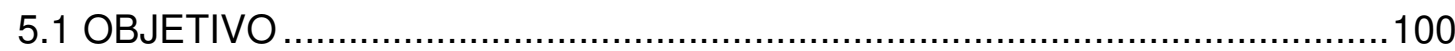

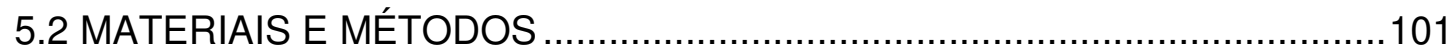

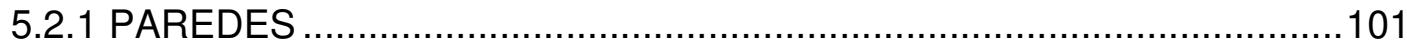

5.2.2 CARACTERIZAÇÃO DOS PRODUTOS ANIDROS ...............................102

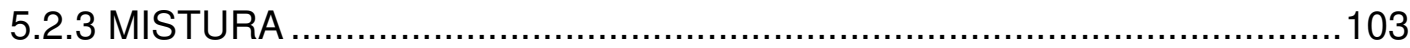




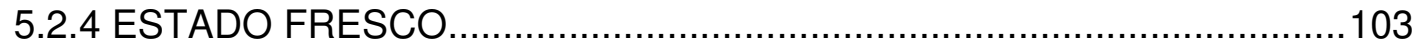

5.2.5 ESTADO ENDURECIDO …..........................................................103

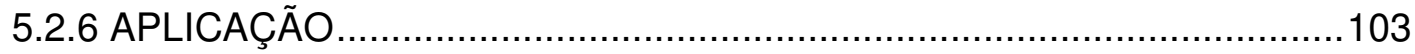

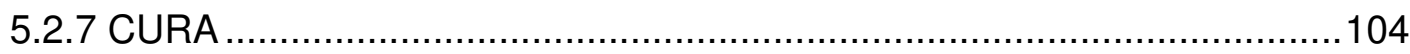

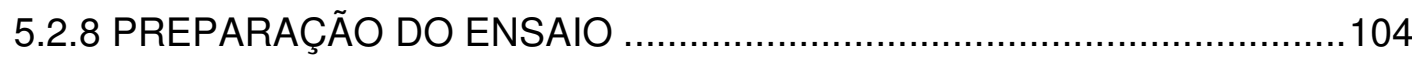

5.2.9 ENSAIOS DE PERMEABILIDADE AO AR ..........................................106

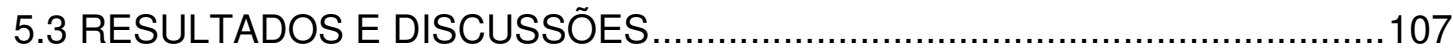

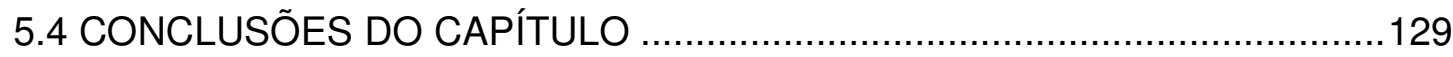

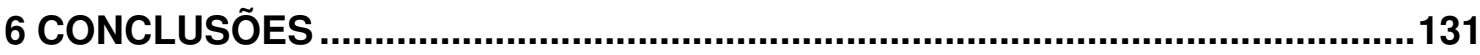

6.1 SUGESTÕES PARA FUTUROS TRABALHOS .......................................132

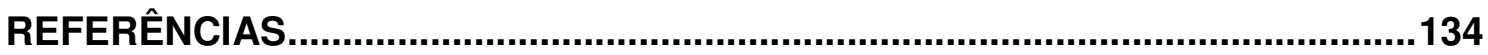




\section{INTRODUÇÃO}

\subsection{CONTEXTO}

Argamassas são compostos cimentícios bastante utilizados na construção civil, sobretudo com a função de assentamento de blocos e revestimento, que tem como funções básicas: isolamento termo-acústico, regularização de superfície, contribuição para melhoria da estética de fachada, proteção dos elementos de vedação, estanqueidade, entre outros (MACIEL; BARROS; SABBATINI, 1998). Entende-se por durabilidade de material cimentíceo, segundo relatório do Instituto Americano de Concreto $(\mathrm{ACl})$, a sua capacidade de resistir às intempéries, ataques químicos, abrasão ou qualquer outro processo de deterioração (ACl COMMITEE 201, 2008). Agentes deletérios penetram no interior de argamassas através de sua estrutura porosa, causando tanto sua própria deterioração quanto dos materiais ao qual está associada. Um dos principais fatores que influenciam a durabilidade e resistência de argamassas de revestimento é sua suscetibilidade a transporte de umidade (MEHTA; MONTEIRO, 1994). Portanto, quanto mais suscetível for essa estrutura capilar ao fluxo de massa através de seus espaços vazios, maior será o grau de degradação ao longo de sua vida útil. Os revestimentos em argamassa, ainda que bastante utilizados, apresentam inúmeros problemas patológicos como fissuração, formação de manchas, descolamento, entre outros (BAÍA; SABBATINI, 2000).

Argamassas, assim como concretos, são compostos de difícil caracterização por se tratarem de materiais bastante heterogêneos e de estrutura bastante complexa. Devido a sua estrutura descontínua, fica complicado estabelecer modelos de estudo para prever o seu comportamento. Cada material constituinte (agregados, cimento, água e adições), possui propriedades e características particulares que, quando combinadas entre si, conferem ao produto final qualidades bastante diferentes das obtidas individualmente.

A permeabilidade está diretamente relacionada às características da estrutura porosa, logo, esse tipo de medida é capaz de fornecer um retrato fiel das condições 
microestruturais de concretos e argamassas. Sendo assim, podem-se associar eventuais diferenças dos parâmetros de permeabilidade a descontinuidades, fissuras, saturação, reações, deteriorações ou qualquer outro tipo de fenômeno de transformação da estrutura porosa de materiais de construção. Portanto, em processos de produção, sobretudo industrial, de peças de materiais compostos de cimento, a permeabilidade pode funcionar como um parâmetro de qualidade para avaliação dos procedimentos de fabricação, acabamentos superficiais, danos ou durabilidade.

Como a permeabilidade depende, além do tipo de fluido percolante, de características de conformação das partículas, pode-se dizer que esta medida pode prover um indicativo das condições microestruturais dos materiais porosos (STORMONT, 1997). Assim, esse tipo de avaliação é capaz de apontar possíveis problemas estruturais como fissuras e descontinuidades (PICANDET; KHELIDJ; BELLEGOU, 2009). Sendo assim, cada material tem certo perfil constante de permeabilidade em função das suas características estruturais em função do fluido percolante, salvo quando apresentar qualquer descontinuidade ou mudança induzida por agentes externos. Deve-se ainda observar que existem outros fatores responsáveis por aumento ou diminuição nos valores de fluxo ao ar que não necessariamente remetem a problemas estruturais, como umidade, temperatura e deformação da estrutura porosa (SUGIYAMA; BREMNER; HOLM, 1996; HILSDORF, 1989; MEHTA; MONTEIRO, 1994).

A avaliação da permeabilidade contribui também na estimativa de outros tipos de características e propriedades mecânicas das argamassas tais como: porosidade, empacotamento de partículas, umidade dos poros, resistência mecânica, fissuração, etc. Para um mesmo composto, medidas sucessivas podem ser realizadas com a finalidade de se avaliar o desenvolvimento de sua estrutura porosa. Diferentes elementos utilizados em sua formulação, distintos tipos de cura utilizados, ocorrência de fenômenos de degradação, entupimento de poros superficiais, formas de acabamento superficial, podem gerar diferenças nos parâmetros de permeabilidade de argamassa pela modificação de seus vazios capilares. 
Existem diversas formas de se medir esse tipo de característica, cada qual com suas particularidades de equipamento, fluido percolante e tratamento dos dados. Algumas dessas técnicas podem ser realizadas em laboratório, com testemunhos moldados ou extraídos, e outras in loco, com características destrutivas ou não. Quase todos os métodos tratam os dados medidos através de resoluções da lei proposta por Henry Darcy em 1856. A maioria delas, porém, desconsidera os efeitos cinéticos em fluxos de grande velocidade, além dos efeitos da densidade do fluido (INNOCENTINI; PANDOLFELLI, 1999). Ainda, muitas das tecnologias utilizadas para se medir permeabilidade ao ar não levam em consideração algumas variáveis fundamentais na definição desse tipo de parâmetro como umidade relativa, caminhos do fluxo de ar (real contribuição da superfície, lateral ou face oposta do substrato), espessura do material, temperatura, pressão atmosférica, etc.

Nesse contexto, a presente dissertação contempla o desenvolvimento de técnica para medir permeabilidade ao ar de argamassas in situ, que considera todas as variáveis tecnológicas descritas quanto a procedimentos de medida, além da etapa de tratamento de dados que deve estar em conformidade com as características de fluxo envolvidas durante o fenômeno. Para isso, primeiramente o equipamento passou por um processo de desenvolvimento por si só para depois serem avaliadas as outras etapas.

\subsection{OBJETIVO}

Essa dissertação de mestrado encontra-se inserida no Programa de PósGraduação em Engenharia de Construção Civil e Urbana da Escola Politécnica da Universidade de São Paulo (PCC - EPUSP) e tem como objetivo principal desenvolver uma nova técnica de medida de permeabilidade ao ar in situ para revestimentos de argamassa através do método de vaccum-decay.

Para isso são necessários como objetivos intermediários:

(a) adequação de equipamento para medida precisa de revestimentos de argamassa, considerando características de superfície, porosidade e velocidade de fluxo; 
(b) avaliação, em laboratório, das principais variáveis que podem influenciar esse tipo de medida em produtos de mercado com diferentes características de estrutura porosa;

(c) avaliação final do produto aplicado in situ.

\subsection{ESTRUTURA DA DISSERTAÇÃO}

- Capítulo 1 - INTRODUÇÃO

- Capítulo 2 - PERMEABILIDADE AO AR EM MATERIAIS CIMENTÍCEOS

Revisão dos principais conceitos de permeabilidade ao ar, assim como duas formas de medida, focado, sobretudo, em materiais de construção cimentíceos.

- Capítulo 3 - DESENVOLVIMENTO DO MÉTOdo DE VACCUM-DECAY PARA ARGAMASSAS

Descrição da metodologia desenvolvida para utilização da técnica de vaccumdecay em argamassas de revestimento. Ensaios experimentais demonstram a potencialidade da técnica para esse e outros materiais cimentíceos ainda inexplorados.

- Capítulo 4 - AVALIAÇÃo DA INFLUÊNCIA DA ESPESSURA E CAMINHO DO FLUXO NO MÉTODO

Avaliação da técnica de medida de permeabilidade quanto à espessura e caminho do fluxo de ar em um conjunto selecionado de argamassas industrializadas. 
- Capítulo 5 - enSAIO DE PERMEABILIDADE AO AR EM PAREDES REVESTIDAS COM ARGAMASSA

Avaliação em superfícies, in situ, de paredes aplicadas com diferentes tipos de argamassas de revestimento. Comparação dos resultados encontrados com os das mesmas argamassas avaliadas em laboratório (Capítulo 4).

- Capítulo 6-CONCLUSÕES

- REFERÊNCIAS 


\section{PERMEABILIDADE AO AR EM MATERIAIS CIMENTÍCEOS}

O estudo dos fenômenos de transporte de massa através de materiais porosos desperta interesse de diversos ramos da ciência, sob diferentes óticas de aplicação, sobretudo da engenharia de materiais de construção civil. O correto entendimento desse tipo de ocorrência é responsável pela melhoria do processo de desenvolvimento de diversos tipos de insumos utilizados na construção, tanto na parte estrutural (concretos, blocos) quanto nos revestimentos e acabamentos (argamassas, pisos, cerâmicas). Vários são os exemplos que podem ser citados quanto à aplicação desse tipo de tecnologia na construção civil. Os elementos de fundação, por exemplo, devem ser confeccionados com concretos quase impermeáveis a fim de se evitar o fenômeno de umidade ascendente responsável por patologias nos elementos contidos acima. Já as argamassas de revestimento devem possuir características mistas quanto ao seu comportamento referente à permeabilidade: o excesso de umidade contida no interior de paredes e elementos estruturais precisa conseguir migrar para fora através dessa última camada de revestimento, ao mesmo tempo em que a umidade externa não pode entrar carregando agentes deletérios que possam causar eventuais danos. No processamento de concretos refratários a saída de vapor de água durante o processo de cura acontece, em função da temperatura de secagem e tempo de exposição, de forma aguda chegando a provocar explosões nos elementos de concreto (CARDOSO et al., 2004). Em concretos expostos a altas temperaturas, como em situações de incêndio, suas águas livres contidas nos poros acabam por exercer elevadas pressões de vapor responsáveis por lascamentos explosivos (spalling), fenômeno em que a permeabilidade acaba sendo determinante para o grau de deterioração (KALIFA; MENNETEAU; QUENARD, 2000).

O transporte de matéria através de meios porosos é determinado pela interação do fluido passante com a estrutura porosa propriamente dita. Entretanto, a força motriz que impulsiona esse tipo de ação é diferente para cada situação, o que caracteriza essencialmente os distintos tipos fenômenos de transportes existentes. Logo, a entrada de água ou gases, carregando agentes agressores, ao interior dos materiais de construção pode ocorrer basicamente através de 3 fenômenos 
fundamentais, a se saber: difusão, capilaridade e permeabilidade. A permeabilidade, então, é apenas um desses eventos e pode ou não estar associada, em um processo natural, aos outros dois tipos de percolação.

Sabe-se que muitas das propriedades observadas em materiais porosos, tanto em seu processo de obtenção quanto no seu estado final de uso e serviço, estão relacionadas ao grau de conformação de suas partículas (SALVINI; INNOCENTINI; PANDOLFELLI, 2000; INNOCENTINI et al., 2003; CASTRO; PANDOLFELLI, 2009). É fundamental então, nesse contexto, primeiramente definir as características e propriedades de uma estrutura de partículas e suas relações com o transporte de matéria. Destaca-se ainda que, o potencial que corpos porosos têm de resistir às condições ambientais, ataques químicos, descontinuidades estéticas ou qualquer processo de deterioração está diretamente ligado a suscetibilidade ao transporte de matéria do meio externo até seu interior (METHA; MONTEIRO, 1994; GARBOCZI; BENTZ, 1999; BENTZ et al., 1999). Então, pode-se dizer que uma maior incidência de fluxo de massa pode resultar em alterações na vida útil dos materiais, contribuindo assim na redução de sua durabilidade (HILSDORF, 1989; CABRERA; CUSENS; LYNSDALE, 1989).

O objetivo desse capítulo é fazer uma revisão ilustrando inicialmente as definições envolvendo o fenômeno de permeabilidade, assim como as diferenças teóricas e práticas referentes aos outras formas de transporte e suas interações. Além disso, com o foco em permeabilidade ao ar, mostrar os diferentes métodos existentes para se realizar essa avaliação, com suas respectivas formas de tratamento dos dados obtidos, assim como suas vantagens e desvantagens.

\subsection{MEIOS POROSOS}

A dinâmica do fluxo de massa através de materiais poroso é definida através da interação entre os meios envolvidos no processo, que são: o fluido percolante e o meio poroso propriamente dito. Sendo assim, é fundamental inicialmente que alguns conceitos sejam definidos a fim de que a compreensão dessa relação seja claramente definida. 
Poros podem ser definidos intuitivamente como espaços vazios distribuídos através de uma matéria densa, seja na forma de partículas soltas (pós) ou consolidadas, que podem ter tamanhos distintos. O tamanho dos poros, assim como sua continuidade, influencia diretamente a ocorrência de todos os fenômenos de transporte de massa.

A formação da estrutura porosa de um corpo está inicialmente relacionada ao estado de empacotamento de suas partículas, o qual depende do tamanho, morfologia, textura e distribuição granulométrica dessas partículas (SCHEIDEGGER, 1974). Além disso, devemos levar em consideração fatores extrínsecos que podem determinar diferentes eficiências de empacotamento em conjuntos de partículas de mesmas características geométricas: efeito parede, grau de compactação e dispersão das partículas (OLIVEIRA et al., 2000). Existe ainda a possibilidade dos grãos serem reativos, como os de cimento, o que pode provocar mudança na estrutura porosa em função da presença e quantidade do reagente (a água, presente na reação do cimento, que inicialmente ocupa espaços os quais darão lugares aos poros após sua posterior evaporação) e do surgimento dos seus eventuais produtos de reação (TAYLOR, 1990).

Os poros ainda podem ser classificados, quanto a sua continuidade, em 4 diferentes tipos, conforme se observa na Figura 2.1:

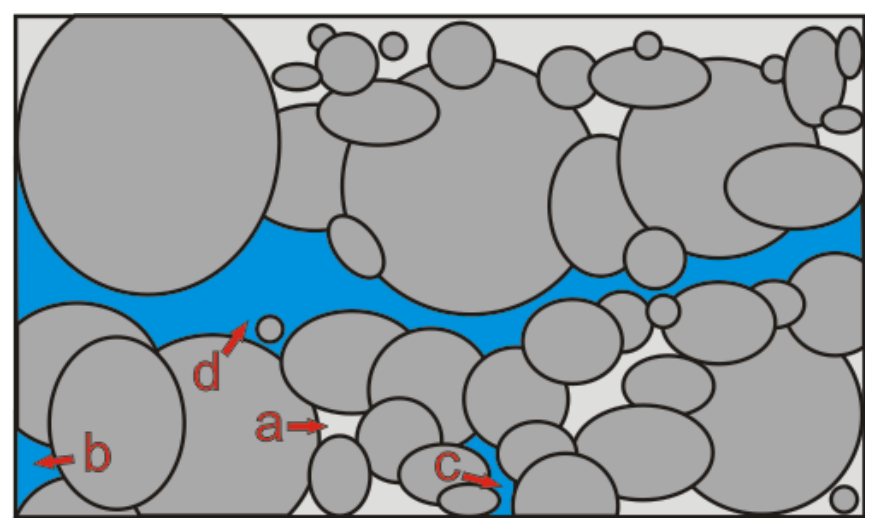

Figura 2.1 - Tipos de poros: a) Fechado ou isolado; b) Aberto; c) Interconectado; d) Permeável. 
- Fechados ou Isolados: São aqueles presentes no interior dos materiais, sem ligação com nenhum outro poro nem ao meio externo. Sendo assim, não contribuem para nenhuma forma de transporte de fluido.

- Abertos: São os que têm ligação direta com o meio externo mas não se conectam com nenhum outro poro. Podem estar relacionados a alguns fenômenos de transporte (difusão e capilaridade).

- Interconectados: São os que têm ligação direta com o meio externo e possuem ligação com outros poros internos, formando um caminho ao interior do material poroso sem, entretanto, ultrapassar até a outra face. Podem estar relacionados também a alguns fenômenos de transporte (difusão e capilaridade).

- Permeáveis: São como os interconectados, porém com acesso ao meio externo de uma face à outra do material poroso. Podem estar associados a todos os fenômenos de transporte de fluidos (difusão, capilaridade e permeabilidade).

Pode-se definir porosidade então como a quantidade efetiva de poros (vazios) presentes em relação a todo o material. Entretanto, essa porosidade leva em consideração todos os tipos de espaços vazios presentes, conectados ou não. Assim, define-se porosidade efetiva como a quantidade de poros interconectados em função do total de espaços vazios. Este sim é um parâmetro fundamental na previsão da permeabilidade dos materiais.

Outro fator geométrico importante na definição da estrutura porosa é a sua distribuição de tamanho dos poros. Entretanto, é um conceito complexo uma vez que se baseia na determinação de diâmetros para caracterizar os espaços, o que não corresponde as suas características geométricas reais (VAN BRAKEL; MODRY; STAVA, 1981).

Além disso, deve-se destacar ainda a tortuosidade, a qual pode ser definida como a propriedade cinemática equivalente ao tamanho médio efetivo do trajeto percorrido de um fluido de um lado até outro do meio poroso (SCHEIDEGGER, 1974). 
Cada um dos fenômenos de transporte esta associado à determinada distribuição e tipo de poros. Além disso, o tamanho vai influenciar também a incidência de cada fenômeno em funcão do tamanho da molécula do fluido percolante. Um exemplo disso pode ser observado na Figura 1.2 (HELENE, 1993), onde a água é representada como fluido nesse caso:

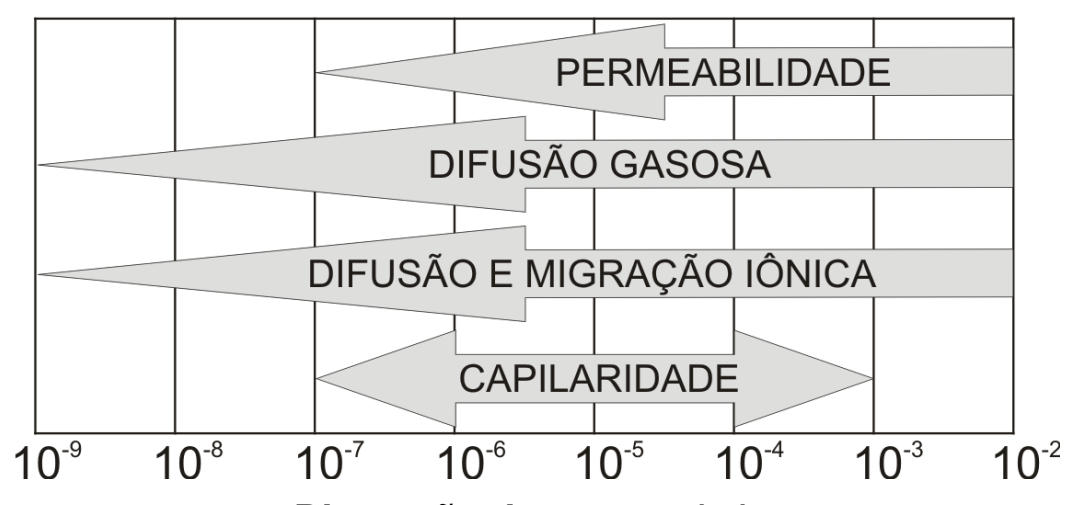

\section{Dimensão dos poros (m)}

Figura 2.2 - Intervalo de dimensões dos poros nas quais ocorre cada tipo de fenômeno de transporte (adaptado de HELENE, 1993).

As características do meio poroso podem influenciar propriedade dos materiais tais como resistência a compressão (MEHTA; MONTEIRO, 1994; SALVINI; INNOCENTINI; PANDOLFELLI, 2000; QUARCIONI et al., 2009), secagem (INNOCENTINI et al., 2002), carbonatação (HELENE, 1993), entre outros. O contrário também é verdadeiro, isto é, alguns fenômenos são responsáveis por mudanças na estrutura porosa, como surgimento de falhas, fissuras, compressão dos poros, etc. Portanto, quanto mais se conhecer sobre as condições da estrutura de porosa a qual está trabalhando, melhor vai ser o entendimento sobre os fenômenos ocorridos, além de prover um melhor uso do material em questão.

\subsection{FLUIDO}

Qualitativamente, pode-se definir um fluido como toda substância que tenha capacidade de escoar, cujo volume toma a forma de seus recipientes e que, quando em equilíbrio, não suportam forças tangenciais ou cisalhantes (GILES; EVETT; LIU, 1994). De forma geral, os fluidos percolantes da natureza podem ser classificados como gases ou líquidos. Suas diferenças são relativas, e podem ser definidas a partir do seu nível de compressibilidade e sua forma (forças intermoleculares). 
O estudo da mecânica dos fluidos na dinâmica de transporte de massa através dos meios porosos pode ser abordado de duas formas distintas: macroscopicamente ou microscopicamente.

A expressão macroscópica baseia-se na condição de que o fluido é considerado um meio contínuo, no qual cada um dos seus pontos pode ser geometricamente descrito a cada instante do evento. Para isso, a teoria da matéria contínua utiliza-se de determinados conceitos para expressar matematicamente estas condições físicas: continuidade, reologia e terceira lei de Newton (lei da ação e reação). Inicialmente a reologia, somada a algumas condições de contorno, pode determinar parâmetros que influenciam significativamente o transporte de massa. Essa avaliação se dá através da relação entre tensão e deformação em função da taxa de solicitação, e gera informações quantitativas importantes para o maior entendimento do fenômeno (MALKIN, 1994). Existem ainda as forças de interação entre fluidos e superfícies sólidas que podem influenciar a ocorrência do fluxo, a se saber: adsorção e tensão interfacial.

Microscopicamente, a interação molecular também influencia no transporte de fluido, porém minoritariamente se comparada aos efeitos macroscópicos. Esse tipo de análise é significativa se a distância entre as paredes dos poros for menor do que o espaço intermolecular livre das partículas do fluido. Além disso, de forma geral, em um mesmo fenômeno pode-se observar a ocorrência de mais de um fluido envolvido no fluxo, os quais podem ser miscíveis ou imiscíveis. Essa condição pode afetar o equilíbrio do sistema e o tratamento é feito de forma particular caso a caso (SCHEIDEGGER, 1974).

\subsection{FENÔMENOS DE TRANSPORTE}

O transporte de massa através de meios porosos pode ocorrer basicamente através de três fenômenos diferentes: difusão, capilaridade e permeabilidade (CEB/90). Como visto anteriormente, cada fenômeno esta relacionado à determinada estrutura de poros. Além disso, o que fundamentalmente os distingue são as suas forças motrizes, diferentes em cada caso. Deve-se ainda destacar que, naturalmente, os três fenômenos geralmente aparecem associados, mas, para fim 
de estudo teórico, são explorados e mensurados de formas distintas. Também, podem estar associados ao ingresso de agentes deletérios ao interior de meios porosos e, por isso, relacionados à sua durabilidade (RILEM TC 116-PCD, 1999).

\subsubsection{Difusão}

Difusão é um fenômeno de transporte de massa a nível molecular, individual e aleatório, impulsionado pela ocorrência de um gradiente de concentração entre dois meios (CALLISTER, 2002). Portanto, existe a tendência espontânea das moléculas em migrar de uma região de maior concentração para uma de menor concentração, até que o sistema esteja em equilíbrio. Entretanto, para que esse movimento ocorra, o meio destino deve estar vazio e os átomos migrantes devem possuir energia suficiente para quebrar suas ligações com os vizinhos, causando assim o movimento de arraste.

O processo de difusão pode acontecer em estado estacionário ou nãoestacionário, no qual os gradientes de concentração podem variar ou manter-se constantes ao longo do tempo. No estado estacionário, a difusão é regida pela 1a Lei de Fick (Equação 2.1), no qual o gradiente de concentração não varia com o tempo:

$$
J=-D\left(\frac{d C}{d x}\right)
$$

Onde $\mathrm{J}$ corresponde ao fluxo de matéria difundida por unidade de tempo $\left(\mathrm{g} / \mathrm{cm}^{2} \mathrm{~s}\right)$; o D ao coeficiente de difusão $\left(\mathrm{cm}^{2} / \mathrm{s}\right)$; C à concentração $\left(\mathrm{g} / \mathrm{cm}^{3}\right)$; e x à distância $(\mathrm{cm})$. O sinal negativo corresponde justamente à indicação de que o movimento acontece do lugar de maior concentração ao de menor.

Já no estado não estacionário, que corresponde à maioria das aplicações práticas de difusão, a equação que rege o transporte de massa é definida pela $2^{2}$ Lei de Fick (Equação 2.2), no qual verifica-se a variação da concentração em função do tempo e da distância:

$$
\left(\frac{d C}{d t}\right)_{x}=D\left(\frac{d^{2} C}{d x^{2}}\right)
$$


Onde $\mathrm{C}$ corresponde à concentração $\left(\mathrm{g} / \mathrm{cm}^{3}\right)$; t ao tempo (s); D ao coeficiente de difusão $\left(\mathrm{cm}^{2} / \mathrm{s}\right)$; e x à distância $(\mathrm{cm})$.

Através da observação do fenômeno e das Leis de Fick pode-se constatar que alguns fatores podem influenciar diretamente a difusão. O coeficiente de difusão D indica o quão susceptível os átomos da espécie difusora são ao movimento difusor. Isto é, o fenômeno pode ocorrer em maior intensidade para algumas substâncias do que a outras. Além disso, a temperatura tem uma influência ainda maior sobre o processo uma vez é capaz de prover energia suficiente de ativação para que os átomos iniciem o processo de migração.

A difusão em materiais cimentíceos pode ser medida através de processos simples de migração iônica, em regime estacionário ou não, por exposição direta. Para isso, utiliza-se um aparato contendo solução(s) com diferentes concentrações iônicas, posicionando um corpo-de-prova entre as duas misturas (PAGE; SHORT; TARRAS, 1981). A concentração das soluções é então mensurada ao longo do tempo e o coeficiente de difusão calculado através da Lei de Fick. Uma variação do ensaio, para regimes não estacionários de fluxo, é imergir o testemunho em solução iônica com apenas uma de suas faces livres (as outras devem estar todas seladas), observando posteriormente à profundidade de penetração desses íons, a qual então serve de parâmetro para o cálculo do coeficiente de difusão pela segunda Lei de Fick (STANISH; HOOTON; THOMAS, 1996).

Pode-se realizada também, por meio elétricos, uma avaliação da difusão através da medida de corrente passante em um corpo-de-prova cilíndrico, onde suas faces são imersas em soluções salinas diferentes (hidróxido de sódio, hidróxido de cálcio, cloreto de sódio, etc), em função de uma tensão aplicada (ASTM C 1202-10, 2007). O ensaio gera uma curva de corrente em função do tempo de ensaio, a qual é integrada para se conhecer a carga elétrica total em determinado tempo de ensaio que funciona como um parâmetro de classificação quanto à susceptibilidade do concreto à corrosão.

Diversos são os casos de difusão relacionados à mudança na propriedade de materiais, sejam eles propositalmente realizados durante seu processo de fabricação ou naturalmente ocasionados quando em exposição natural. A difusão é 
o principal responsável pela penetração dos cloretos ao interior de materiais cimentícios, desde que exista interconectividade dos capilares e haja eletrólito, sendo função da umidade relativa do ar e da porosidade da pasta de cimento (CASCUDO, 1997). É ainda, a principal responsável pela entrada de gás carbônico, principalmente na fase gasosa (104 vezes maior que na fase líquida), na estrutura do revestimento, o que pode provocar reações de carbonatação, as quais são agressivas aos materiais compostos de cimento (HELENE, 1993).

\subsubsection{Capilaridade}

A absorção capilar constitui-se em um fenômeno ocasionado por tensões capilares, ocorrendo imediatamente após o contato superficial do líquido com o material poroso. Portanto, pode-se entender como a tendência natural que os líquidos têm de se movimentar espontaneamente por superfícies sólidas compostas por poros capilares. Está diretamente ligada à energia de molhamento, a qual modifica o equilíbrio da interação sólido/ar através da interface sólido/líquido por meio de suas tensões superficiais (MARTYS; FERRARIS, 1997). Essa é uma das principais propriedades responsável pelo transporte de íons ao interior de concretos (HELENE, 1993).

A capilaridade é a medida do fluxo de um líquido sob pressão em materiais não saturados, ao contrário da permeabilidade que ocorre em poros saturados (MOREIRA; FIGUEIREDO; HELENE, 2001). Deve-se observar que forças capilares em poros de diâmetro menor são maiores (SATO, 1998), portanto, à medida que apresentamos aumento no diâmetro dos poros temos uma queda do fenômeno de capilaridade. Isto quer dizer que o transporte capilar se prevalece nas camadas mais superficiais, os quais apresentam poros mais abertos e conectados. Mesmo que a interconectividade dos poros se estenda até a região mais interna do material o mecanismo de capilaridade acaba sendo interrompido, pois os poros acabam promovendo uma resistência ao escoamento dos fluidos, devido fundamentalmente as suas dimensões. Deve-se observar também que os poros podem assumir formatos diferentes ocasionados pelo movimento da interface água-ar, podendo ser cessado quando atinge uma situação conhecida por "menisco estável", conseqüente 
do aumento do diâmetro do poro (MARTYS; FERRARIS, 1997), conforme mostra a Figura 2.3:

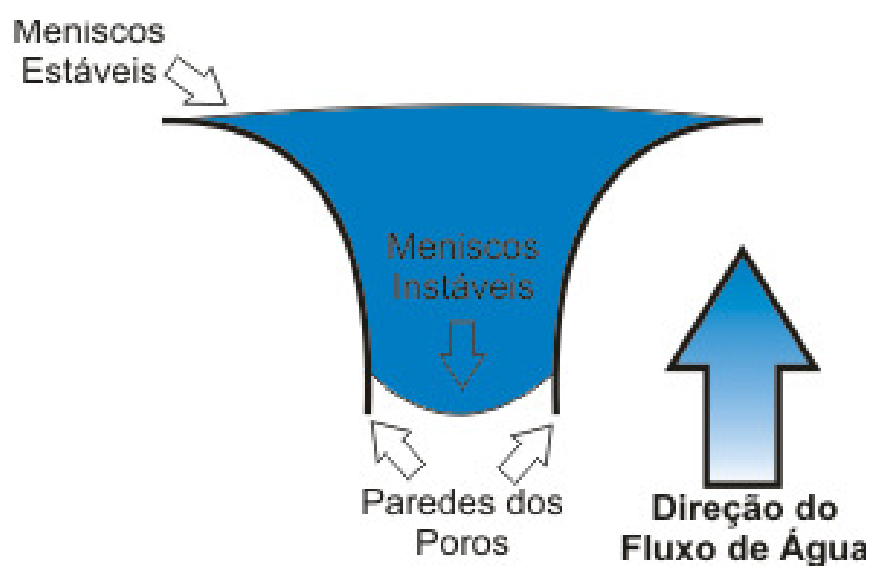

Figura 2.3 - Situação de meniscos estáveis e instáveis em poros (adaptado de MARTYS; FERRARIS, 1997).

Para se avaliar a absorção capilar de concretos e argamassas é comum utilizar um método baseado na exposição de uma das superfícies de um corpo-deprova, em geral de forma cilíndrica, a uma lâmina de água que não tenha uma altura de coluna muito efetiva a fim de não descaracterizar o fenômeno de capilaridade. Conhecendo-se a massa do espécime seco, realizam-se então novas medidas em função de intervalos de tempo pré-estabelecidos, que podem durar de horas até dias. O resultado do ensaio é uma curva de absorção de água, com unidade de massa por área de seção transversal exposta ao ensaio, em função do tempo (NBR 9779, 1995).

A entrada de umidade através da capilaridade em concretos e revestimentos de argamassa é geralmente mais incidente que pelos outros fenômenos, devido a sua velocidade de ocorrência e força motriz, principalmente aqueles expostos a ciclos de molhagem e secagem (MOREIRA; FIGUEIREDO; HELENE, 2001). Apesar de ser um fenômeno de influência mais expressiva às superfícies dos concretos do que ao seu núcleo, estudos mostram que os valores de absorção capilar estão relacionados à durabilidade desses materiais a fenômenos de carbonatação, ataque por sulfato, reações alcalinas, ataque de ácidos, etc (KROPP, 1995). Portanto, a 
determinação dos valores de capilaridade pode dar um indicativo fidedigno da vida útil de materiais cimentíceos.

Pode-se entender então que o fenômeno de capilaridade constitui-se em um mecanismo importante de entrada de fluidos ao interior das argamassas, por conseqüência a penetração de agressores, portanto deve ser mensurado e analisado juntamente com os outros fenômenos para que se consiga obter uma total compreensão dos efeitos nocivos dos fenômenos de transporte de massa.

\subsubsection{Permeabilidade}

Permeabilidade pode ser definida como a medida macroscópica da facilidade com a qual um fluido pode fluir através dos espaços de um meio poroso (INNOCENTINI; SEPULVEDA; ORTEGA, 2005). Trata-se então da interação entre o meio poroso e o fluido passante, e não de uma propriedade intrínseca a qualquer um dos dois apenas (SCHEIDEGGER, 1974). Como comprovado anteriormente, depende do tamanho e continuidade dos poros (MEHTA; MONTEIRO, 1994). Sua medida está associada a diversas aplicações, sobretudo referente à microestrutura de meios porosos.

A característica principal que indica a ocorrência de um fenômeno de permeabilidade é a existência de um gradiente de pressão entre dois meios, capaz de impulsionar o fluido de uma região de pressão mais elevada até a de menor pressão. Entretanto, dependendo das condições de pressão e características do meio, esse vazão pode apresentar regimes de escoamento que variam do laminar ao turbulento.

A teoria clássica para os fenômenos de permeabilidade, considerando fluxos laminares homogêneos, é baseada na lei expressa a partir dos experimentos de Henry Darcy de 1856 (SCHEIDEGGER, 1974). Através deles, Darcy comprovou que a velocidade de um fluido que percola um meio poroso homogêneo é constante, portanto de regime laminar, e foi expressa na forma da Equação 3, conhecida como Lei de Darcy: 


$$
Q=\frac{-K A(\Delta h)}{L}
$$

Onde $Q$ corresponde ao volume total do fluido percolante por unidade de tempo $\left(\mathrm{m}^{3} / \mathrm{s}\right) ; \mathrm{K}$ à condutividade hidráulica, que depende das propriedades do fluido e do meio poroso (m/s); A à área da seção transversal pela qual percola o fluido $\left(\mathrm{m}^{2}\right) ; \Delta \mathrm{h}$ à carga hidráulica medida pela diferença de altura nos piezômetros $(\mathrm{m})$; e $\mathrm{L}$ à distância da trajetória do fluxo.

Observa-se na Lei de Darcy, que a variação da carga hidráulica $(\Delta \mathrm{h})$ em função da trajetória do fluxo (L) representa a condutividade hidráulica, termo que depende tanto da natureza do meio percolante quanto da densidade e viscosidade do fluido. Sendo assim, a equação pode ser reescrita, ainda em termos da variação de pressão exercida ao fluido (Equação 4):

$$
-\frac{d P}{d x}=\frac{\mu}{k_{1}} v_{S}
$$

Onde $-\mathrm{dP} / \mathrm{dx}$ corresponde ao gradiente de pressão ao longo da trajetória do fluxo; $\mu$ à viscosidade do fluido $\left(\mathrm{Pa} \mathrm{s}^{-1}\right) ; \mathrm{v}_{\mathrm{s}}$ à velocidade superficial do fluido $(\mathrm{m} / \mathrm{s})$, definida pela razão entre a vazão e a área da seção percolante; e k à constante de permeabilidade Darciana $\left(\mathrm{m}^{2}\right)$, a qual representa apenas a estrutura porosa. Integrando-se a Equação 2.4, obtemos a Equação 2.5 para fluidos incompressíveis:

$$
\frac{\Delta P}{L}=\frac{\mu}{k_{1}} v_{S}
$$

Deve-se destacar que a Lei de Darcy é estritamente válida para regimes de escoamento laminar, levando em consideração apenas os efeitos de atrito na queda de pressão ao longo do meio. Além disso, os efeitos moleculares, sobretudo dos gases, são limitantes no uso da lei de Darcy, uma vez que pode ocorrer que o diâmetro dos poros pode ser igual, ou menor que, o caminho livre das moléculas em fluxo do fluido. Ainda tem-se os efeitos de adsorção, condensação capilar, difusão molecular, efeitos de borda e presença de íon no fluido que podem influenciar na medida da permeabilidade, quando analisada através de Darcy (SCHEIDEGGER, 1974). 
Para essas diversas condições de contorno observadas anteriormente existem diferentes resoluções da equação de Darcy que corrigem os efeitos que tornam a resolução clássica inválida (SCHEIDEGGER, 1974). O gradiente de pressão apresenta uma tendência parabólica com um aumento na velocidade do fluido, devido à contribuição da inércia e turbulência, observado por Forchheimer em 1901. Ele então sugeriu que a Lei de Darcy fosse modificada (Equação 2.6), incluindo-se um segundo termo que representa os efeitos cinéticos da interação entre fluido e sólido (INNOCENTINI, 1999).

$$
\frac{\Delta P}{L}=\frac{\mu}{k_{1}} v_{S}+\frac{\rho}{k_{2}} v_{s}^{2}
$$

Onde a diferença existente da Lei de Darcy (fluidos incompressíveis) está mesmo na incorporação deste segundo termo, no qual $\rho$ corresponde à densidade do fluido $\left(\mathrm{kg} / \mathrm{m}^{3}\right)$; e $\mathrm{k}_{2}$ à constante de permeabilidade não-Darciana $(\mathrm{m})$.

Como já foi observado anteriormente, existem diversas soluções da equação de Darcy que contemplam a correção das diferentes situações apresentadas durante o transporte de massa. Entretanto, a equação de Forchheimer é a que se apresenta de maneira mais simplificada e contempla, de modo geral, diversas condições referentes à interação entre o fluido percolante e o meio poroso.

Finalmente, é importante observar que os fluidos compressíveis expandem ao longo de seu escoamento, fazendo com que sua velocidade de saída seja maior do que de entrada, o que afeta o parâmetro de queda de pressão. Como as Equações 2.7 e 2.8 levam em consideração a percolação de um fluido incompressível, devemse integrar as relações para considerar os efeitos de compressibilidade, os quais são mais visíveis para materiais de baixa porosidade:

$$
\begin{aligned}
& \frac{P e^{2}-P s^{2}}{2 P L}=\frac{\mu}{k_{1}} v_{S} \\
& \frac{P e^{2}-P s^{2}}{2 P L}=\frac{\mu}{k_{1}} v_{S}+\frac{\rho}{k_{2}} v_{S}{ }^{2}
\end{aligned}
$$


Onde Pe corresponde à pressão de entrada $\left(\mathrm{N} / \mathrm{m}^{2}\right)$; Ps à pressão de saída $\left(\mathrm{N} / \mathrm{m}^{2}\right)$; e $\mathrm{P}$ à pressão absoluta do fluido para qual os parâmetros vs, $\mu$ e $\rho$ foram obtidos $\left(\mathrm{N} / \mathrm{m}^{2}\right)$.

\subsection{MÉTODOS DE MEDIÇÃO DE PERMEABILIDADE AO AR}

Existem diversos métodos para se determinar a permeabilidade de materiais porosos ao ar, cada qual com suas características, aparatos, tratamento dos dados, vantagens e desvantagens. Ainda, existem técnicas desenvolvidas para a realização de ensaios em ambiente de laboratório, em corpos-de-prova confeccionados ou extraídos, e aqueles que se realizam no próprio local onde se deseja medir a permeabilidade, conhecido como ensaios in situ. Estes ainda podem ser caracterizados como ensaios destrutivos ou não, em função de algum eventual dano que possam causar na estrutura avaliada.

Os métodos para se obter a permeabilidade de materiais porosos podem ser realizados a partir de diversos aparatos existentes, tanto em ambiente de laboratório quanto in situ. Cada procedimento tem suas vantagens e desvantagens, porém todos devem conduzir a medidas equivalentes, pois, se mantidas inalteradas as características estruturais do corpo-de-prova, os parâmetros referentes à permeabilidade devem manter-se constantes. $\mathrm{Na}$ determinação numérica das constantes de permeabilidade, quase sempre se utiliza, nos diferentes métodos de medida existentes, a lei de Darcy, com distintas soluções propostas em função das condições de cada ensaio (KOLLEK, 1989; SCHÖNLIN; HILSDORF, 1987; TORRENT, 1992). Além disso, geralmente utiliza-se água ou ar como fluido percolante para execução da medida, que se diferenciam, fundamentalmente, pelo valor de viscosidade, densidade e compressibilidade associada a cada um. Diferentes fluidos são responsáveis por fluxos de diferentes velocidades, que podem ser corrigidos para se obter medidas equivalentes (LOOSVELDT; LAFHAJ; SKOCZYLAS, 2002). 


\subsubsection{Métodos de ensaio em laboratório}

\subsubsection{Método Cembureau}

O método Cembureau foi proposto pelo Cembureau Committee, um comitê organizado pela RILEM em 1981 com o objetivo de desenvolver um método adequado para medidas de permeabilidade em concretos a fim de determinar os efeitos da proporção da mistura e cura e também estabelecer um método viável para se obter resultados concordantes entre participantes de vários laboratórios (KOLLEK, 1989).

Consiste basicamente na aplicação de uma determinada pressão, em regime permanente, em uma das faces de um corpo-de-prova de material poroso, com conseqüente determinação de sua vazão de saída, conforme mostra a Figura 2.4.

Portanto, o fluxo depende dessa diferença de pressão, da área de seção a ser testada, da espessura do corpo de prova, da estrutura de poros e da viscosidade do gás em teste. É importante que o ar passe exclusivamente ao longo do corpo, e não pode vazar pelas laterais, pois estaria descaracterizando o ensaio. Por isso, é necessário um cuidado especial na confecção das células ou até mesmo um isolamento lateral dos espécimes. $O$ ar deve ser seco, livre de qualquer tipo de umidade que possa influenciar no ensaio, possibilitando até uma mudança na permeabilidade ao longo do tempo.

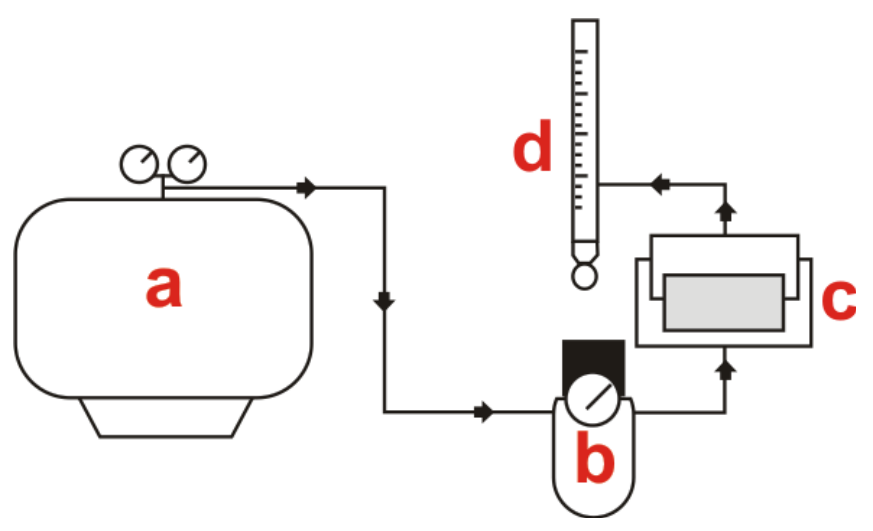


Figura 2.4 - Esquema de funcionamento do método Cembureau de medida de permeabilidade (adaptado de KOLLEK, 1989). Onde: a) Suprimento de ar; b) Regulador de pressão com manômetro; c) Célula de ensaio com corpo-de-prova; d) Bolhômetro (vazão).

O coeficiente de permeabilidade é calculado segundo a segundo a relação de Hagen-Poiseuille, que nada mais é do que uma interpretação da Lei de Darcy para fluidos compressíveis sob condições de fluxo estacionário (Equação 2.7):

$$
K=\frac{2 Q p_{0} L \mu}{A\left(p^{2}-p_{a}^{2}\right)}
$$

Onde $Q$ representa a vazão de gás $\left(\mathrm{m}^{3} / \mathrm{s}\right)$, obtida através da observação dos bolhômetros; $p_{0}$ à pressão na qual a vazão foi determinada, assumido como sendo a pressão atmosférica $\left(\mathrm{N} / \mathrm{m}^{2}\right)$; $\mathrm{L}$ à espessura do corpo-de-prova $(\mathrm{m})$; $A$ à área da seção transversal $\left(\mathrm{m}^{2}\right)$; $p$ à pressão de entrada $\left(\mathrm{N} / \mathrm{m}^{2}\right)$; e pa à pressão de saída que normalmente é também atribuída a pressão atmosférica $\left(\mathrm{N} / \mathrm{m}^{2}\right)$.

O método é bastante consagrado na literatura e usado amplamente não apenas em materiais cimentíceos como também nos cerâmicos (INNOCENTINI; SEPULVEDA; ORTEGA, 2005; QUARCIONI et al., 2007; ABBAS; CARCASSES; OLLIVIER, 1999). Deve-se destacar também sua grande consistência de resultados. Em 5 testes, no mesmo corpo, realizados pelo mesmo operador a variação de resultados não ultrapassou os $2 \%$, o que demonstra uma considerável repetibilidade. Fazendo ainda a mesma medida em 7 laboratórios diferentes, essa diferença nos resultados ficou na casa dos 4\% (KOLLEK, 1989).

Existem, entretanto, alguns aspectos negativos em relação a este método. Quando o corpo ensaiado apresenta uma porosidade muito alta, consequentemente, os valores de sua resistência mecânica também são baixos. Quando acondicionados nas células de medida podem sofrer uma ruptura precoce, antes mesmo de iniciar a medida, ou ainda fraturar quando na aplicação de pressões muito elevadas. Para avaliação de argamassas in situ, nesse caso é necessário a extração do corpo de prova do lugar onde ele se encontra, o que, dependendo da fragilidade de sua estrutura, pode provocar algum tipo de dano que talvez fique evidenciado nos resultados, além de tornar o método destrutivo. 


\subsubsection{Vaccum test}

O teste de vácuo foi proposto inicialmente por Schönlin em 1987, e consiste de uma câmara cilíndrica ligada a uma bomba que produz vácuo até uma pressão média de 20 mbar (SCHÖNLIN; HILSDORF, 1987). O ensaio propriamente dito inicia quando a bomba é desligada, e sua conexão com a câmara fechada, e a pressão interna da câmara começa a estabilizar até a faixa de pressão atmosférica, durante um intervalo de tempo. Esse ajuste de pressão no interior da câmara é causado por um fluxo não estacionário através do corpo-de-prova. O esquema de funcionamento do aparato pode ser observado na Figura 2.5.

A constante de permeabilidade aqui é mais uma vez calculada através de equação derivada de Darcy, supondo-se que o escoamento seja laminar e negligenciando a compressibilidade do gás. Neste caso ainda são ignoradas as propriedades do fluido, resultando um $\mathrm{K}$ com unidade de $\mathrm{m}^{2} / \mathrm{s}$, o que torna incomparável a diversos outros métodos. Ainda, como dito anteriormente, esse tipo de solução ignora condições de contorno as quais a Lei de Darcy não é válida, além dos efeitos cinéticos de interação entre fluido e sólido.

Este método de ensaio é relativamente simples de ser realizado, de rápida execução e de baixo custo implementação. Deve-se, porém, considerar a efetividade para diferentes espessuras de corpos-de-prova, além da ocorrência de fluxo de ar através de outras direções diferentes como pelas laterais ou até mesmo de uma eventual superfície livre do espécime. 


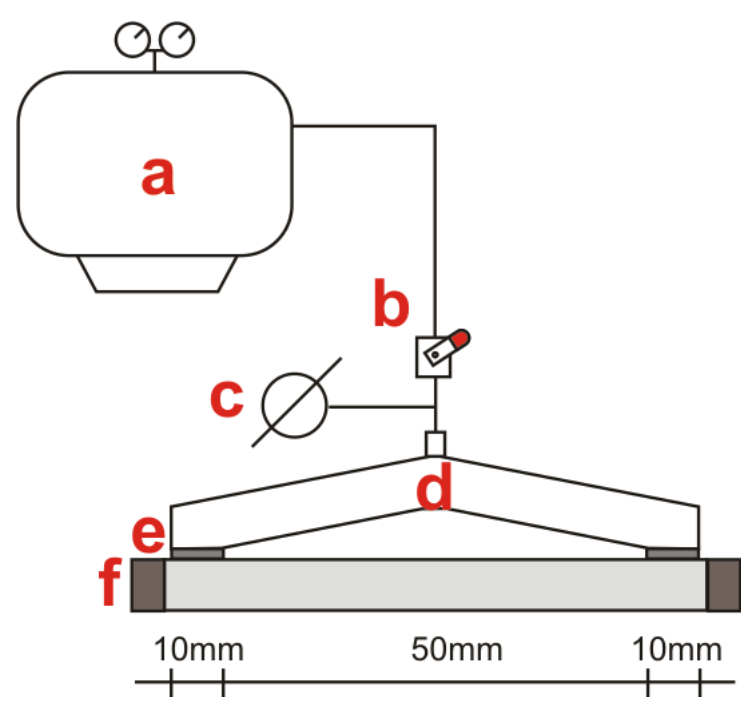

Figura 2.5 - Aparato de ensaio de permeabilidade através do teste de vácuo (adaptador de SCHÖNLIN,1987). Onde: a) Bomba de vácuo; b) Válvula; c) Manômetro; d) Câmara de vácuo; e) Material de vedação; f) Anel de polímero.

Outras variações do método foram propostas com mudanças apenas de algumas características de configuração do aparato (DHIR et al., 1995) ou através de injeção de gás em detrimento do vácuo (VALEK; HUGHES; BARTOS, 2000). Entretanto, todas as verificações tem resolução matemática semelhante à de Schönlin e não possuem tratamento específico quanto à direção do fluxo de ar até as câmaras.

\subsubsection{Métodos de teste in situ}

\subsubsection{Método de Figg}

É um método criado por Figg em 1973, baseado na recuperação de uma região de vácuo, criada através de uma sonda, em um pequeno orifício, o qual deve ser confeccionado no material de ensaio, conforme ilustra a Figura 2.6.

O orifício deve ter um tamanho médio de $10 \mathrm{~mm}$ de diâmetro por $40 \mathrm{~mm}$ de profundidade. Lateralmente a sonda, que tem um diâmetro bem inferior a cavidade, providencia-se uma vedação a fim de que não existam vazamentos que possam influenciar na medida. Ainda, é recomendável que se faça uma regularização da 
superfície para evitar que qualquer dano eventualmente causado durante a confecção do furo possa comprometer a avaliação.

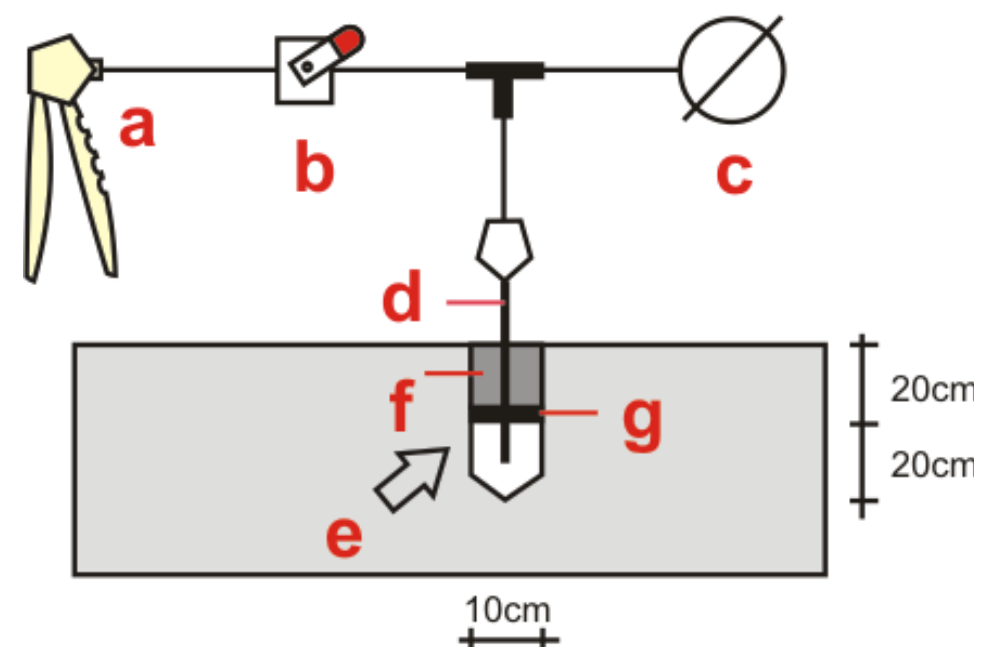

Figura 2.6 - Aparato do ensaio de permeabilidade pelo método de Figg (Adaptado de FIGG, 1973). Onde: a) Bomba de vácuo manual; b) Válvula; c) Manômetro; d) Agulha hipodérmica; e) Buraco perfurado na superfície do concreto; f) Vedação de silicone; g) Rolha.

A partir do vácuo criado no furo, inicia-se então a tomada de dados e mede-se o tempo necessário para que a pressão aumente de $-55 \mathrm{kPa}$ para $-50 \mathrm{kPa}$. Nesse caso, o cálculo do coeficiente de permeabilidade não foi proposto através de nenhum método. O tempo apenas representa um parâmetro qualitativo de análise dos materiais.

Uma variação do mesmo método foi proposta por diversos autores (KASAl; MATSUI; KAMOHARA, 1983; CLAISSE; GANJIAN; ADHAM, 2003; REINHARDT; MIJNSBERGEN, 1989) que vai desde a mudança de configuração do furo, presença de furos laterais adicionais, injeção de ar em ao invés de vácuo e proposta de equacionamento para o cálculo de $\mathrm{K}$, baseado no modelo de Darcy.

Além de ser um ensaio destrutivo, de alto custo de operação e elevado tempo de preparação, não é tão eficiente na análise quantitativa da permeabilidade. $O$ modelo original de Figg sequer propunha esse tipo de tratamento, pois é bastante complicado determinar qual a região de fluxo por onde existe a recuperação da pressão, isto é, qual o volume de material efetivo o qual está sendo permeado pelo ar. 


\subsubsection{Método de Paulmann}

O método de Paulmann (1989), ao contrário dos anteriores, propõe a injeção de um fluxo de ar através do orifício, de dimensões também diferentes $(11 \mathrm{~mm}$ de diâmetro e 40 a $45 \mathrm{~mm}$ de profundidade), circundado por superfícies anelares coletoras de ar na superfície (Figura 2.7). As mesmas condições, vistas anteriormente, de vedação do furo devem ser observadas. O furo é então submetido a uma pressão de 2 bar e as câmaras coletoras posicionadas na superfície captam esse fluxo, além de mensurá-lo através de um fluxômetro, e o tempo para se elevar a pressão de 0,2 mbar até 0,5 mbar é medido. Uma avaliação de permeabilidade pode ser estimada a partir desse ensaio e posteriormente usada para o cálculo efetivo da constante $\mathrm{K}$.

Esse é mais um método que provoca destruição do material pela confecção do furo e pelo posicionamento das câmaras coletoras na superfície que devem ser seladas com vaselina. Ainda, a medida de permeabilidade pode ser apenas estimada devido à inexatidão de volume de sólido envolvido no ensaio e caminho do fluxo de ar pelo corpo.

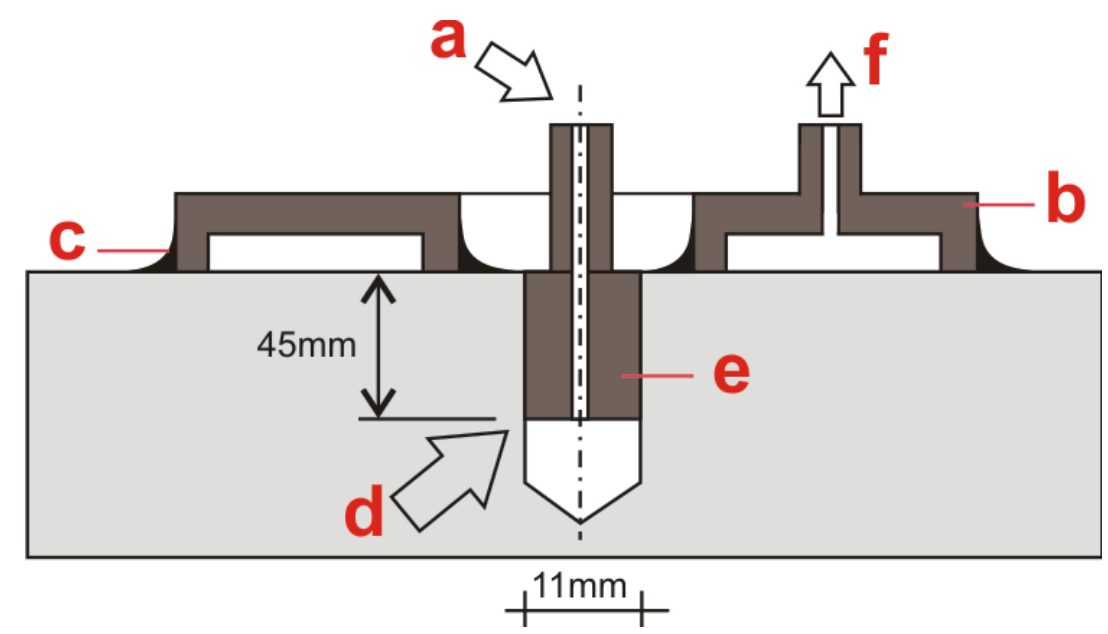

Figura 2.7 - Aparato do ensaio de permeabilidade pelo método de Paulmann (adaptado de PAULMANN; MOLIN, 1995). Onde: a) Injeção de gás; b) Superfície coletora de ar; c) Vaselina;

d) Buraco perfurado na superfície do material; e) Injetor de ar; f) Saída de gás (bolhômetro). 


\subsubsection{Método de Germann (GGT)}

Esse teste proposto por Hansen, Ottosen e Petersen, em 1984, consiste na injeção de ar (1 a 4 bar) na superfície do material estudado, o qual é monitorado, através de um sensor posicionado logo abaixo, ao longo do tempo. O anel de teste, injetor de ar é posicionado no plano superior através de grampos que o mantém fixo ao material, enquanto o sensor é introduzido logo ao lado, formando um ângulo de $45^{\circ}$ com a superfície, em um buraco de $60 \mathrm{~mm}$ de diâmetro por 15 a $35 \mathrm{~mm}$ de profundidade, afim de que fique posicionado abaixo da injeção de ar (Figura 2.8).

Este é outro ensaio destrutivo, de difícil configuração, alto custo de implementação e elevado tempo de preparação. Além disso, o coeficiente $\mathrm{K}$ de permeabilidade é definido indiretamente em relação à porosidade do material.

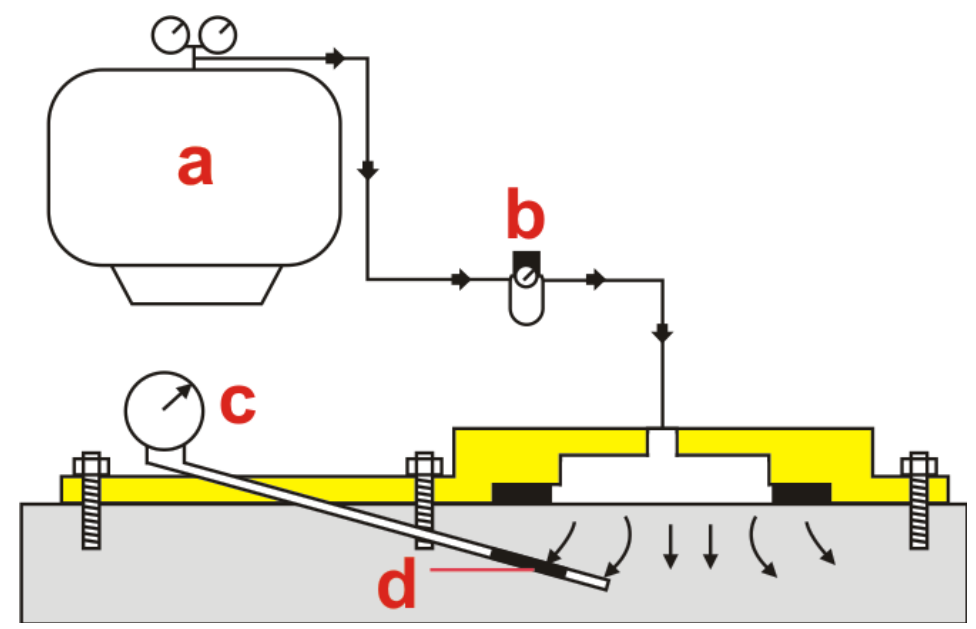

Figura 2.8 - Aparato do ensaio de permeabilidade pelo método de Germann - GGT (adapatado de HANSEN; OTTOSEN; PETERSEN, 1984). Onde: a) Suprimento de ar; b) Regulador de pressão com manômetro; c) Manômetro; d) Sensor de pressão.

\subsubsection{Método de Hong-Parrot}

Método de ensaio proposto por Hong e Parrot (PARROT; HONG, 1991) baseia-se na aplicação de ar (1 atm), através de uma câmara chumbada a superfície do material, em um orifício confeccionado no material $(20 \mathrm{~mm}$ de diâmetro e $35 \mathrm{~mm}$ de profundidade), conforme observado na Figura 2.9. Mede-se então, com o auxílio 
de um transdutor ligado a câmara de pressão, o tempo necessário para que a pressão caia de $50 \mathrm{kPa}$ para $35 \mathrm{kPa}$.

Neste caso, um coeficiente de permeabilidade aparente pode ser calculado, pois uma solução de detergente (tensoativo) é aplicada posteriormente a fim de indicar qual o trajeto de escoamento de ensaio.

O método tem como desvantagem sua característica destrutiva e graus de incerteza quanto ao trajeto de escoamento do ar mensurado pela solução de detergente.

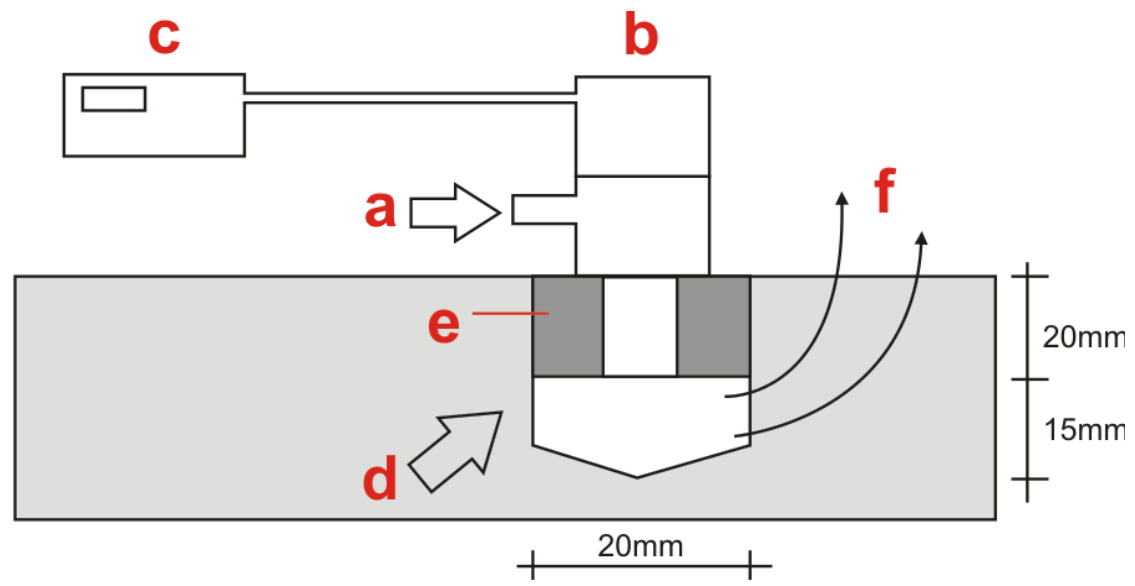

Figura 2.9 - Aparato do ensaio de permeabilidade pelo método de Hong Parrot (adaptado de PARROT; HONG, 1991). Onde: a) Injeção de ar; b) Transdutor de pressão; c) Indicador digital de pressão; d) Buraco perfurado na superfície do material; e) Vedação; f) Fluxo de ar.

\subsubsection{Método de Torrent}

Método desenvolvido por Roberto Torrent (TORRENT, 1992) é o mais próximo ao em desenvolvimento neste trabalho e consiste basicamente no uso de uma câmara de célula dupla (interna e externa) aonde é produzida uma pressão negativa, com o auxílio de uma bomba de vácuo, sob a superfície do material o qual se deseja ensaiar (Figura 2.10.1). O ensaio propriamente dito começa a partir do ponto máximo de pressão negativa permitido pela configuração do ensaio (aproximadamente 30 mbar). A partir daí, a câmara interna começa a recuperar a pressão até atingir o equilíbrio com os valores atmosféricos. A câmara externa tem sua pressão regulada durante toda a execução do ensaio, através de um regulador 
que mantém as pressões entre as duas câmaras iguais durante todo o ensaio, para excluir qualquer tipo de influência de ar que possa vir da superfície, tornando o fluxo teoricamente unidirecional. O ensaio dura cerca de $360 \mathrm{~s}$ ou até que a pressão da câmara interna se iguale a 20 mbar.

De todos os métodos apresentados nesta seção, este é o único realmente não-destrutivo, de rápida execução, controle e baixo custo de implementação. É comercializado desde 1993 e tem sido desenvolvido para a área de concreto a mais de 15 anos. Por isso, muitos são os artigos e resultados publicados com este equipamento que corroboram o uso deste método para avaliação, sobretudo de superfícies de concreto. Foi incluído em 2003 na norma Suíça de especificações para construções de concreto para avaliação quanto à permeabilidade ao ar para esse tipo de estrutura (SIA 262, 2003).

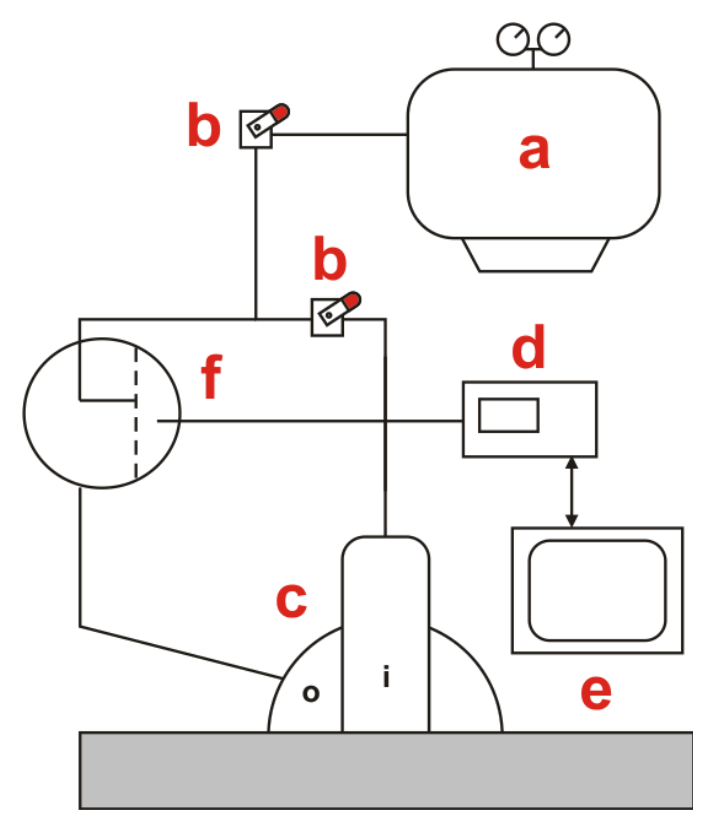

Figura 2.10.1 - Aparato do ensaio de permeabilidade pelo método de Torrent (adaptado de TORRENT, 1992). Onde: a) Bomba de vácuo; b) Válvula; c) Célula de duas câmaras; d) Medidor de pressão; e) Data-logger; f) Diafragma regulador de pressão ( $\mathrm{Pi}=\mathrm{Po})$.

Para efeito de cálculo do coeficiente de permeabilidade, o qual é denominado de kT (de acordo com o método de Torrent), o autor assume que a estrutura é homogênea e isotrópica, isto é, não muda sua porosidade (consequentemente sua permeabilidade) ao longo de todo o cp; a pressão da câmara externa é exatamente 
a mesma que da interna ao longo de todo o ensaio, o que promove um fluxo laminar perpendicular a direção núcleo/superfície do cp; depois de aplicada pressão negativa entre superfície e câmaras, o diagrama de pressão ao longo do cp é equivalente ao apresetando na Figura 2.10.2:

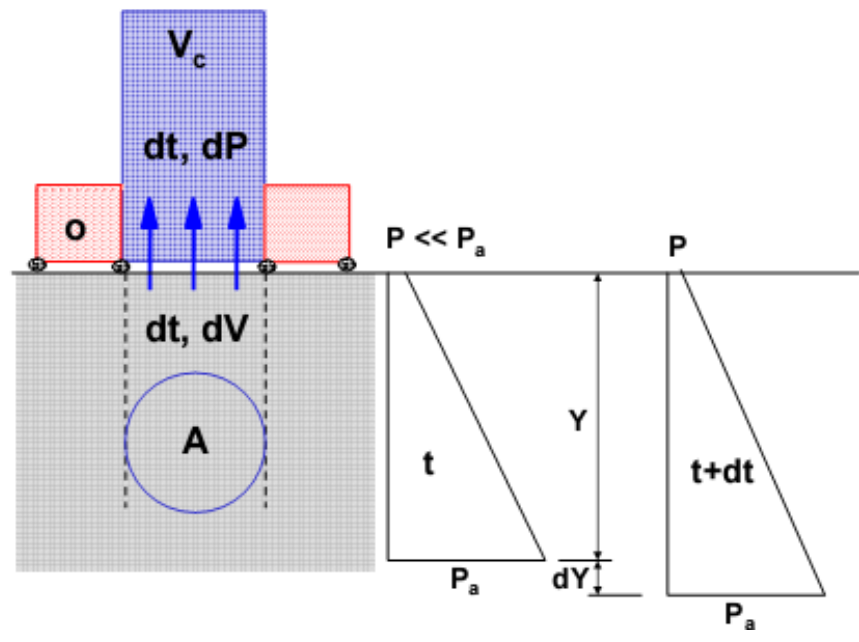

Figura 2.10.2 - Diagrama de pressões assumido pelo método de Torrent. Onde a pressão interna da câmara (P) é menor que a pressão atmosférica (Pa) durante fluxo (TORRENT, 2010).

O fluxo de ar ao interior da câmera então é descrito através da equação de Hagen-Poiseuille para fluidos compressíveis, combinada a equação geral dos gases de Clapeyron, resultando então, após integrações e rearranjos, em:

$$
k T=\left(\frac{V c}{A}\right)^{2} \frac{\mu}{2 \epsilon P a}\left(\frac{\ln \frac{P a+\Delta P i}{P a-\Delta P i}}{\sqrt{t f}-\sqrt{t 0}}\right)^{2}
$$

Onde kT é o coeficiente de permeabilidade ao ar de Torrent $\left(\mathrm{m}^{2}\right)$; Vc o volume útil da câmara interna $\left(\mathrm{m}^{3}\right)$; A seção transversal útil da câmara interna $\left(\mathrm{m}^{2}\right) ; \mu$ a viscosidade do ar $\left(\mathrm{N} . \mathrm{s} / \mathrm{m}^{2}\right) ; \varepsilon$ a porosidade estimada da superfície do concreto (que é considerada como 0,15$) ; \mathrm{Pa}$ a pressão atmosférica $\left(\mathrm{N} / \mathrm{m}^{2}\right) ; \Delta \mathrm{Pi}$ a variação de pressão no interior da câmara até o tempo tf $\left(\mathrm{N} / \mathrm{m}^{2}\right)$; tf é o tempo final do teste (s); t0 o tempo inicial de de teste (s).

A eficiência do método de medida é comprovada justamente através das diversas publicações com o uso da técnica, utilizada para medir várias condições de emprego em superfícies de concreto, tanto em laboratório quanto in situ. Como 
exemplo, pode-se observar, na Figura 2.10.3, uma avaliação de antigas pontes de concreto Suíças frente ao processo de carbonatação pelo método de Torrent em relação à avaliação por fenolftaleína (TORRENT; FRENZER, 1995):

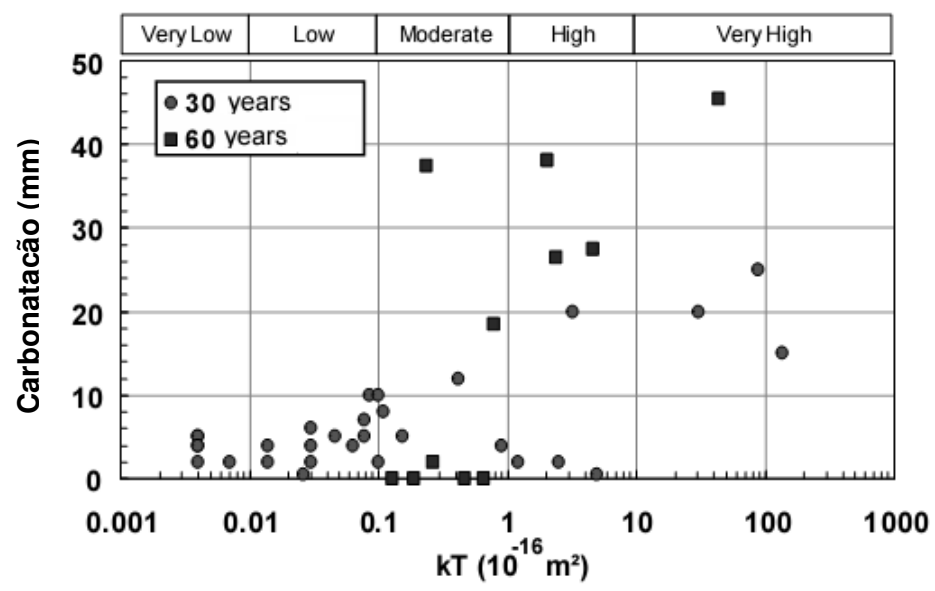

Figura 2.10.3 - Relação entre kT e profundidade de carbonatação (TORRENT; FRENZER, 1995)

Também, como título de exemplo, em outro estudo (QUOC; KISHI, 2006) foram medidas através do método duas superfícies de concreto, uma com tratamento superficial e outra sem tratamento, e seus resultados foram ilustrados graficamente através de curvas de permeabilidade, conforme mostra a Figura 2.10.4. Pode-se observar que a face tratada apresenta níveis de permeabilidade muito menores do que a sem tratamento, conforme se esperava.

a) Tratado $\quad(\mathrm{kTgm}=0.4310-16 \mathrm{~m} 2)$

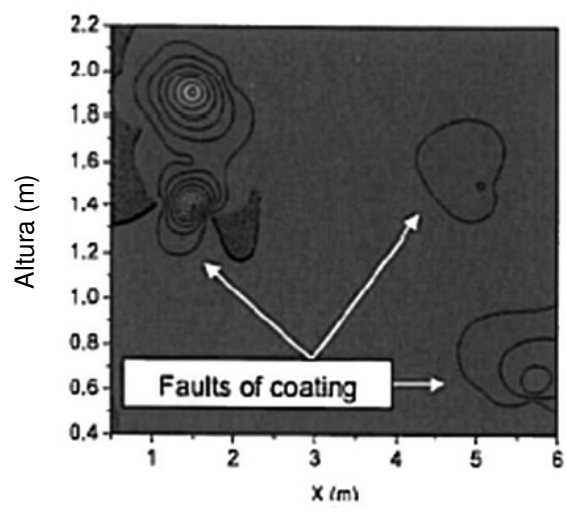

b) Sem tratamento $\quad(\mathrm{kTgm}=4.9610-16 \mathrm{~m} 2)$

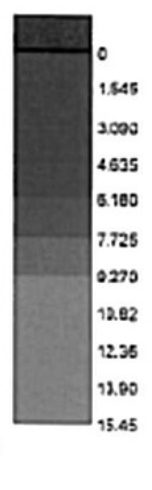

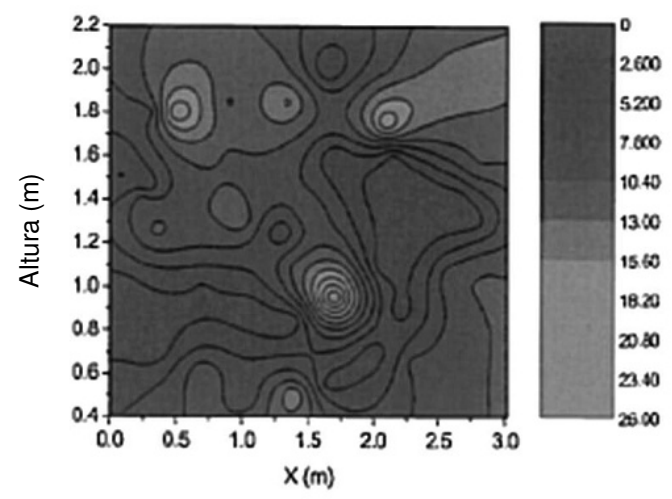

Figura 2.10.4 - Curva de valores de kT em duas faces de uma parede de concreto (EBENSPERGER; TORRENT, 2009). 
Ainda, a correlação do método com outros importantes testes de transporte de massa foi comprovadamente demonstrada, conforme demonstram as Figuras 2.10.5; 2.10.6; 2.10.7:

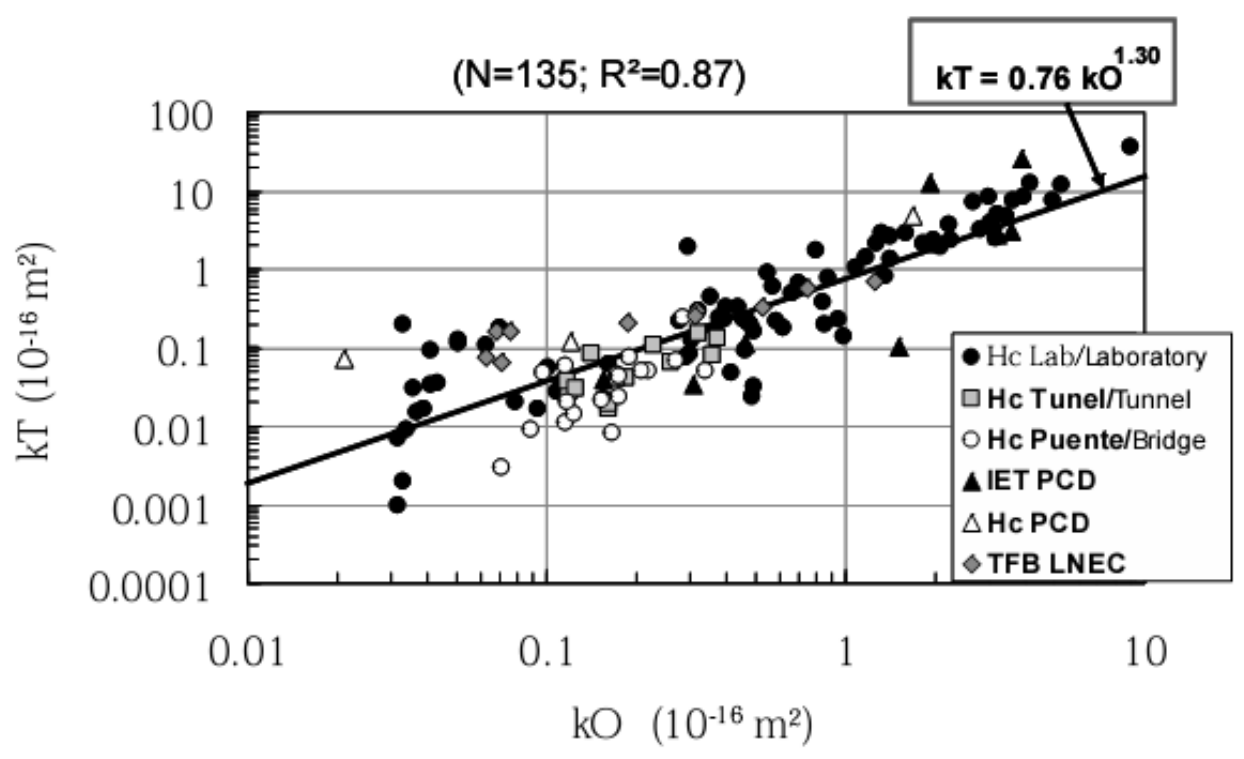

Figura 2.10.5 - Correlação entre kT (coeficiente de Torrent) e o kO (método de Cembureau) (EBENSPERGER; TORRENT, 2009).

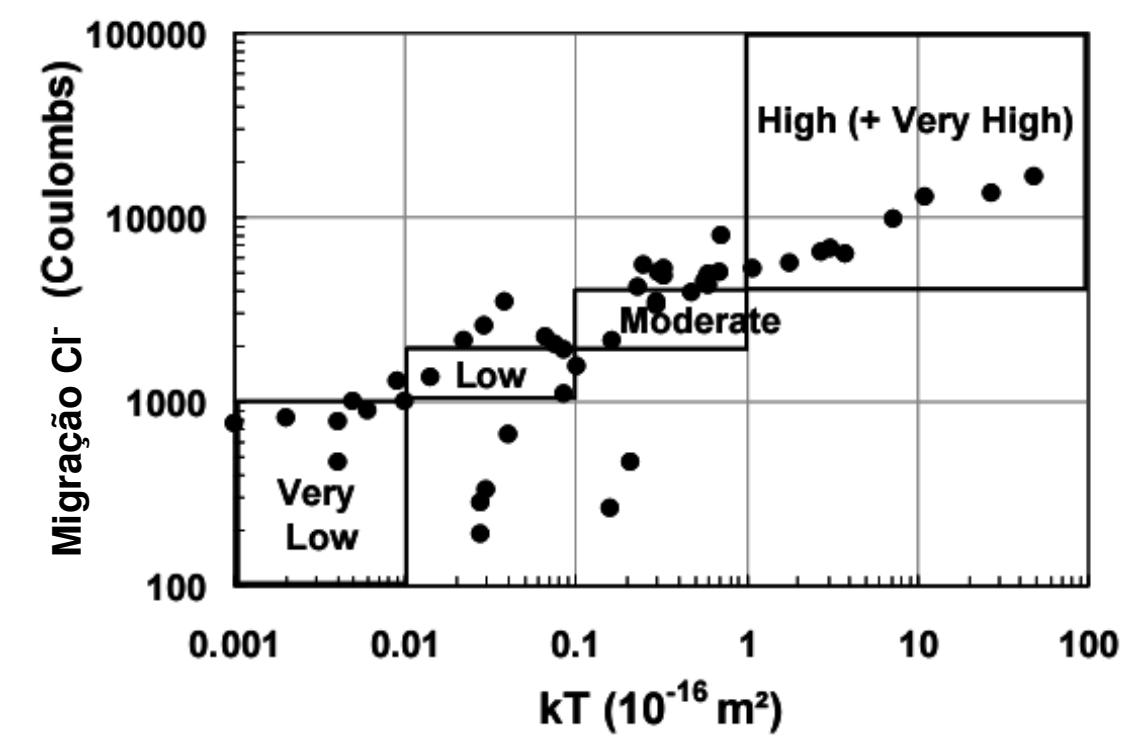

Figura 2.10.6 - Correlação entre kT e o método de migração de cloretos da ASTM C1202 (EBENSPERGER; TORRENT, 2009). 


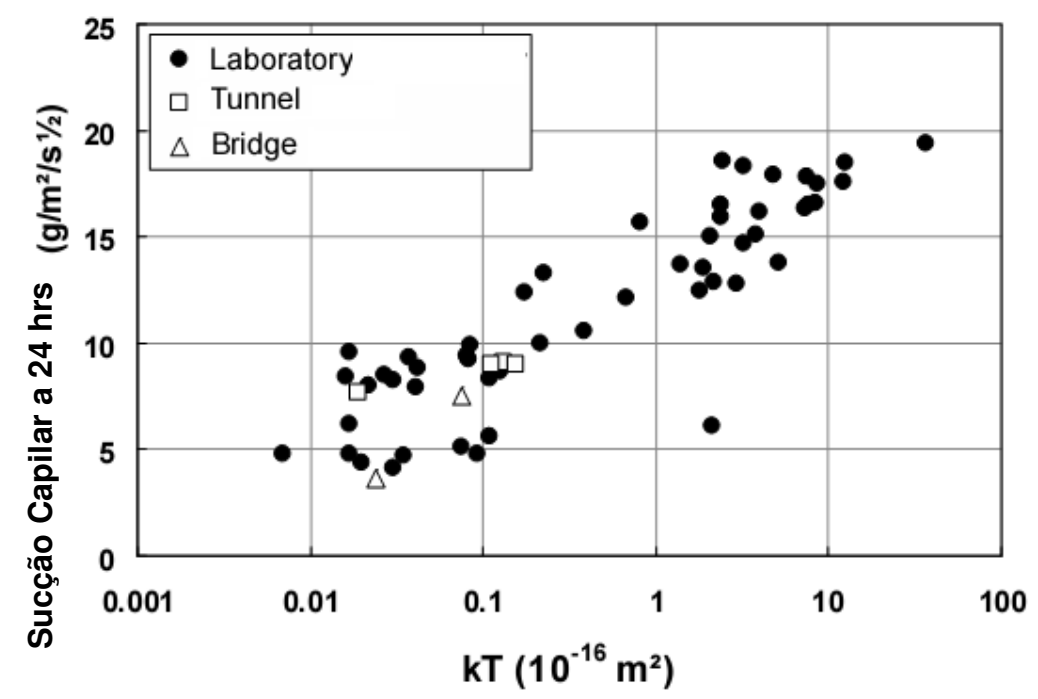

Figura 2.10.7 - Correlação entre kT e o coeficiente de sucção capilar em 24h da SIA 262/1A (EBENSPERGER; TORRENT, 2009).

Como se pode observar, a técnica baseada no método de vaccum-decay tem potencial de avaliar com sucesso microestruturas de materiais cimentíceos porosos como é o caso de superfície de concretos de diversas categorias. Entretanto, as considerações feitas pelo modelo criado por Torrent, sobretudo em seu equacionamento, nem sempre correspondem à realidade do fenômeno relacionado a argamassas de revestimento. Os detalhes do equipamento, com o uso de uma câmara externa, trazem a dúvida se essa é mesmo a situação ideal uso em materiais tão porosos como é o caso de argamassas, que têm um tempo de recuperação muito superior ao de concretos. Isso pode modificar a dinâmica de vazão, uma vez que esse tipo de controle de pressão (entre câmara interna e externa) utilizado por Torrent pode não ser tão eficiente para altas velocidades.

\subsection{VARIÁVEIS DO MATERIAL QUE INFLUENCIAM A MEDIDA DE PERMEABILIDADE AO AR}

As medidas de permeabilidade ao ar podem ser influenciadas por diversas variáveis que afetam as características da estrutura de poros, como uma possível descontinuidade, presença de água ou umidade, surgimento de produtos de reações, fissuras, etc. Portanto, fatores como formulação, características ambientais, qualidade de uso e condições do espécime devem ser considerados na 
interpretação dos resultados do monitoramento de permeabilidade de estruturas porosas.

Com relação à formulação, fatores como empacotamento das partículas, tipos de agregado utilizados, relação água/cimento e tipos de adições tem uma influência direta sobre a formação da estrutura capilar de materiais porosos. Diferenças nos coeficientes de empacotamento são responsáveis por alterações da distância entre os grãos de agregados que, por conseguinte, alteram os valores de permeabilidade (INNOCENTINI et al., 2002), conforme se pode observar na Figura 2.11 que demonstra experiência realizada com concretos refratários:
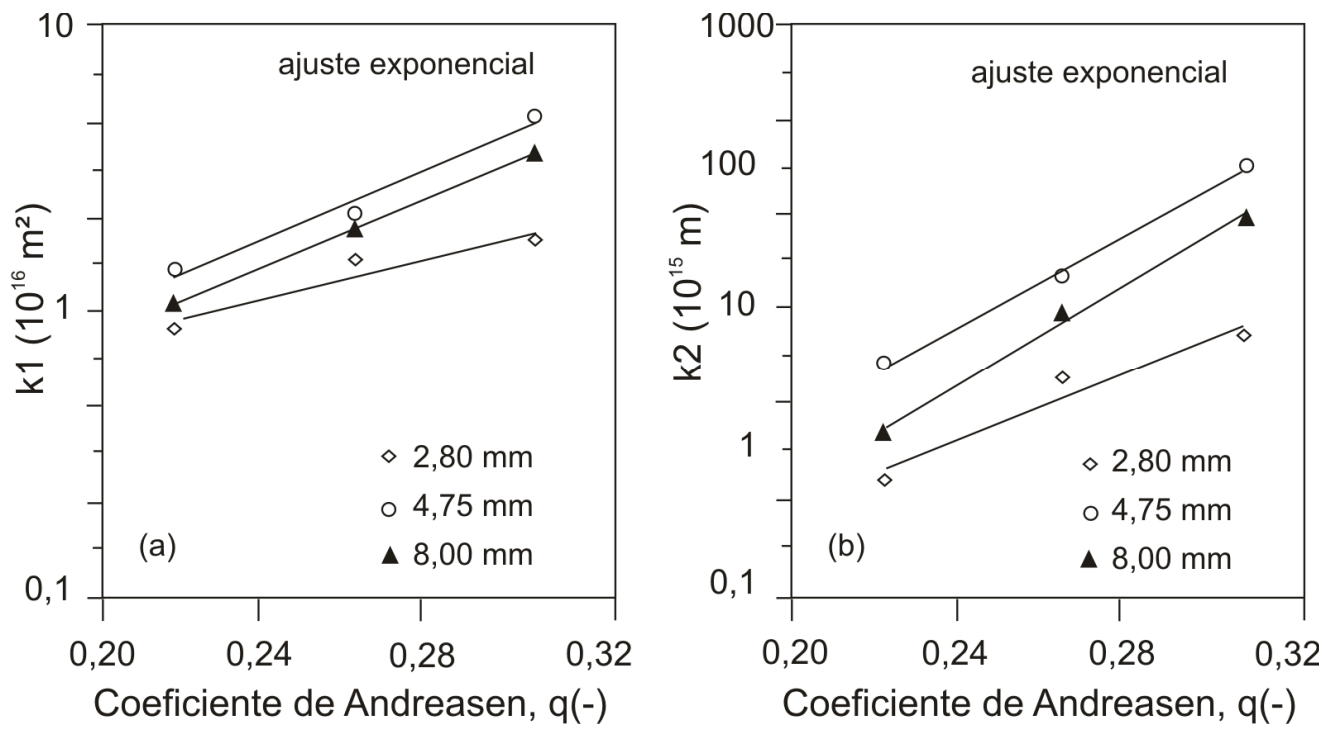

Figura 2.11 - Influência do grau de empacotamento de partículas na permeabilidade de concretos refratários (INNOCENTINI et al, 2002).

A porosidade e tamanho dos agregados também têm relação direta com a permeabilidade dos materiais (MEHTA; MONTEIRO, 1994). Considera-se intuitivamente que agregados com uma porosidade maior em relação à matriz contribuem para um aumento na medida da permeabilidade de concretos, mas essa não é a sua principal contribuição. Quanto maior o tamanho efetivo dos grãos, maior será a interface entre matriz e agregado, o que aumenta a influência da zona de transição. Essa região é vulnerável a diversos tipos de movimentações, geradas por diferentes esforços, que geram microfissuras de tamanho maior que muitos poros 
capilares da pasta, as quais acabam por se propagar e aumentar o volume de vazios interconectáveis e, conseqüentemente, os valores de permeabilidade.

O efeito da relação água/cimento na permeabilidade de materiais cimentíceos ao ar está inicialmente atribuído a sua influência na porosidade do material hidratado. Porém, esse tipo de análise torna-se mais complexo em concretos, como visto anteriormente, devido a gama de tamanhos dos materiais de sua composição, que pode provocar diferenças substanciais na quantidade de água/cimento entre a matriz e da sua zona de transição. Ainda assim, as Figuras 2.12 e 2.13 mostram a relação entre os valores permeabilidade em concretos com diferentes relações água/cimento, para distintas situações de ensaio.

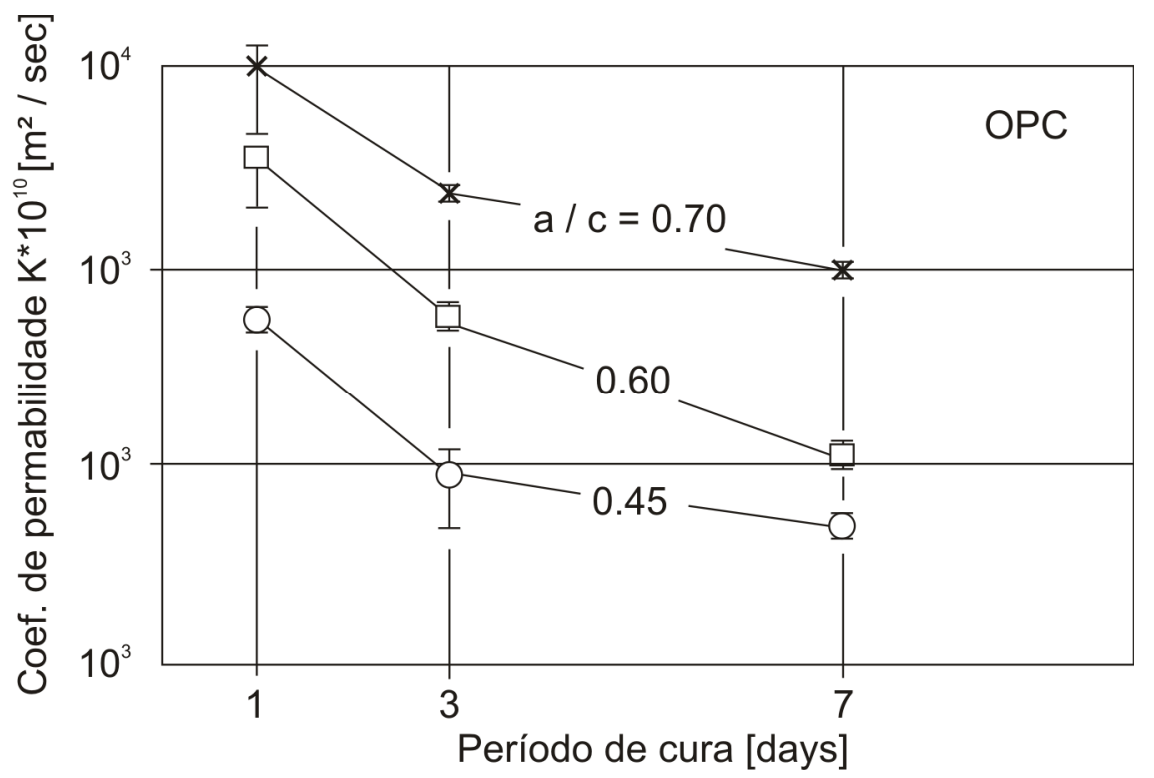

Figura 2.12 - Influência da relação água/cimento na permeabilidade ao ar em concretos (HILSDORF, 1989).

Deve-se observar que a idade do material cimentíceo influencia em seu estado da estrutura, o que provoca uma mudança nos valores de permeabilidade ao longo de muito tempo (SANJUAN; MUNOZ MARTIALAY, 1995). Se levarmos em consideração apenas o fator período, quanto maior o tempo de cura menor serão os valores relacionados às suas constantes de permeabilidade, conforme mostram os resultados obtidos com concretos refratários mostrados na Figura 2.13 (CARDOSO et al., 2003). Isso pode ser explicado devido ao surgimento de produtos de 
hidratação, desde que não haja qualquer tipo de degradação provocada (TAYLOR, 1990).
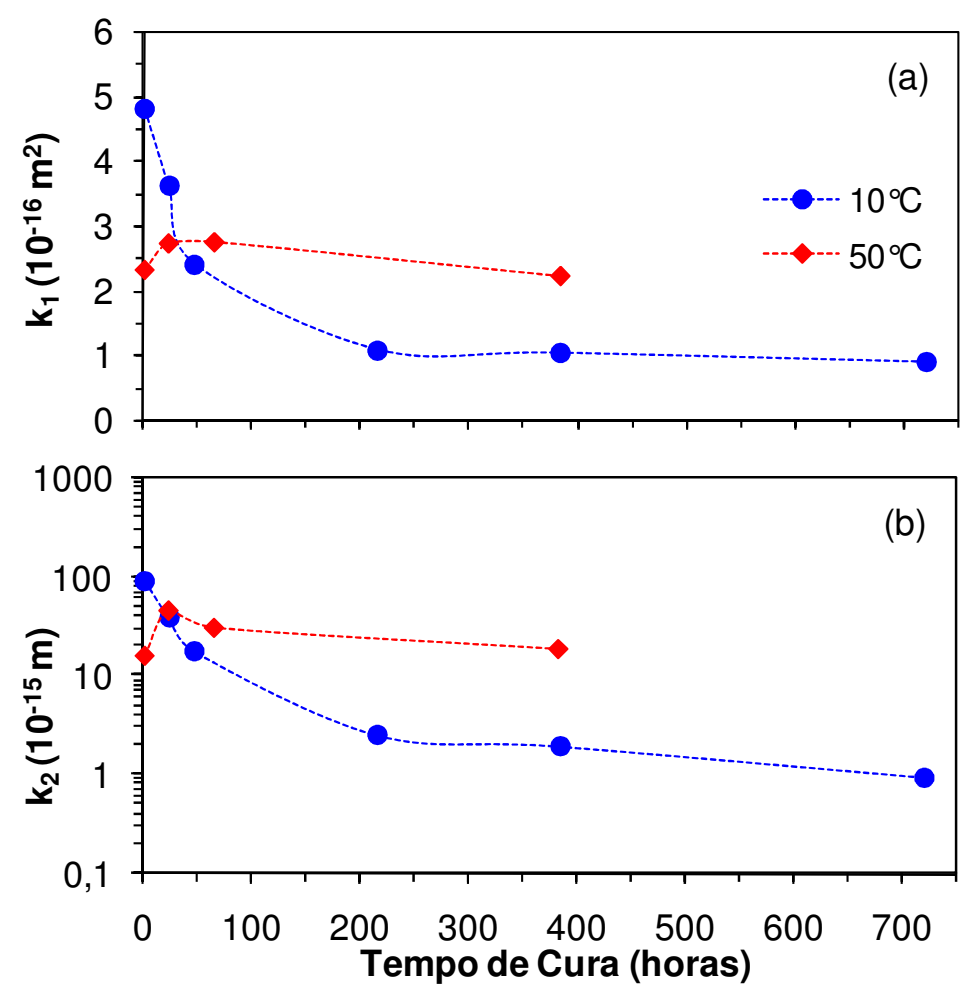

Figura 2.13 - Influência da idade e temperatura de cura na estrutura porosa e, consequentemente, nos parâmetros de permeabilidade ao ar (CARDOSO et al., 2003).

Também, durante o processo de secagem ou cura, principalmente em ambientes de laboratório, deve-se atentar para a temperatura a qual o material será submetido para que não haja dissociação de alguns dos produtos e alterações na cinética de hidratação de alguns componentes do material, de o que pode provocar mudanças na sua estrutura (TAYLOR, 1990; CARDOSO et al., 2004).

Ainda com relação à formulação, o uso de adições (pozolanas, cinzas volantes, cal, etc) também é responsável por alterações na permeabilidade dos concretos e argamassas. Inicialmente, se partículas menores forem incorporadas ao material, isso significa um aumento no consumo de água em relação à referência, o que ocasiona as alterações mostradas anteriormente. Além disso, partículas de tamanhos diferentes misturadas a granulometria de referência podem gerar graus de empacotamento distintos. Também existem adições com características 
cimentantes, com formação de produtos de hidratação, o que pode provocar tanto a comatação dos poros existentes na estrutura quanto sua destruição se esses produtos tiverem tamanho suficiente para provocar uma expansão ou descontinuidade do material.

A evolução dos valores de permeabilidade também pode ser observada com o surgimento de microfissuras (superficiais) e macrofissuras (profundas) decorrentes de carregamentos e acomodações dos artefatos cimentíceos em serviço (PICANDET; KHELIDJ; BELLEGOU, 2009). O surgimento de fissuras provoca alterações na estrutura porosa tanto em relação à distribuição de tamanho dos poros quanto na comunicação entre eventuais espaços fechados ou isolados que passam a constituir-se em caminhos para passagem de fluido no interior de concretos e argamassas. Conforme se pode observar na Figura 2.14, os valores de permeabilidade crescem proporcionalmente ao aumento do tamanho de fissuras induzidas em diferentes corpos-de-prova de concreto através de equipamento adaptado em máquina de ensaio universal. Sugiyama constatou ainda, através de um estudo com concretos de diferentes proporções de água/cimento, que a permeabilidade do concreto cresce a partir de níveis de $75 \%$ a $90 \%$ da carga de rompimento em função do grau de saturação do $\mathrm{cp}$, devido ao surgimento de microfissuras (SUGIYAMA; BREMNER; HOLM, 1996).

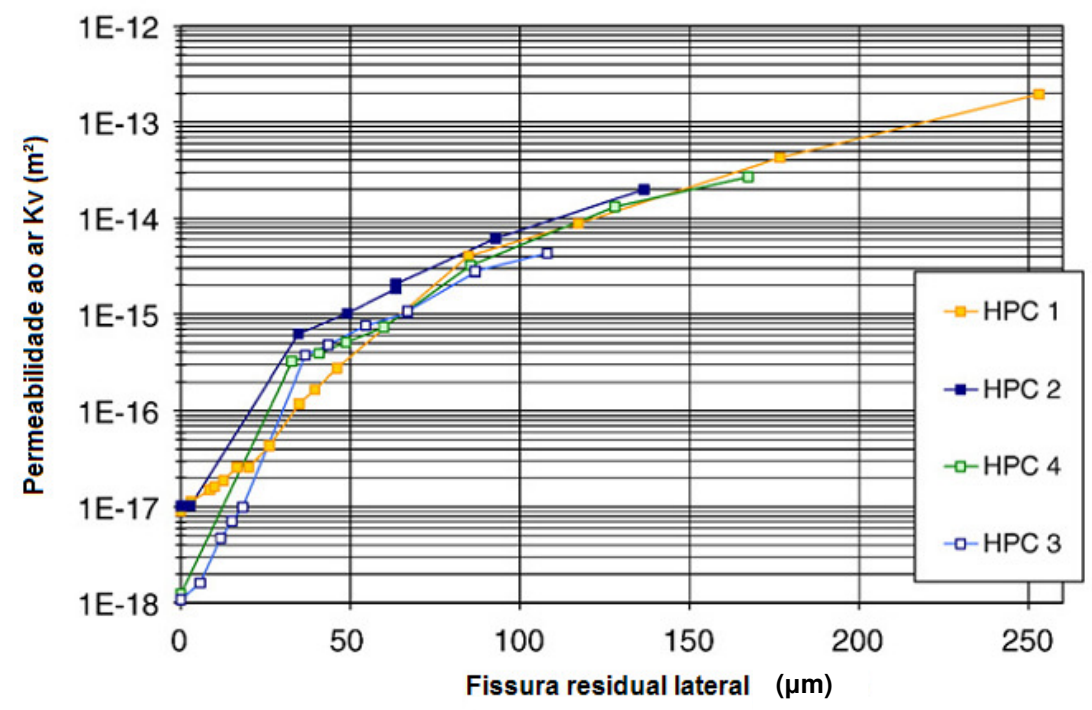

Figura 2.14 - Relação entre permeabilidade e tamanho de fissuras para diferentes corpos-deprova de concreto (PICANDET; KHELIDJ; BELLEGOU, 2009). 
Por se tratar de dois fluidos imiscíveis, a medida de permeabilidade ao ar é afetada pela presença de água nos poros de concretos e argamassas (ABBAS; CARCASSES; OLLIVIER, 1999). A presença da umidade provoca o entupimento dos poros que acaba por subestimar os valores de permeabilidade de concretos (ROMER, 2005). Em umidades próximas a 95\% o fluxo de ar encontrava-se bastante reduzido, tornando a medida difícil de ser realizada e com uma dispersão de resultados considerável (RILEM TC 116-PCD, 1999). Portanto, quanto maior for o grau de umidade de um corpo-de-prova, menor será o valor sua constante de permeabilidade ao ar, não necessariamente em uma relação linear, para um mesmo material, conforme mostram os resultados da Figura 2.15:

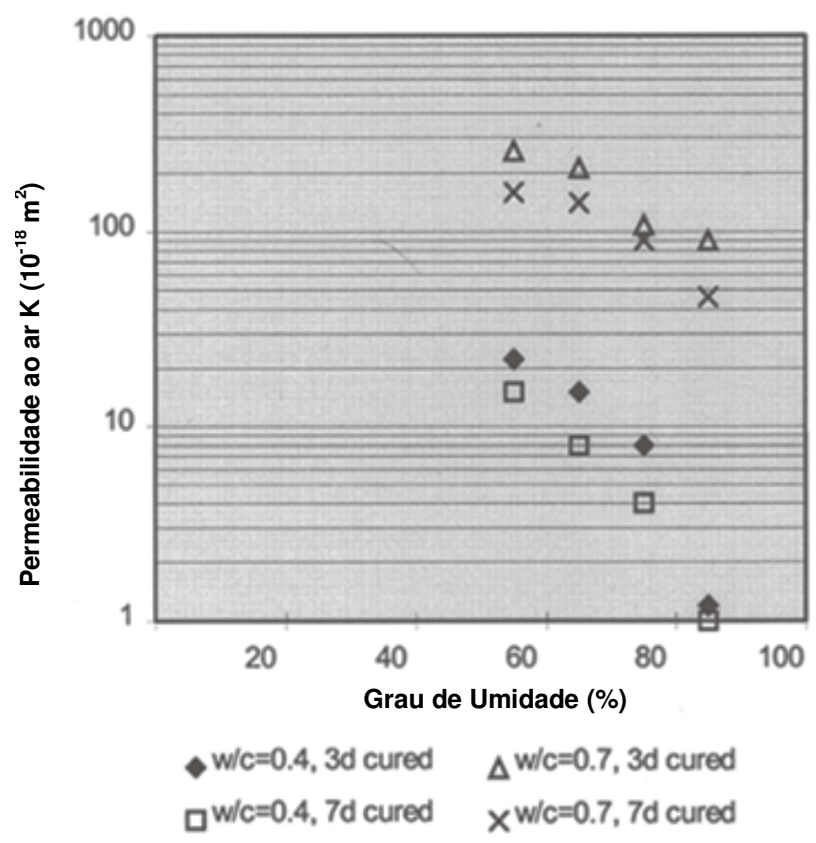

Figura 2.15 - Evolução dos valores de permeabilidade em função do aumento da UR de um concreto (RILEM TC 116-PCD, 1999).

Concluindo, a permeabilidade de um material cimentíceo é função da sua estrutura de poros (microestutura) - distribuição de tamanhos e interconectividade. É um fenômeno difícil de ser analisado para esse tipo de material devido ao grande número de variáveis envolvidas, as quais podem influenciar diretamente sua determinação, seja em relação à formulação, exposição, idade e serviço. Portanto, esse tipo de estudo deve ser conduzido de forma a considerar todos esses tipos de 
intercorrências e a obtenção de resultados deve acontecer de maneira que todas as condições de ensaio estejam cuidadosamente padronizadas.

\subsection{CONCLUSÕES DO CAPÍTULO}

A medida de permeabilidade ao ar é uma importante ferramenta para determinação das características e condições de microestrutura dos materiais, desde a sua concepção até ao longo de todo o seu período de utilização. Deve-se observar, porém, que a permeabilidade é apenas um dos diferentes fenômenos de transporte de massa existente na natureza e está relacionado a determinado tipo de condição tanto de estrutura quanto de funcionamento. É uma propriedade que trata da interação entre fluido e sólido, e não uma característica de qualquer um dos dois materiais. Portanto, podem-se relacionar medidas de permeabilidade a diferentes fenômenos naturais a fim de se obter características quanto à utilização fim de diversos tipos de materiais, entretanto deve-se ter em mente que não é um evento de ocorrência individual nem resolve todas as condições de contorno existentes no processo.

Existem hoje diversos métodos para mensurar a permeabilidade ao ar em materiais porosos, cada qual com suas vantagens e desvantagens. No entanto, ainda há uma lacuna na área de argamassas de revestimento no tocante a ensaios dessa natureza, sobretudo in situ, que representem da melhor forma as condições da estrutura avaliada. Além disso, as argamassas são compósitos complexos, de natureza bifásica, que apresentam características e empregos diferentes de concretos ou outros tipos de materiais, portanto existe a necessidade do desenvolvimento de um método que contemple todas essas particularidades desse tipo de insumo. Ainda, a forma de tratamento dos dados obtidos deve ir ao encontro das condições de ensaio as quais a medida foi realizada. Deve-se atentar, portanto, as condições que influenciam mudanças e alterações nos valores de permeabilidade para análise estrutural dos materiais, que podem eventualmente ser corrigidas se necessário. 


\section{DESENVOLVIMENTO DO MÉTODO DE VACCUM-DECAY PARA ARGAMASSAS}

O método de medida de permeabilidade ao ar in situ através da técnica de vaccum-decay já foi aplicado por outros autores para ensaios, sobretudo, de concretos (TORRENT, 1992; DHIR et al., 1995; CALOGOVIC, 1995; GUTH; ZIA, 2001). Entretanto, a avaliação de materiais superficiais como argamassas de revestimento requer um projeto adequado que contemple toda e qualquer variável de controle do fenômeno, suas particularidades, correta análise e interpretação dos resultados em função da velocidade do fluido proposto, além de simulação de situações práticas.

\subsection{OBJETIVO}

O objetivo deste capítulo é detalhar o desenvolvimento do método, desde detalhes referentes à construção e adaptação do equipamento até as formas de tratamento dos dados de medição, fechando com ensaios teste em argamassa industrializada, além de placas de fibrocimento, demonstrando assim toda a potencialidade da técnica utilizada.

\subsection{EQUIPAMENTO}

Uma das principais características, tomada como premissa, de grande importância para o desenvolvimento do método foi a da execução de um ensaio de baixo custo e fácil reprodutibilidade, que começa ainda na construção do equipamento. O aparelho foi desenvolvido inicialmente pelo Prof. Dr. Murilo Daniel de Mello Innocentini, através de projeto financiado pelo CNPq (CNPq Universal 019/2004, processo 474155/2004-8), para medida de permeabilidade em materiais cerâmicos. Uma réplica foi construída com a finalidade inicial de ensaiar blocos permeáveis de pavimento de concreto intertravado e adaptado então para o uso em argamassas de revestimento (Figura 3.1), o que já demonstra de antemão que o aparato, desde que adaptado, pode ser utilizado na análise de diversos tipos de materiais porosos. 


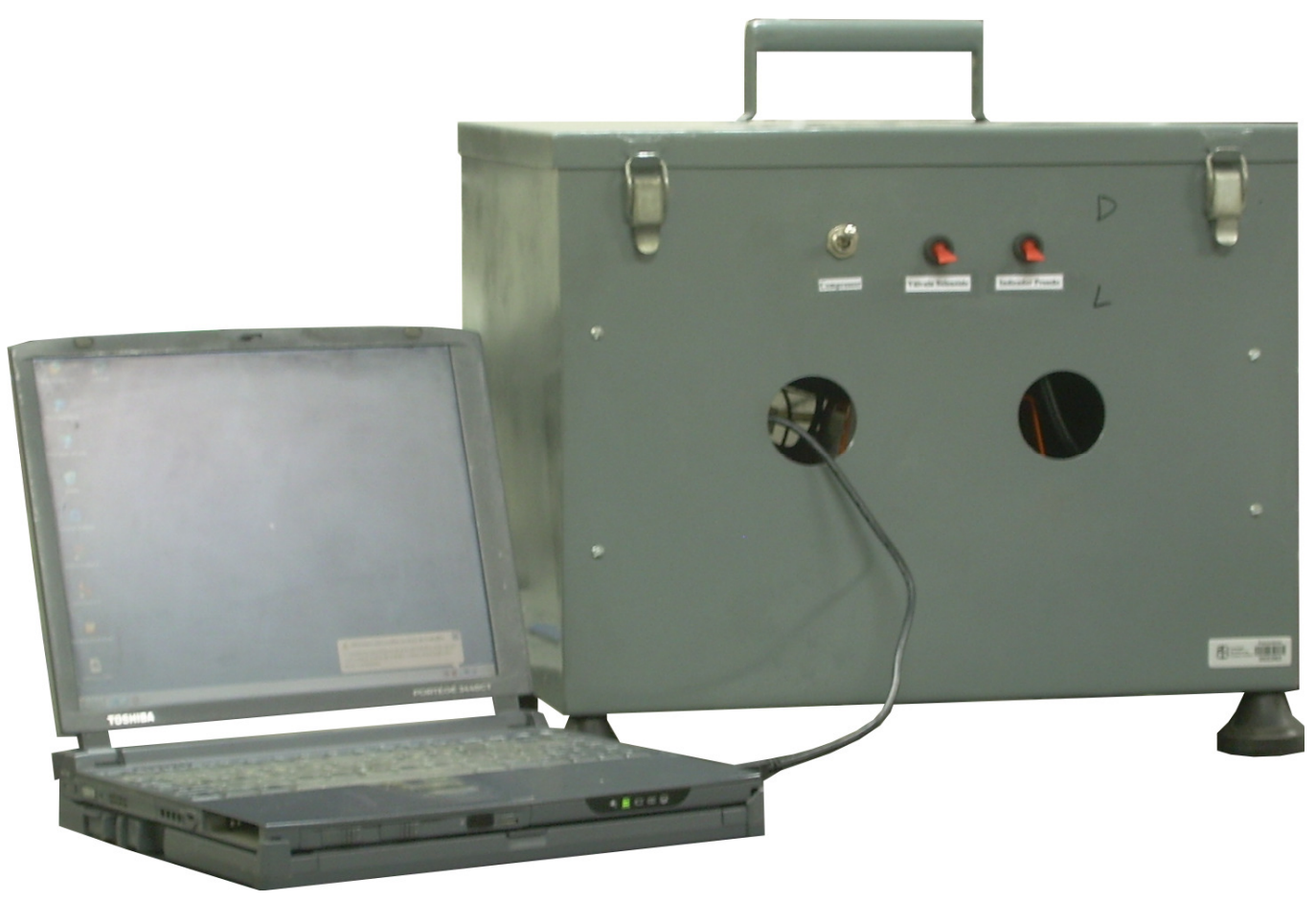

Figura 3.1 - Aparelho construído e adaptado para medida de permeabilidade em argamassas.

\subsubsection{Configuração}

A configuração do aparelho conta basicamente com uma bomba de vácuo ligada a uma câmara (confeccionada neste caso em nylon), que fica em contato com uma das superfícies da argamassa, onde é formada inicialmente uma região de pressão negativa. Ligada a câmara de vácuo, existe um transdutor que registra as variações de pressão ao longo de todo o tempo de ensaio. Para que os dados possam ser coletados, uma placa aquisitora (data-logger) fica ligada a um computador que, em tempo real, registra todo o processo através de um software genérico adquirido junto com este dispositivo. Um mostrador digital de pressão, ligado ao transdutor, permite que o operador tenha um controle visual do momento de estabilização das pressões tanto de vácuo (quando a bomba está acionada) quanto da atmosférica (que representa o fim de ensaio). Além disso, uma válvula solenóide restringe o fluxo de ar somente no sentido da argamassa à bomba de vácuo, para permitir que a recuperação de pressão na câmara aconteça, conforme desejado, apenas de uma face à outra do corpo-de-prova. O esquema de 
funcionamento do equipamento, assim como as dimensões da câmara de vácuo utilizada, é detalhado na Figura 3.2:
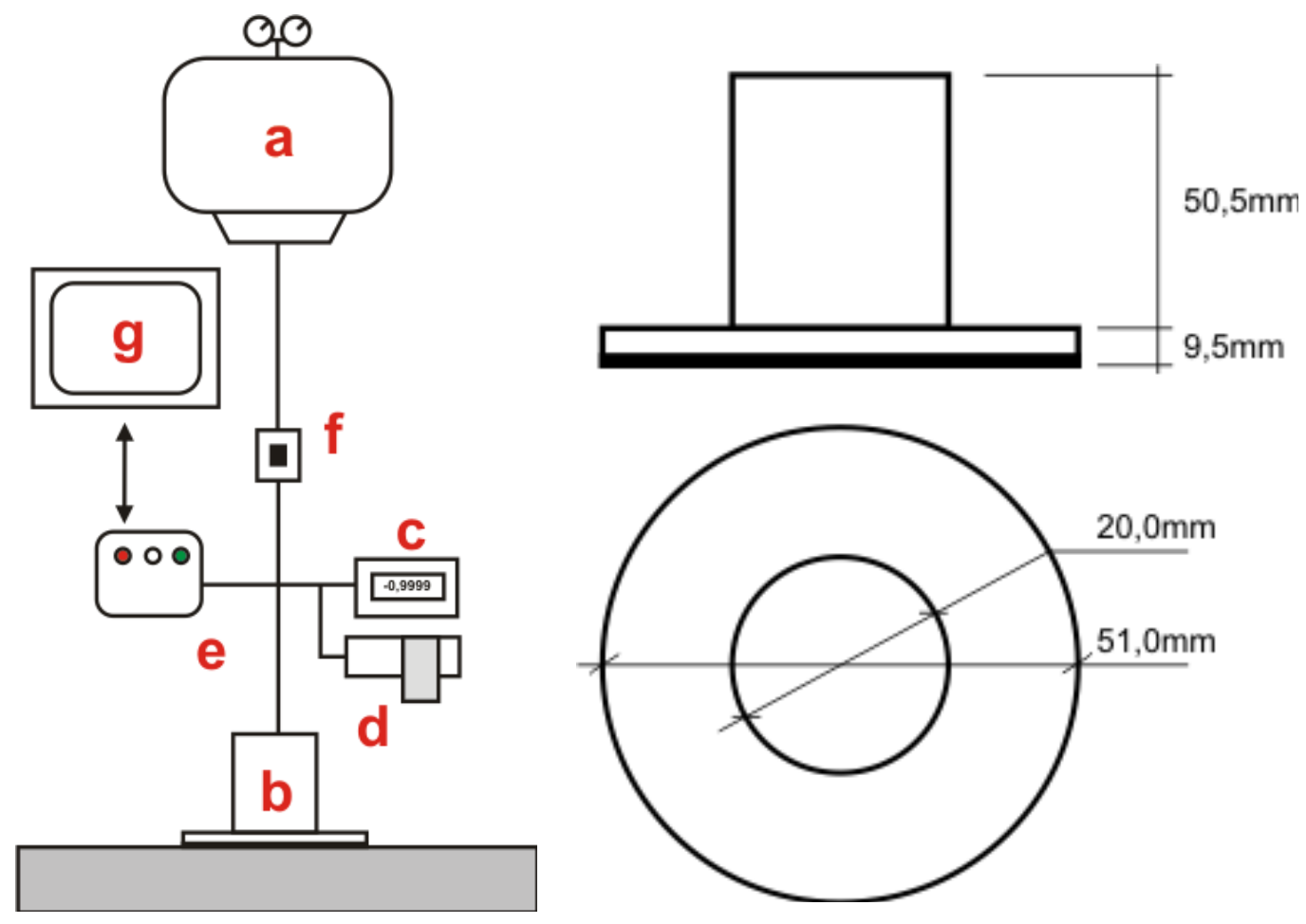

Figura 3.2 - Esquema de funcionamento do aparelho de permeabilidade e detalhamento das dimensões da câmara de vácuo. Onde: a) Bomba de vácuo; b) Câmara de vácuo; c) Mostrador de pressão digital; d) Transdutor de pressão; e) Placa aquisitora de dados (data-logger); f) Válvula solenóide; g) Computador.

O perfil típico de um ensaio de permeabilidade, através de decaimento de vácuo, é bastante característico (TORRENT, 1992; CALOGOVIC, 1995) e pode ser observado na Figura 3.3.1. Nota-se que a curva de variação de pressão vai sofrendo uma desaceleração em função do tempo devido à diminuição do gradiente de pressão entre o meio externo e o interior da câmara de vácuo. Isto é, a medida que o ar movimenta-se do meio de maior pressão a região de pressão negativa essa variação diminui e a força motriz que impulsiona o movimento do fluido, consequentemente, é reduzida. 


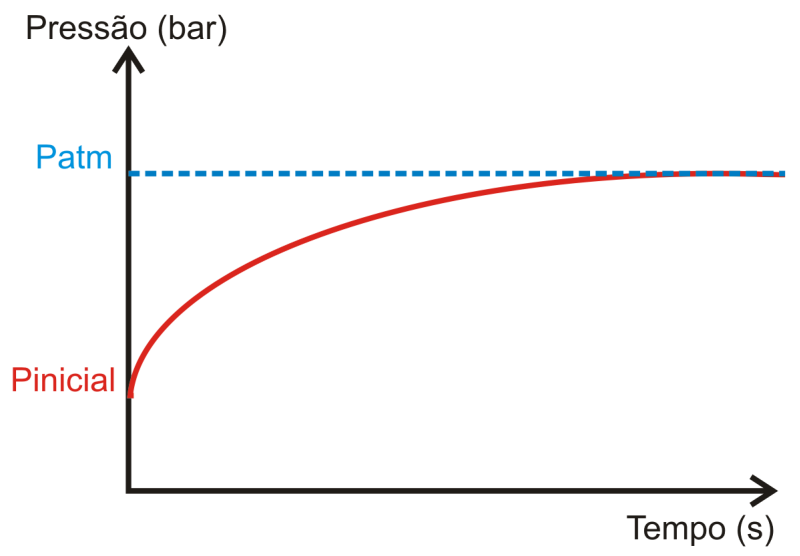

Figura 3.3.1 - Perfil típico de um ensaio de permeabilidade através do método de vaccumdecay.

\subsubsection{Vedações}

Quando os primeiros ensaios foram realizados, as curvas obtidas demonstravam perfis semelhantes aos da Figura 3.3.2. Ao invés de ocorrer uma desaceleração, como relatado anteriormente, a curva apresentava uma aceleração de ganhos de pressão, o que indicava uma possível incidência de um fluxo de ar adicional provindo de outra direção ou de vazamentos do próprio equipamento. Inicialmente, todas as conexões do aparelho foram revisadas e isoladas, mas o problema parecia persistir.

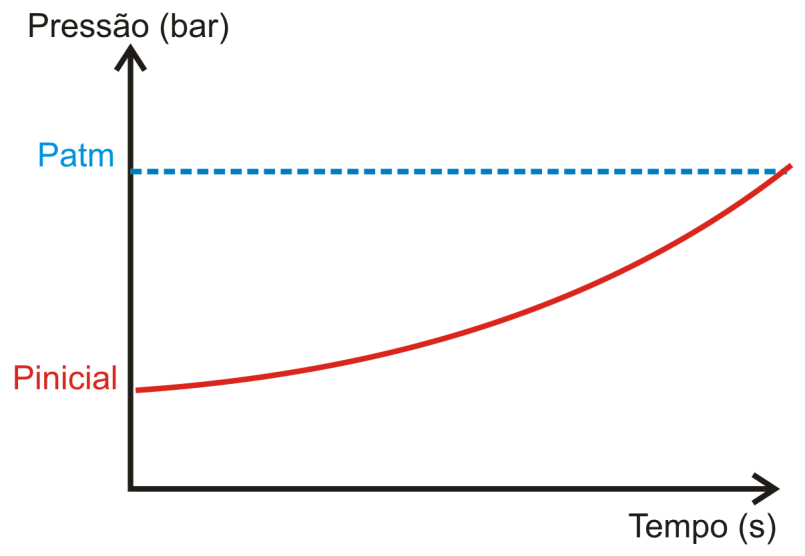

Figura 3.3.2 - Curva de recuperação de pressão acelerada, denotando vazamentos durante o ensaio. 
Antes de qualquer ensaio, uma verificação é feita em material que tenha porosidade (poros permeáveis) próxima ou igual a zero, como é o caso de metais e vidros. A curva para esse tipo de insumo deve apresentar um patamar de pressão por um tempo igual ou superior a, pelo menos, 5 minutos, que corresponde a um intervalo suficiente para verificação de ensaios em argamassas. Conforme descrito anteriormente, mesmo depois de todas as conexões terem sido revisadas a curva continuava apresentando uma aceleração nos ganhos de pressão quando eram realizados ensaios com argamassa. Entretanto, no metal o ensaio demonstrava justamente o comportamento esperado, demonstrando que o equipamento já não poderia mais estar com qualquer tipo de vazamento, mas o problema estava sim na interface com o material ensaiado. A borracha de vedação responsável pelo isolamento entre superfície do material ensaiado e meio externo não era suficientemente macia para exercer eficientemente sua função, fazendo com que o ar entrasse também através deste contato ao interior da câmara (Figura 3.4), explicando o comportamento anômalo indicado na curva.

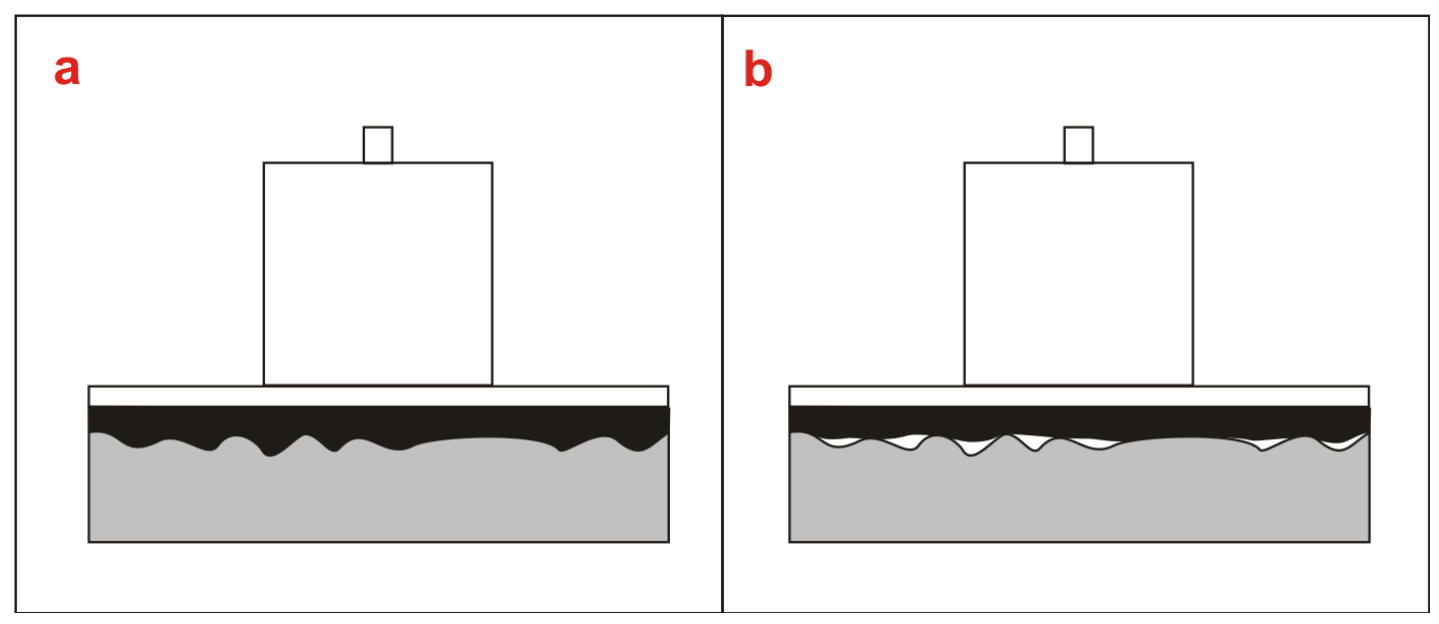

Figura 3.4 - Esquema representativo do contato entre a câmara de vácuo e argamassa. Onde: a) Material provendo interface ideal, sem defeitos de contato; b) Material com flexibilidade insuficiente para promover interface ideal, com defeitos de contato.

A fim de resolver essa questão, diversos tipo de espumas e elastômeros foram testados. As espumas e elastômeros com perfis esponjosos são bastante dúcteis e resilientes, perfeitas para preencher as imperfeições do contato com a superfície rugosa de argamassas, contudo, têm uma porosidade bastante elevada, mesmo as mais densas, o que não impede o fluxo do ar ao interior da câmara de 
vácuo. No entanto, as borrachas são ótimos materiais de vedação, porém não possuem, na sua maioria, a dureza adequada para preencher os defeitos (rugosidade) na interface entre equipamento de argamassa. Alguns tipos de elastômeros testados têm suas propriedades físico-químicas e mecânicas listados abaixo na Tabela 3.1:

Tabela 3.1 - Propriedades físico-químicas e mecânicas de elastômeros testados na vedação de interface entre câmara de vácuo e argamassa (Fonte: IBC Indústria de Borrachas Caxias Ltda.).

\begin{tabular}{|c|c|c|c|c|c|c|c|}
\hline \multicolumn{2}{|c|}{ ELASTÔMEROS } & $\begin{array}{l}\text { NATURAL } \\
\text { NR }\end{array}$ & SBR & EPDM & $\begin{array}{c}\text { NITRILICA } \\
\text { NBR }\end{array}$ & $\begin{array}{c}\text { NEOPRENE } \\
\text { CR }\end{array}$ & SILICONE \\
\hline \multirow{2}{*}{$\begin{array}{c}\text { FAIXA DE DUREZA } \\
(\text { SHORE A) }\end{array}$} & MACIÇOS & $30-100$ & $35-90$ & $40-90$ & $40-100$ & $40-90$ & $35-90$ \\
\hline & ESPONJOSOS & $10-30$ & $10-30$ & $10-30$ & $10-30$ & $10-30$ & - \\
\hline \multicolumn{2}{|c|}{ TENSÃO DE RUPTURA MEEDIA $\left(\mathrm{kg} / \mathrm{cm}^{2}\right)$} & 200 & 120 & 100 & 120 & 150 & 70 \\
\hline \multicolumn{2}{|c|}{ ALONGAMENTO MÁXIMO NA RUPTURA } & 800 & 600 & 600 & 650 & 600 & 800 \\
\hline \multicolumn{2}{|c|}{ RESISTÉNCIA AO RASGAMENTO } & ÓTIMO & REGULAR & REGULAR & REGULAR & ÓTIMO & REGULAR-BOM \\
\hline \multicolumn{2}{|c|}{ DEFORM. PERMAN. Ȧ COMPRESSÃO } & ÓTIMO & BOM & REGULAR & REGULAR & BOM & REGULAR \\
\hline \multicolumn{2}{|c|}{ RESISTÉNCIA A ABRASÃO } & ÓTIMO & REGULAR - BOM & $\mathrm{BOM}$ & $\mathrm{BOM}$ & ÓTIMO & REGULAR \\
\hline \multicolumn{2}{|c|}{ RESISTÉNCIA AO IMPACTO } & ÓTIMO & BOM & BOM & REGULAR & $\mathrm{BOM}$ & - \\
\hline \multicolumn{2}{|l|}{ RESISTÉNCIA Ȧ FLEXĀO } & ÓTIMO & $\mathrm{BOM}$ & REGULAR & REGULAR & ÓTIMO & $\mathrm{BOM}$ \\
\hline \multicolumn{2}{|c|}{ IMPERMEABILIDADE Aं GASES } & ÓTIMO & REGULAR & REGULAR & REGULAR & $\mathrm{BOM}$ & - \\
\hline \multicolumn{2}{|c|}{ RESISTÉNCIA AO INTEMPERISMO } & - & REGULAR & ÓTIMO & REGULAR & ÓTIMO & ÓTIMO \\
\hline \multicolumn{2}{|c|}{ RESISTÊNCIA À OXIDAÇÂO } & REGULAR & REGULAR & ÓTIMO & BOM & ÓTIMO & ÓTIMO \\
\hline \multicolumn{2}{|c|}{ RESISTÉNCIA AO OZŌNIO } & - & REGULAR & ÓTIMO & REGULAR & ÓTIMO & ÓTIMO \\
\hline \multicolumn{2}{|l|}{ RESISTÉNCIA Ȧ CHAMA } & REGULAR & - & - & - & ÓTIMO & BOM \\
\hline \multirow{2}{*}{$\begin{array}{l}\text { TEMPERATURAS DE } \\
\text { TRABALHO }\left({ }^{\circ} \mathrm{C}\right)\end{array}$} & MÁXIMA & 70 & 70 & 150 & 130 & 100 & 250 \\
\hline & MÍNIMA & -20 & -20 & -35 & -15 & -10 & -80 \\
\hline \multicolumn{2}{|c|}{ RES. Á ÓLEOS MINER. E SOLVENTES } & - & - & - & ÓTIMO & $\mathrm{BOM}$ & - \\
\hline \multicolumn{2}{|c|}{ RES. À ÓLEOS VEGETAL E ANIMAL } & REGULAR & REGULAR & BOM & ÓTIMO & BOM & ÓTIMO \\
\hline \multicolumn{2}{|c|}{ RESISTÉNCIA AOS ÁCIDOS } & REGULAR & REGULAR & ÓTIMO & REGULAR & $\mathrm{BOM}$ & BOM \\
\hline \multicolumn{2}{|c|}{ RESISTÊNCIA AOS ÁLCALIS } & BOM & REGULAR & ÓTIMO & REGULAR & $\mathrm{BOM}$ & $\mathrm{BOM}$ \\
\hline
\end{tabular}

Uma das soluções também testada foi o Policloreto de Vinila flexível, encontrado naturalmente em dispersão líquida. São materiais para aplicação por envase ou injeção, que catalisam em processos de moldagem a quente, com durezas que vão desde o gel até uma borracha dura conforme necessidade. Para o uso no equipamento de permeabilidade, foi utilizado o PVC líquido fabricado pela empresa SILAEX Química LTDA, que tem como nome comercial SQ 5015. Esse produto tem uma dureza Shore A de até 15, mas dependendo de suas condições de catalisação pode apresentar até menos. Para argamassas moldadas em laboratórios, com processos cuidadosos de acabamento superficial, esse tipo de solução mostrou-se perfeitamente eficiente, resolvendo assim o vazamento de interface. Para outros tipos de medição, como em superfícies chapiscadas ou com acabamento superficial muito rugoso, materiais com rugosidade profunda ou desníveis, ou ainda qualquer tipo de descontinuidade, o PVC líquido talvez não seja necessariamente tão maleável a ponto de corrigir tais imperfeições. 


\subsubsection{Reservatório de ar}

Inicialmente, o equipamento foi projetado para realizar ensaios em materiais que possuem baixa porosidade, como é o caso de peças cerâmicas, portanto a estabilização de pressão na câmara de vácuo é lenta o suficiente para que vários pontos possam ser coletados no intervalo de 1 segundo. Isso também é válido para concretos convencionais, por isso não existem relatos de problemas enfrentados com o intervalo de tempo de ensaio neste tipo de material. Entretanto, existem argamassas muitas vezes tão porosas, ou com poros de diâmetros tão grandes, que a recuperação da pressão na câmara de vácuo se dá em questão de segundos, o que inviabiliza a coleta de pontos suficientes para determinação de sua permeabilidade. Isso acontece não somente em argamassas como em concretos muitos porosos, materiais que possuem alguma descontinuidade muito grande (fissuras), filtros cerâmicos com poros muito abertos, etc.

Por isso, os ensaios preliminares em amostras para teste mostraram que em argamassas com porosidade estimada acima de $40 \%$, por exemplo, o número de pontos coletados durante o ensaio era tão pequeno, devido à rápida recuperação de pressão, que sua análise se torna imprecisa. $O$ início do ensaio propriamente dito se da quando da interrupção da bomba de vácuo paralelamente a inicialização da coleta de dados, ambos acionados manualmente. Quando se avalia um corpo-deprova de alta porosidade, onde a pressão cai vertiginosamente imediatamente após o desligamento do vácuo, a repetibilidade pode ficar comprometida uma vez que essa defasagem (causada por um erro humano) pode gerar curvas de pressão com diferentes valores ao longo do tempo. Isto é, um mesmo testemunho, ensaiado diversas vezes, pode gerar curvas de recuperação diferentes.

Pensando nisso, a solução proposta foi a da incorporação de um reservatório de ar, entre a câmara de vácuo e o ponto de coleta de dados, que funciona analogamente a um pulmão, onde o ar que passa pelo sistema percorre um caminho maior até seu registro através do transdutor (Figura 3.5). Isto dá mais tempo ao sistema de coletar pontos durante a realização do ensaio, além de ser facilmente considerado no tratamento dos dados para obtenção do coeficiente de permeabilidade. 


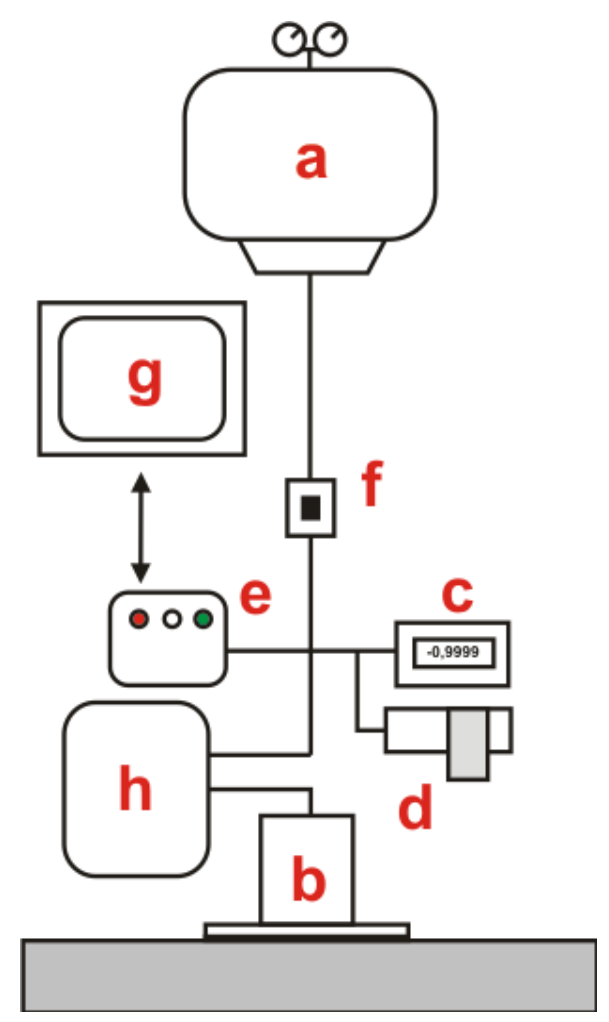

Figura 3.5 - Detalhe do reservatório de ar instalado no equipamento. Onde: a) Bomba de vácuo;

b) Câmara de vácuo; c) Mostrador de pressão digital; d) Transdutor de pressão; e) Placa aquisitora de dados (data-logger); f) Válvula solenóide; g) Computador; h) Reservatório de ar.

\subsection{PROCEDIMENTOS DE ENSAIO}

Para realização do ensaio de permeabilidade em argamassas pelo método de vaccum-decay, através do aparato proposto e desenvolvido neste trabalho, algumas considerações devem ser feitas a fim de que o método se torne padronizado e reprodutível.

Os corpos-de-prova passam por um processo de secagem em estufa objetivando a retirada de qualquer umidade contida em seus poros e permanece no dissecador até o momento de seu ensaio. Conforme já discutido anteriormente, a presença de umidade pode provocar alteração na permeabilidade ao ar de estruturas porosas (MONLOUIS-BONNAIRE; VERDIER; PERRIN, 2004). A temperatura de secagem foi padronizada em $50 \stackrel{\circ}{ } \mathrm{C}$, pois produtos de hidratação podem sofrer dissociação quando em temperaturas maiores (TAYLOR, 1990). O 
tempo de secagem depende da estrutura de poros da argamassa, portanto sua massa deve ser monitorada durante esse processo até que se mantenha constante.

A permeabilidade, conforme descrito anteriormente, é um fenômeno caracterizado pelo fluxo de um fluido qualquer através de um material poroso, isto é, o transporte entre faces no meio poroso. Este é o caminho que deve ser percorrido pelo ar para que o ensaio fique caracterizado por permeabilidade e possa retratar fielmente a estrutura porosa da argamassa. Para isso então as duas faces do corpode-prova devem estar livres de qualquer tipo de impedimento. A superior recebe 0 contato da câmara onde uma região de vácuo vai ser formada justamente para impulsionar o movimento de ar proveniente da outra face até a recuperação total da pressão inicial. O corte inferior fica então em contato com uma placa furada que sustenta o corpo-de-prova sem impedir a condução do ar até a região de menor pressão (Figura 3.6). A placa deve ser o mais plana possível para evitar que o material fique apoiado pontualmente, evitando assim a quebra do mesmo ou a ocasião de fissuras decorrentes da pressão exercida no contato entre câmara e material.

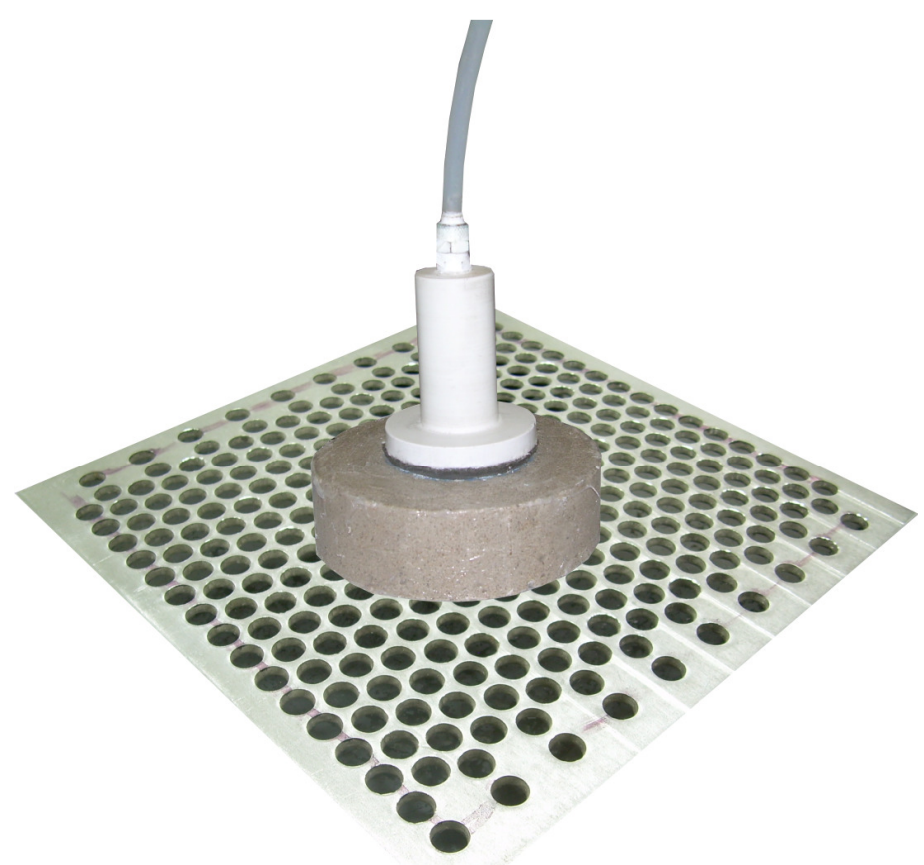

Figura 3.6 - Placa de apoio furada para ensaio do corpo-de-prova. 
A placa aquisitora de dados, adquirida da empresa NOVUS Produtos Eletrônicos Ltda, modelo myPCLab, tem um software de coleta de dados que permite alguma configurações simples para obtenção dos pontos. Parâmetros importantes a ser considerados nessa etapa são as velocidades de leitura e gravação dos dados, que não precisam ser necessariamente iguais. A velocidade de leitura indica quantos pontos por segundo o programa vai coletar e plotar na curva do ensaio e mostrar em tempo real na tela do computador. Já a velocidade de gravação vai determinar quantos pontos vão ser coletados no intervalo de 1 segundo e gravados no arquivo que será registrado pelo software. Certamente, o segundo parâmetro é o mais importante, pois é com ele que os dados podem ser posteriormente tratados e analisados. A resolução máxima de coleta de pontos, tanto para leitura quanto para gravação, no caso da placa escolhida, é de 4 pontos por segundo. Esse é um valor de gravação padronizado para o caso de argamassas, pois a alta porosidade em muitas ocasiões faz com que a velocidade de recuperação seja elevada e taxas de gravação superiores acabam gerando curvas um número de pontos insuficiente para análise.

O procedimento é composto por uma fase inicial de bombeamento para criação da zona de vácuo na face superior do corpo-de-prova. É interessante que esta etapa dure pelo menos 60 segundos para que todo o reservatório de ar contido no interior dos poros da argamassa possa ser efetivamente esgotado, além de promover uma desobstrução de poros que eventualmente estiverem entravados por algum tipo de agente de simples remoção, como no caso de pó na superfície. Esse passo pode ser acompanhado por um mostrador digital de pressão que registra a diminuição da pressão na câmara é um determinado patamar máximo determinado pela potência da bomba. No caso desse equipamento, para poros pequenos, baixa porosidade e materiais praticamente impermeáveis (como é o caso de metais), esse patamar é atingido a -0,90 \pm 0,01 bar. Valores de estabilização diferentes já podem indicar condições significativas, tais como: alta porosidade, tamanho elevado de poros, fissuras, quebras, vazamentos, fenômenos de superfície, produtos de hidratação, etc. Por exemplo, se uma argamassa de alta porosidade, exposta a algum tipo de ataque, está sendo avaliada ao longo do tempo tiver a formação de algum produto que promova o entupimento superficial de seus poros, esse valor de pressão inicial pode diminuir ainda mais durante seu processo de estabilização. 
Ainda, uma argamassa de baixa porosidade, que atinge seu patamar em valores próximos ao máximo permitido pela bomba, pode quebrar durante a estabilização, evidenciando assim ao operador pelo aumento da pressão registrada no mostrador.

Depois de criada a zona de vácuo que possibilita a movimentação do ar através da amostra o ensaio está pronto para realmente iniciar. O ar precisa migrar de um lado a outro e a variação de pressão registrada pelo computador, só que para que tudo isso aconteça o acionamento de todos esses comandos é feito de forma manual (Figura 3.7) e devem ser sincronizados para que não se perca nenhum ponto durante a coleta. Dessa forma, foi padronizada uma sequência que permite que um único usuário possa operar o equipamento e tornar o ensaio repetitivo e reprodutivo por qualquer outra pessoa. Inicialmente, ainda com a bomba de vácuo ligada, inicia-se a coleta de pontos, através do software no computador. A captação dos pares de pressão-tempo começa nesse momento para que não sejam perdidos os pontos iniciais da curva caso a amostra sofra uma recuperação muito rápida. Então, desliga-se a válvula solenóide para impedir que o ar percorra, além de uma face à outra, da parte anterior a câmara, descaracterizando assim o ensaio. Observa-se que a válvula restringe apenas uma das direções do fluxo, portanto o ar continua sendo succionado pela bomba. Logo em seguida, a bomba de vácuo é desligada permitindo assim que o ar seja transportado através da argamassa.

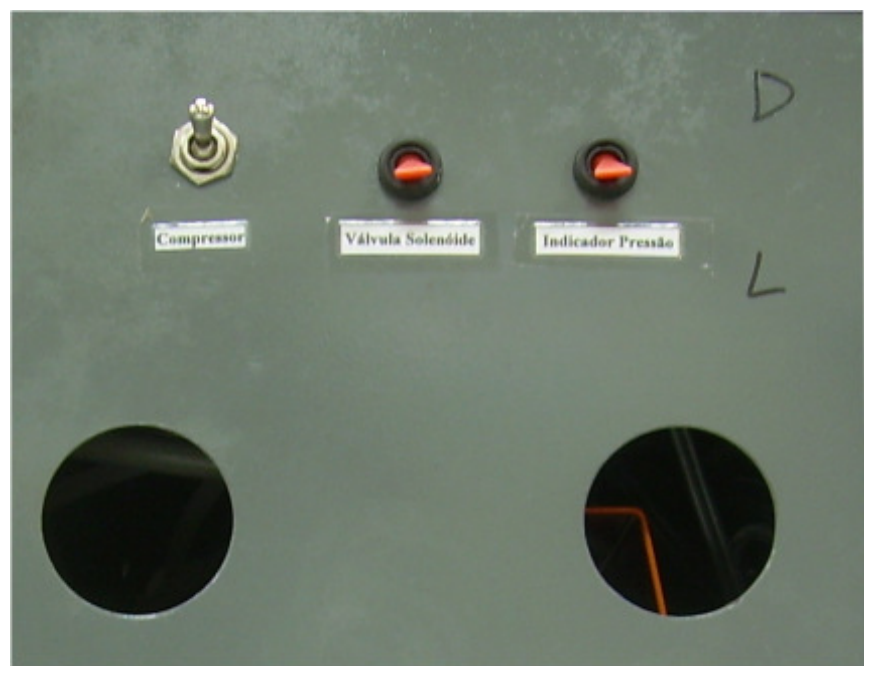

Figura 3.7 - Botões de acionamento manual da válvula solenóide e da bomba de vácuo, além do indicador digital de pressão, posicionados na caixa do equipamento. 
A face do corpo-de-prova que fica em contato com o equipamento teoricamente não tem nenhuma influência sobre os resultados e curvas obtidas, já que a permeabilidade, por definição, é uma propriedade intrínseca que reflete as condições da estrutura porosa do material avaliado. Existem, porém, efeitos de superfície que podem interferir na obtenção dos resultados e ser responsáveis por diferenças nos resultados, dependendo do sentido em que a argamassa estiver sendo ensaiada: da face superior à inferior ou vice-versa. Entretanto, a ocorrência deste fenômeno fica vinculada à existência de uma área útil livre no corpo-de-prova, em torno da seção circular da câmera de vácuo, que permite que o ar possa penetrar, além da outra face, também pela superfície. A ocorrência deste evento pode depender também de outros fatores como porosidade da argamassa, acabamento superficial, tamanho da área útil livre, entre outros, já que o fluido percorre sempre o trajeto mais fácil durante sua condução. Contudo, a influência dos efeitos superficiais na determinação da permeabilidade precisa ser estudada nas argamassas para que o real caminho de percolação do ar durante o ensaio possa ser definido. Desta forma, decidiu-se adotar como face superior aquela que fica em contato com a placa de moldagem, por ter um acabamento superficial mais plano.

Para que o fluxo de ar aconteça exclusivamente através de um extremo a outro, as laterais do cp são vedadas, com silicone, evitando assim que a percolação aconteça em direções diferentes. Este também é outro aspecto que deve ser estudado para que se possa conhecer o trajeto real do ar quando em movimento através da argamassa e se a inserção de ar pela lateral é significativa a ponto de influenciar essa dinâmica com essa potência de bomba utilizada.

Esse conjunto de ajustes deve sempre ser observado quando da execução do ensaio de permeabilidade em argamassas através deste método a fim de que os resultados possam ser facilmente reprodutíveis em qualquer outro lugar e possam produzir resultados repetitivos e que demonstrem realmente quais as condições estruturais em que a composição se encontra. 


\subsection{TRATAMENTO DOS DADOS}

Após a realização da parte física do ensaio, os dados obtidos precisam ser extraídos, exportados e tratados adequadamente. O software de coleta de dados da placa aquisitora salva os resultados em arquivo com extensão própria (.mpc) que pode ser facilmente exportado para o Excel através da própria interface do programa. Com isso, um conjunto de pares de pressão-tempo são obtidos e podem ser utilizados na confecção de curvas, calculo de k1, ou qualquer outro tipo de análise que queira ser realizado, como da pressão inicial de estabilização, por exemplo. É interessante observar que a variável tempo é registrada no formato de hora, em conformidade com o horário do sistema operacional utilizado no computador ligado ao equipamento. Se estiver ajustado corretamente, pode-se saber exatamente o horário de início e fim de ensaio.

A curva conta em seu início, conforme descrito nas configurações de ensaio, com um patamar de pressão correspondente ao valor da estabilização para a argamassa ensaiada. Esse platô pode ser maior ou menor em função do tempo em que a bomba permanece acionada. Desta forma, para padronizar e tornar as curvas comparáveis entre si, convencionou-se tomar como início justamente o valor da pressão do patamar para os dois primeiros pontos, independente do número de repetições registrado. Por exemplo, se a argamassa ensaiada estabiliza na pressão de -0,88 bar, e entre o início da coleta de pontos e o desligamento da bomba decorrerem 10 segundos, isso corresponde a um início de curva real com 40 pontos correspondente ao valor de $-0,88$ bar (supondo que sejam pegos 4 pontos por segundo, conforme sugerido). Neste caso, para fins de tratamento, considera-se que existam apenas 2 pontos iniciais correspondentes a $-0,88$ bar, e nãos os 40 gravados.

Para efeito de cálculo do parâmetro de permeabilidade $k 1$, não há a necessidade da realização do ensaio do início ao fim, com a geração de toda a curva de recuperação de pressão. Porém, as curvas por si só já são capazes de fornecer parâmetros suficientes para análise qualitativa de argamassas, sobretudo de forma comparativa, de maneira rápida e eficiente. Através da sua análise, por meio da inclinação relativa, pode-se observar a velocidade média de recuperação, 
possibilitando a identificação qualitativa da argamassa mais e menos permeável em um grupo de comparação, ainda mostrar um ponto de fissura em um pano de revestimento ou até mesmo uma falha na conformação de um processo industrial de blocos de argamassa.

Sabe-se, entretanto, que estruturas porosas diferentes podem gerar curvas com início diferentes. Se, por exemplo, amostras distintas de uma mesma argamassa, que apresenta um teor de porosidade homogêneo, mas com pequenas diferenças no início de suas curvas, forem comparadas, podem gerar interpretações erradas quanto à análise de suas permeabilidades. Eles podem apresentar tempos de recuperação diferentes, entretanto, uma mesma inclinação relativa, o que visualmente da à impressão que um cp é mais permeável do que outro. No entanto, todos podem estar associados a uma mesma dificuldade de transporte do ar, nesta argamassa, através de seus poros, que corresponde justamente a sua permeabilidade. Esse tipo de situação fica perfeitamente ilustrado na Figura 3.8, onde as curvas aparentemente representam diferentes velocidades de recuperação, entretanto todas estão associadas a valores correspondentes de permeabilidade. Por isso, convencionou-se, para efeito de comparação, que todas as curvas analisadas devem começar sempre do mesmo ponto. No exemplo citado acima, aquela porção da argamassa que apresenta maior curva de recuperação deve ser ajustada de forma que tenha o seu ponto de pressão inicial (instante 0) igual a da que se deseja confrontar.

Algumas vezes, a quantidade de pontos gravados durante o ensaio é insuficiente para realizar o artifício descrito acima. Isso porque a curva de maior amplitude pode não possuir o menor valor de pressão associado ao início da curva do material em comparação. Isso acontece geralmente quando o número de pontos coletados é inferior ao recomendado nas configurações de ensaio (4 pontos por segundo), ou ainda o tempo de recuperação é muito rápido, impossibilitando assim a coleta adequada de pares. Nesse caso, a equação das curvas é determinada de forma que seja possível redesenhá-las com quantos valores forem necessários para promover suas aproximações. Essa não é a forma mais precisa e interessante de tratamento recomendada já que esse tipo de reformatação pode acabar gerando 
algum tipo de erro que pode acumular-se por todo o processo de análise posterior, além de ser muito mais custoso em tempo de trabalho.

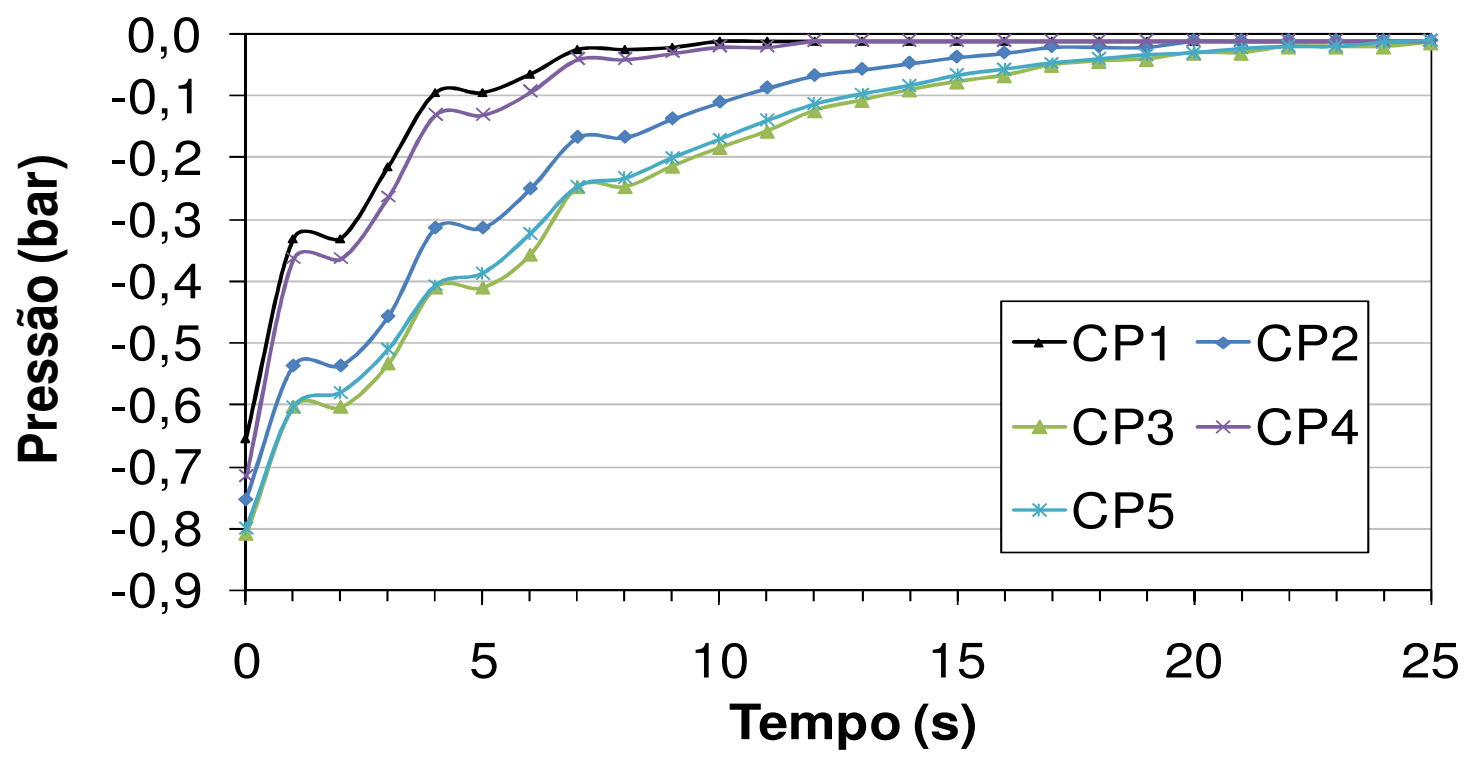

Figura 3.8 - Exemplo de curvas com diferentes tempos de recuperação, em função das distintas pressões de estabilização de vácuo, referentes a valores de permeabilidade equivalentes de uma mesma argamassa.

Conforme descrito anteriormente, o resultado gerado pelo software na realização do ensaio é um conjunto de pontos de pressão-tempo. Entretanto, o cálculo da velocidade superficial em cada um desses pares pode ser realizado através de um simples balanço de massa no interior da câmara de vácuo, através da Equação 3.1:

$$
\frac{d M}{d t}=w_{e}-w_{S}
$$

Onde dM/dt corresponde à variação de massa; $w_{e}$ à vazão mássica do ar que entra na câmara; e ws à vazão mássica do ar que sai da câmara de vácuo.

Assumindo, para efeitos de simplificação, $w_{\mathrm{s}}=0$ e o comportamento ideal de gás, com base na equação geral dos gases de Clapeyron, obtém-se a Equação 3.2:

$$
\frac{d \frac{M M P c V c}{R T}}{d t}=w_{e}
$$


Onde $\mathrm{MM}$ corresponde à massa molar do gás (ar atmosférico); $\mathrm{Pc}$ à pressão absoluta no interior da câmara; Vc ao volume útil da câmara; R à constante universal dos gases (8,31 Joule/(mol.K)); e T a temperatura absoluta do ar permeado.

Entretanto, a vazão mássica de ar que sai da câmara também pode ser escrita através da Equação 3.3:

$$
w_{e}=\rho v_{s} A
$$

Onde $\rho$ corresponde à densidade do gás (ar atmosférico); vs à velocidade superficial do ar; e A à área da seção transversal pelo qual o ar permeia.

Considerando que grande parte dos dados referentes as equação anteriormente demonstradas correspondem às condições do gás utilizado no ensaio e, portanto, são valores constantes, a Equação 3.2 pode ser reescrita na forma da Equação 3.4:

$$
\frac{d P c}{d t}=\frac{R T \rho v_{S} A}{M M V c}
$$

Então, para o calculo de k1 pode-se utilizar a equação proposta por Forchheimer (Equação 2.5.1) considerando, para efeito de simplificação, duas hipóteses: compressibilidade do gás desprezível e utilização apenas do termo linear. Substituindo os termos da Equação 2.5.1 pela Equação 3.3, e adequando seus termos:

$$
\frac{d P c}{\left(P_{a t m}-P c\right) d t}=\frac{k 1 R T \rho A}{M M \mu V c L}
$$

Integrando a Equação 3.4 para o tempo $(\mathrm{t}=0$ até $\mathrm{t})$ e para a variação de pressão do ensaio $(\mathrm{Pc}=\mathrm{Pi}$ até $\mathrm{Pc})$, tem-se a Equação 3.5 , que posteriormente resulta na Equação 3.6:

$$
\begin{aligned}
& \int_{P i}^{P c} \frac{d P c}{\left(P_{a t m}-P c\right)}=\int_{0}^{t} \frac{k 1 R T \rho A}{M M \mu V c L} d t \\
& \operatorname{Ln}\left(\frac{P_{a t m}-P i}{P_{a t m}-P c}\right)=\frac{k 1 R T \rho A}{M M \mu V c L} t
\end{aligned}
$$


Finalmente, através do ajuste Equação 3.6 aos dados experimentais, pelo método dos mínimos quadrados, pode-se obter o valor de $\mathrm{k}_{1}$, por meio do coeficiente angular obtido pela reta. Todo esse modelamento matemático foi também um trabalho de desenvolvimento do professor Murilo Daniel de Mello Innocentini no desenvolvimento deste e outros equipamentos para medição de permeabilidade (INNOCENTINI, 2000).

Com a finalidade de desenvolvimento do método, todos os ensaios realizados são repetidos sempre 3 vezes para o mesmo ponto (ensaio, réplica e tréplica). Portanto, cada ponto ou amostra ensaiada gera três curvas de pares de pressão, as quais são tratadas individualmente e comparadas (também seus valores de $\mathrm{k}_{1}$ ) para efeito de verificação de repetibilidade do ensaio. Após, se os três resultados estiverem em conformidade e não houver a necessidade de descartar nenhum, uma curva média é gerada a partir do valor médio das pressões em todos os intervalos de tempo das 3 repetições. O parâmetro de permeabilidade $k_{1}$ é calculado a partir dos novos pares de dados obtidos, e não das médias de $k_{1}$ das curvas de origem.

Se diversos corpos-de-prova de uma mesma argamassa estão sendo avaliados quanto à permeabilidade por esse método, cada um deles vai gerar 3 curvas correspondentes as repetições de ensaio realizadas assim como uma curva média representante, além dos parâmetros $k_{1}$ referentes. Para esse conjunto uma nova curva média pode ser gerada da mesma forma que a descrita anteriormente, a partir da média de todos os pontos das curvas médias de cada $\mathrm{cp}$. Novamente, $\mathrm{k}_{1}$ é calculado a partir dessa curva "média das médias", e não com a média dos $k_{1}$ de todas as amostras.

Ainda, com o desvio padrão da média de pressões em cada instante de ensaio, consegue-se ter uma idéia da dispersão de resultados visualmente, plotando-se os valores em barras de erro na geração do gráfico. Quanto maior a nuvem de pontos acima e abaixo da curva, maiores as diferenças relativas entre as repetições realizadas ou entre as amostras ensaiadas. 


\subsection{ENSAIOS PRELIMINARES}

Após o desenvolvimento do equipamento, com todas as correções, adaptações e configurações realizadas, assim como definidas e implementadas a forma e planilhas de tratamento dos dados, é interessante que ensaios preliminares sejam executados com o objetivo de validar a técnica e identificar possíveis alterações e melhorias.

\subsubsection{Argamassa Industrializada}

Para isso, uma argamassa de revestimento industrializada foi escolhida para avaliação, denominada como Argamassa_33\% em função da sua porosidade. Para determinação de sua massa real específica foi utilizado um picnômetro de gás Helio, marca Quantacrome, modelo MVO 5DC. A área superficial específica foi medida através do procedimento BET (Brunauer, Emmet e Teller), em equipamento Gemini III 2375 - Micromeritics, seguindo a norma técnica ASTM C 1274-00 (ASTM C 127400). A Tabela 3.2 apresenta as características físicas das frações agregado e fino no estado anidro da argamassa utilizada.

Tabela 3.2 - Características físicas da argamassa ensaiada.

\begin{tabular}{l|cc}
\hline \multicolumn{1}{c|}{ PROPRIEDADE } & \multicolumn{2}{c}{ ARGAMASSA_33\% } \\
\cline { 2 - 3 } & AGREGADOS & FINOS \\
\hline Densidade real $\left(\mathrm{g} / \mathrm{cm}^{3}\right)$ & 2,79 & 2,88 \\
Área superficial específica $\left(\mathrm{m}^{2} / \mathrm{g}\right)$ & 0,90 & 1,28 \\
\hline
\end{tabular}

A distribuição granulométrica foi obtida em granulômetro a laser Mastersizer S, V. 2.19 - Malvern Instruments Ltd. - faixa de identificação: 50 nm - $3500 \mu \mathrm{m}$, e pode ser observada na Figura 3.9. 


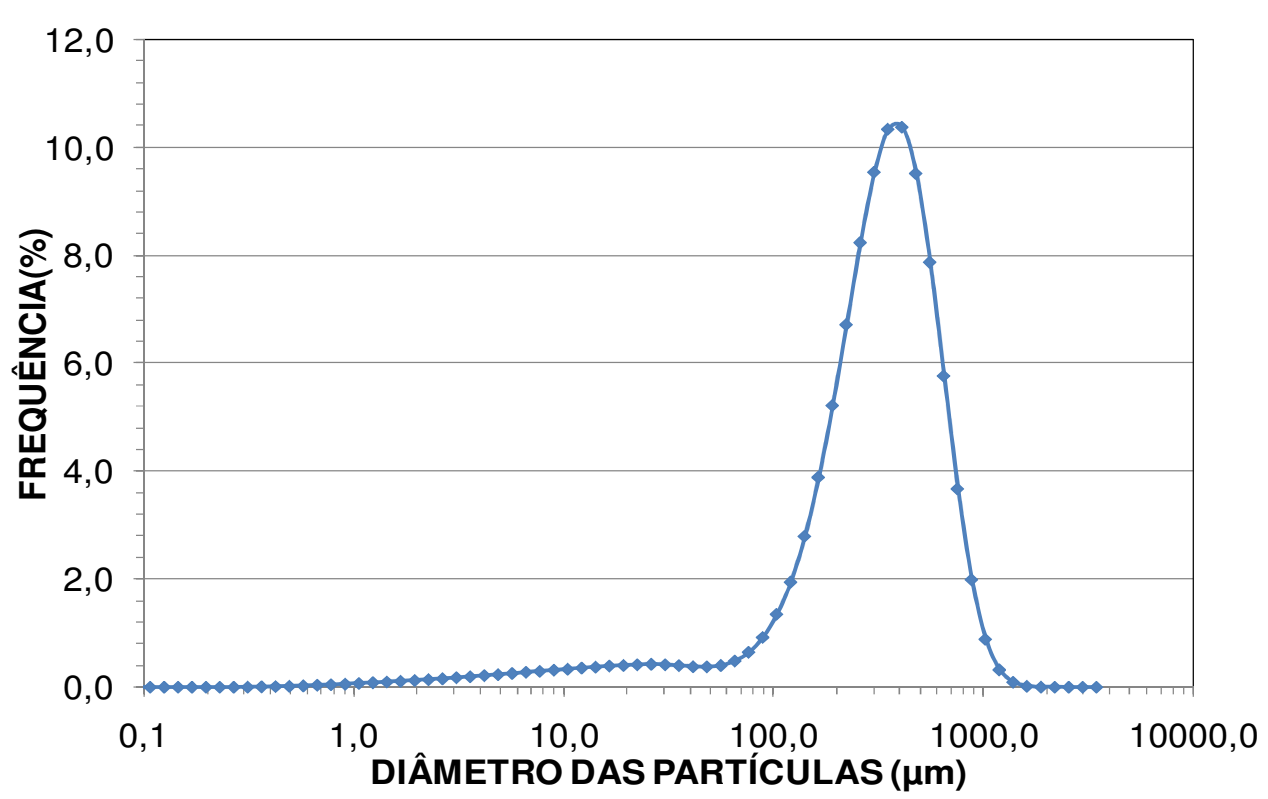

Figura 3.9 - Distribuição granulométrica da argamassa ensaiada.

A mistura foi realizada em um reômetro para argamassas e concretos existente no Laboratório de Microestrutura da Escola Politécnica da USP (projeto FAPESP no 03/12199-4), a partir do controle preciso da velocidade de rotação e aquisição do torque equivalente. Inicialmente, o pó seco foi homogeneizado e adicionado na cuba do reômetro e, após 10 segundos do início do programa, foi adicionado o volume total de água numa vazão constante de $45 \mathrm{~g} / \mathrm{s}$. A argamassa foi misturada então com um tempo total de 5 minutos, sob rotação constante de 500 rpm.

Foram moldados 12 corpos-de-prova cilíndricos, de 2 polegadas $(50,8$ milímetros) de diâmetro por 20,45 milímetros de altura, em moldes confeccionados de PVC, disposto em apenas uma camada e compactado com 20 golpes com a ajuda de um soquete metálico. Após, todos os $\mathrm{cp}$ 's foram submetidos a um processo de cura em câmara de temperatura controlada $\left(26^{\circ} \mathrm{C}\right)$, mantendo uma umidade constante e próxima de $100 \%$ com o auxílio de um recipiente com água, por um período de 15 dias. Após a cura, todos passaram por um processo de secagem em estufa a $50^{\circ} \mathrm{C}$ até sua constância de massa e armazenados em dissecador para não absorver nenhum tipo de umidade. 
Como o diâmetro do cp é igual ao da câmara de vácuo, quando da realização do ensaio de permeabilidade não fica nenhuma superfície livre no contato com a face superior, apenas nas laterais da amostra. Por isso, nesse momento inicial optou-se por realizar a vedação lateral com silicone para impedir que o ar pudesse vir de outra direção que não da face inferior. Além disso, foi aplicado um aditivo hidrofugante líquido em metade dos corpos-de-prova com o objetivo de investigar qual a sua real influência nos resultados de permeabilidade ao ar.

Cada amostra foi ensaiada uma vez, sequencialmente, para depois passar por uma réplica e por fim por uma terceira repetição. Optou-se por não realizar as 3 medidas consecutivamente no corpo-de-prova com o intuito de avaliar repetibilidade do ensaio de maneira que pudesse ser eliminado qualquer tipo de condição que induzisse a resultados iguais, e seu resultado pode ser observado na Figura 3.10, que ilustra o comportamento da totalidade dos cp's ensaiados.

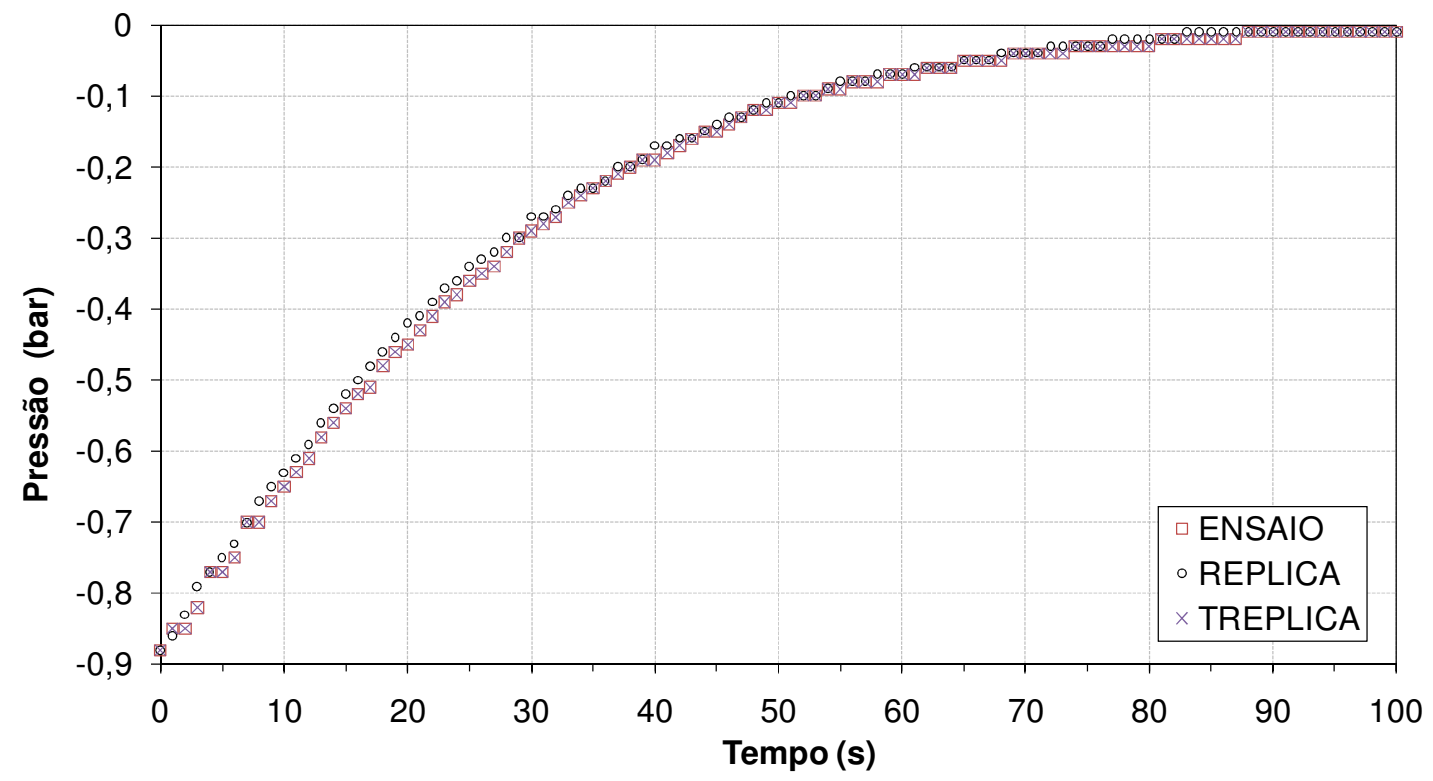

Figura 3.10 - Repetibilidade do ensaio de permeabilidade através do método desenvolvido.

Todas as amostras atingiram os mesmos patamares de estabilização de pressão, que foi de $-0,89$ bar, que, nesse caso, indica que não houve diferença significativa quanto a distribuição de poros, tampouco o surgimento de qualquer tipo de falha ou descontinuidade. Para efeito de análise comparativa, nenhuma das 
curvas de recuperação precisou então passar por cortes durante o processo de análise, e podem ser observadas nas Figuras 3.11.1 e 3.11.2.

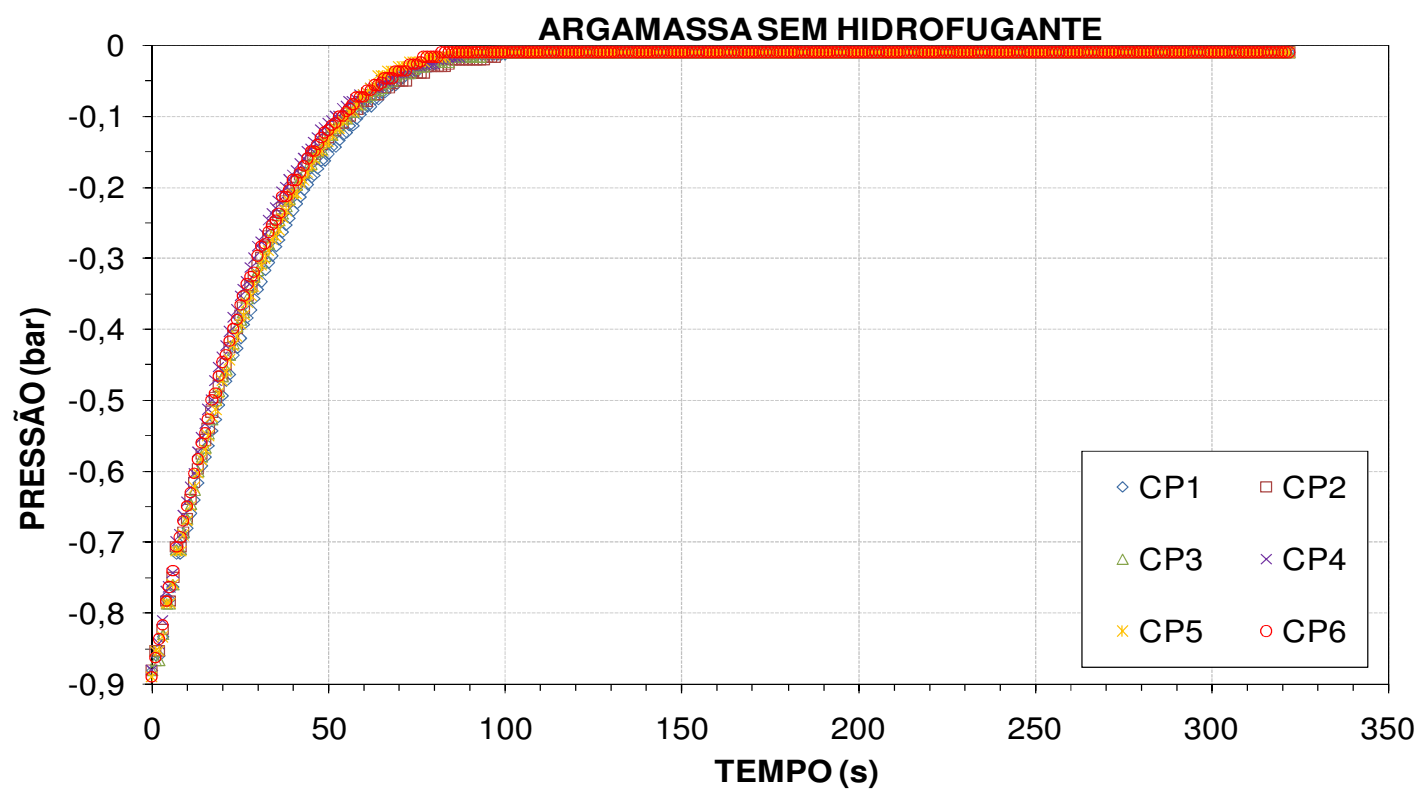

Figura 3.11.1 - Curvas de recuperação de pressão das amostras das argamassas sem hidrofugante.

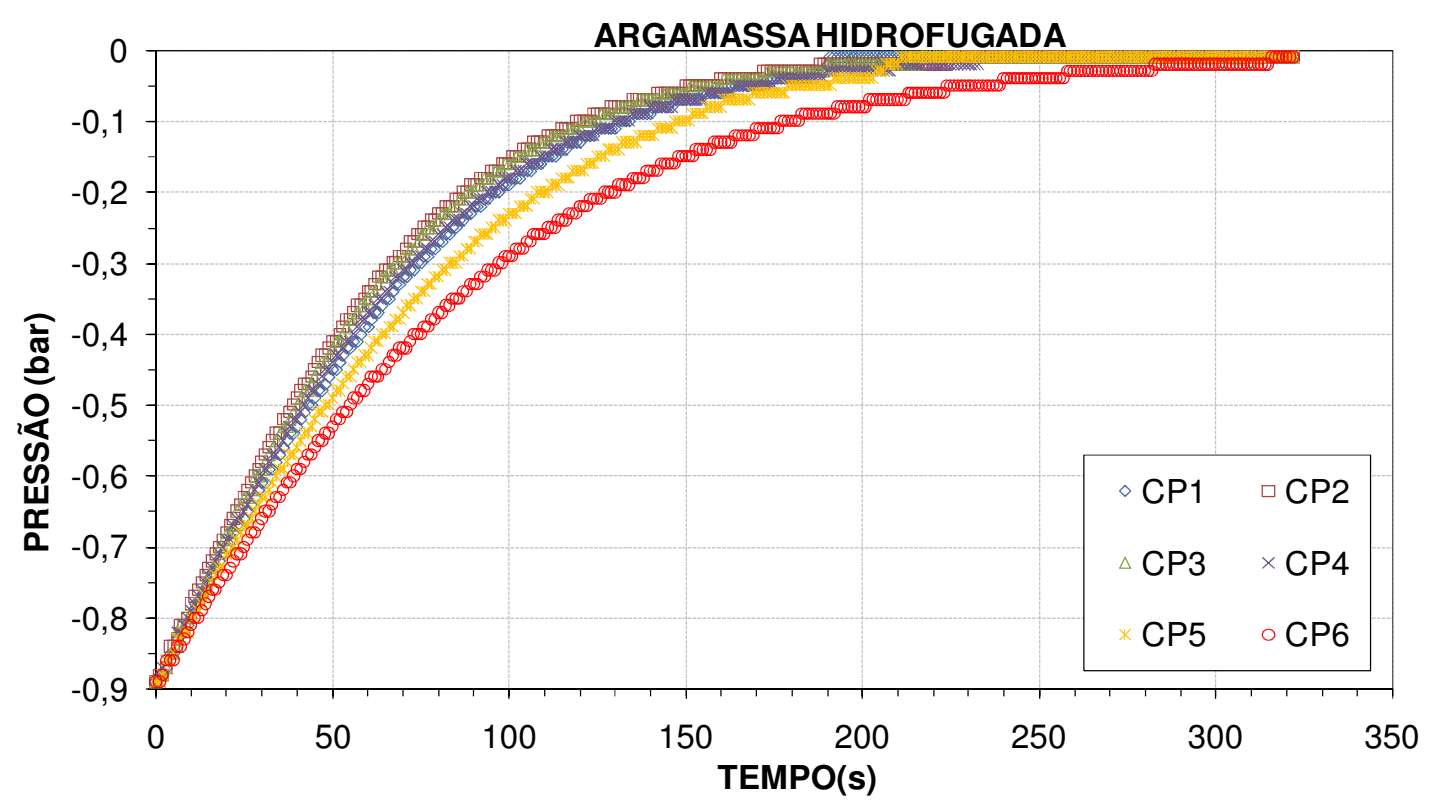

Figura 3.11.2 - Curvas de recuperação de pressão das amostras das argamassas hidrofugadas. 
Pode-se concluir em ambas as curvas que, a dispersão de resultados entre corpos-de-prova não é significativa, o que indica uma estrutura porosa homogênea entre amostras do mesmo grupo. Portanto, a análise comparativa entre as duas diferentes condições pode ser observada na Figura 3.12 que mostra a curva média de cada conjunto de argamassas com suas respectivas dispersões.

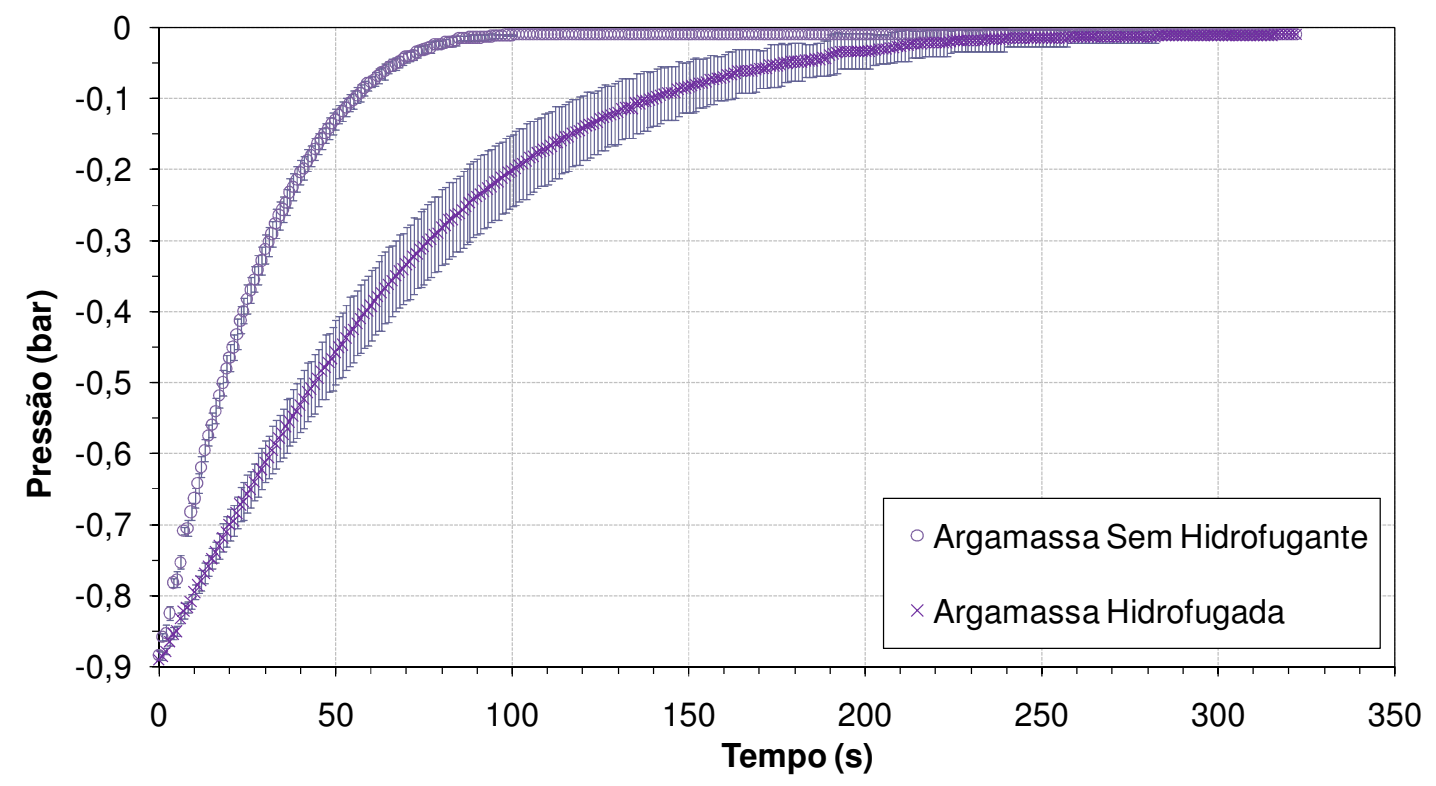

Figura 3.12 - Curvas médias de recuperação, com suas respectivas dispersões, dos grupos de argamassa ensaiados.

Esse tipo de aditivo é utilizado na construção civil com a finalidade de repelir eletricamente a água para reduzir a penetração de umidade em materiais porosos como argamassas e concretos. Geralmente, não modifica a estrutura porosa dos materiais, mantendo as mesmas características estruturais. Portanto, nesse caso, não deveria promover diferenças quanto à permeabilidade ao ar da argamassa estudada, mesmo porque o hidrofugante foi aplicado posteriormente apenas superficialmente nas amostras, mantendo sua estrutura interna integra.

Entretanto, na Figura 3.10 fica nítida a diferença existente entre os dois conjuntos de argamassas ensaiadas, provenientes da mesma mistura. Aquele grupo que não possui hidrofugante teve uma recuperação mais rápida do que aquele onde o produto foi aplicado. Isto pode ser explicado pelo surgimento, comprovado também visualmente, de uma fina película residual do aditivo na superfície da argamassa, 
que provocou a obstrução de alguns poros na face inferior dos corpos de prova. A dispersão maior de resultados no conjunto de argamassas hidrofugadas demonstra que que nem todos os poros superficiais foram obstruídos, uma vez que foi aplicada apenas uma camada de aditivo, e a película formada não se apresentava homogênea. Estes resultados demonstram que os efeitos de superfície (acabamentos, produtos de hidratação, ataques químicos, etc) podem ser responsáveis por alterações significativas na permeabilidade ao ar de argamassas de revestimento.

Ainda, os valores de $\mathrm{k}$ foram calculados e podem ser observados na Figura 3.13 .
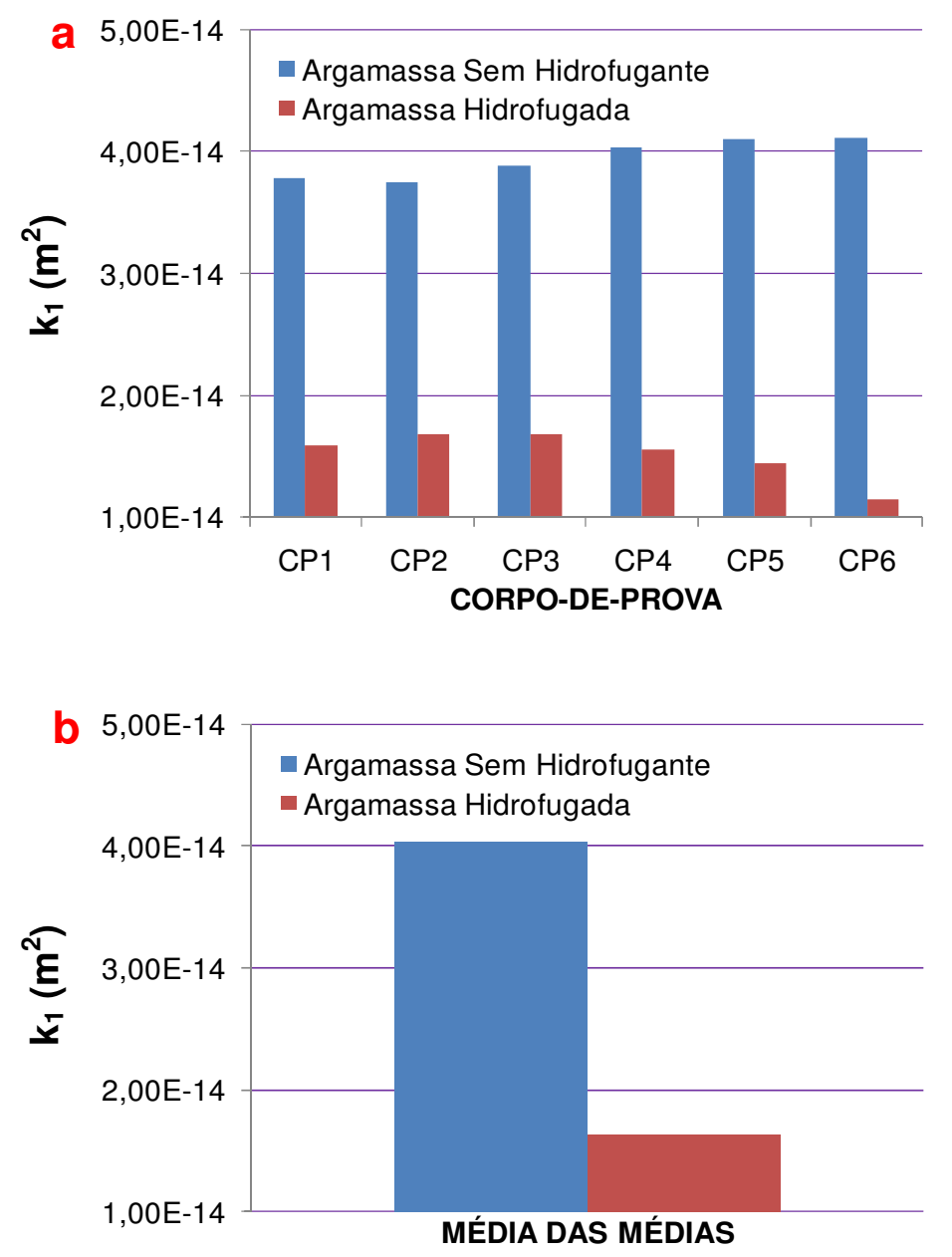

Figura 3.13 - Valores de k1 para os grupos de argamassa ensaiadas. Onde: a) k1 de cada amostra por grupo; b) Valor médio de k1 para cada grupo. 
Os resultados de $\mathrm{k}_{1}$ comprovam e quantificam o comportamento demonstrado nas curvas de recuperação mostradas anteriormente onde a argamassa sem hidrofugante é mais permeável do que a que contém o aditivo. Analisando cada grupo separadamente, os parâmetros de permeabilidade mostram-se compatíveis com o comportamento das curvas de recuperação, onde pequenas diferenças na inclinação relativa das curvas remetem a pequenas diferenças nos valores de k1.

Ainda, para verificar a real potencialidade do aditivo hidrofugante, foram realizados ensaios de absorção nos dois grupos de argamassas, baseados na norma NBR 9779/1995, e seus resultados são dispostos na Figura 3.14.

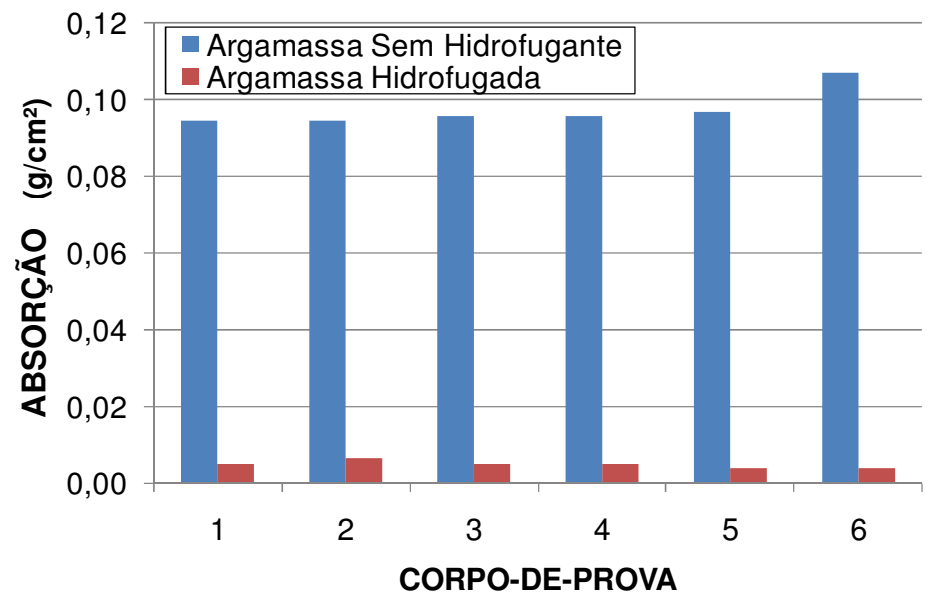

Figura 3.14 - Coeficiente de absorção dos grupos de argamassa ensaiada.

Conforme esperado, os resultados do ensaio de absorção reiteram o comportamento das argamassas frente o ensaio de permeabilidade ao ar. Analisando os corpos-de-prova separadamente por grupo, verifica-se ainda que aqueles que apresentam maior permeabilidade ao ar foram os que tiveram maior coeficiente de absorção. O ensaio de absorção, apesar de não representar puramente o fenômeno de permeabilidade, já que existem fenômenos de capilaridade e/ou difusão envolvidos em seu mecanismo, demonstram a homogeneidade da estrutura porosa dos grupos de argamassa e a influência deste aditivo em argamassas de revestimento. Possivelmente, a diferença nos coeficientes de absorção seria relativamente menor que 0 hidrofugante não tivesse essa 
característica de formação de película, que incrementaria a absorção por capilaridade nas amostras.

\subsubsection{Fibrocimento}

Para reforçar os conceitos e configurações desenvolvidas ao método pelo presente trabalho, além de demonstrar outras potencialidades de uso da ferramenta, placas de fibrocimento foram também avaliadas.

O fibrocimento é hoje um material de grande foco de estudo devido ao seu potencial uso em telhas em substituição ao uso do amianto, que está proibido no Brasil. Por isso, deve ter características mecânicas semelhantes, ou ainda melhores, que às confeccionadas com o uso de amianto. A função fundamental de uma telha é de proteção de uma edificação tanto quanto a partículas e radiação solar quanto à água das chuvas. Portanto, o escopo deste estudo foi investigar se o processo de moldagem e conformação das placas era eficiente e se as diferenças de formulação poderiam provocar algum tipo de descontinuidade microestrutural nas telhas.

Para isso, dois tipos de formulação foram avaliados, uma com o uso combinado de fibra de PP (Polipropileno), PVA (Poli Acetato de Vinila) com sílica e a outra mistura sem o uso da sílica. As placas foram extraídas durante o processo de produção da telha (retalhos dos cortes laterais) na fábrica e possuem dimensão média de $270 \mathrm{~mm} \times 150 \mathrm{~mm}$. Cada placa foi então divida em 6 pontos (Figura 3.15), devido o tamanho da câmara de vácuo não ter condições de contemplar o retalho por inteiro. Além disso, nem sempre o material encontra-se de forma homogênea ao longo de todo a sua composição, devido a problemas de mistura, prensagem, cura, estocagem, trabalho, entre outros. Portanto, uma avaliação dessa natureza para um processo industrial de desenvolvimento de produto, nos dá condições de desenvolver um controle de qualidade para aceitação para comercialização ou ainda acompanhamento das condições estruturais da telha em serviço. 


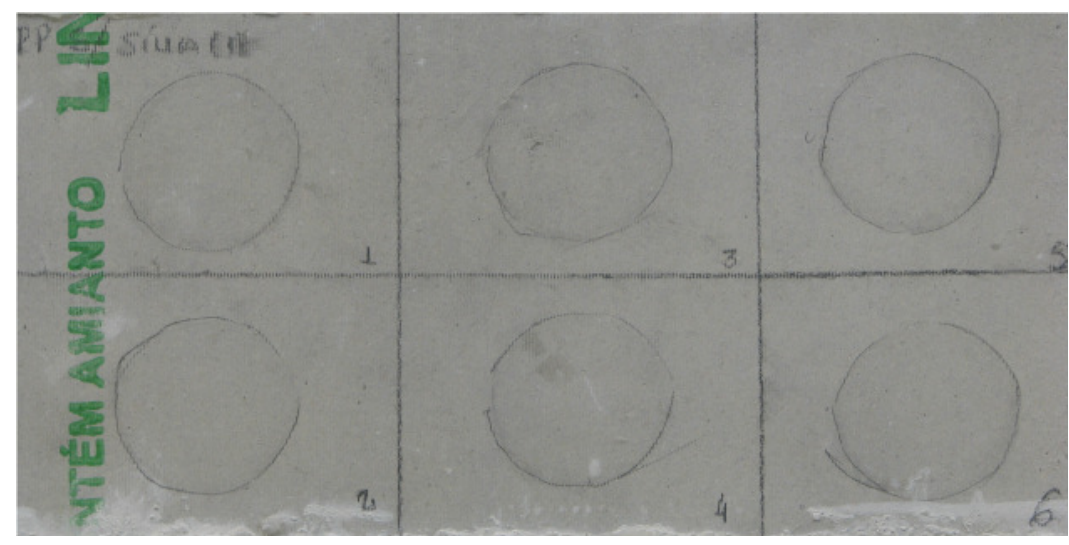

Figura 3.15 - Placa da telha de fibrocimento dividida em 6 regiões para ensaio de permeabilidade ao ar.

Como se tratava apenas de uma análise comparativa entre formulações e pontos de uma mesma composição, e devido à baixa porosidade desse tipo de material, optou-se por um tempo de ensaio de apenas 55s para cada região ( 1 ponto a cada 5s). Nesse momento, a geração de curva na sua totalidade não traria contribuições significativas, além de gerar um tempo de ensaio desnecessariamente elevado. Os resultados de permeabilidade ao ar, através do método desenvolvido neste trabalho, estão demonstrados nas Figuras 3.16.1 e 3.16.2.

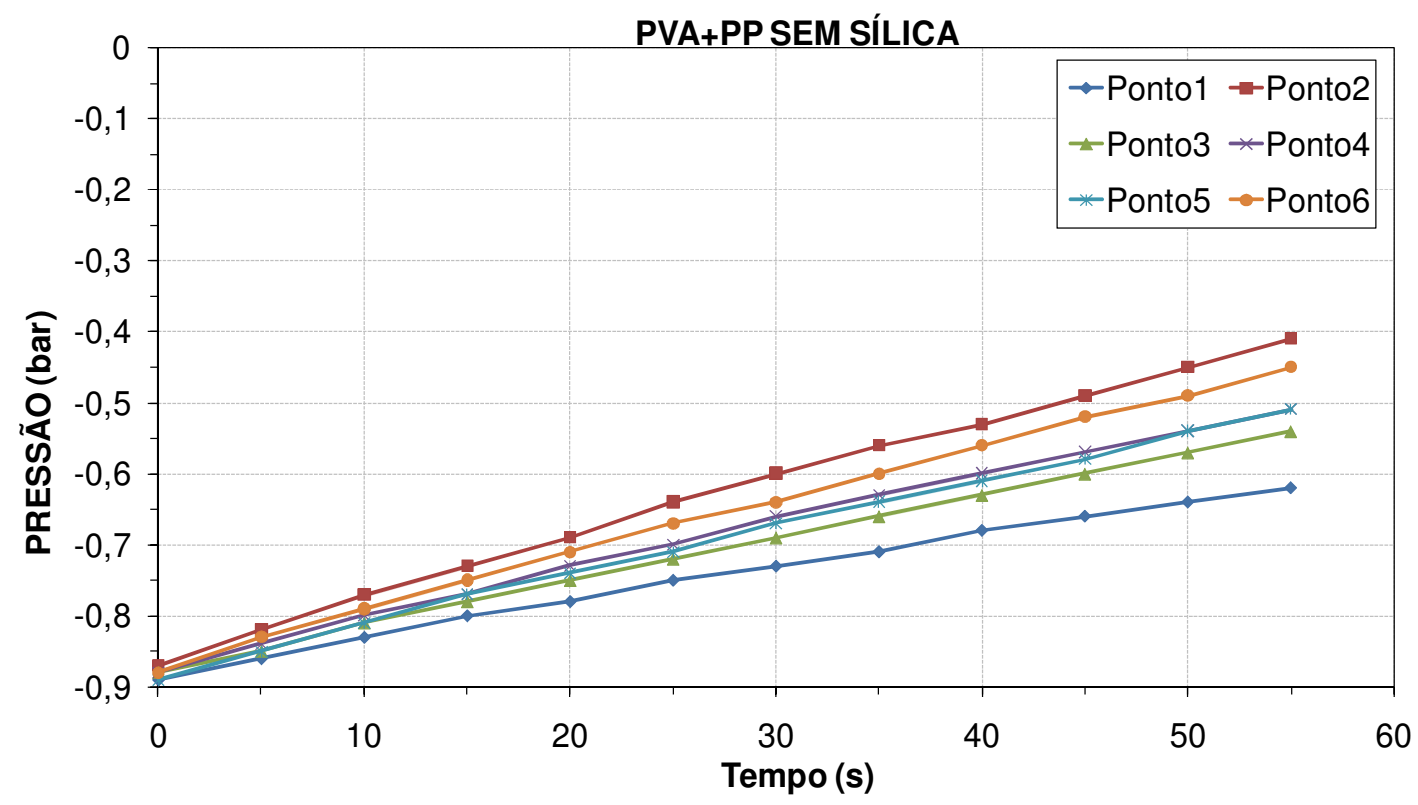

Figura 3.16.1 - Curvas de recuperação de pressão da placa de PVA+PP sem Sílica. 


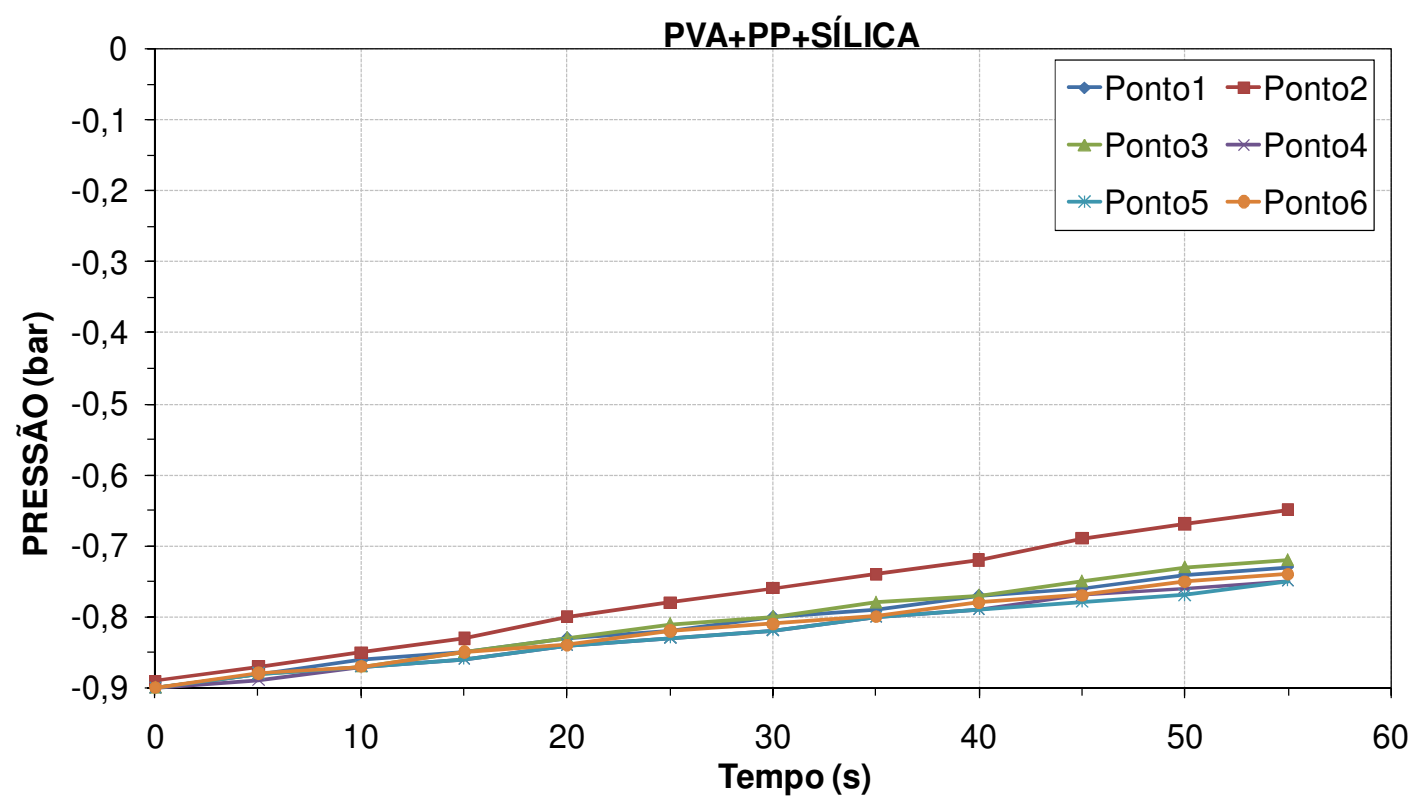

Figura 3.16.2 - Curvas de recuperação de pressão da placa de PVA+PP com Sílica.

Pode-se concluir através dos resultados de permeabilidade que diferenças na formulação, apenas com a incorporação de mais um tipo de material, provoca diferença no perfil das curvas de recuperação das telhas de fibrocimento, melhor ainda observado na Figura 3.17.

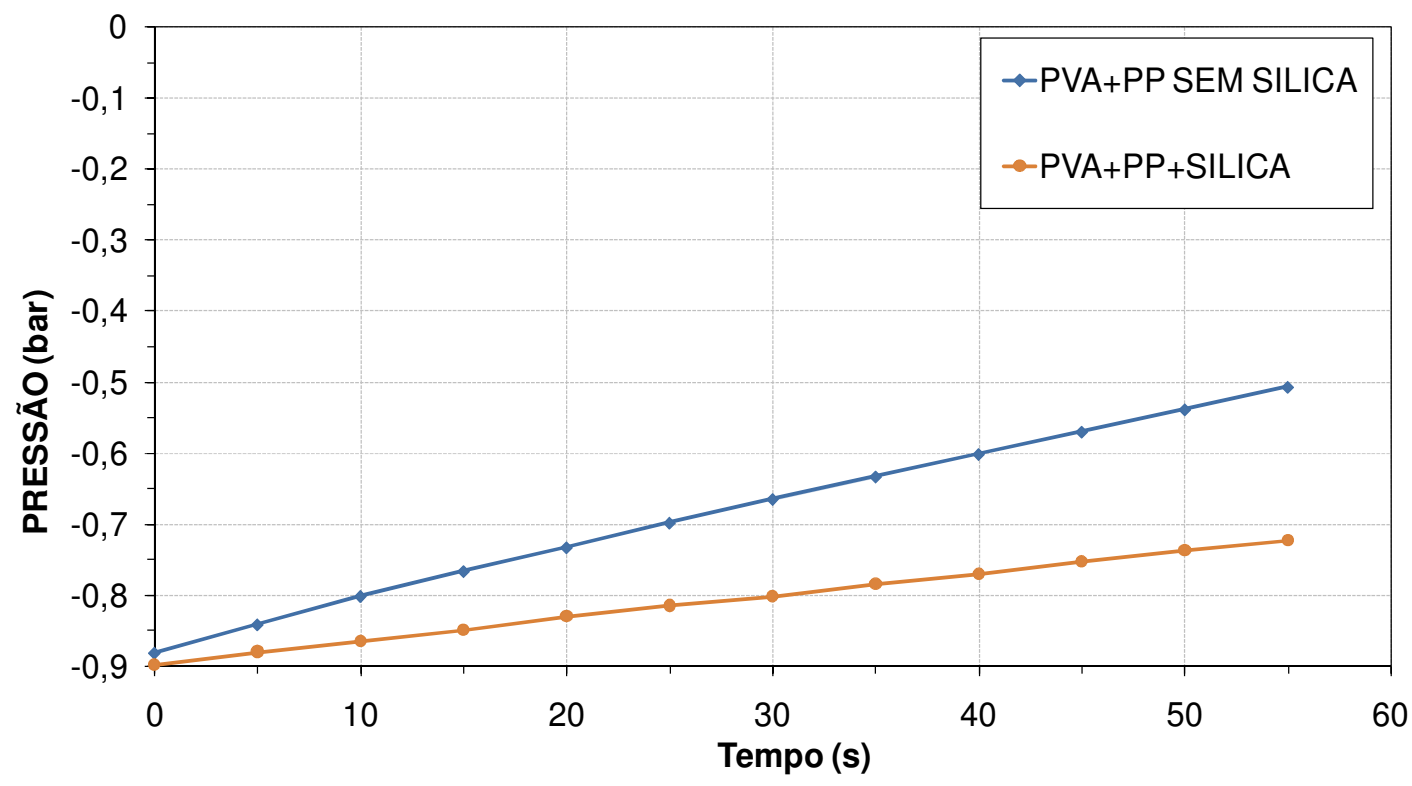

Figura 3.17 - Diferenças entre formulações representadas a partir de suas curvas médias. 
Esse tipo de comportamento pode ser explicado por diferenças no coeficiente de empacotamento das partículas componentes da mistura (INNOCENTINI et al., 2002). Além disso, a incorporação de determinados tipos de materiais pode gerar reações responsáveis pelo surgimento de diferentes produtos de hidratação responsáveis por mudanças na estrutura porosa do material (TAYLOR, 1990), o que não deve ser o caso do produto avaliado. Os resultados de permeabilidade através de $\mathrm{k} 1$ reiteram e quantificam os comportamentos observados nas curvas, e podem ser observados na Figura 3.18.

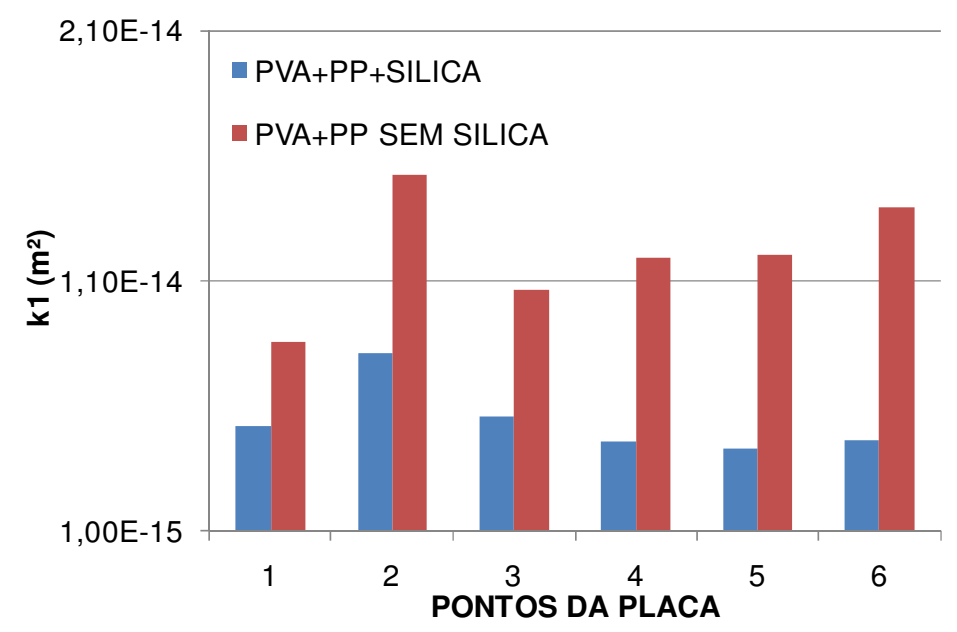

Figura 3.18 - Valores de k1 para as diferentes formulações.

O processo industrial de fabricação das telhas é bastante eficiente e, conforme observado, produz um material bastante homogêneo ao longo de toda a sua composição. A diferença relativa aos pontos de diferentes regiões na placa mostrou-se pequena, sobretudo na composição contendo sílica. A presença desse novo componente pode ter atuado na melhoria de distribuição granulométrica da mistura que, consequentemente, é responsável por modificações no seu grau de empacotamento (OLIVEIRA et. al, 2000).

O Departamento de Construção Civil da Universidade de São Paulo possui um grupo de pesquisa na área de Cimento Celulose que trabalha junto às indústrias produtoras de telhas de fibrocimento para o desenvolvimento do produto. Para isso, o processo de fabricação é simulado em laboratório, porém sem a mesma eficiência que possui na indústria. Como a escala de produção de uma fábrica é bastante 
elevada, os equipamentos utilizados tem a robustez e eficiência que um laboratório não é capaz de reproduzir fielmente em escala reduzida. Por isso, o método de moldagem do grupo foi avaliado com o objetivo de avaliar se produzia placas suficientemente homogêneas e com a mesma qualidade das produzidas industrialmente.

Primeiramente, as mantas de fibrocimento, $200 \times 200 \mathrm{~mm}$, foram fabricadas seguindo as formulações tipicamente utilizadas pelas indústrias nacionais, através do método de drenagem a vácuo utilizado por Savastano Jr. (2004). Os materiais foram misturados em agitador mecânico IKA (Labortechnik RW20) a 2000 rpm e adicionados na seguinte seqüência: água $\rightarrow$ polpa de celulose $(2,5 \mathrm{~min}) \rightarrow$ fibra sintética (2,5 $\mathrm{min}) \rightarrow$ minerais - cimento, escória, filler calcário e sílica ativa (3 min), formando uma suspensão aquosa. Após a mistura, a suspensão foi despejada em recipiente especial onde recebeu uma pressão de vácuo $(200 \mathrm{mmHg}$ ) para retirada da água em excesso, conformando uma manta de espessura 2,5 mm.

As placas de fibrocimento foram produzidas através da superposição de três mantas, em processo similar ao que acontece em máquinas Hatschek (indústria). Entre duas mantas compostas de cimento foi aplicada com um pincel a solução de silicato de sódio. O silicato tem por objetivo ativar a escória de alto-forno presente na formulação. Por fim, as placas constituídas de três camadas foram prensadas a uma tensão máxima de 3,2 MPa pelo período de 5 minutos. A espessura final dos corpos de prova é de $7,0 \mathrm{~mm}$.

Um segundo método de moldagem adiciona a fibra de celulose à água e misturada em agitador mecânico Hobart na velocidade média (2 min). Os materiais particulados foram adicionados na velocidade lenta durante 1 min e ficaram misturando por 3 min na velocidade média para homogeneizar a pasta. $\mathrm{O}$ restante da água da suspensão com concentração foi adicionada na velocidade lenta durante 2 min e seguiu misturando por mais 2 min. Após a mistura, suspensão foi divida em três partes por conta da moldagem em camadas. Em cada terça parte foi depositada a fibra de PVA dispersa em saco plástico através de ar comprimido com pressão de $400 \mathrm{mmHg}$. Em seguida, a suspensão foi despejada num recipiente especial (175 x 
$175 \mathrm{~mm})$ onde recebeu uma pressão de vácuo $(200 \mathrm{mmHg})$ para retirada da água em excesso.

Uma placa foi produzida a partir de cada método de moldagem, curadas em câmara climática a temperatura constante de $26^{\circ} \mathrm{C}$ e umidade relativa de $100 \%$ por um período de 7 dias e posteriormente passou por secagem em estufa a uma temperatura de $50^{\circ} \mathrm{C}$ até a sua constância de massa. Assim como nas extraídas na indústria, as placas foram divididas em 5 regiões distintas (1 ponto central e mais 1 em cada extremidade), para avaliar a homogeneidade que o método provê aos produtos finais.

Para testar novos parâmetros de ensaio para esse tipo de material, dessa vez decidiu-se pela coleta de 4 pontos por segundo, mas em função ainda de sua baixa porosidade foi estipulado um tempo total de ensaio de apenas 60 segundos por região. Os resultados de permeabilidade de ambos os métodos de moldagem podem ser observados nas Figuras 3.19.1 e 3.19.2.

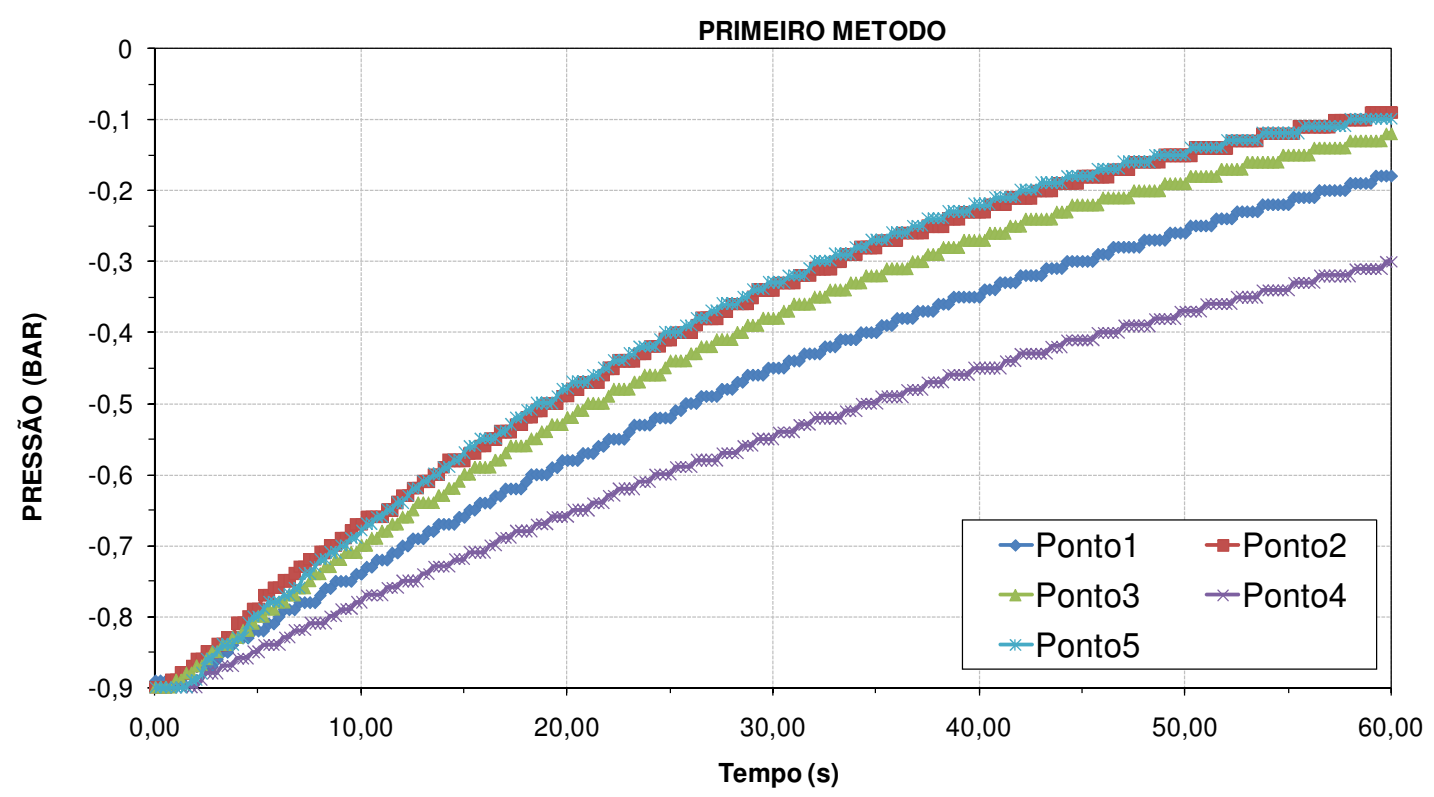

Figura 3.19.1 - Curvas de recuperação de pressão da placa moldada segundo o primeiro método apresentado. 


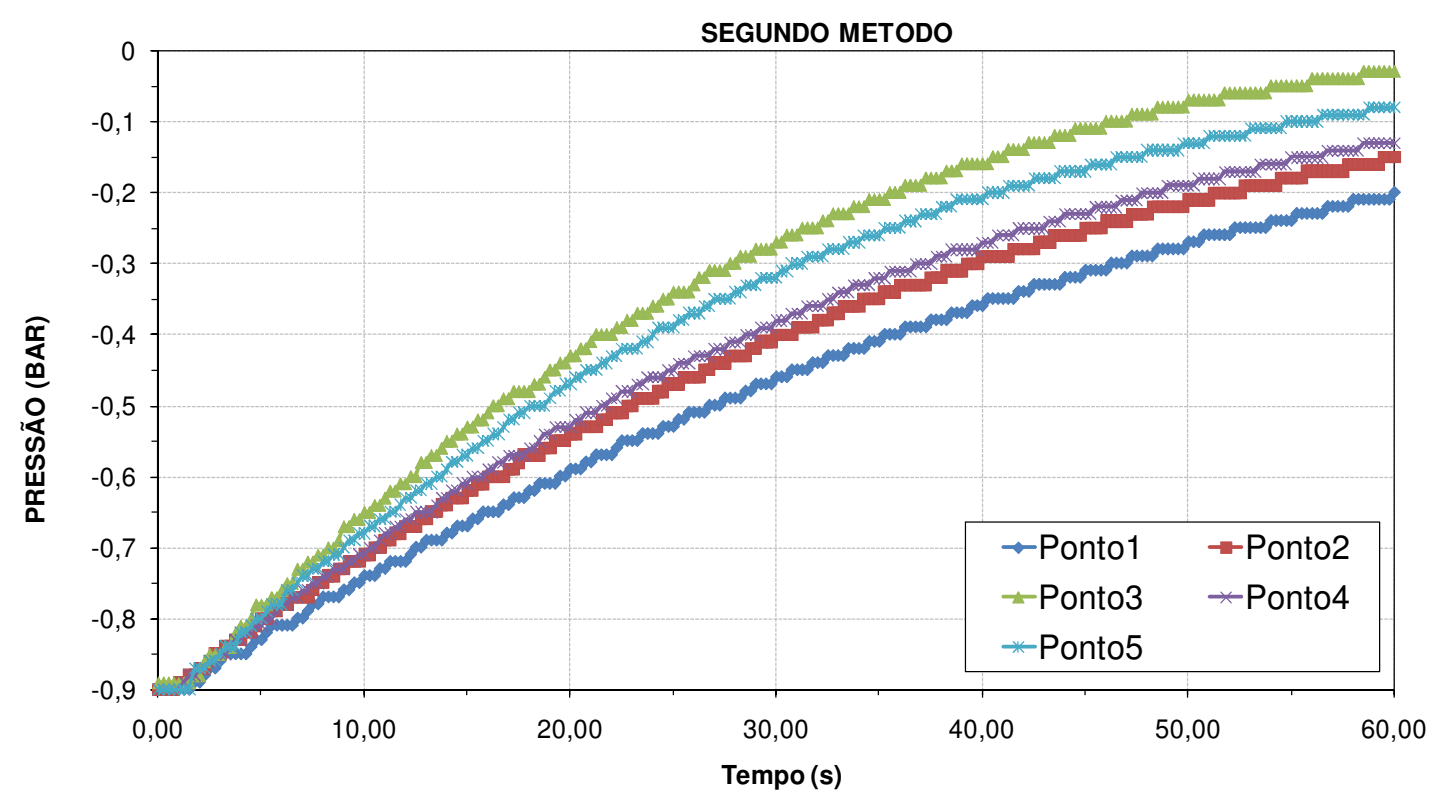

Figura 3.19.2 - Curvas de recuperação de pressão da placa moldada através do segundo método apresentado.

Em termos de análise qualitativa das curvas, os resultados mostram-se bastante parecidos, uma vez que apresentam uma dispersão de resultados semelhante. Isso indica que ambos os métodos produzem placas de fibrocimento de distribuição desigual de materiais, com acúmulo de fibras em determinados pontos da placa ou melhor eficiência de prensagem, que faz com que algumas regiões do material estejam com uma porosidade menor do que em outras. Nesse caso, a avaliação dos métodos quanto à homogeneidade da mistura e confecção do material nos leva a conclusão de que os procedimentos conduzem a resultados bastante semelhantes, portanto, não houve melhoria significativa nesse quesito.

Conforme citado anteriormente, o problema pode estar tanto na dispersão e mistura dos componentes da formulação, principalmente das fibras de celulose e PVA que visualmente mostram-se acumuladas em nichos determinados das placas. Outro problema ainda relacionado pode ser a prensagem do material que ocorre de forma desigual, pois, apesar de ser controlado através de uma máquina universal de ensaios (prensa), tem como geometria de compactação um quadrado. Portanto, se houver qualquer desalinho significativo entre colunas do equipamento, isso pode gerar uma diferença de tensão em diferentes pontos da placa. 
Ainda, os resultados de $\mathrm{k} 1$ obtidos para cada ponto nos diferentes métodos estudados comprovam e quantificam a dispersão de resultados obtidos em uma mesma placa, e podem ser observados na Figura 3.20.

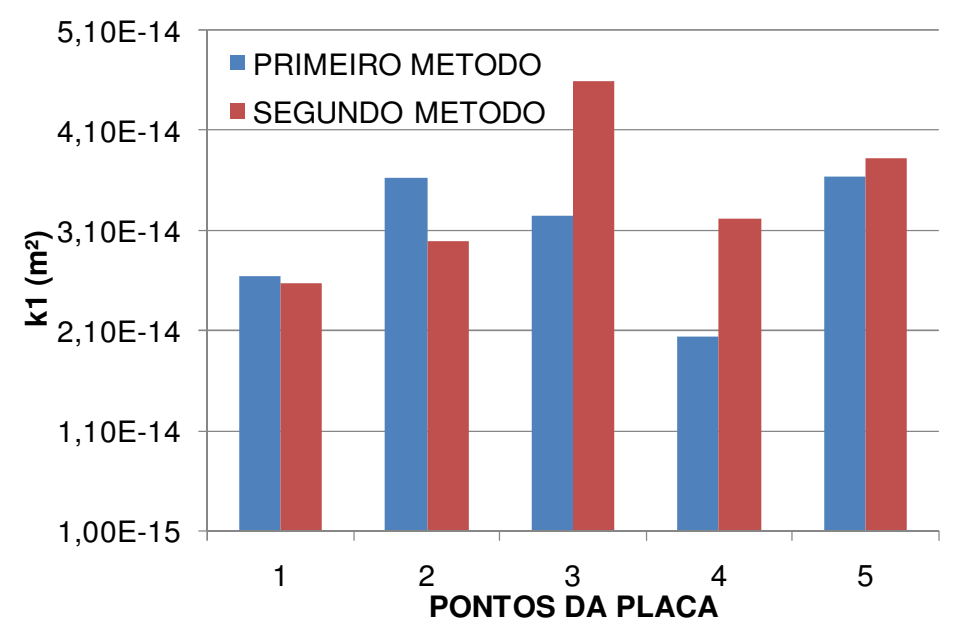

Figura 3.20 - Valores de k1 para os diferentes métodos de moldagem.

\subsection{CONCLUSÕES DO CAPÍTULO}

O desenvolvimento de um novo método de permeabilidade ao ar a argamassas de revestimento traz novas possibilidades de avaliação para esse que é um material de amplo uso na construção civil. As informações obtidas pelo ensaio, desde o processo de estabilização até o tratamento dos dados coletados, permitem definir uma real representação do estado do material, desde as suas condições de serviço até seu estado microestrutural.

Entretanto, para a geração de resultados representativos, é importante observar todo e qualquer tipo de variável interveniente no evento para que se possa configurar o equipamento, ou até mesmo considerá-los durante o processo de tratamento dos dados, de forma que se possa obter um retrato fiel da estrutura avaliada. Resultados preliminares demonstram a velocidade de obtenção e qualidade dos resultados obtidos, além da potencialidade da técnica para outras aplicações. 
Este método tem potencialidades que vão desde uma simples análise qualitiva de suas curvas de recuperação, para um eventual controle de produção industrial ou comparação entre produtos da mesma categoria, até o cálculo de parâmetros de permeabilidade que possibilitam a quantificação do fenômeno para diferentes situações microestruturais avaliadas. Além disso, por tratar-se de um ensaio barato, de fácil implementação e execução, e em função de suas características que permitem a execução in situ, vem exatamente ao encontro das necessidades de correta avaliação de revestimento de argamassas quanto as suas características de uso e serviço. 


\section{AVALIAÇÃO DA INFLUÊNCIA DA ESPESSURA DO CORPO-DE- PROVA E TRAJETO DE PERCOLAÇÃO NO MÉTODO EM DESENVOLVIMENTO}

O desenvolvimento do procedimento de medida de permeabilidade ao ar em argamassas, através do método de vaccum-decay, apesar de inédito na área, baseia-se na experiência de outros processos bastante explorados, sobretudo em concretos. Entretanto, trata-se de materiais de características e aplicações distintas, cada qual com suas particularidades de uso e serviço.

Os revestimentos em argamassa, de forma geral, apresentam como função básica: vedação termo-acústica, regularização da base sob a qual foi aplicada para acabamento final, contribuição na estética de fachada, proteção dos elementos de vedação da ação direta de agentes agressivos, estanqueidade (MACIEL; BARROS; SABBATINI, 1998). A porosidade efetiva, tamanho e distribuição de poros em argamassas de revestimento são, de forma geral, bastante diferentes de concretos convencionais. Entretanto, sabe-se que a camada superficial de elementos de concreto tem uma importância destacada quanto à defesa da entrada de agentes agressivos e, consequentemente, a sua durabilidade (CLAISSE; GANJIAN; ADHAM, 2003). De forma análoga, as argamassas de revestimento possuem como atributo de fundamental importância a proteção de outros elementos constituintes do conjunto ao qual está inserida contra efeitos deletérios. Logo, pode-se observar que sua qualidade e longevidade estão diretamente relacionadas à durabilidade da edificação como um todo.

A permeabilidade de um material poroso esta relacionada ao grau de dificuldade de escoamento de um fluido através de um volume de dimensões conhecidas, isto é, com espessura e área de secção determinadas. Revestimentos de argamassa, para que preservem suas funções e características, devem ser empregados na construção civil com espessuras que variam de $5 \mathrm{~mm}$ a $30 \mathrm{~mm}$ (NBR 13749, 1996). A espessura dos materiais ensaiados, através do procedimento desenvolvido nesse trabalho, é levada em consideração no tratamento dos dados obtidos, conforme se observa nas Equações demonstradas nos Capítulos 2 e 3. 
Entretanto, é importante que a influência da espessura de argamassas seja comprovada na prática para verificar se o equacionamento utilizado resolve corretamente a medida de permeabilidade para esse tipo de material. Além disso, em situações práticas, como na medida de revestimentos aplicados em paredes, não se sabe ao certo qual a espessura avaliada durante o ensaio, a qual pode variar ponto a ponto na mesma área.

Considera-se, para efeito de simplificação e caracterização do fenômeno de permeabilidade, que 0 ar penetre apenas de uma face à outra da argamassa ensaiada pelo método. Entretanto, analisando todas as possibilidades, verifica-se que o trajeto do fluido pode ocorrer por todo e qualquer espaço do meio poroso que possibilite a passagem de ar do meio externo até a câmara de vácuo, conforme mostra o esquema da Figura 4.1. Isto é, o ar sempre tende a percorrer a direção mais fácil, portanto pode penetrar na argamassa tanto por sua face oposta como pela superfície e laterais livres. Provavelmente, o que determinará qual vai ser esse caminho será a porosidade, a potência da bomba de vácuo, a espessura do elemento e a estrutura de poros (tortuosidade).

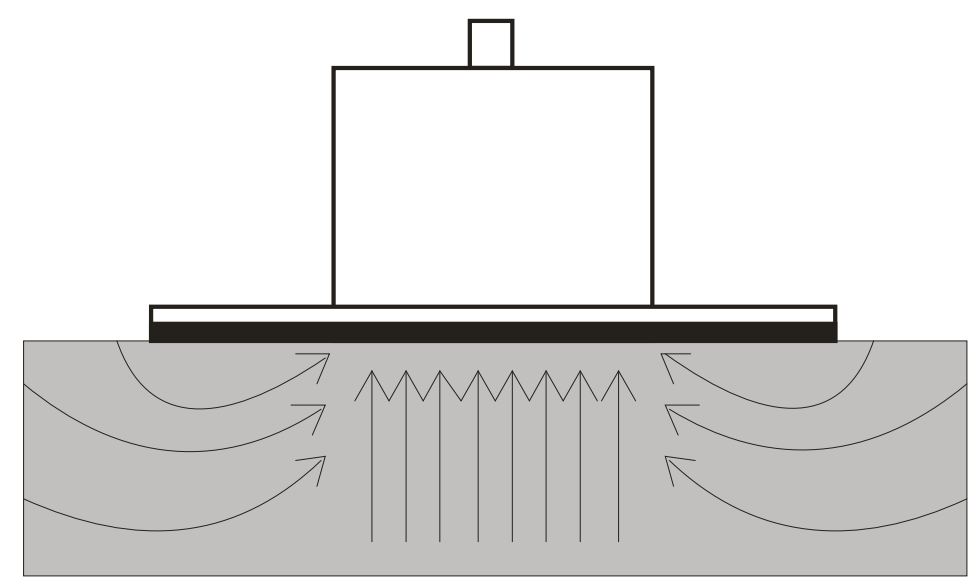

Figura 4.1 - Esquema de possíveis fluxos de ar durante ensaio de permeabilidade.

Logo, é importante que o trajeto do ar através do ensaio deva ser determinado e qual a real contribuição de todas as faces livres, nessa configuração de equipamento, para real determinação da permeabilidade. Esse tipo de conhecimento é de fundamental importância também para que se possam determinar os efeitos superficiais para a medida, tão importantes no emprego de 
argamassas. Também, em ensaios de paredes, o trajeto do que o fluido percorre até a câmara pode determinar qual a real permeabilidade em ensaio e a contribuição dos outros elementos do sistema revestimento para essa determinação.

Portanto, a determinação da real influência da espessura do revestimento ensaiado e direção do ar no desenvolvimento do método de permeabilidade ao ar em argamassas e de fundamental importância para a compreensão completa do fenômeno envolvido na medida, pois as curvas de recuperação do ensaio, assim como seu parâmetro de permeabilidade $\mathrm{k}_{1}$, podem gerar resultados diferentes para o mesmo tipo de material. Esse tipo de alteração deve ser passível de identificação, análise e eventuais correções para que a caracterização do material seja precisa e fiel a estrutura avaliada. Além disso, esse tipo de influência é importante para determinar parâmetros de ensaio in situ de argamassas como, por exemplo, tamanho de câmera ou área de vedação superficial, e também não se sabe ao certo qual a espessura do ponto de ensaio.

\subsection{OBJETIVO}

O objetivo deste capítulo é verificar qual a influência da espessura e a real contribuição de todas as faces livres de corpos-de-prova de diferentes argamassas para determinação de suas permeabilidades ao ar, através do método de vaccumdecay, pela técnica em desenvolvimento neste trabalho.

\subsection{MATERIAIS E MÉTODOS}

Para realização desse estudo foram avaliadas duas argamassas de revestimento industrializadas, denominadas aqui como Arg29\% e Arg44\% em função das suas porosidades.

\subsubsection{CARACTERIZAÇÃO DOS PRODUTOS ANIDROS}

Para determinação dos teores de finos e agregados 2 amostras de $500 \mathrm{~g}$ de material foram peneiradas em malha $200(75 \mu \mathrm{m})$ por 30 minutos em equipamento do tipo "Ro-Tap". As partículas passantes (finos $<75 \mu \mathrm{m}$ ) e retidas (agregados $>75$ 
$\mu \mathrm{m})$ foram pesadas, sendo que as últimas foram posteriormente lavadas e secas para precisa determinação dos teores de cada fração. A média das duas determinações foi então utilizada. Após $24 \mathrm{~h}$ em estufa a $110{ }^{\circ} \mathrm{C}$, os materiais foram submetidos aos ensaios de picnometria de gás Hélio (MultiPycnometer Quantachrome Instruments, modelo MVO 5DC) para determinação da densidade real (massa específica) de cada fração; determinação da área superficial BET (Brunauer, Emmet e Teller) dos finos por adsorção de gás Nitrogênio (Micromeritics ASAP 2010, modelo Gemini III 2375) seguindo a norma técnica ASTM C 1274-00. As características físicas das argamassas podem ser observadas na Tabela 4.1:

Tabela 4.1 - Características físicas das argamassas no estado anidro.

\begin{tabular}{c|cc}
\hline Características Físicas & Arg29\% & Arg44\% \\
\hline Densidade real - argamassa $\left(\mathrm{g} / \mathrm{cm}^{3}\right)$ & 2,61 & 2,71 \\
Densidade real - agregados $\left(\mathrm{g} / \mathrm{cm}^{3}\right)$ & 2,59 & 2,64 \\
Densidade real - finos $\left(\mathrm{g} / \mathrm{cm}^{3}\right)$ & 2,67 & 2,86 \\
Teor finos [<100 $\mu \mathrm{m}(\%-\mathrm{v})]$ & 17,2 & 32,4 \\
Teor agregados [> $100 \mu \mathrm{m}(\%-\mathrm{v})]$ & 82,8 & 67,6 \\
Área superficial específica $\left(\mathrm{m}^{2} / \mathrm{g}\right)$ & 4,53 & 1,24 \\
Teor de água/materiais secos - & 0,154 & 0,163 \\
indicado pelo fabricante $(\mathrm{g} / \mathrm{g})$ & &
\end{tabular}

\subsubsection{MISTURA}

O procedimento de mistura foi realizado em um reômetro rotacional para argamassas e concretos existente no Laboratório de Microestrutura da Escola Politécnica da USP, a partir do controle preciso da velocidade de rotação e aquisição do torque equivalente. Inicialmente, o pó seco foi homogeneizado e despejado na cuba do reômetro e, após 10 segundos do início do programa, foi adicionado o volume total de água, proposto pelo fabricante, numa vazão constante de $45 \mathrm{~g} / \mathrm{s}$. A argamassa foi misturada então com um tempo total de 5 minutos, sob rotação constante de 500 rpm. 


\subsubsection{ESTADO FRESCO}

A densidade aparente e o teor de ar incorporado foram determinados através do método gravimétrico de acordo com a norma brasileira vigente (NBR 13278, 2005).

\subsubsection{ESTADO ENDURECIDO}

Para determinação do módulo de elasticidade foram moldados nove corposde-prova cilíndricos, de $50 \mathrm{~mm}$ diâmetro por $60 \mathrm{~mm}$ de altura, para cada composição de argamassa, com preenchimento realizado em 3 camadas (aplicação de 10 golpes com soquete por camada). Após os procedimentos de cura e secagem, as amostras foram ensaiadas através do método de ultra-som (equipamento Pundit) para determinação do módulo de elasticidade (MONTE et al., 2007).

A resistência à tração por compressão diametral foi medida nas mesmas amostras utilizadas para os ensaios de módulo de elasticidade. $O$ ensaio é baseado na norma ASTM 496C/ 496M-04, adaptado às amostras de menores dimensões, e foi executado utilizando uma INSTRON (modelo 5569) com célula de carga de 50kN e controle por carga (taxa de carregamento utilizada $0,833 \mathrm{MPa} / \mathrm{min}$ ).

\subsubsection{MOLDAGEM}

A confecção dos corpos-de-prova para ensaio de permeabilidade foi realizada em moldes de PVC cilíndricos de 101,6mm de diâmetro, disposto em camadas, compactadas com ajuda de um soquete metálico. As espessuras moldadas foram de $5 \mathrm{~mm}, 10 \mathrm{~mm}, 30 \mathrm{~mm}$ e $50 \mathrm{~mm}$, cada uma representada por 5 corpos-de-prova, totalizando um espaço amostral de 20 amostras para cada argamassa ensaiada.

\subsubsection{CURA}

Todos os $\mathrm{cp}$ 's foram submetidos a um processo de cura com temperatura controlada $\left(27^{\circ} \mathrm{C} \pm 1\right)$, mantendo uma umidade constante com o auxílio de um recipiente com água, por um período de 7 dias. Após a cura, as amostras passavam 
por um processo de secagem em estufa $\left(50^{\circ} \mathrm{C}\right)$ até praticamente sua constância de massa (variação máxima de $0,1 \mathrm{~g}$ ), para posteriormente serem armazenados em dissecador a fim de evitar a absorção de umidade.

\subsubsection{VEDAÇÕES}

Para verificar a influência de cada face livre para recuperação da câmara de vácuo, diferentes caminhos que o ar percorria, as amostras foram submetidas ao ensaio de permeabilidade ao ar em diferentes condições de vedação (normal, lateral, inferior e superior), sucessivamente no mesmo $\mathrm{cp}$, conforme pode ser observado na Figura 4.3.

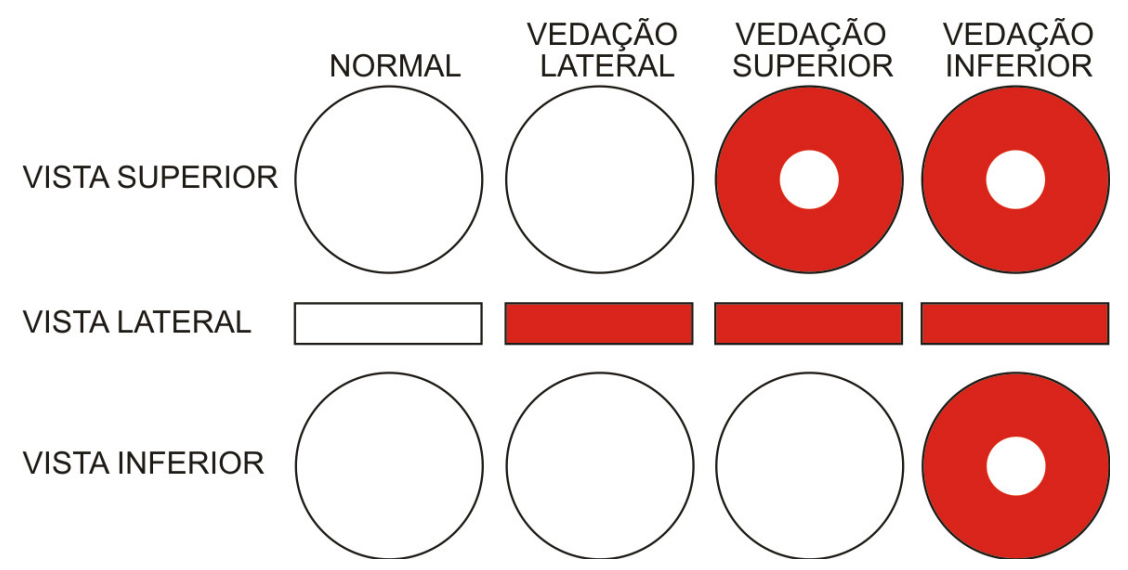

Figura 4.3 - Esquema de vedações sucessivas em cada corpo-de-prova de argamassa, nas diferentes espessuras, ensaiado por permeabilidade ao ar através do novo método de vaccumdecay.

Cada corpo-de-prova, para as diferentes condições de vedação, foi ensaiado por três vezes (ensaio, réplica e tréplica), de forma não sucessivas para que a repetibilidade do ensaio pudesse ser avaliada de forma a eliminar qualquer tipo de variável de operação. Considerando que cada argamassa possui um total de 5 corpos-de-prova para cada espessura avaliada (4 espessuras diferentes), onde cada conjunto possui 4 diferentes tipos de vedação, isto corresponde a um total de 240 repetições de ensaio para cada uma das misturas. 


\subsubsection{PERMEABILIDADE}

Para medida de permeabilidade ao ar foi utilizado o equipamento em desenvolvimento no trabalho, através dos procedimentos relatados anteriormente no Capítulo 3. Optou-se por realizar a coleta de pontos da curva completa, isto é, o ensaio só terminava quando da recuperação completa da câmara de vácuo $(0,00$ bar $\pm 0,01)$.

Ainda, para cada mistura, foram moldados mais 3 corpos-de-prova, de $72 \mathrm{~mm}$ de diâmetro por $22 \mathrm{~mm}$ de altura, para realização de ensaio de permeabilidade ao ar através do consagrado método Cembureau (KOLEK, 1989), em equipamento desenvolvido à Escola Politécnica da USP para concretos e argamassas, para servir como parâmetro base de análise dos resultados obtidos pelo método de vaccumdecay em desenvolvimento nesta dissertação. Neste caso, o tratamento dos dados também é realizado através das equações de Forchheimer, obtendo-se então como resultados os parâmetros de permeabilidade para a argamassa avaliada. A diferença básica entre o método avaliado e o de referência está apenas no regime de escoamento de ar, onde o de vaccum-decay apresenta um regime transiente e o de Cembureau um regime permanente. A Figura 4.6 ilustra os detalhes do equipamento, assim como seu esquema de funcionamento.

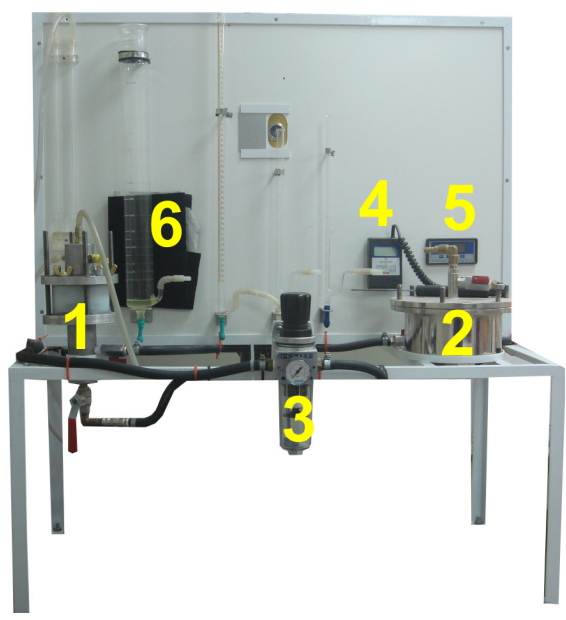

a

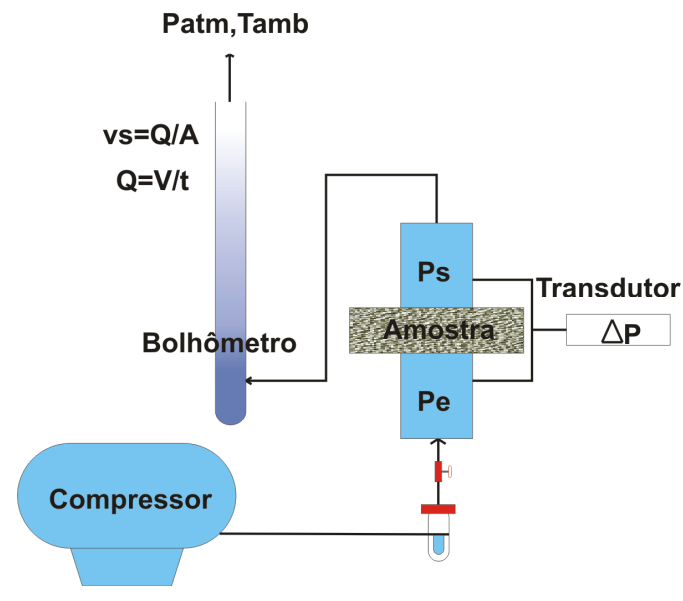

b

Figura 4.6 - a) Permeâmetro para concretos e argamassas. Onde: 1) Porta-amostras para argamassas; 2) Porta-amostras para concreto; 3) Manômetro com filtro; 4) Medidor de temperatura; 5) Display de medida de pressão 6) Bolhômetro. b) Esquema de funcionamento do permeâmetro. 


\subsection{RESULTADOS E DISCUSSÕES}

Os resultados das propriedades das argamassas avaliadas após a etapa de processamento encontram-se ilustrados na Tabela 4.2.

Tabela 4.2 - Propriedades das argamassas ensaiadas após a etapa de processamento.

\begin{tabular}{c|c|c|c|c}
\hline Argamassa & $\begin{array}{c}\text { Ar } \\
\text { incorporado } \\
\text { (\%) }\end{array}$ & $\begin{array}{c}\text { Resistência } \\
\text { Mecânica } \\
\text { (MPa) }\end{array}$ & $\begin{array}{c}\text { Módulo de } \\
\text { elasticidade } \\
\text { (GPa) }\end{array}$ & $\begin{array}{c}\text { Porosidade } \\
\text { (\%) }\end{array}$ \\
\hline Arg29\% & 5,5 & 0,50 & 10,36 & 29,33 \\
Arg44\% & 24,5 & 0,95 & 6,93 & 44,77 \\
\hline
\end{tabular}

A resistência a tração das argamassas define o máximo valor que a resistência de aderência que o sistema pode atingir. Apesar da tendência natural de argamassas mais porosas apresentarem menores resistências à tração do que as de menor porosidade, deve-se atentar ao fato de que a resistência da matriz (pasta) exerce grande influência pelos valores do compósito como um todo (agregados + pasta cimentícea). Portanto, possivelmente a Arg29\% apresente pouca adição de cimento, ou ainda a utilização de outro tipo de aglomerante como cal ou material pozolânico.

Os resultados dos módulos de elasticidade, representantes da rigidez ou capacidade de deformação das argamassas, estão de acordo com os valores de porosidade, já que materiais menos densos, portanto os menos porosos, são aqueles que possuem maior módulo.

Conforme discutido no Capítulo 3 dessa dissertação, os resultados de permeabilidade ao ar pelo método de vaccum-decay em desenvolvimento podem ser avaliados tanto a partir das suas curvas de recuperação (análise qualitativa) quanto de seu parâmetro de permeabilidade k1 (análise quantitativa). As curvas de recuperação para as duas argamassas avaliadas podem ser observados na Figura 4.4 . 

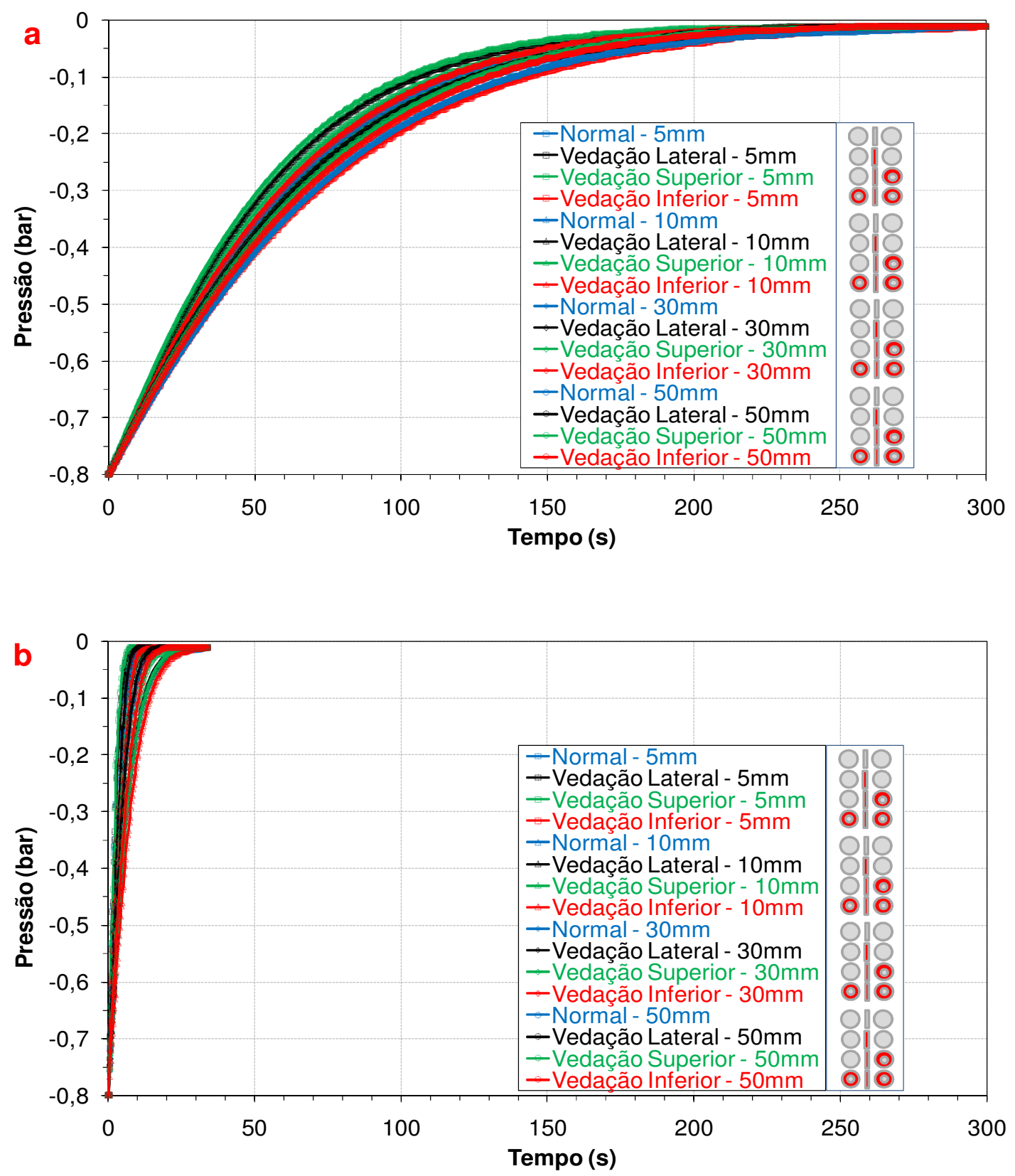

Figura 4.4 - Curvas de recuperação de pressão do ensaio de permeabilidade ao ar em desenvolvimento. Onde: a) Arg29\%; b) Arg44\%.

As curvas de recuperação de pressão demonstradas na Figura 4.4 já sinalizam, independentemente das questões de espessura ou vedações, a potencialidade do método de realizar uma análise qualitativa de argamassas com diferentes estrutura de poros. A permeabilidade de materiais porosos é função de sua estrutura de poros, portanto, diferentes teores de porosidade devem ser 
responsáveis por distintos níveis de permeabilidade ao ar, conforme se pode observar nos resultados acima. O tempo de recuperação total da Arg29\% é cerca de 10 vezes maior do que o da Arg44\%, o que demonstra sua menor susceptibilidade ao fluxo de ar justamente por possuir uma estrutura de vazios menos densa, representando assim uma menor permeabilidade.

A Figura 4.4 mostra um conjunto de curvas, em toda a extensão do ensaio, para as diferentes espessuras e condições de vedação dos corpos-de-prova em ambas as argamassas estudadas. Devido ao grande número de diferentes condições ensaiadas, e pela pequena dispersão aparente de resultados entre espessuras e vedações, fica difícil identificar os diferentes grupos de resultados para efetuar uma análise correta das condições propostas. Portanto, para avaliar fidedignamente os efeitos propostos no desenvolvimento desse estudo, novas curvas foram geradas apenas com os pontos de maior dispersão de resultados (tempos de 50 s, 100 s e 150 s para Arg29\% e 3 s, 5 s e 7 s para Arg44\%), para as diferentes espessuras, e podem ser observados nas Figuras 4.5.1 e 4.5.2.

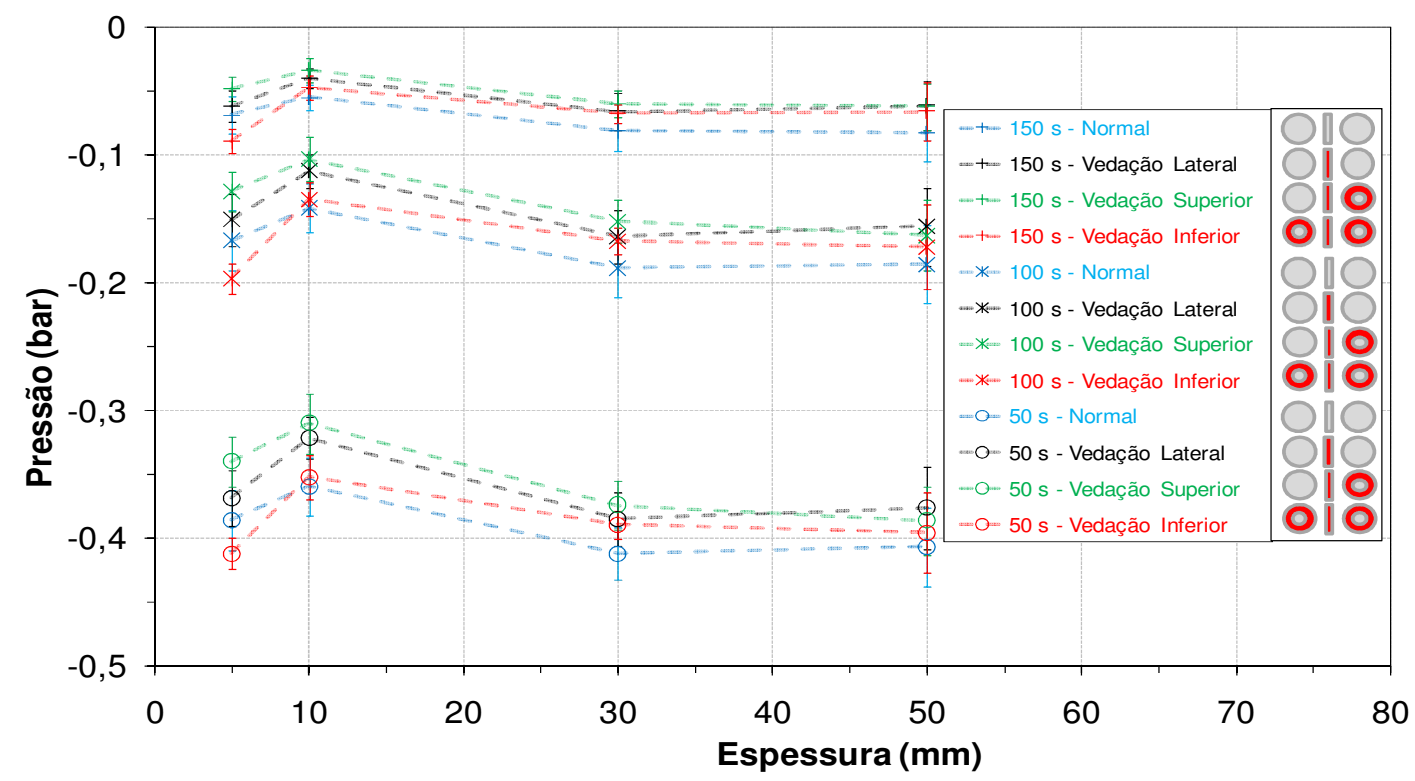

Figura 4.5.1 - Representação esquemática das curvas de recuperação de pressão apenas nos pontos de maior dispersão de resultados, para as diferentes espessuras, da Arg29\%. 


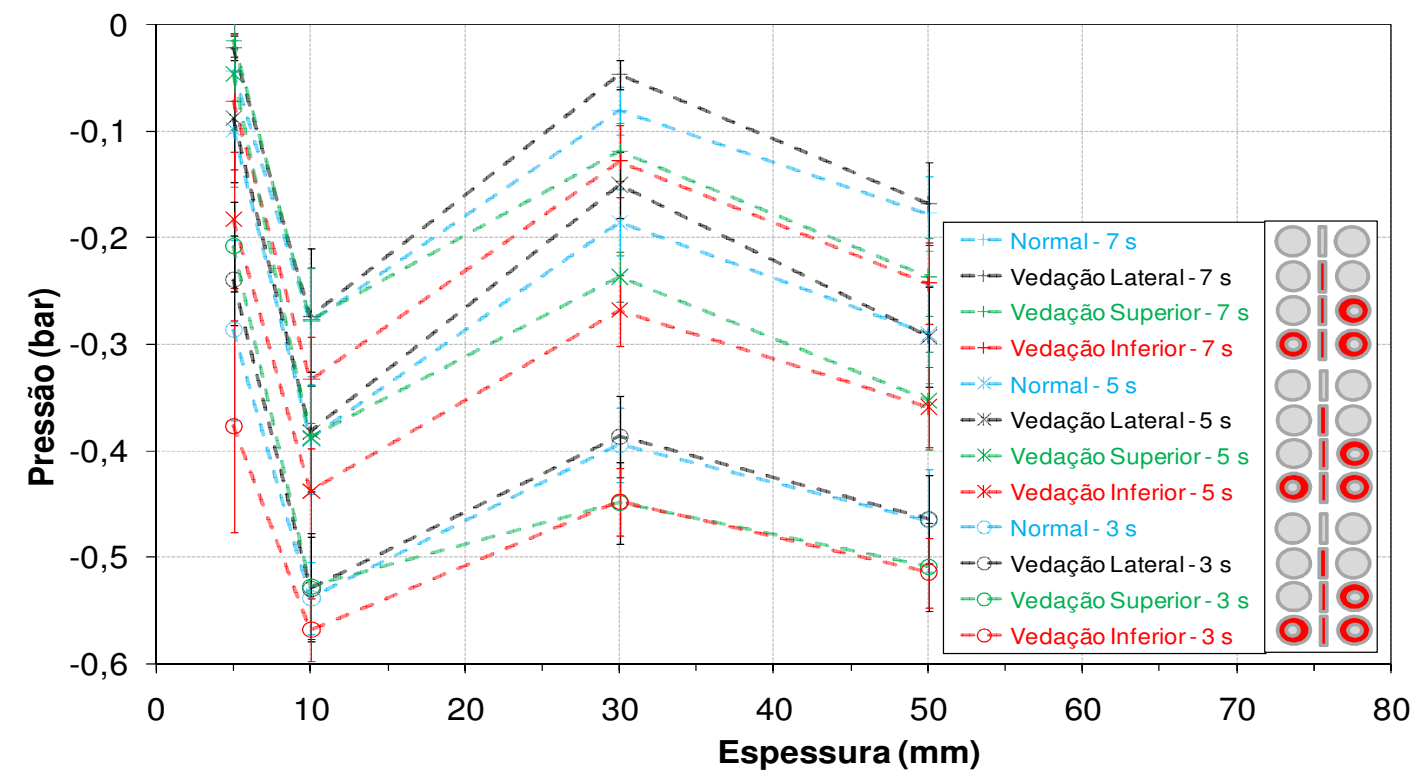

Figura 4.5.2 - Representação esquemática das curvas de recuperação de pressão apenas nos pontos de maior dispersão de resultados, para as diferentes espessuras, da Arg44\%.

Inicialmente, levando-se em consideração somente as diferentes vedações aplicadas aos corpos-de-prova, os pontos mostram que não existem diferenças significativas, tanto para uma argamassa quanto para a outra, para as distintas espessuras ensaiadas. Apenas nas menores espessuras pode-se notar uma pequena dispersão de resultados, onde a vedação inferior é a que apresenta maiores diferenças em relação às demais situações, mostrando-se menos permeável. Isto é, para pequenas espessuras de amostra, a restrição máxima do fluxo (vedação inferior) pode ser responsável pela determinação de uma direção de percolação no interior da amostra diferente de outras condições verificadas.

Analisando as curvas de ambas as argamassas, levando-se agora em consideração apenas as espessuras, pode-se concluir que esse tipo de variável tem pouca influência sobre a recuperação, sobretudo se considerados os desvios representados pela barra de erros em cada ponto representado. Mesmo no caso da Arg44\%, que apresenta uma maior amplitude entre pontos para as diferentes espessuras e a primeira vista remete ã existência de uma relação com a permeabilidade, não pode ser considerada devido aos seus grandes desvios. Portanto, a grande dispersão de resultados desta argamassa não permite chegar à 
conclusão precisa sobre qualquer tipo de influência, direta ou indireta, da espessura do cp na determinação da permeabilidade.

É interessante observar que, na faixa entre $20 \mathrm{~mm}$ e $30 \mathrm{~mm}$, usualmente recomendada para emprego na construção civil em revestimentos de argamassa, as variações tanto de espessura quanto de vedação, para ambas as misturas, não foram significativas, consideradas as dispersões nos resultados. Isso é importante na definição do ensaio in situ, pois demonstra que não são necessárias intervenções ou considerações significativas para esse tipo de situação.

Portanto, esse tipo de análise curvas de recuperação, meramente qualitativa, não se mostrou capaz de identificar com precisão a real influência da espessura na determinação da permeabilidade ao ar através do método em desenvolvimento. Além disso, as duas argamassas escolhidas representam dois extremos bastante distantes quanto as suas estruturas porosas, evidenciado pelos diferentes perfis de curvas de recuperação entre os dois conjuntos. Assim, uma análise quantitativa pode ser muito mais elucidativa no que diz respeito à avaliação das variáveis propostas. Deste modo, foram calculados os parâmetros de permeabilidade k1 sempre a partir da curva média, obtida através das médias de todas as repetibilidades de cada ensaio, para todas as amostras, nas diferentes situações de vedação. Os resultados de k1, calculados a partir do ensaio por ambos os métodos, podem ser visualizados na Figura 4.7. 


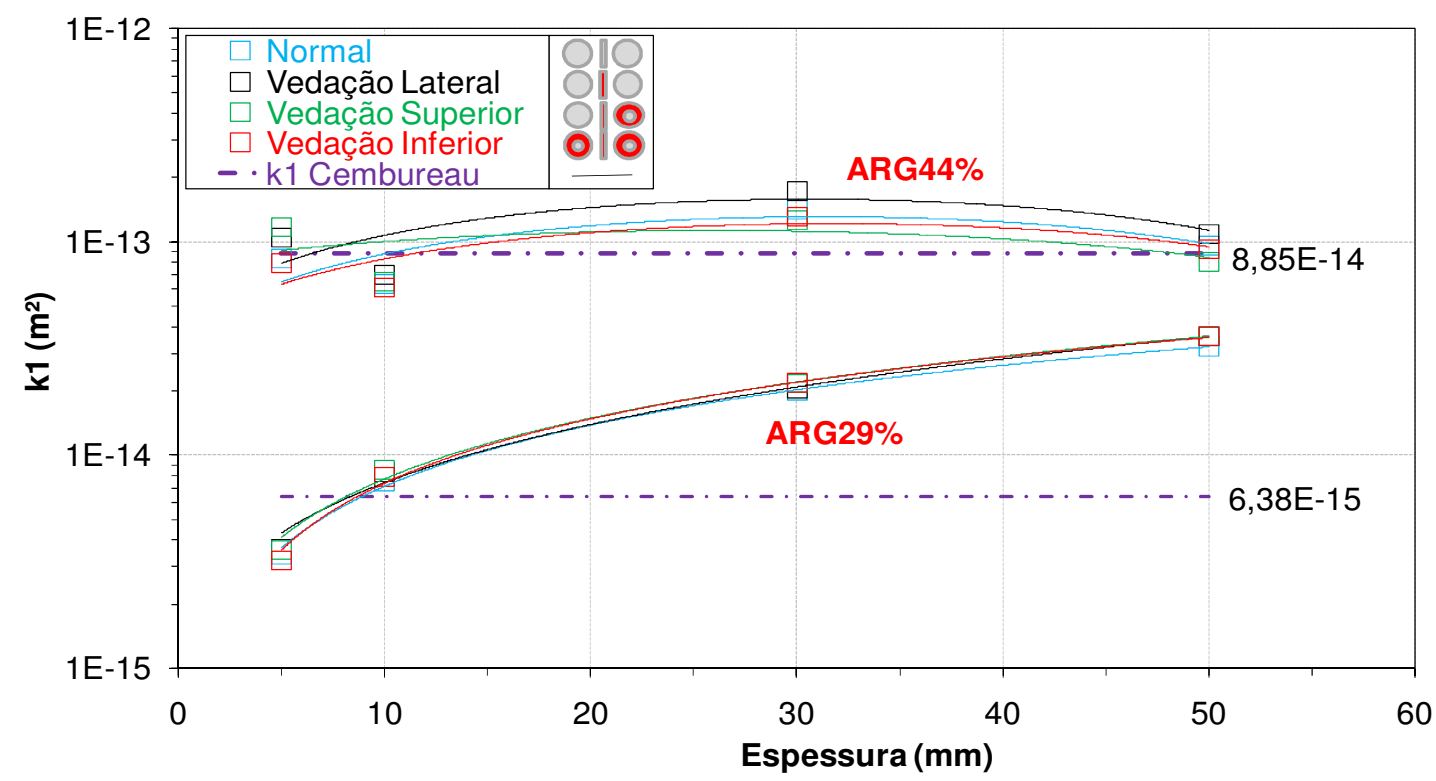

Figura 4.7 - Valores de k1 de ambas as argamassas, obtidos através do método de Cembureau e vaccum-decay, para as diferentes situações de estudo.

Observa-se nitidamente que para a Arg44\% tanto a espessura quanto a vedação não tiveram influência significativa nos resultados de permeabilidade. A estrutura dessa argamassa é possivelmente formada por poros de tão grandes dimensões que, o fluxo de ar, para o nível de vácuo imposto pela bomba do equipamento, tem a mesma dificuldade de ultrapassar o corpo da amostra por qualquer uma das direções impostas pelas vedações ou pelas espessuras propostas no estudo. Além disso, espera-se mesmo que os valores de permeabilidade permaneçam constantes uma vez que essa é uma característica associada ao tipo de material avaliado e uma vez que a espessura de permeação é considerada no tratamento dos dados obtidos no ensaio.

Contudo, no caso da argamassa Arg29\%, apesar dos diferentes tipos de vedação também não causarem influência significativa nos valores de permeabilidade, percebe-se que o aumento da espessura resulta em um aumento, não linear e com um possível patamar de estabilização para maiores espessuras, nos valores de $\mathrm{k}_{1}$. Isso possivelmente acontece porque o fluxo de ar, para o caso de argamassas com um volume de poros reduzido, não se dá de forma retilínea como considerado nas simplificações do modelo de permeabilidade (INNOCENTINI et al., 
2010). Isto é, a seção do fluxo de ar através da amostra sofre um espalhamento, aumento assim o caminho de percolação do fluido e, principalmente, a área útil da amostra ensaiada (Figura 4.8).

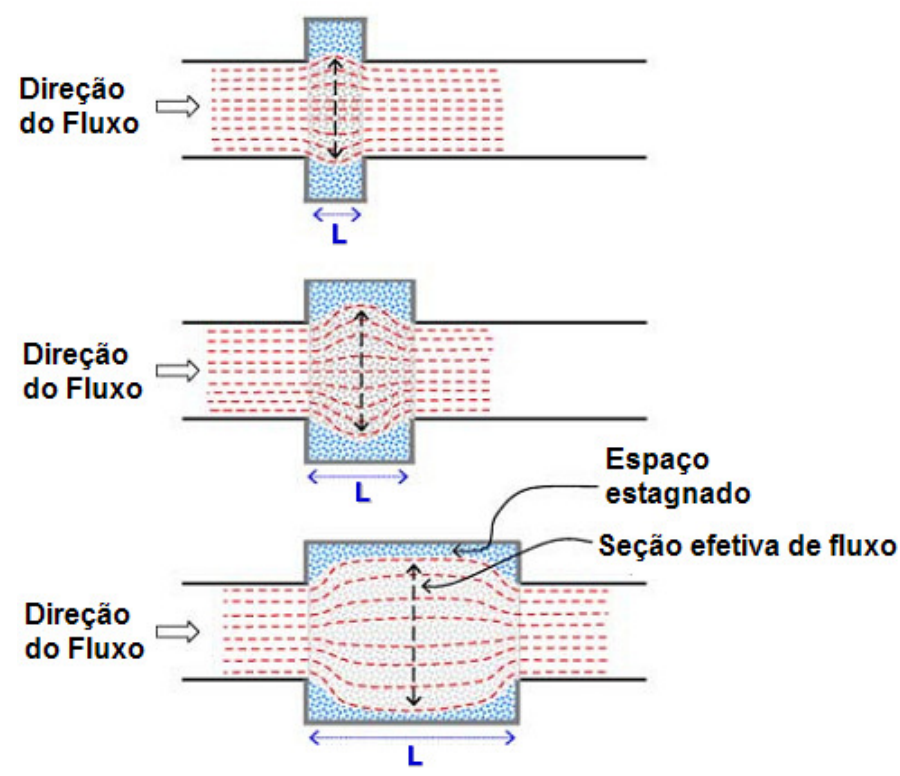

Figura 4.8 - Esquema do espalhamento das linhas de fluxo de ar nos ensaios de permeabilidade (adaptado de INNOCENTINI, 2010).

Esse é um caminho hipotético proposto por INNOCENTINI (et al., 2010) refere-se a ensaios em filtros metálicos, que tem estrutura porosa bastante homogênea em toda a sua composição e durante todo o seu ciclo de vida. Entretanto, sabe-se que a estrutura de poros de materiais cimentíceos é bastante heterogênea e variável ao longo de sua idade. Além disso, em argamassas tem-se a presença do efeito de superfície que é responsável ainda pela geração de poros significativamente diferentes do resto da estrutura. Isso quer dizer que, o fluxo de ar pode estar sim sofrendo uma mudança no seu trajeto ao longo do material ensaiado, que não seja necessariamente o proposto por INNOCENTINI. Esse tipo de mudança pode explicar o aumento da permeabilidade, da argamassa menos porosa, em função do aumento de sua espessura, ao contrário do que se esperaria através do esquema proposto na Figura 4.8.

Outra hipótese é de que a bomba, durante a execução do vácuo, realize apenas o esgotamento do reservatório de ar contido nos poros da argamassa, que é 
imediatamente reabastecido pelo ar contido no meio externo com velocidade variável em função de sua estrutura porosa. Cria-se então um bulbo de pressão, de geometria variável, logo abaixo da câmara de vácuo. Essa região de mínima pressão depende tanto da potência da bomba quanto da estrutura porosa, mas não da espessura do corpo-de-prova e tem uma área de influência ao seu redor que permanece constante (Figura 4.9). Desta forma, considerando que o fluxo de ar se dá através do gradiente de pressão entre a câmara de vácuo e a outra face do $\mathrm{cp}, \mathrm{e}$ que essa variação não é necessariamente linear ao longo da estrutura da amostra ensaiada, pode-se explicar essas diferenças de k1 observadas na Arg29\% conforme a sua espessura foi sendo variada.
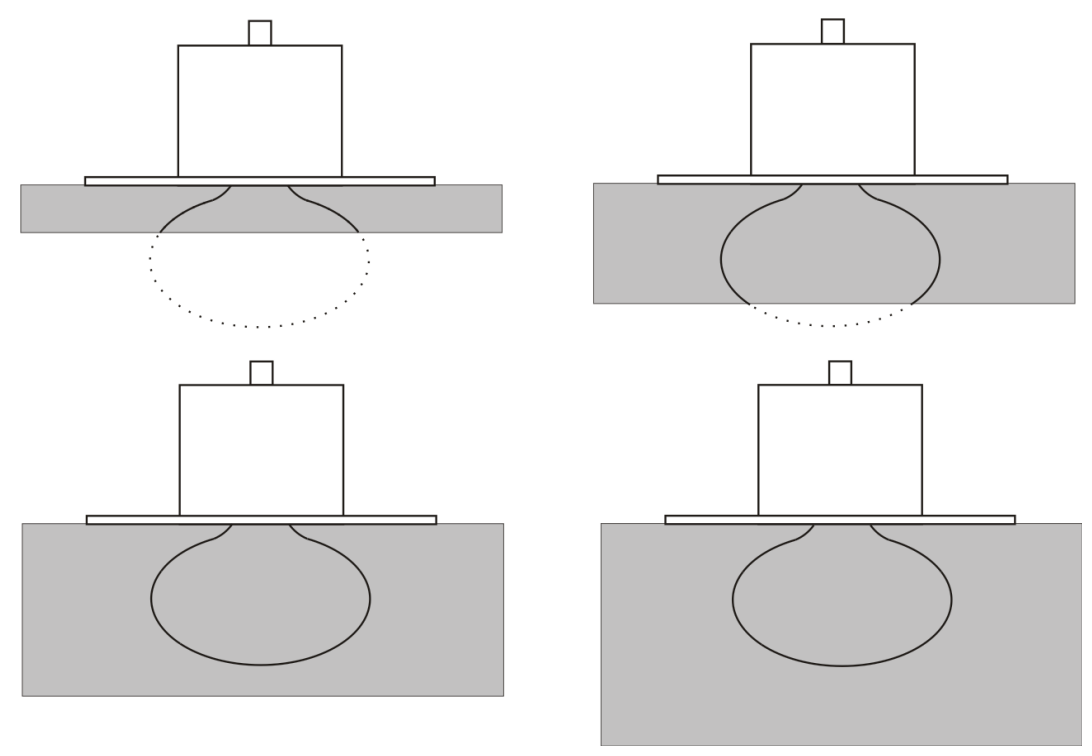

Figura 4.9 - Formação de um bulbo de pressão negativa responsável pelo esgotamento do ar dos poros da argamassa nas diferentes espessuras.

Logo, supõe-se que a argamassa mais porosa (Arg44\%) deve ter sido ensaiada por completo (de face a face para todas as espessuras avaliadas). Já na argamassa menos porosa (Arg29\%), a variação de pressão gerada por essa potência de bomba só é suficiente para medir uma determinada espessura que não é a efetiva utilizada no equacionamento. Isso é, superestima-se a espessura de permeação do ar no ensaio e isso faz com que os valores também sigam essa mesma variação. Por isso os valores de $k_{1}$ obtidos pelo método de Cembureau correspondem aos calculados em pequenas espessuras. 
Portanto, para diferentes estruturas de argamassas, com diferentes distribuições de poros, nessa configuração de ensaio (potência de bomba), o comportamento do fluxo de ar a luz desse fenômeno de esgotamento dos poros pode acontecer de formas bastante distintas, e necessitam um estudo mais aprofundado.

É importante mais uma vez mencionar que, para ambas as argamassas estudadas, dentro da faixa normal de espessuras recomendada para execução de revestimentos $(20 \mathrm{~mm}$ a $30 \mathrm{~mm})$, não se observa variação significativa de $\mathrm{k} 1$, o que representa que o ensaio não requer nenhum tipo de adaptação ou consideração para sua execução em paredes in situ.

Fazendo uma comparação dos valores mensurados pelo método de Cembureau, onde o fluxo se mantém permanente ao longo do ensaio, com os calculado a partir dos resultados obtidos pelo método de vaccum-decay em desenvolvimento, percebe-se que existe uma correlação importante de resultados. Isso demonstra que o novo ensaio também é capaz de quantificar os parâmetros de permeabilidade em argamassas de revestimento dentro de uma faixa de resultados pertinentes. Entretanto, ainda é necessário entender com precisão qual o verdadeiro fenômeno que provoca essa alteração dos valores de k1 em função da espessura dos corpos-de-prova para poder estabelecer uma eventual correção ou consideração que se faça necessária a fim de corresponder os resultados de ambos os métodos.

\subsection{CONCLUSÕES DO CAPÍTULO}

O método de vaccum-decay em desenvolvimento permite diferenciar com clareza, somente a partir de suas curvas de recuperação de pressão, as diferentes estruturas porosas de argamassas avaliadas. Isso por si só, já torna o método inédito na área e abre caminhos para caracterização de diversos tipos de fenômenos que possam provocar qualquer eventual tipo de modificação de estrutura, tanto superficial quanto interna. 
A seleção das argamassas para fazer parte do estudo da influência de espessura de corpo-de-prova e trajeto de escoamento na medida de permeabilidade pelo método de vaccum-decay se deu pelas diferenças nas suas estruturas evidenciadas por suas porosidades. Entretanto, as duas representam extremos bastante opostos quanto à porosidade. Possivelmente aquela de maior permeabilidade represente uma situação, em relação ao ensaio proposto, que não acompanhe um padrão de comportamento verificado para as de menor valor de porosidade, o que impossibilitou a conclusões decisivas sobre a real influência das variáveis sugeridas neste estudo. Mais estudos devem ser realizados nesse sentido a fim de verificar as possibilidades levantadas quanto aos resultados obtidos nestas argamassas.

É interessante observar que, mesmo não seguindo um padrão de comportamento para as diferentes situações impostas em ambas as argamassas avaliadas, tanto a espessura quanto a direção do fluxo não foram de significante relevância para situações reais de revestimentos em paredes de edificações. Portanto, pode-se considerar que o ensaio deve ser capaz de avaliar com eficiência esse tipo de insumo in situ, já aplicado em blocos ou elementos de concreto. 


\section{ENSAIO DE PERMEABILIDADE AO AR EM PAREDES REVESTIDAS COM ARGAMASSA}

Para avaliar a real potencialidade que a técnica tem de caracterizar superfícies de revestimentos compostos por argamassas, nada mais adequado que realizar essa análise em situações reais de uso e serviço do material. Portanto, além dos ensaios realizados anteriormente em ambiente laboratorial, constatou-se a necessidade de experimentar também as mesmas argamassas in situ para verificar se existe algum tipo de relação entre os valores encontrados tanto em condições controladas quanto sob a influência de variáveis externas. Ainda, verificar se existe alguma influência do conjunto revestimento (bloco, chapisco, etc) na determinação da permeabilidade ao ar do material argamassa, que é quem compõe a superfície.

Além disso, esse tipo de análise pode ser capaz de identificar outros tipos de variáveis e questionamentos, quanto ao desenvolvimento do método, que antes não foram observados devido às condições de preparo e exposição das amostras. Também, listar defeitos e necessidades de aprimoramento do projeto para que o método de medida corresponda ao que se propõe essencialmente.

Algumas técnicas observadas anteriormente foram projetadas e desenvolvidas para realizar medida de permeabilidade ao ar em materiais de construção porosos, sobretudo em concretos. Algumas delas, como se apresentam originalmente, precisariam de adaptações primeiramente de ordem estrutural, como é o caso de Figg (FIGG, 1973), por exemplo, para poder ser utilizadas no estudo de argamassas de revestimento. Portanto, o estudo das características desse tipo de insumo requer, devido as suas particularidades de microestrutura e uso, um estudo específico e dirigido a fim de contemplar todas as particularidades observadas nesse tipo de material, desde detalhes de construção a modelagem matemática do fenômeno em si.

\subsection{OBJETIVO}

O objetivo deste capítulo é verificar o potencial que o método em desenvolvimento tem de medir a permeabilidade ao ar em superfícies de 
argamassas in situ, e qual a relação destes resultados com os obtidos em laboratório com os mesmos materiais.

\subsection{MATERIAIS E MÉTODOS}

Em continuação ao estudo de caracterização reológica e aplicabilidade de argamassas de revestimento desenvolvido na Escola Politécnica da USP (CARDOSO, 2009 ; CARDOSO; PILEGGI; JOHN, 2010), foram avaliados seis diferentes produtos, do mercado nacional, 2 dentre os quais utilizados anteriormente (em laboratório) no desenvolver do Capítulo 4 desta dissertação. Também, como no Capítulo anterior, as argamassas foram denominadas em função de suas porosidades como: Arg29\%; Arg40\%; Arg38\%; Arg36\%; Arg44\% e Arg32\%.

\subsubsection{PAREDES}

Foram construídas 5 paredes sob pórticos de concreto, compostas por blocos de revestimentos cerâmicos, revestidas com chapisco industrializados, conforme mostra a Figura 5.1:

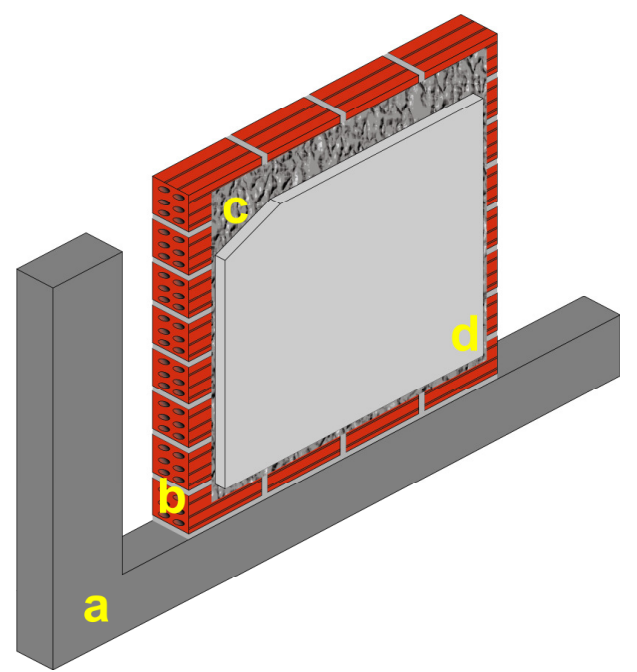

Figura 5.1 - Detalhe da confecção da parede. Onde: a) Pórtico em concreto; b) Bloco cerâmico; c) Chapisco industrializado; d) Revestimento de argamassa.

Em cada uma de suas faces, foram aplicados dois diferentes painéis de argamassa de aproximadamente $1 \mathrm{~m}^{2}$, com uma espessura média de $2,5 \mathrm{~cm}$, totalizando 4 painéis por parede. 


\subsubsection{CARACTERIZAÇÃO DOS PRODUTOS ANIDROS}

Para determinação dos teores de finos e agregados 2 amostras de $500 \mathrm{~g}$ de material foram peneiradas em malha $200(75 \mu \mathrm{m})$ por 30 minutos em equipamento do tipo "Ro-Tap". As partículas passantes (finos $<75 \mu \mathrm{m}$ ) e retidas (agregados $>75 \mu \mathrm{m}$ ) foram pesadas, sendo que as últimas foram posteriormente lavadas e secas para precisa determinação dos teores de cada fração. A média das duas determinações foi então utilizada. Após $24 \mathrm{~h}$ em estufa a $110^{\circ} \mathrm{C}$, os materiais foram submetidos aos ensaios de picnometria de gás Hélio (MultiPycnometer - Quantachrome Instruments, modelo MVO 5DC) para determinação da densidade real (massa específica) de cada fração; determinação da área superficial BET (Brunauer, Emmet e Teller) dos finos por adsorção de gás Nitrogênio (Micromeritics ASAP 2010, modelo Gemini III 2375) seguindo a norma técnica ASTM C 1274-00. As características físicas das argamassas podem ser observadas na Tabela 5.1:

Tabela 5.1 - Características físicas das argamassas no estado anidro.

\begin{tabular}{|c|c|c|c|c|c|c|}
\hline Características Físicas & Arg29\% & Arg $40 \%$ & Arg38\% & $\operatorname{Arg} 36 \%$ & Arg44\% & Arg32\% \\
\hline $\begin{array}{c}\text { Densidade real - } \\
\text { argamassa }\left(\mathrm{g} / \mathrm{cm}^{3}\right)\end{array}$ & 2,61 & 2,81 & 2,82 & 2,65 & 2,71 & 2,6 \\
\hline $\begin{array}{l}\text { Densidade real - } \\
\text { agregados }\left(\mathrm{g} / \mathrm{cm}^{3}\right)\end{array}$ & 2,59 & 2,81 & 2,77 & 2,61 & 2,64 & 2,58 \\
\hline $\begin{array}{l}\text { Densidade real - finos } \\
\qquad\left(\mathrm{g} / \mathrm{cm}^{3}\right)\end{array}$ & 2,67 & 2,80 & 2,90 & 2,77 & 2,86 & 2,71 \\
\hline $\begin{array}{c}\text { Teor finos }[<100 \mu \mathrm{m}(\%- \\
\mathrm{v})]\end{array}$ & 17,2 & 31,1 & 33,1 & 25,6 & 32,4 & 14,3 \\
\hline $\begin{array}{c}\text { Teor agregados }[>100 \mu \mathrm{m} \\
(\%-\mathrm{v})]\end{array}$ & 82,8 & 68,9 & 66,9 & 74,4 & 67,6 & 85,7 \\
\hline $\begin{array}{l}\text { Área superficial específica } \\
\qquad\left(\mathrm{m}^{2} / \mathrm{g}\right)\end{array}$ & 4,53 & 0,75 & 1,36 & 1,76 & 1,24 & 2,70 \\
\hline $\begin{array}{l}\text { Teor de água/materiais } \\
\operatorname{secos}(\mathrm{g} / \mathrm{g})\end{array}$ & 0,154 & 0,165 & 0,152 & 0,140 & 0,163 & 0,164 \\
\hline
\end{tabular}




\subsubsection{MISTURA}

O procedimento de mistura foi realizado em um misturador de eixo horizontal (Consolid) com os teores de água indicados pelo fabricante, observados na Tabela 5.1 acima. Cada batelada foi composta por $35 \mathrm{~kg}$ de material e o tempo de mistura variou entre 2 e 3 minutos em função da argamassa utilizada.

\subsubsection{ESTADO FRESCO}

A densidade aparente e o teor de ar incorporado foram determinados através do método gravimétrico de acordo com a norma brasileira vigente (NBR 13278, 2005).

\subsubsection{ESTADO ENDURECIDO}

Para determinação do módulo de elasticidade foram moldados 5 corpos-deprova cilíndricos, de $50 \mathrm{~mm}$ diâmetro por $60 \mathrm{~mm}$ de altura, para cada composição, com preenchimento em 3 camadas e aplicação de 10 golpes com soquete a cada camada aplicada. Após os procedimentos de cura e secagem, as amostras foram ensaiadas através do método de ultra-som (equipamento Pundit) para determinação do módulo de elasticidade (MONTE et al., 2007).

A resistência à tração por compressão diametral foi medida nas mesmas amostras utilizadas para os ensaios de módulo de elasticidade. O ensaio é baseado na norma ASTM 496C/ 496M-04, adaptado às amostras de menores dimensões, e foi executado utilizando uma INSTRON (modelo 5569) com célula de carga de $50 \mathrm{kN}$ e controle por carga (taxa de carregamento utilizada $0,833 \mathrm{MPa} / \mathrm{min}$ ).

\subsubsection{APLICAÇÃO}

Três diferentes aplicadores (pedreiros A, B e C), foram responsáveis por efetuar 6 diferentes painéis de argamassas, em dias distintos entre os meses de setembro e outubro de 2008, sem que 2 ou mais deles tivessem qualquer tipo de influência sobre o tipo ou forma de execução do outro. As ordens de aplicação, 
assim como a produtividade, de cada colaborador foram diferentes, conforme mostram as características da Tabela 5.2:

Tabela 5.2 - Condições de aplicação para as diferentes argamassas ensaidas.

\begin{tabular}{c|cccccccccc}
\hline \multirow{2}{*}{ Argamassa } & \multicolumn{3}{|c}{ Aplicador A } & \multicolumn{3}{c}{ Aplicador B } & \multicolumn{3}{c}{ Aplicador C } \\
\cline { 2 - 11 } & Data & T ( $\left.{ }^{\circ} \mathbf{C}\right)$ & UR (\%) & Data & T $\left({ }^{\circ} \mathbf{C}\right)$ & UR (\%) & Data & T $\left({ }^{\circ} \mathbf{C}\right)$ & UR (\%) \\
\hline Arg29\% & $16 /$ Set & 19 & 60 & $26 /$ Set & 18 & 68 & $19 /$ Set & 21 & 52 \\
Arg40\% & $16 /$ Set & 19 & 60 & $25 /$ Set & 22 & 60 & $7 /$ Out & $25^{*}$ & 70 \\
Arg38\% & $16 /$ Set & 19 & 60 & $25 /$ Set & 22 & 60 & $7 /$ Out & $25^{*}$ & 60 \\
Arg36\% & $2 /$ Out & 23 & 61 & $26 /$ Set & 18 & 68 & $18 /$ Set & 20 & 44 \\
Arg44\% & 2/Out & 23 & 61 & $25 /$ Set & 22 & 60 & $18 /$ Set & 21 & 43 \\
Arg32\% & $2 /$ Out & 23 & 61 & $25 /$ Set & 22 & 60 & $19 /$ Set & 21 & 52 \\
\hline
\end{tabular}

As argamassas Arg40\% e Arg38\%, para o Aplicador C, tiveram seus painéis expostos a uma iluminação artificial (spots de luz), a pedido do próprio colaborador que se utilizou desse artifício para tentar diminuir o tempo que antecede o desempeno da argamassa, denominado "puxamento". Esse pode ser um fator determinante de alterações microestruturais as quais podem influenciar posteriormente na medida de permeabilidade ao ar da estrutura.

\subsubsection{CURA}

Após as aplicações, as paredes permaneceram em local coberto, porém expostas as distintas variações climáticas decorrentes do ambiente, por pouco mais de 24 meses até seu ensaio de permeabilidade pelo método em questão. Nenhum tipo de intervenção especial ou ciclo foi imposto a qualquer um dos painéis, que possa ser considerado como significativo para análise dos dados, durante seu processo de cura.

\subsubsection{PREPARAÇÃO DO ENSAIO}

Como forma de preparação, foram removidas partículas, com auxílio de aspirador, da superfície dos revestimentos, com a finalidade de evitar que qualquer 
um desses elementos pudesse provocar eventual entupimento nos poros que levasse a alterações nos seus resultados de permeabilidade ao ar.

A borracha de PVC líquido, utilizada para medida dos corpos de prova no Capítulo 4, a fim de promover a mais perfeita interface possível entre equipamento e material, não era suficiente para vencer as deformidades dos revestimentos em questão, provocando então vazamentos. Nesse caso então, foi utilizado um produto à base de borrachas sintéticas, cargas minerais e plastificantes, conhecida popularmente como "massa de calafetar". Além de evitar qualquer tipo de vazamento de ar entre câmara de vácuo e argamassa, a massa promovia uma aderência entre os dois elementos do início ao fim do ensaio, conforme mostra e Figura 5.2:

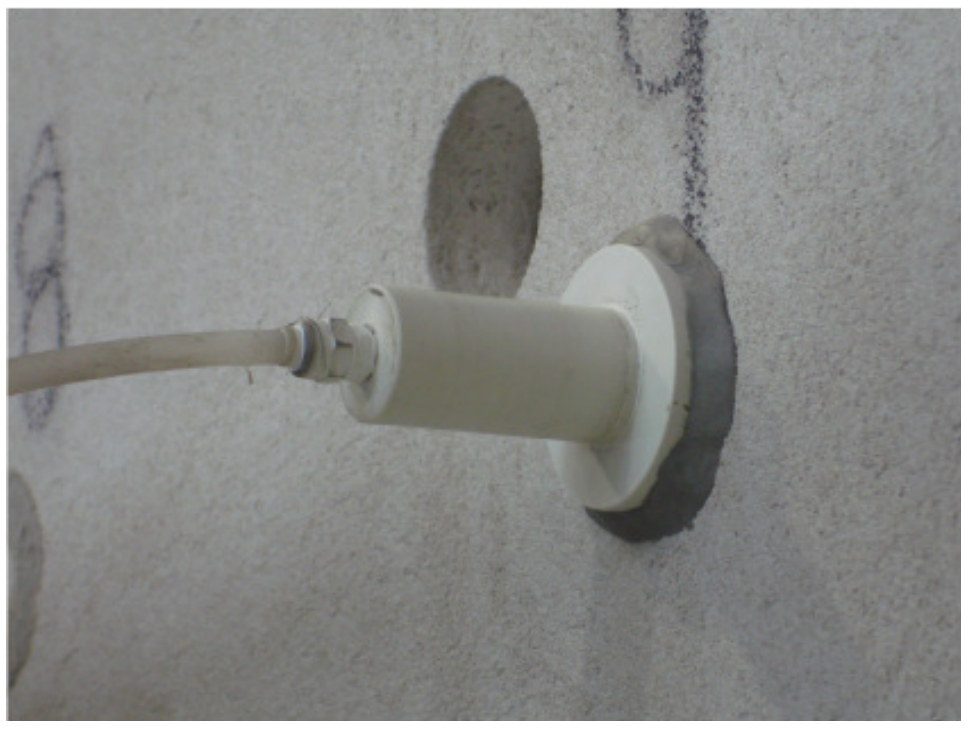

Figura 5.2 - Detalhe da interface Câmara de Vácuo / Revestimento Parede, realizada com massa de calafetar, para o método em desenvolvimento.

As mesmas configurações de ensaio realizadas em laboratório e descritas no Capítulo 4 foram utilizadas aqui com a finalidade de se obter dados comparáveis entre os dois conjuntos resultados.

Cada painel foi divido em 9 pontos distintos, representando diferentes regiões das argamassas, conforme mostra a Figura 5.3. 

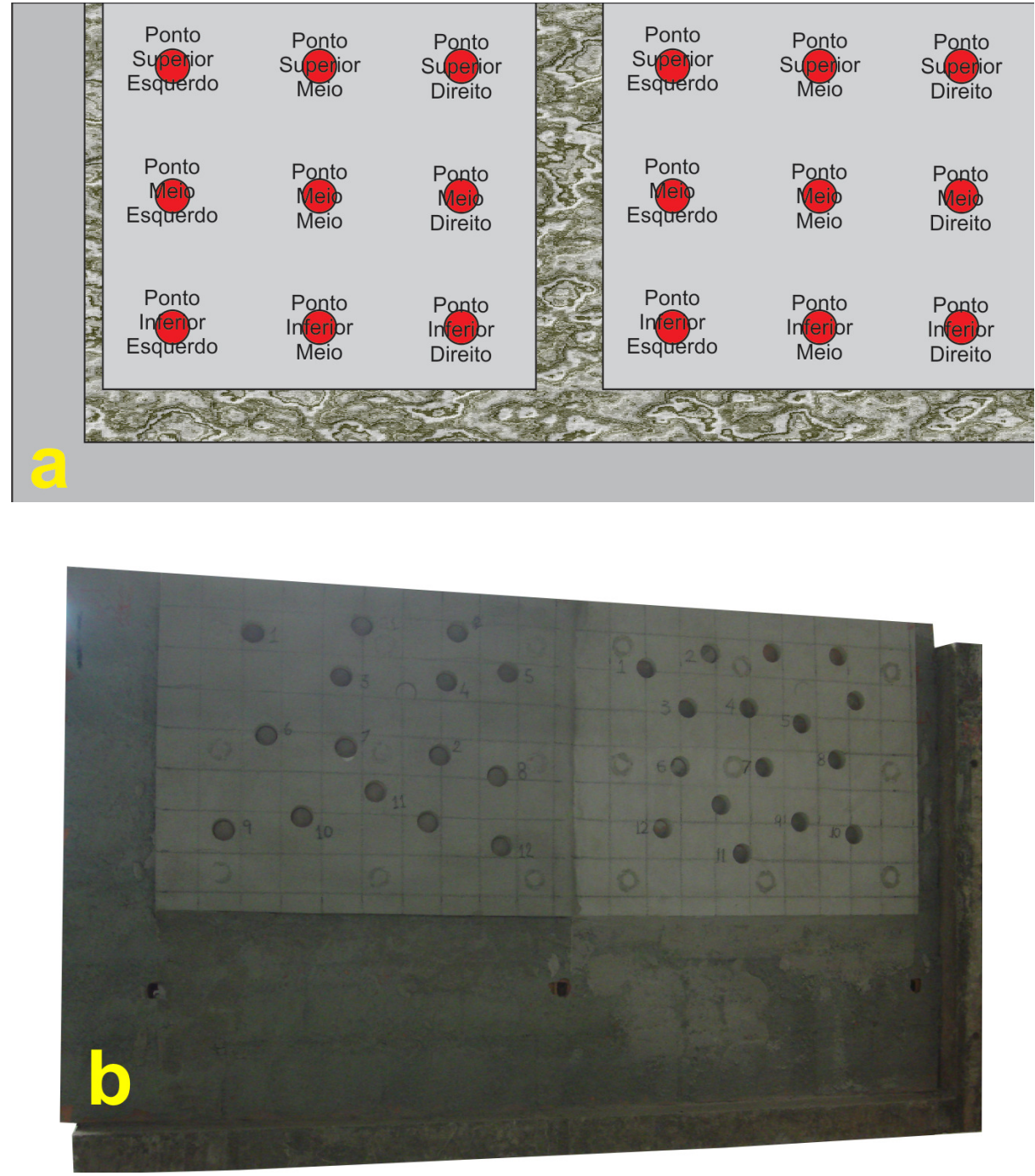

Figura 5.3 - a) Esquema de divisão das regiões de ensaio nas paredes. b) Imagem dos painéis de argamassa na parede reticulados.

\subsubsection{ENSAIOS DE PERMEABILIDADE AO AR}

Cada um dos 9 pontos foi ensaiado, através do método proposto, 3 repetidas vezes (ensaio, réplica e tréplica). Isto é, como foram preparadas 6 formulações distintas, com 3 diferentes aplicadores para cada argamassa, isto corresponde a um total de 486 ensaios de permeabilidade ao ar só no conjunto de paredes.

Além disso, foram preparados 3 corpos de prova para alguns dos revestimentos preparados, com a finalidade de ser ensaiados através do método de Cembureau (referência) em laboratório, com as dimensões características 
suportadas pelo equipamento da EPUSP $(72 \mathrm{~mm}$ de diâmetro por $22 \mathrm{~mm}$ de espessura). A logística de ensaios, associada ao tempo de preparação, não permitiu que todas as argamassas (preparadas pelos distintos aplicadores) fossem moldadas para tal finalidade.

\subsection{RESULTADOS E DISCUSSÕES}

Os resultados das propriedades das argamassas avaliadas após a etapa de processamento encontram-se ilustrados na Tabela 5.3:

Tabela 5.3 - Propriedades das argamassas ensaiadas após a etapa de processamento.

\begin{tabular}{c|c|c|c|c}
\hline Argamassa & $\begin{array}{c}\text { Ar } \\
\text { incorporado } \\
\text { (\%) }\end{array}$ & $\begin{array}{c}\text { Resistência } \\
\text { Mecânica } \\
\text { (MPa) }\end{array}$ & $\begin{array}{c}\text { Módulo de } \\
\text { elasticidade } \\
\text { (GPa) }\end{array}$ & $\begin{array}{c}\text { Porosidade } \\
\text { (\%) }\end{array}$ \\
\hline Arg29\% & 5,5 & 0,50 & 10,36 & 29,33 \\
Arg40\% & 16,6 & 1,07 & 9,63 & 40,37 \\
Arg38\% & 15,6 & 1,62 & 13,86 & 38,19 \\
Arg36\% & 16,7 & 1,29 & 12,55 & 36,86 \\
Arg44\% & 24,5 & 0,95 & 6,93 & 44,77 \\
Arg32\% & 8,2 & 0,75 & 9,51 & 32,22 \\
\hline
\end{tabular}

Mais uma vez podemos observar que nem sempre aquelas argamassas que apresentam maior teor de porosidade total são as que possuem menores valores de resistência mecânica, uma vez que essa propriedade esta relacionada também a resistência da matriz (tipo de aglomerante utilizado).

Ainda, os valores detalhados de k1 e k2, obtidos através do método de Cembureau, encontram-se dispostos na Tabela 5.4, em função da argamassa e aplicador utilizados. 


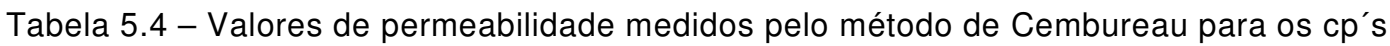
moldados durante o processo de confecção das paredes.

\begin{tabular}{c|c|c|c|c|c|c}
\hline \multirow{2}{*}{ Argamassa } & \multicolumn{2}{|c|}{ APLICADOR A } & \multicolumn{2}{c}{ APLICADOR B } & \multicolumn{2}{c}{ APLICADOR C } \\
\cline { 2 - 7 } & $\left.\mathbf{k}_{\mathbf{1}} \mathbf{( m}^{\mathbf{2}}\right)$ & $\mathbf{k}_{\mathbf{2}} \mathbf{( m )}$ & $\left.\mathbf{k}_{\mathbf{1}} \mathbf{( m}^{\mathbf{2}}\right)$ & $\mathbf{k}_{\mathbf{2}} \mathbf{( m )}$ & $\mathbf{k}_{\mathbf{1}} \mathbf{( m}_{\mathbf{2}} \mathbf{)}$ & $\mathbf{k}_{\mathbf{2}} \mathbf{( m )}$ \\
\hline Arg29\% & $1,76 \mathrm{E}-15$ & $2,77 \mathrm{E}-13$ & $2,32 \mathrm{E}-15$ & $6,16 \mathrm{E}-13$ & $1,98 \mathrm{E}-15$ & $3,38 \mathrm{E}-12$ \\
Arg40\% & $3,52 \mathrm{E}-15$ & $6,80 \mathrm{E}-12$ & $1,89 \mathrm{E}-15$ & $1,31 \mathrm{E}-12$ & - & - \\
Arg38\% & $1,48 \mathrm{E}-15$ & $3,93 \mathrm{E}-13$ & $1,05 \mathrm{E}-15$ & $6,24 \mathrm{E}-13$ & - & - \\
Arg36\% & - & - & $1,07 \mathrm{E}-15$ & $1,54 \mathrm{E}-13$ & $2,26 \mathrm{E}-15$ & $8,5 \mathrm{E}-13$ \\
Arg44\% & - & - & $3,62 \mathrm{E}-14$ & $1,46 \mathrm{E}-10$ & $3,72 \mathrm{E}-14$ & $1,14 \mathrm{E}-10$ \\
Arg32\% & - & - & $2,20 \mathrm{E}-15$ & $4,69 \mathrm{E}-13$ & $1,92 \mathrm{E}-15$ & $3,77 \mathrm{E}-13$ \\
\hline
\end{tabular}

Através das curvas de recuperação dos ensaios de permeabilidade ao ar das paredes, pode-se realizar uma primeira análise qualitativa dos perfis dos distintos painéis preparados com argamassas desiguais e, ainda, as diferenças de aplicação representada pelos diferentes colaboradores. Essas curvas podem ser observadas nas Figuras 5.4, 5.5, 5.6, 5.7, 5.8 e 5.9, agrupadas por argamassas.

A análise das curvas permite observar diferenças tanto entre as distintas argamassas ensaiadas quanto entre os diversos aplicadores. As dispersões de resultados entre pontos do mesmo painel aparecem em maior ou menor incidência em função da formulação avaliada, mas aparentemente não tem uma relação direta com o colaborador envolvido. Através de avaliação visual, pode-se destacar que esse tipo de variação está sim relacionada a defeitos de superfície (Figura 5.10) os quais não podemos dizer que estão associados a somente um tipo de causa, tal qual a sua forma de aplicação. 

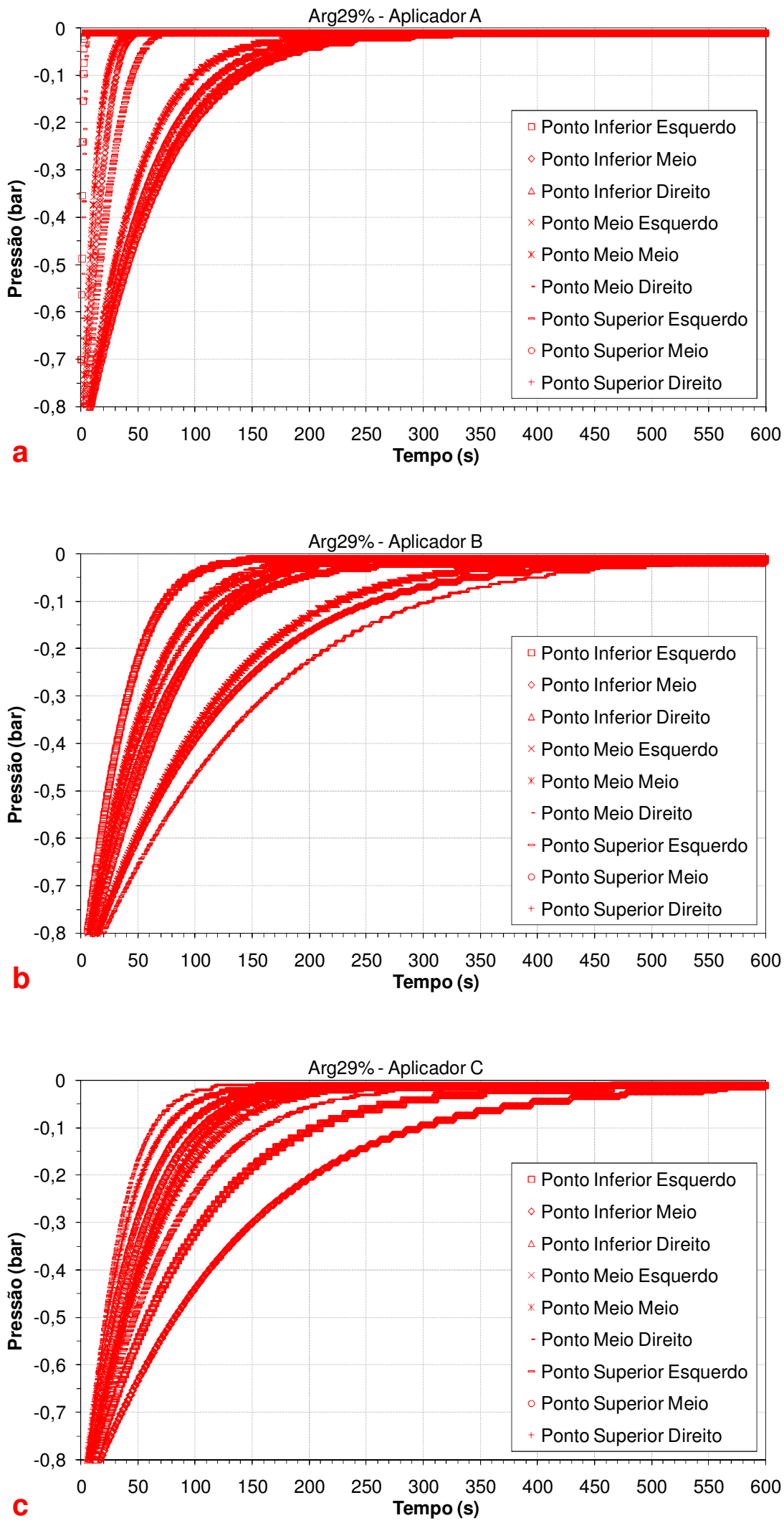

Figura 5.4 - Curvas de recuperação da Arg29\%, para os 3 diferentes aplicadores. 

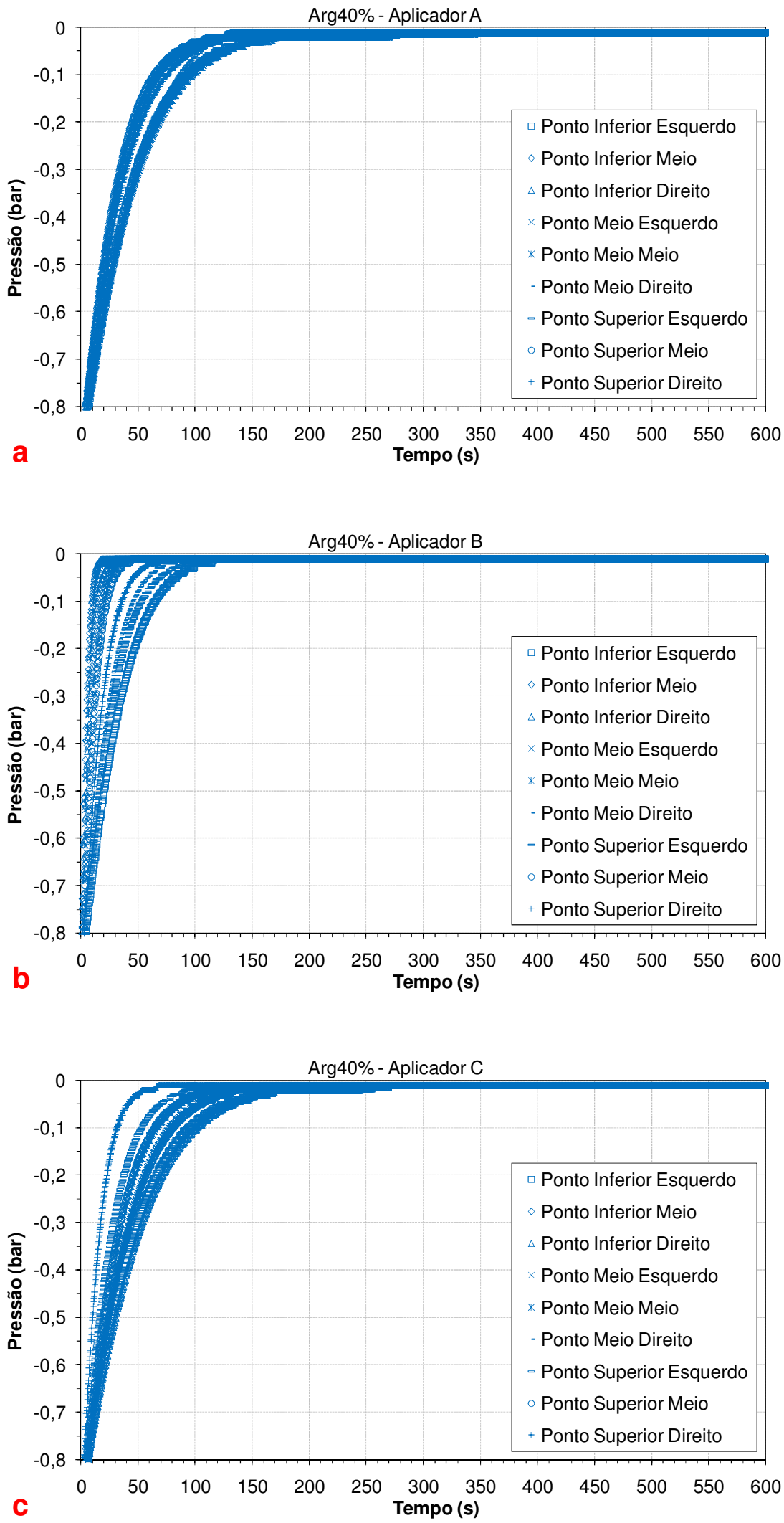

Figura 5.5 - Curvas de recuperação da Arg40\%, para os 3 diferentes aplicadores. 

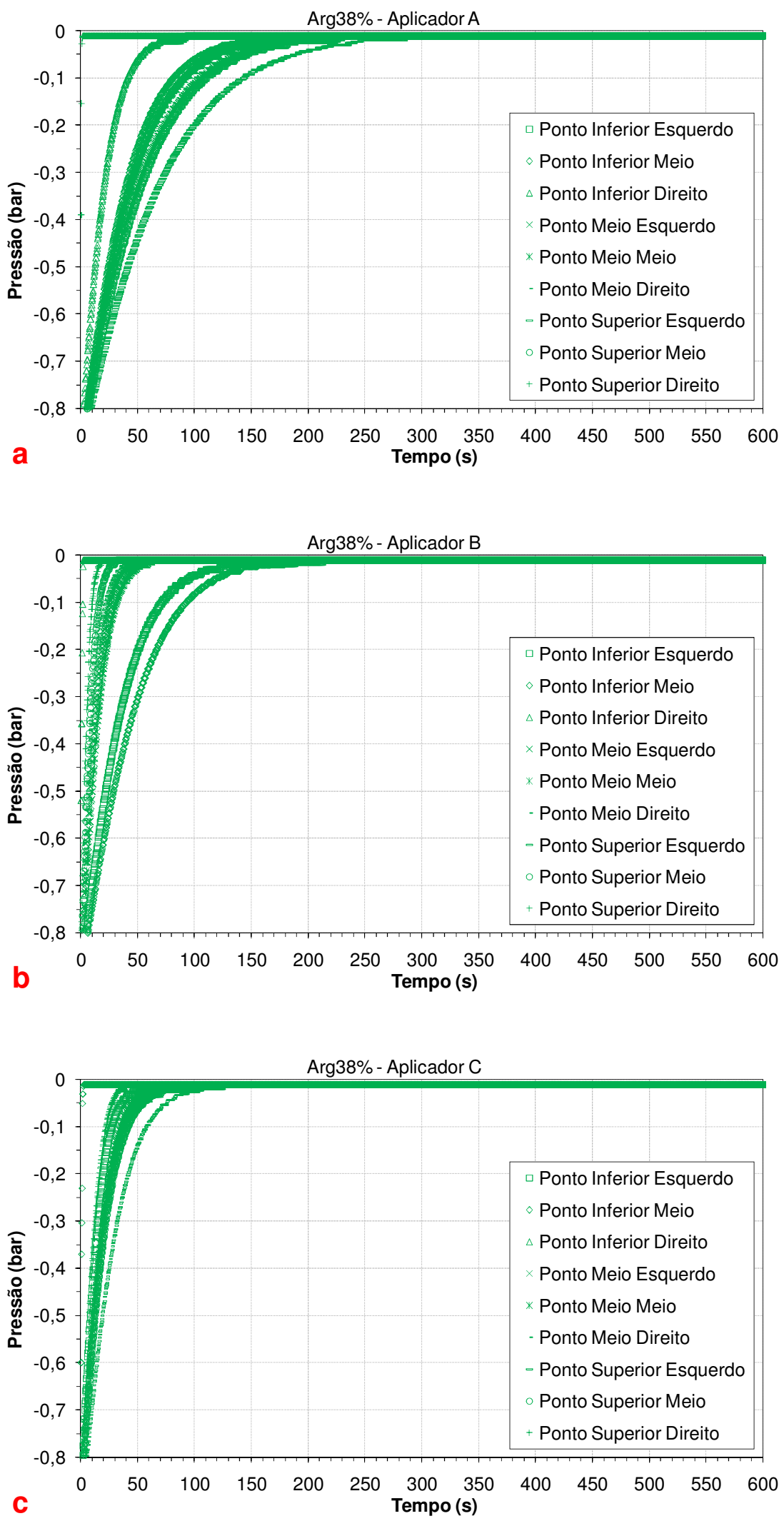

Figura 5.6 - Curvas de recuperação da Arg38\%, para os 3 diferentes aplicadores. 

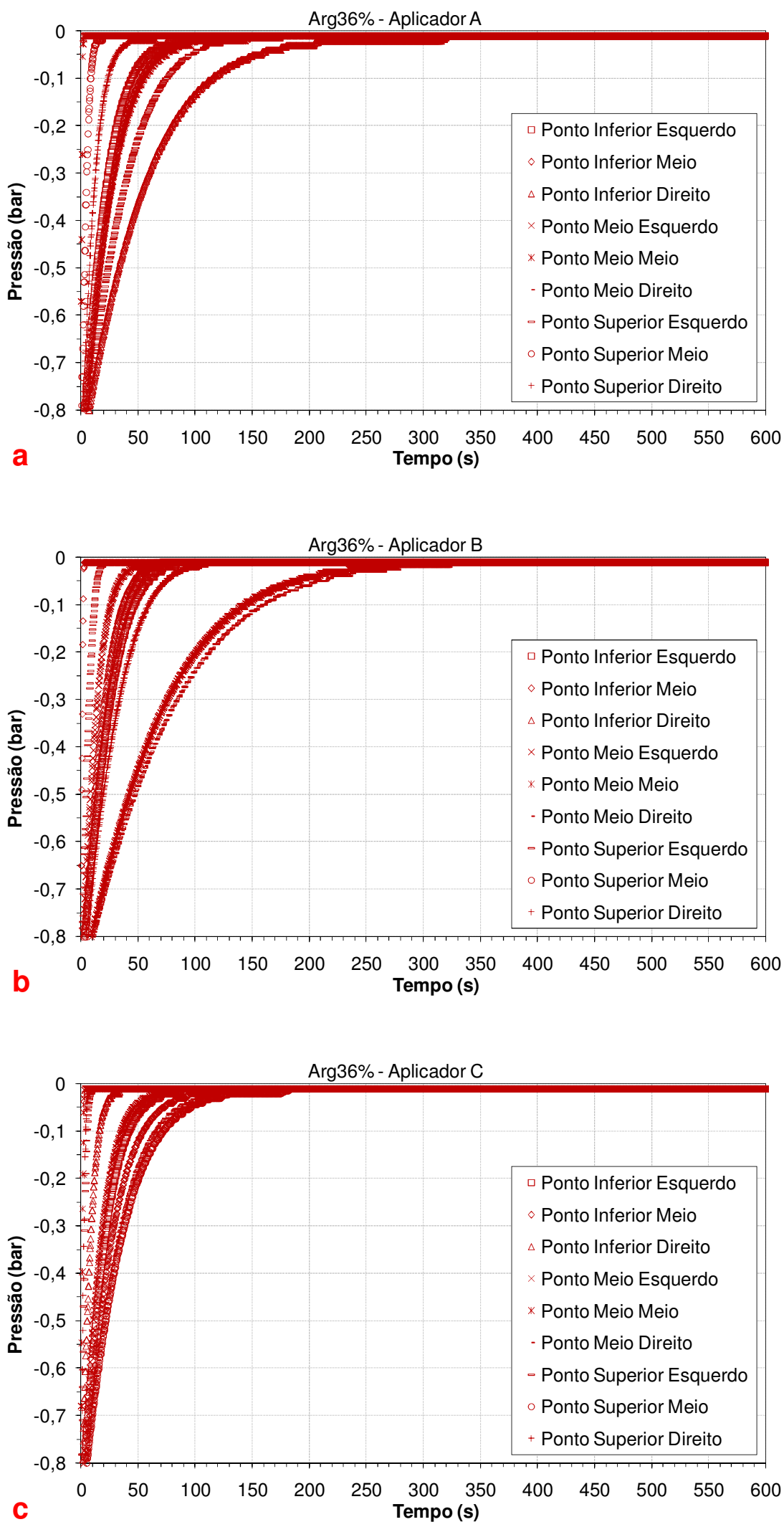

Figura 5.7 - Curvas de recuperação da Arg36\%, para os 3 diferentes aplicadores. 

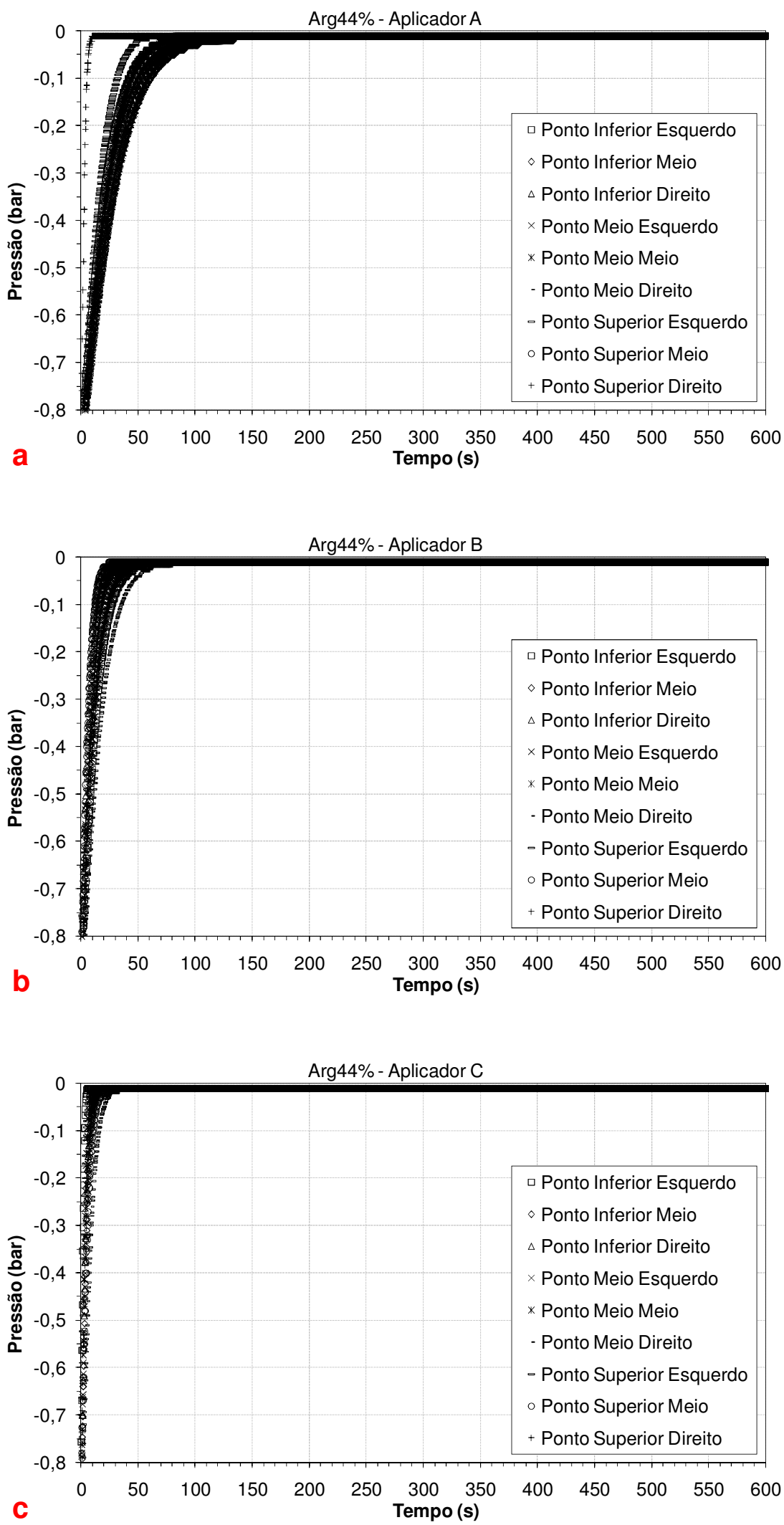

Figura 5.8 - Curvas de recuperação da Arg44\%, para os 3 diferentes aplicadores. 

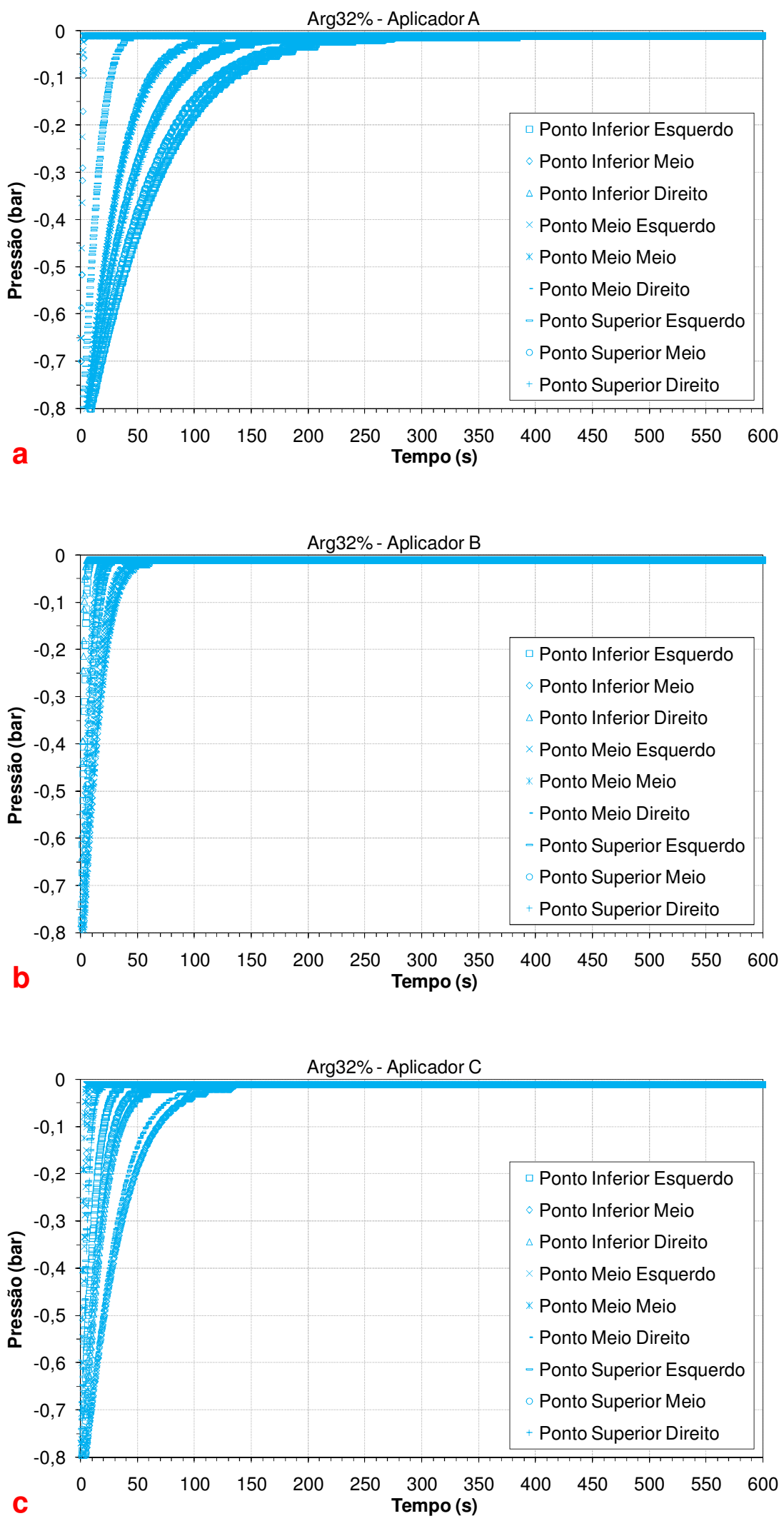

Figura 5.9 - Curvas de recuperação da Arg32\%, para os 3 diferentes aplicadores. 


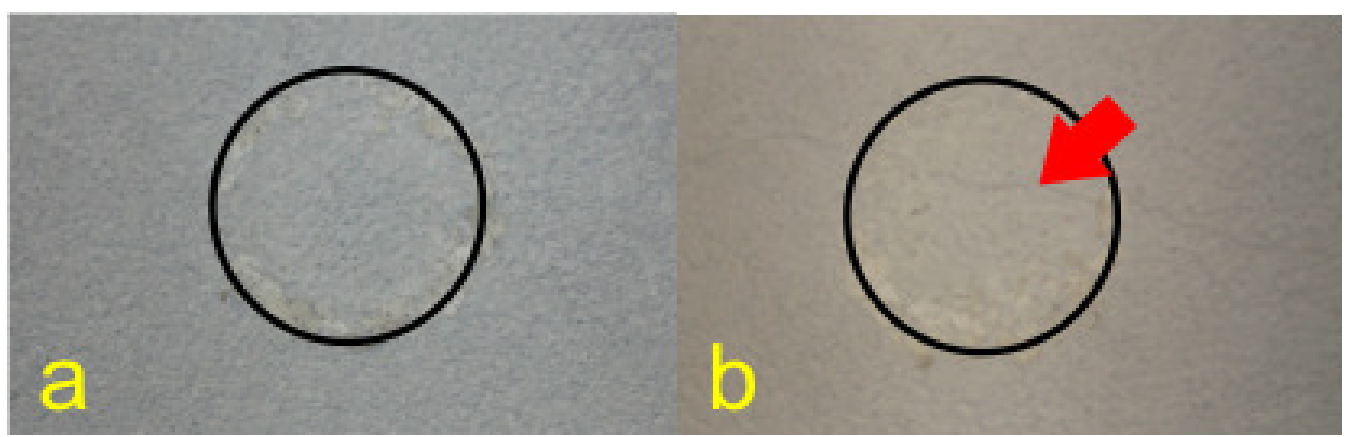

Figura 5.10 - Pontos de ensaio da mesmo painel de argamassa. Onde: a) Visualmente íntegro; b) Visualmente apresenta defeito (fissura).

Analisando qualitativamente os grupos de argamassas, separadamente entre pedreiros, observar-se que, salvo os pontos de maior dispersão que representam falhas, a técnica consegue distinguir satisfatoriamente diferentes perfis microestruturais representados por distintos níveis de porosidade de cada mistura. Também, cada operador é responsável por determinado perfil de permeabilidade entre os painéis de argamassa, dentro de uma faixa normal de valores associado à mistura em questão. Isso ocorre provavelmente devido as diferenças empregadas na forma característica de cada colaborador na hora de trabalhar com o insumo, dentre as quais podemos citar a energia de lançamento da argamassa ao substrato, a energia de compactação do material, o tempo de "puxamento" da água da mistura para a base, a energia e forma de acabamento superficial (desempeno), o tamanho médio da camada de revestimento, etc.

Comparando as curvas de recuperação obtidas nas paredes com as de laboratório (Capítulo 4), onde foram usadas as mesmas argamassas (Arg29\% e Arg44\%), pode-se observar que as primeiras apresentam níveis de permeabilidade menores do que as segundas. Isso de deve, muito provavelmente, devido a uma série de fatores, dentre os quais podemos destacar a energia de compactação, exposição a variáveis externa (temperatura, umidade, contaminantes provindos do próprio ar, etc) e, principalmente, o tempo de cura do material. Enquanto que, no laboratório, os cp's eram ensaiados com uma idade média de 10 dias, as paredes foram avaliadas com um intervalo de pouco mais de 24 meses entre confecção e ensaio. 
Também, somente pelas curvas não foi possível identificar qualquer tipo de comportamento anômalo pelo uso de luz (pelo Operador C, nas argamassas Arg $40 \%$ e Arg38\%), durante o período de "puxamento", que pudesse modificar a estrutura a ponto de provocar qualquer tipo de alteração significativa no perfil de permeabilidade ao ar dessas misturas.

Portanto, somente através desse tipo de análise, sem levar ainda em consideração valores associados ao fenômeno de permeabilidade (como a constante k1), pode-se perceber que essa técnica apresenta um potencial de distinguir diferentes tipos de revestimento de argamassa, identificando variáveis microestruturais de diferentes tipos tais como: formulação, tipo de mistura, acabamento de superfície, defeitos, etc. Enfim, tudo aquilo que pode provocar mudança na estrutural desse tipo de material pode ser claramente percebido somente através da análise de suas curvas de recuperação. Portanto, uma análise qualitativa tanto de produção quanto de aplicação, ou até mesmo a evolução de um revestimento ao longo de sua vida útil, pode ser realizada através de uma medida dessa natureza.

Para complementar as verificações anteriores, uma análise quantitativa da microestrutura dos painéis de argamassa nas paredes pode ser realizada através da verificação das constantes de permeabilidade $\mathrm{k} 1$, as quais estão demonstradas na Figuras $5.11,5.12,5.13,5.14,5.15,5.16$. Alguns dos painéis tiveram suas permeabilidades também avaliadas pelo método de Cembureau e seus respectivos valores acompanham alguns dos gráficos (linha tracejada) demonstrados a seguir. 

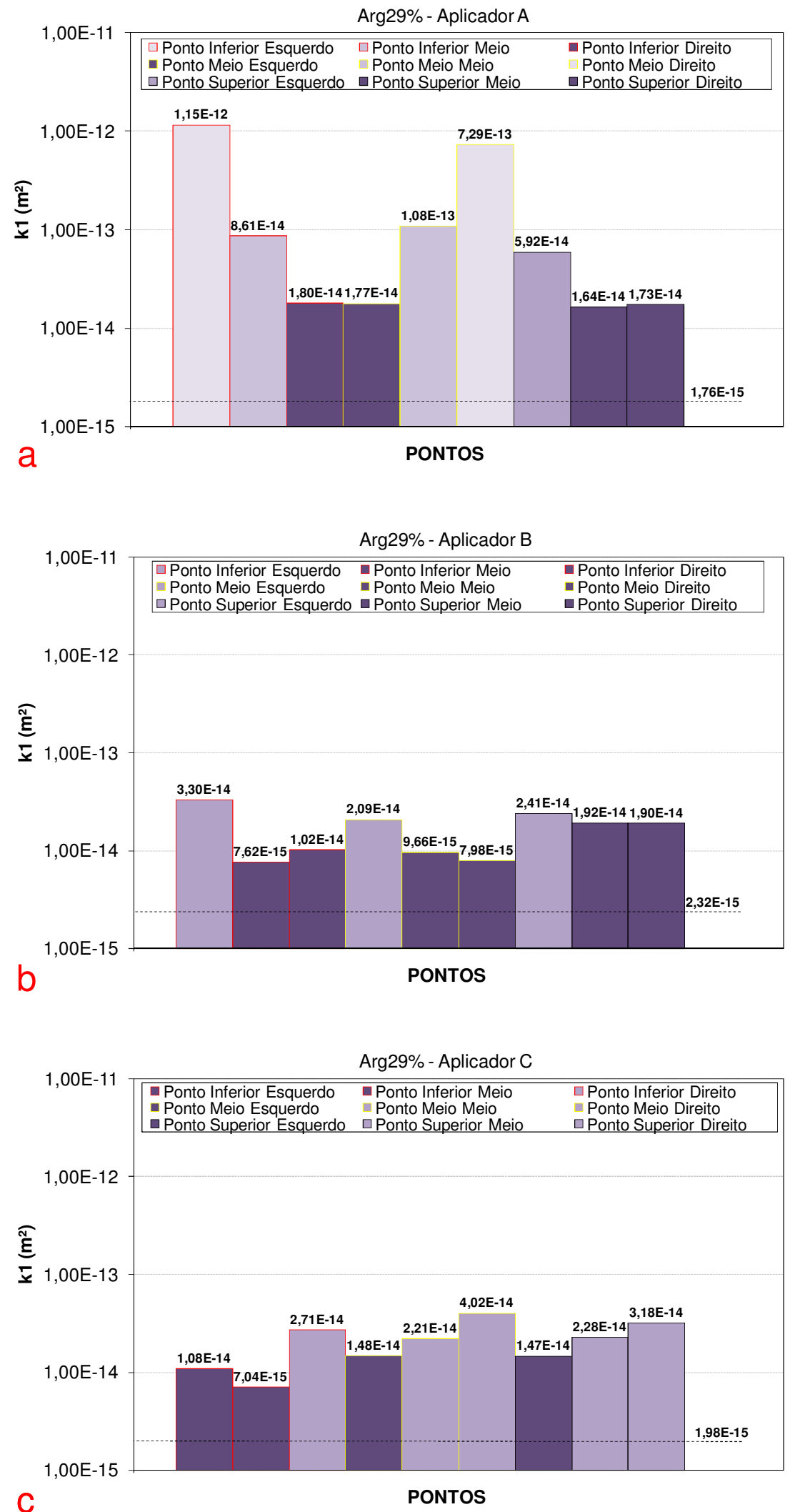

Figura 5.11 - Valores de k1 da Arg29\%, para os 3 diferentes aplicadores. 


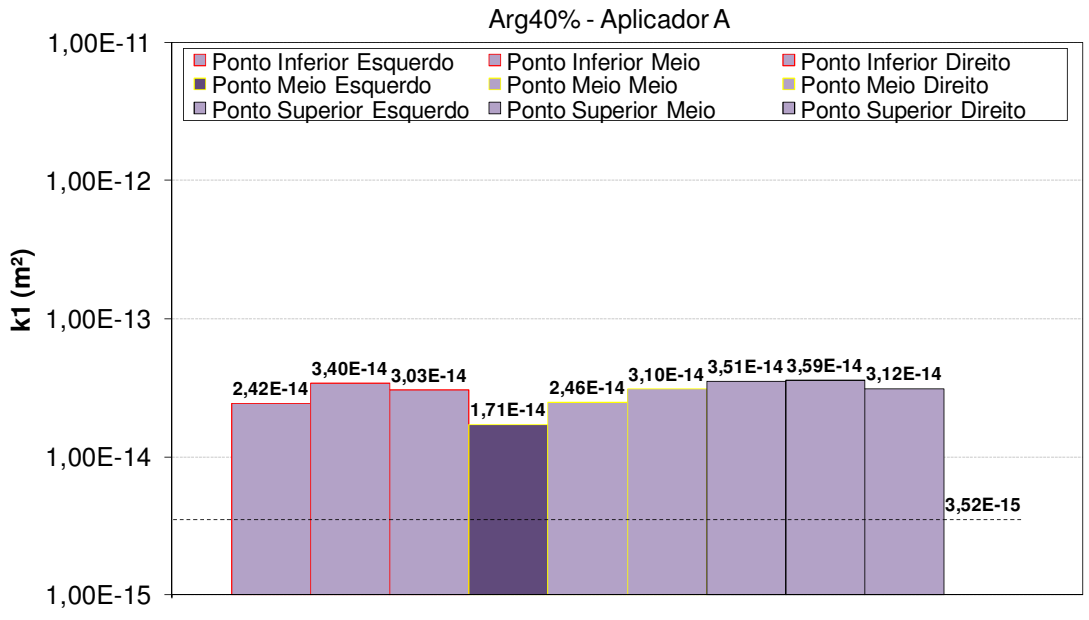

a

PONTOS

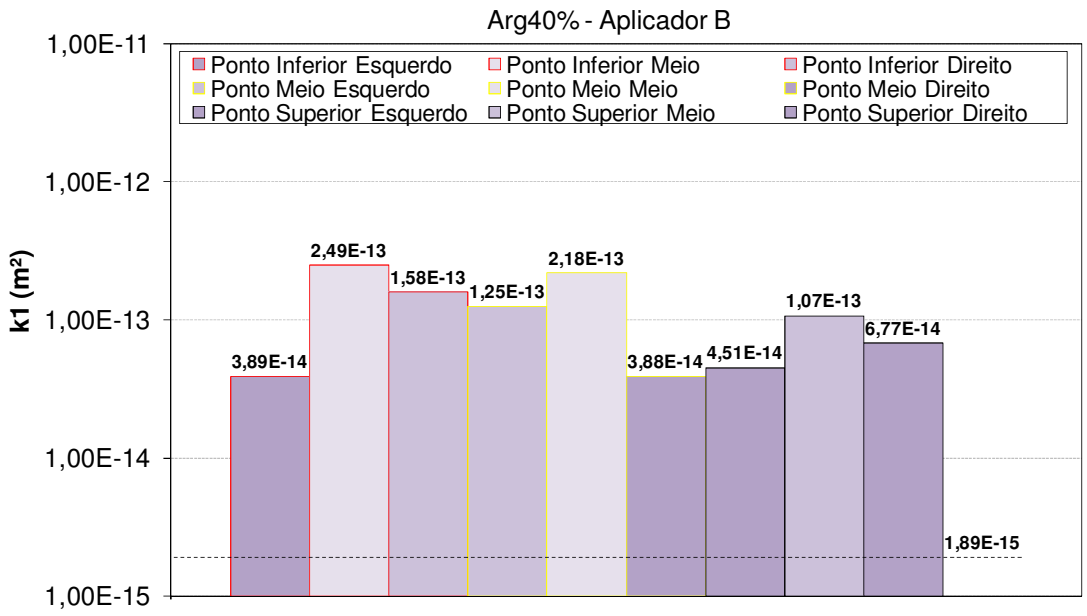

b

PONTOS

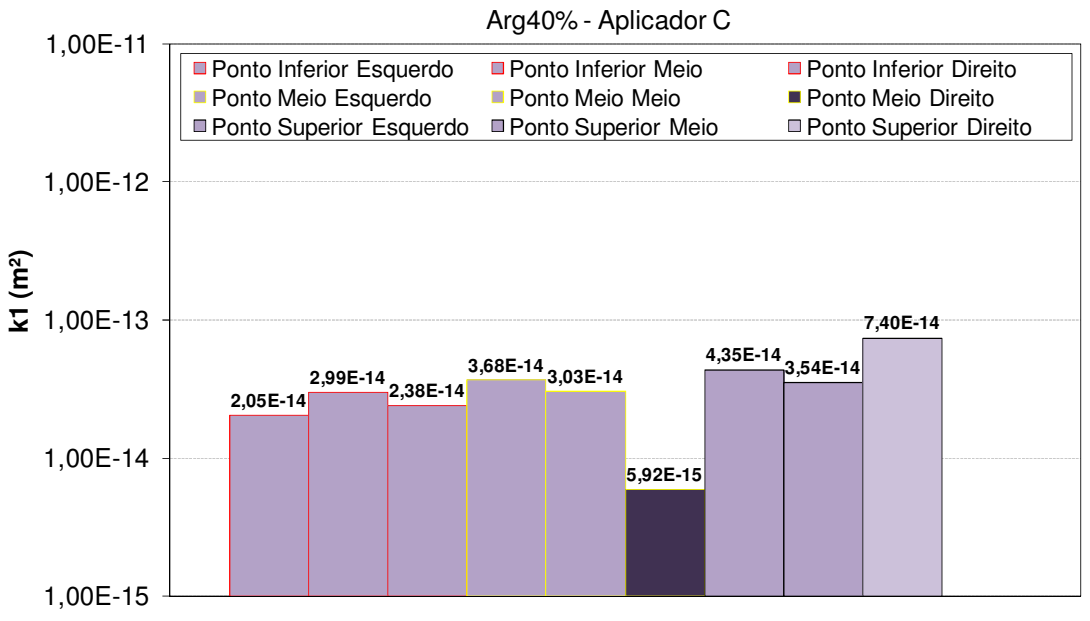

C

PONTOS

Figura 5.12 - Valores de $\mathrm{k} 1$ da Arg40\%, para os 3 diferentes aplicadores. 

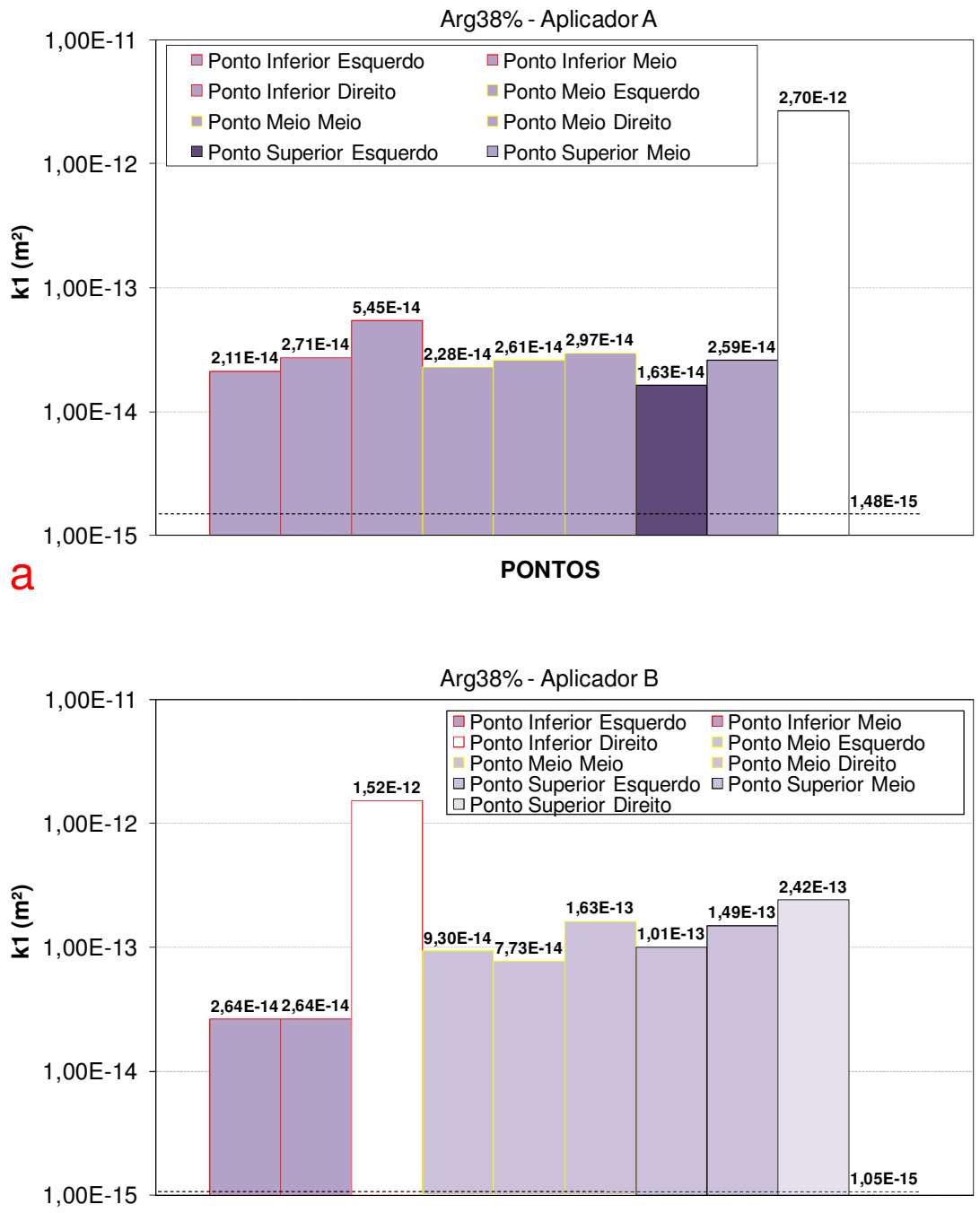

b

PONTOS

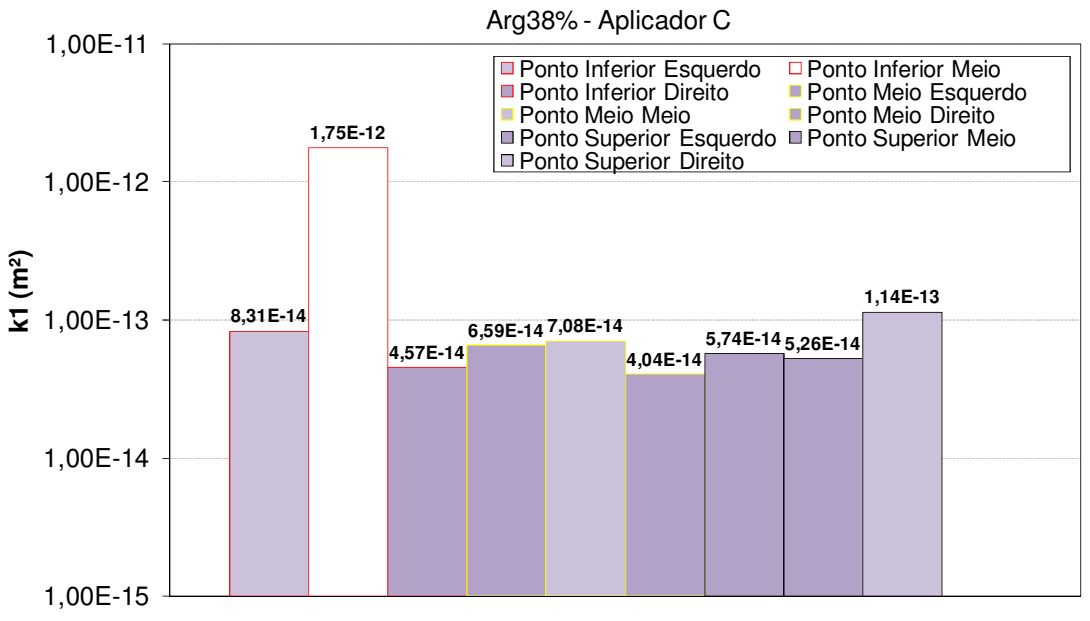

C

PONTOS

Figura 5.13 - Valores de $\mathrm{k} 1$ da Arg38\%, para os 3 diferentes aplicadores. 


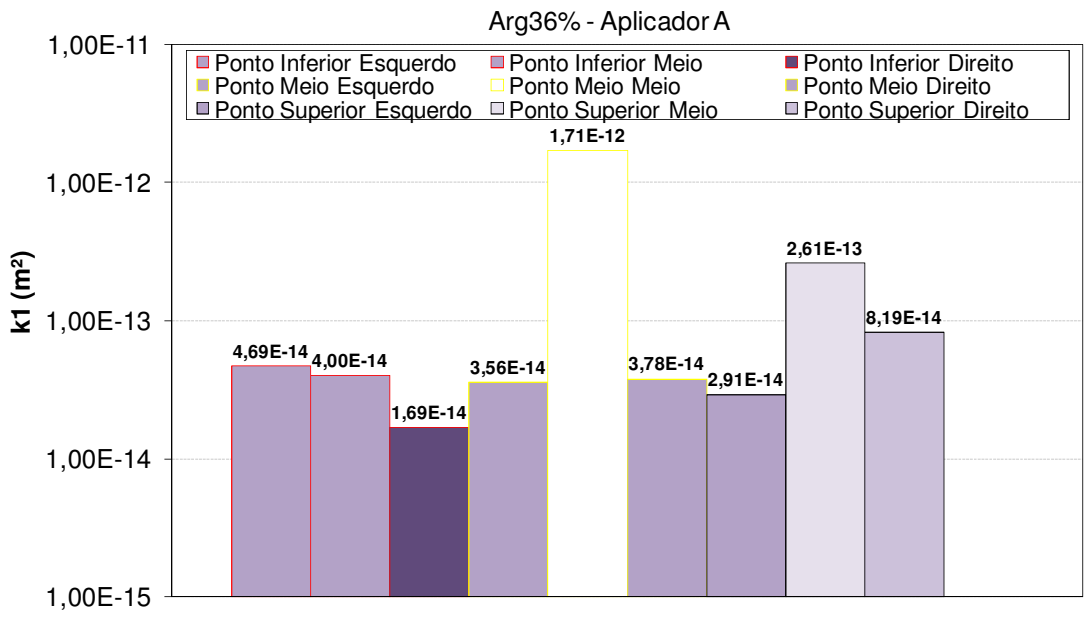

a

PONTOS
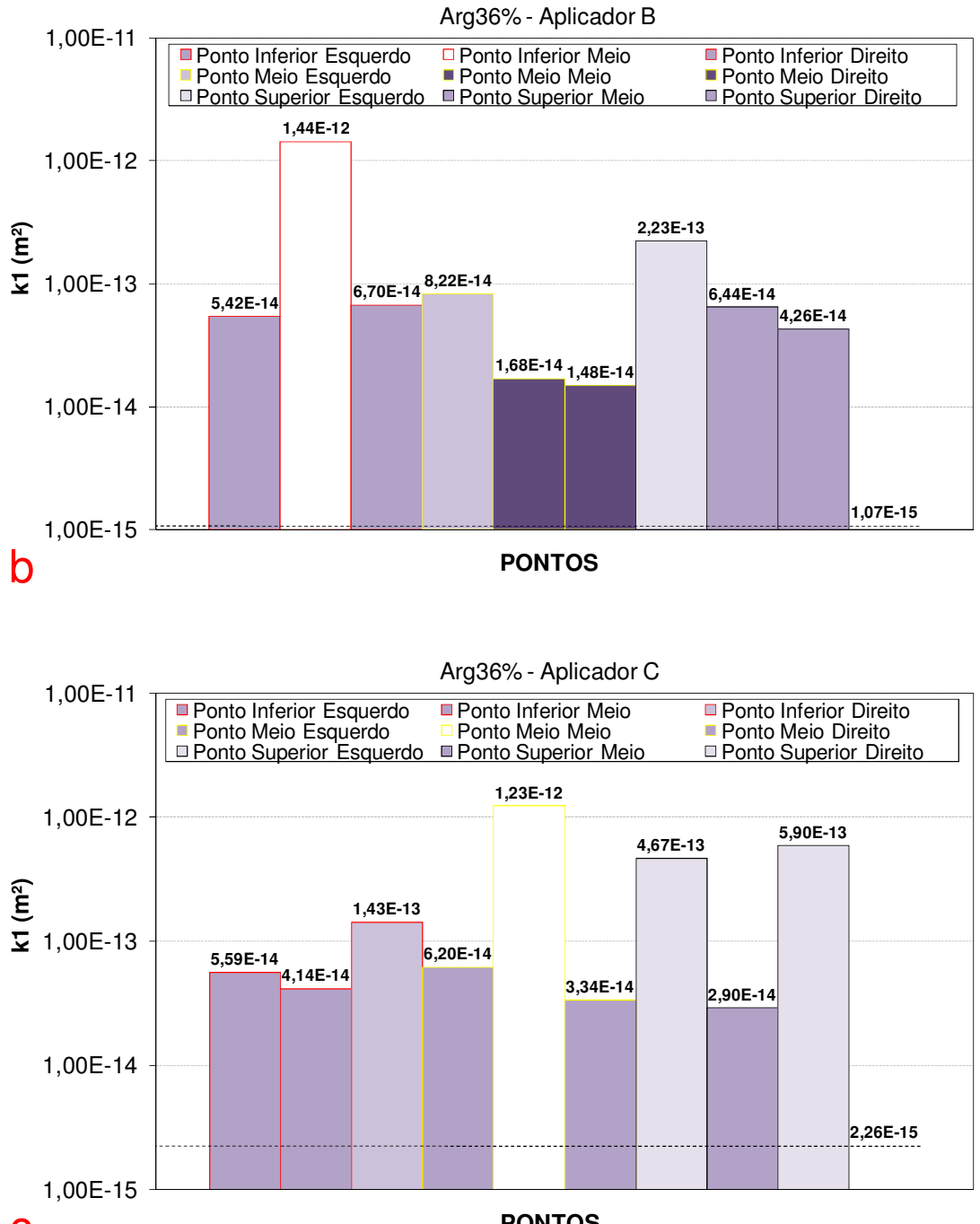

$\mathrm{C}$

PONTOS

Figura 5.14 - Valores de $\mathrm{k} 1$ da Arg36\%, para os 3 diferentes aplicadores. 


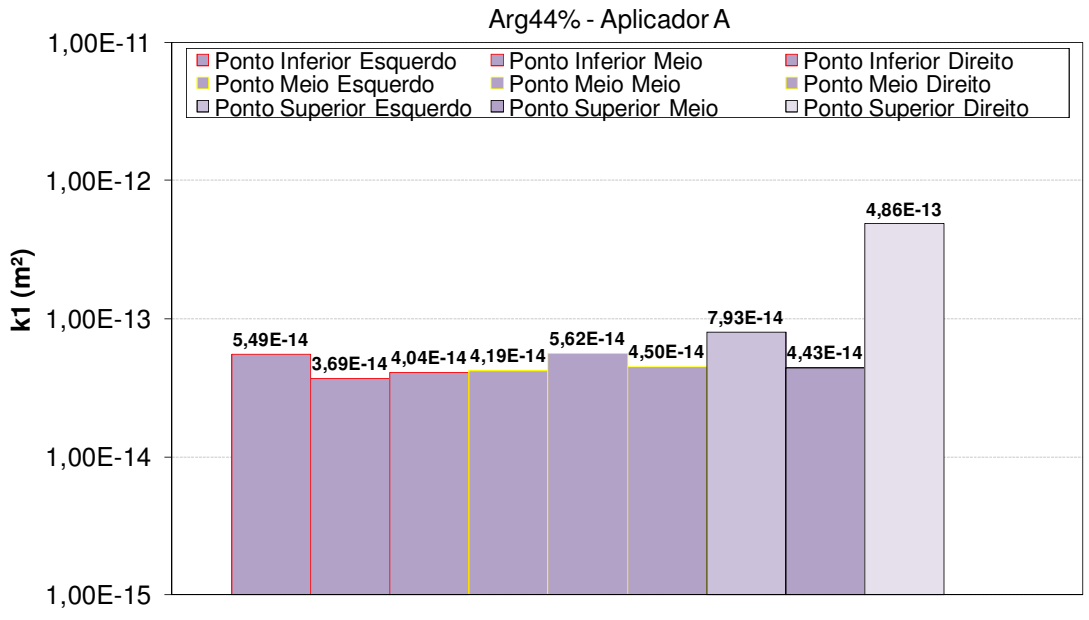

a

PONTOS

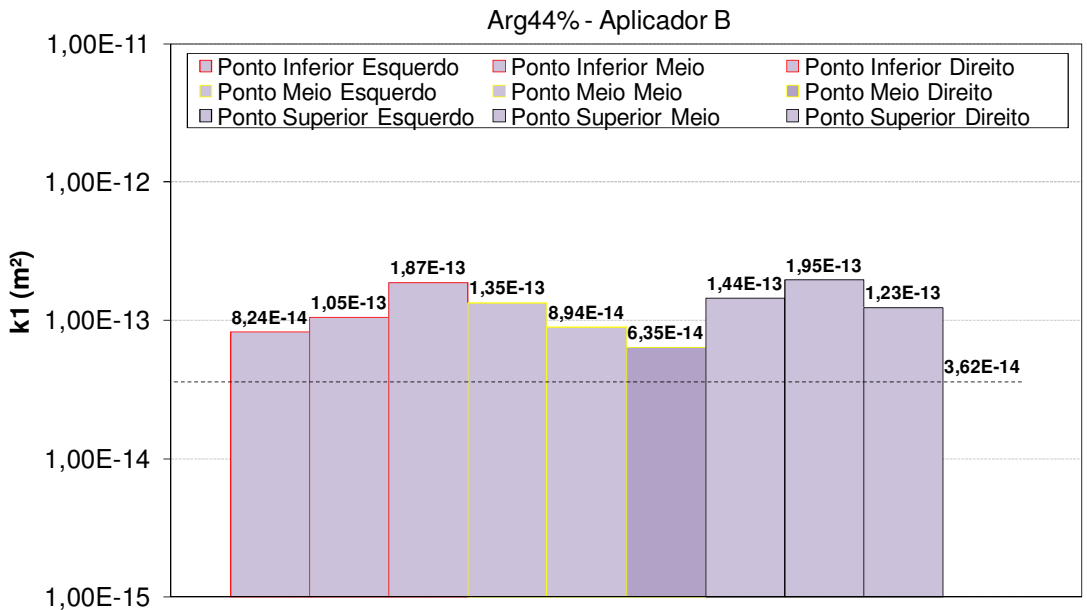

b

PONTOS

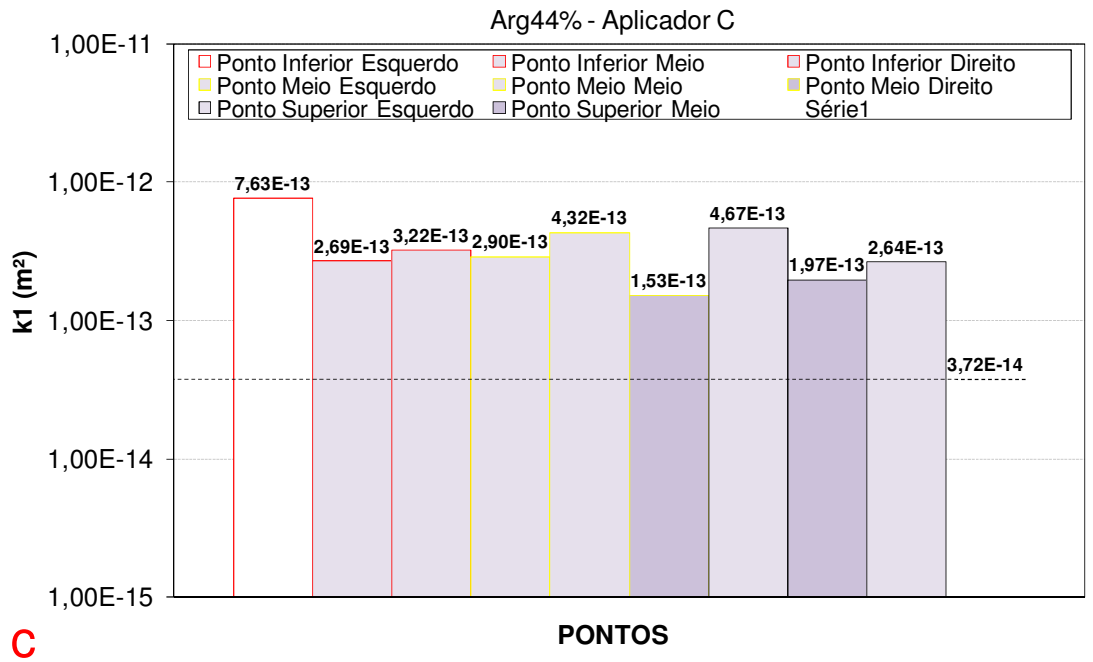

Figura 5.15 - Valores de k1 da Arg44\%, para os 3 diferentes aplicadores. 


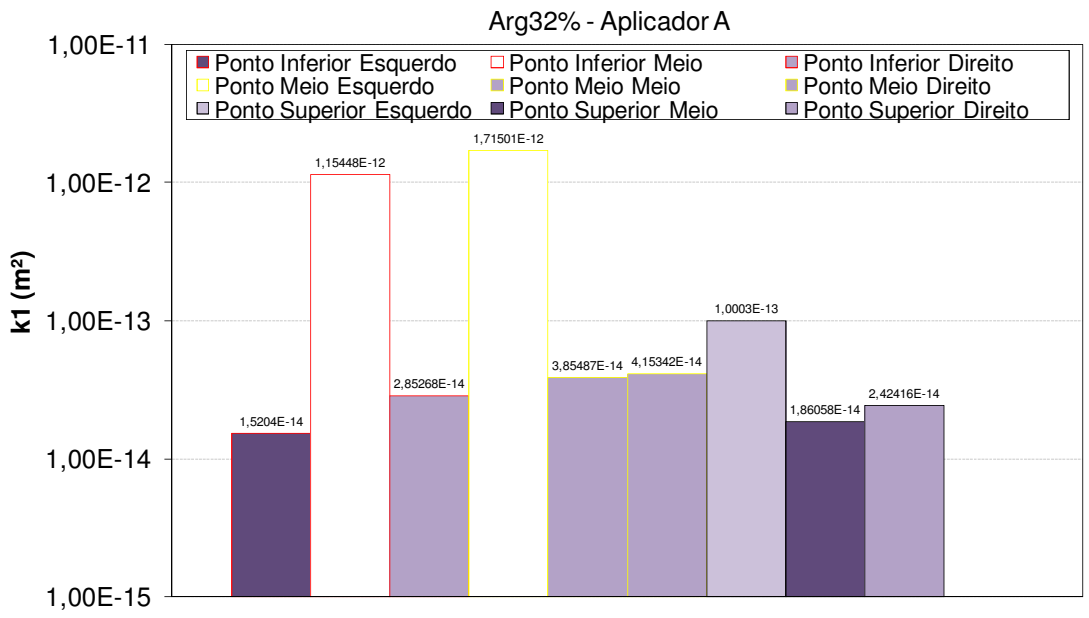

a

PONTOS

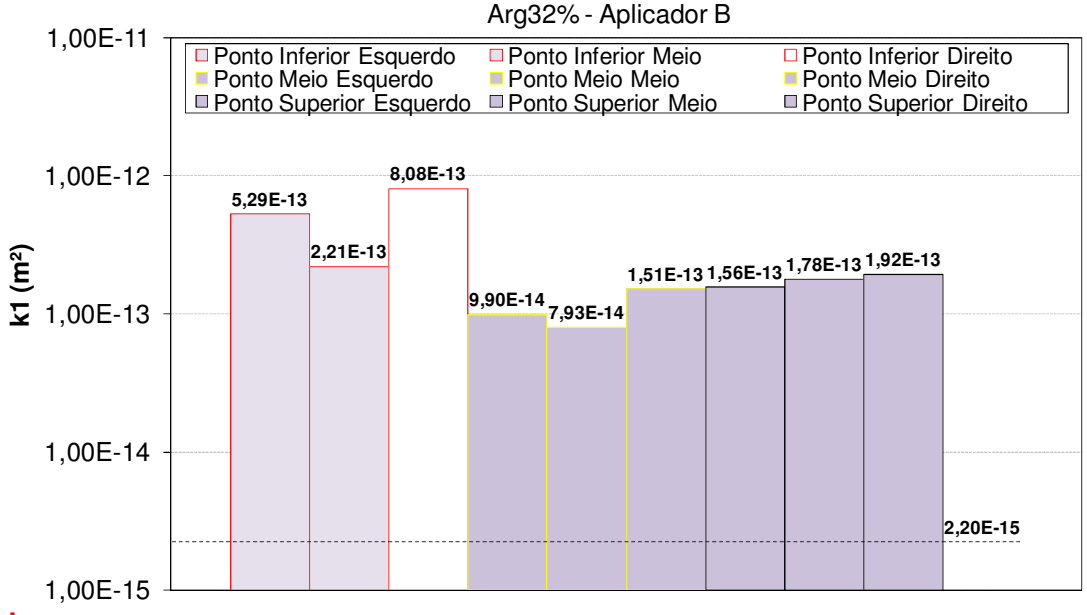

b

PONTOS

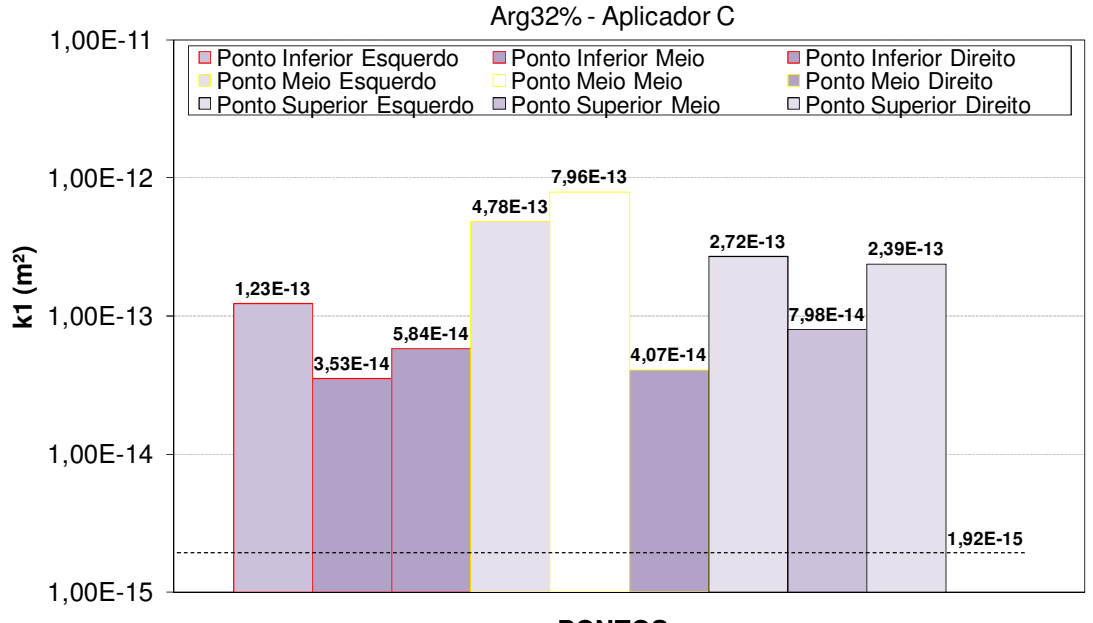

C

PONTOS

Figura 5.16 - Valores de $\mathrm{k} 1$ da Arg32\%, para os 3 diferentes aplicadores. 
Com a finalidade de realizar uma análise comparativa entre as diferentes argamassas e condições de aplicação, convencionou-se utilizar nos gráficos acima uma variação de cores, em tons de roxo, para sinalizar a variação dos pontos de menor permeabilidade (tons mais escuros) para os mais permeáveis (branco).

Os valores de $\mathrm{k} 1$ expressam em números o comportamento demonstrado anteriormente nas curvas de recuperação de pressão, onde os elementos mais permeáveis (com maiores constantes $\mathrm{k} 1$ ) são aqueles que recuperam suas pressões mais rapidamente, e vice versa.

Fazendo uma análise entre argamassas, sem levar em consideração o operador nem os pontos representantes de grandes defeitos superficiais (maior k1, cor branca), observa-se na média uma diferença perceptível entre os dois extremos microestruturais avaliados. Nas porosidades intermediárias, a dispersão de valores, resultado da exposição não controlada dos painéis a variáveis de produção e cura ao longo dos mais de 24 meses, não se consegue perceber uma tendência de comportamento específica com relação ao fator permeabilidade em função somente do nível de porosidade avaliado em laboratório para cada tipo de formulação durante a etapa de processamento. Os diferentes níveis de defeitos superficiais, não avaliados especificamente nesse trabalho, são responsáveis por uma variação dos valores de k1 dentro de um mesmo painel. Essa relação não pode ser quantificada apenas com uma simples análise visual de fissuras.

É importante ressaltar que a técnica foi capaz de mapear, tanto através de suas curvas de recuperação quanto dos valores de $\mathrm{k} 1$ associados, tanto os defeitos superficiais visíveis a olho nu quanto aqueles de microestrutura presentes muitas vezes um pouco abaixo da camada de superfície. Isso já demonstra a potencialidade que o método tem de identificar diferenças, defeitos e fenômenos associados a mudanças na estrutura de superfície de argamassas.

A Figura 5.17, a seguir, apresenta os valores médios de k1 para cada painel de argamassa, para os 3 diferentes pedreiros associados, ensaiadas através do método em desenvolvimento. 


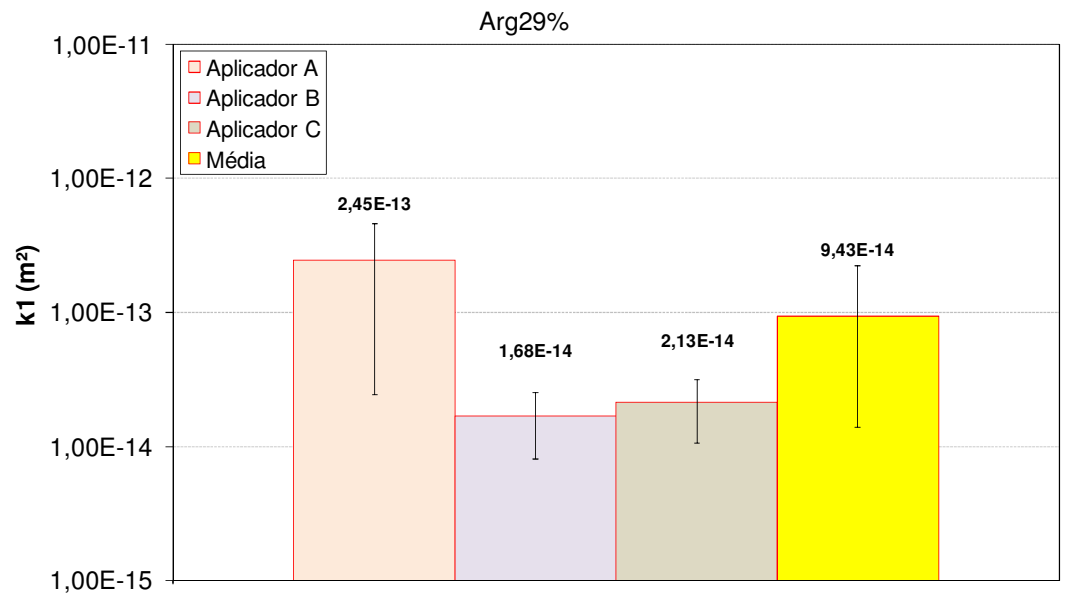

a

PONTOS
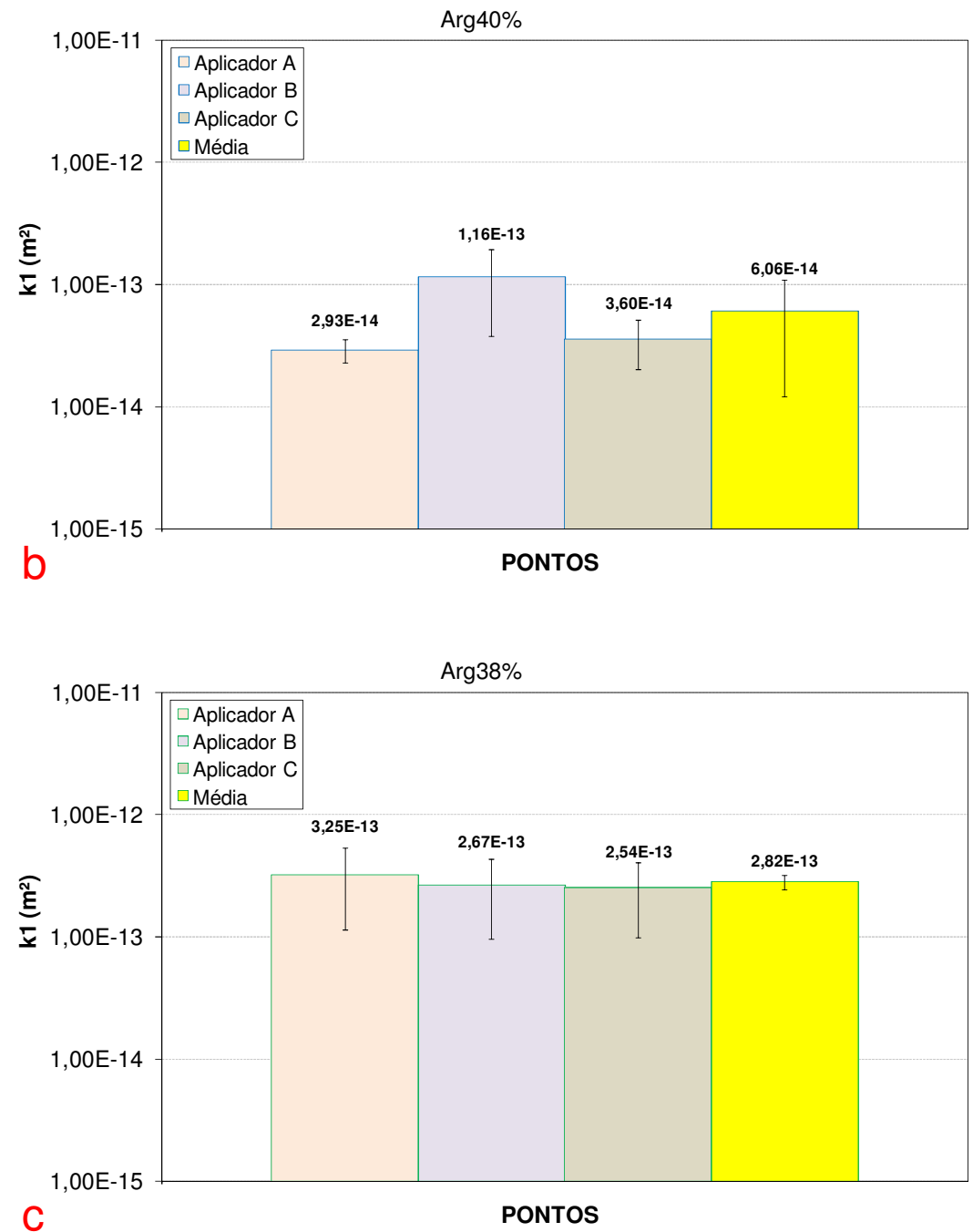

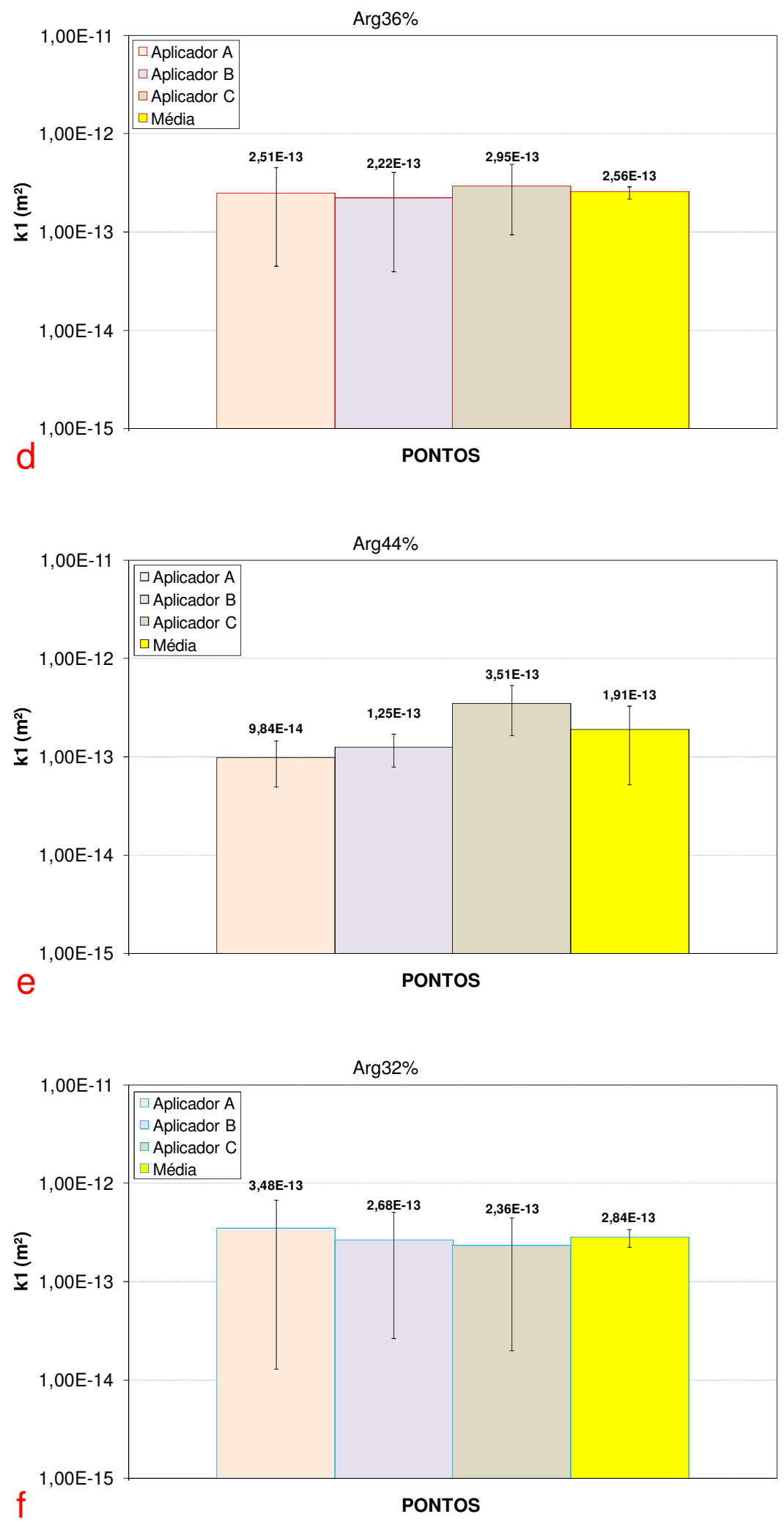

Figura 5.17 - Valores médios de k1 de cada argamassa estudada para os diferentes aplicadores, calculados a partir do método em desenvolvimento. 
Na Figura 5.17 os valores médios de k1 foram calculados com relação à média de todos os pontos avaliados em cada painel de argamassa, independentemente da quantidade ou tipo de falha representado nas diferentes regiões. Na teoria, as argamassas que apresentam maiores níveis de porosidade deveriam ser aquelas em que 0 valor médio de k1 também alcançaria proporcionalmente valores mais altos. Entretanto, na média, esse tipo de comportamento não foi observado nas misturas avaliadas, devido à quantidade de defeitos diferentes apresentada por cada painel. Esse pode ser um indicativo do grau de homogeneidade que cada formulação, em função dos tipos de componentes adicionados, pode apresentar no estado endurecido. Ainda, analisando-se os valores médios de k1, o tipo de aplicador pode influenciar mais ou menos na determinação da permeabilidade média de cada argamassa. Isso também depende do tipo de mistura a qual esta sendo utilizada, dando também um indicativo de maior ou menor sensibilidade da mistura a variável de aplicação na determinação de sua microestrutura.

Ainda, a Figura 5.22 ilustra graficamente os coeficientes de permeabilidade $\mathrm{k} 1$ (método de Cembureau) demonstrados anteriormente na Tabela 5.4, com suas respectivas barras de erro.

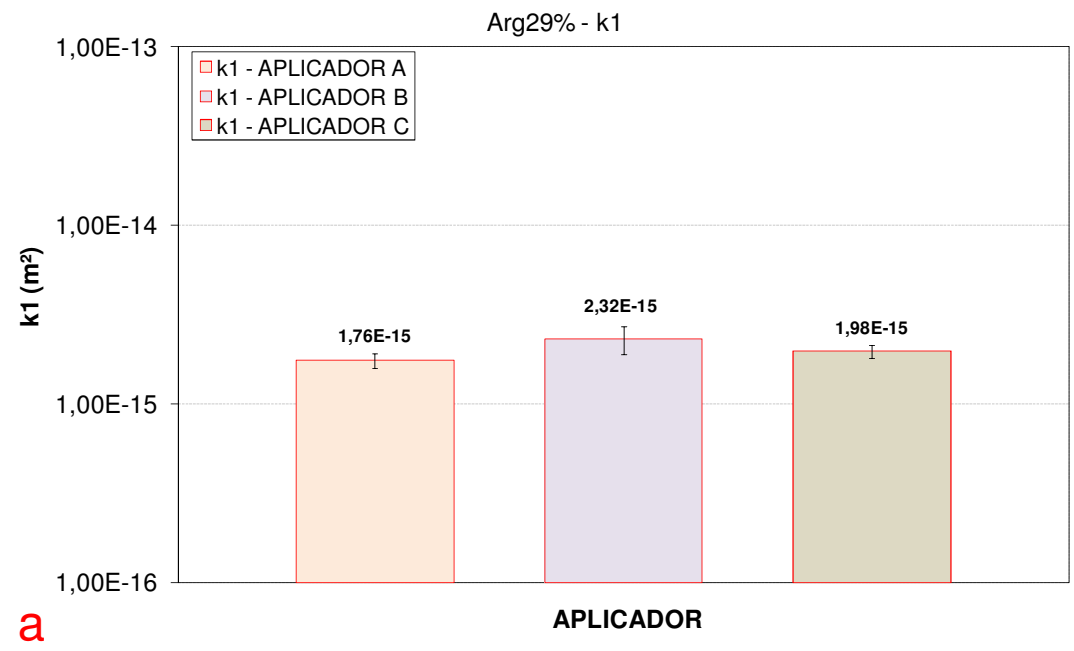



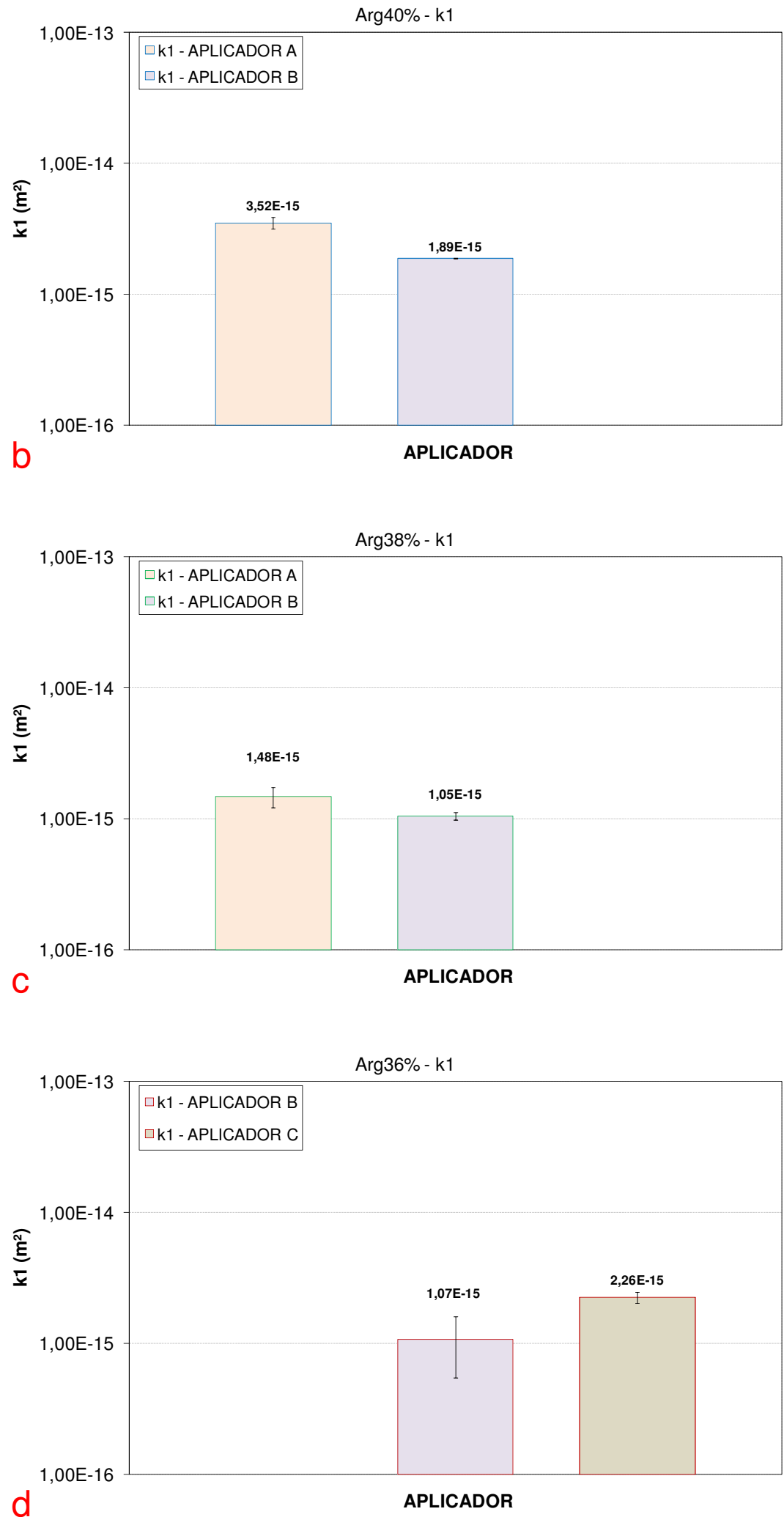

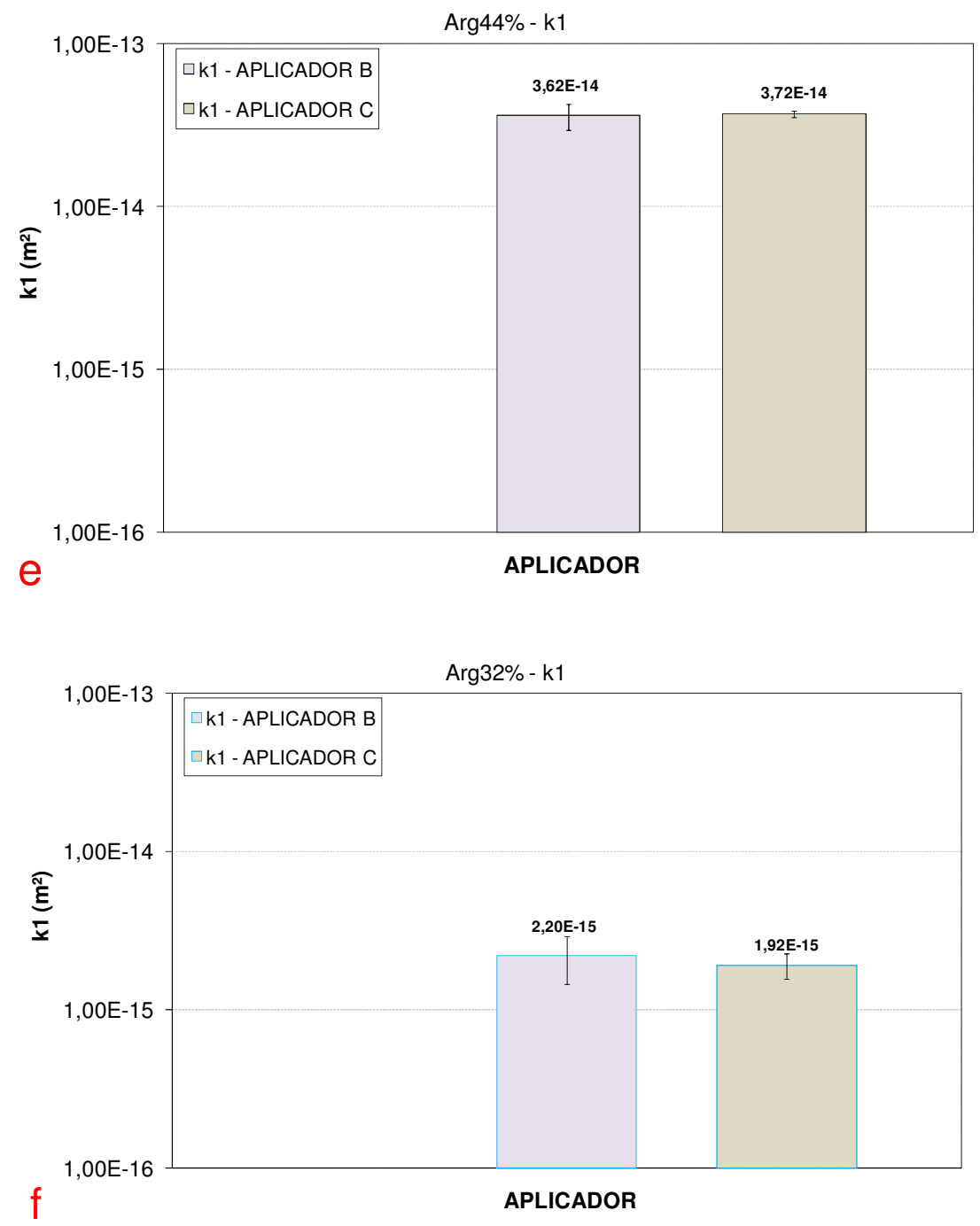

Figura 5.21 - Valores de k1, calculados a partir do método de Cembureau, representados graficamente com suas respectivas barras de erro.

Os valores de $\mathrm{k} 1$ medidos através do método de Cembureau para algumas das argamassas aplicadas em paredes ficaram bem abaixo de qualquer uma das regiões avaliadas in situ. Isto pode sinalizar que o ensaio, devido as suas características de configuração, pode estar restrito a uma camada superficial menor do que a considerada em cálculo. Isto é, os valores de espessura considerados para efeito de calculo podem estar superestimados em relação à realidade do fenômeno descrito pelo ensaio. 
Mais uma vez, pela análise de k1, não se evidencia diferenças significativas quanto ao uso da luz no período de "puxamento" pelo aplicador C nas argamassas $\operatorname{Arg} 40 \%$ e Arg38\%.

Analisando a variação do tipo de aplicador para características de microestrutura de revestimento de argamassa no estado endurecido, pode-se concluir que não existem diferenças perceptíveis quanto ao nível de regularidade frente ao padrão de permeabilidade para cada painel de argamassa. Isto é, todos os 3 pedreiros apresentaram dispersão de resultados para todas as argamassas aplicadas, mais em umas do que em outras, aleatoriamente. Portanto, esse pode ser mais um ponto de análise diferencial realizado através deste método de medida em um processo de produção padrão em grande escala, seja em obras de grande porte ou fabricação de peças de argamassa.

As permeabilidades das Arg29\% e 44\% estão próximas, em média, a curva de permeabilidades, para as diferentes espessuras, também ensaiadas em laboratório pela mesma técnica. As diferenças equivalentes aqui também podem ser causa da espessura definida como padrão para efeito de calculo de k1, o que pode não corresponder exatamente à realidade do fenômeno para os painéis ensaiados in situ. Mais uma vez, os valores de permeabilidade medidos através do método de Cembureau mostram-se menores, possivelmente também devido à idade dos $\mathrm{cp}$ 's avaliados, que determina mudanças significativas principalmente na estrutura da argamassa mais porosa (Arg44\%).

\subsection{CONCLUSÕES DO CAPÍTULO}

A determinação da permeabilidade através do método em desenvolvimento neste trabalho se constitui em um importante passo para o estudo desse tipo de insumo de propriedades e características tão particulares como é o caso de superfícies de argamassas de revestimento.

Das 6 formulações avaliadas, todas demonstraram diferentes níveis de permeabilidade tanto em função dos seus níveis de porosidade no estado endurecido quanto do tipo de falha, ou até mesmo da espessura de sua camada, 
demonstrada seja no mesmo bloco ou entre misturas. A dispersão de resultados aponta para variação existente em sistemas de revestimento dessa natureza, e não permite que, nesse caso, uma tendência comportamental direta possa ser identificada entre propriedades do material endurecido frente os padrões de permeabilidade das paredes avaliadas. Portanto, qualquer tipo de valor médio de permeabilidade não seria suficiente para expressar o comportamento de uma ou de outro painel para representar o comportamento de sua microestrutura como um todo devido às inúmeras diferenças presentes ao longo de todo o espécime (defeitos, falhas, fenômenos de superfície, efeitos deletérios, etc).

O mais importante é que a técnica demonstrada mostrou-se capaz de identificar detalhes desse tipo de material que vão desde diferenças de formulação, passando por detalhes de aplicação, até defeitos de microestrutura de superfície em paredes revestidas com o material. 


\section{CONCLUSÕES}

Esta pesquisa teve como escopo principal o desenvolvimento de uma técnica capaz de mapear a permeabilidade superficial de argamassas de revestimento através de um método simples, não destrutivo, de fácil implementação, rápida execução, barato, de execução tanto em ambiente laboratorial quanto em obra e que pudesse trazer informações fidedignas a respeitos das condições microestruturais do revestimento em toda a sua vida útil. Isso significa dizer que o uso de uma técnica desenvolvida para a avaliação da permeabilidade ao ar em qualquer outro tipo de material poroso talvez não fosse suficiente para atender todas as peculiaridades que esse tipo particular de material, como é o caso das argamassas, pudesse ter. Portanto, nesse caso, optou-se pela construção do método por inteiro, desde a concepção e adaptação do equipamento as características do material em questão, até o estudo da melhor forma de modelamento e tratamento dos dados obtidos no ensaio com o objetivo de expressar quantitativamente de forma real a susceptibilidade que cada tipo de argamassa possa ter ao transporte de massa do ambiente externo até o interior de revestimentos.

Portanto, a influência de fatores como a espessura do revestimento avaliado e caminho do fluxo de ar foram avaliados nesse estudo, com o objetivo de determinar qual o grau de controle desse tipo de variáveis na determinação da permeabilidade superficial ao ar através do método proposto. Através dos resultados, pode-se concluir que a influência da espessura do material e da direção do escoamento de ar esta relacionada tanto ao nível de porosidade avaliada quanto a configuração de ensaio realizada para a argamassa em questão. Isto é, diferentes níveis, distribuições e volume de poros podem determinar um comportamento particular para cada tipo de argamassa. Com o espaço amostral avaliado, não se pode chegar a nenhuma conclusão definitiva sobre esse tipo de influência na determinação da permeabilidade ao ar pelo método proposto.

Ensaios in situ comprovaram a potencialidade que o método tem de identificar características de cada tipo de formulação, além de mapear defeitos superficiais, prováveis incidência de fenômenos de modificação superficiais, variáveis de produção do estado fresco no estado endurecido, entre outras. 
Finalmente, é importante ressaltar o método como válido e capaz de identificar diferentes microestruturas de revestimentos de argamassa através de sua avaliação superficial de permeabilidade ao ar, seja de forma qualitativa ou quantitativa. São muitas as questões ainda que devem ser investigadas para o satisfatório desenvolvimento da técnica, entretanto, essa pesquisa foi capaz de identificar diversas das potencialidades que o procedimento tem de avaliar as condições em que a microestrutura superficiais de argamassas se encontra e quais as conseqüências desse tipo de informação para o seu uso e serviço ao longo de sua vida útil.

\subsection{SUGESTÕES PARA FUTUROS TRABALHOS}

- Uma gama maior de resultados, com argamassas mais e menos porosas do que as avaliadas no Capítulo 4, podem corroborar os resultados obtidos nessa dissertação e permitir a determinação de um padrão de comportamento modelável em função do nível de vazios interconectáveis de cada mistura;

- A avaliação periódica de revestimentos ao longo do tempo, desde o seu endurecimento até o fim do seu ganho de resistência, por exemplo, pode dar um volume de informações necessárias ao entendimento de questões que ainda não foram completamente respondidas nessa dissertação como o comportamento não linear das permeabilidades em relação à porosidade das argamassas, relação entre os valores obtidos em laboratório, relação com os valores de referência (Cembureau), etc.

- Análises microestruturais detalhadas, com a quantificação de reações de modificação de estrutura e análises microscópicas, associados aos ensaios de permeabilidade, podem dar subsídios necessários para o entendimento de questões levantadas na análise dos resultados das paredes ensaiadas nessa dissertação.

- Análise da relação entre os valores de permeabilidade ao ar com diferentes tipos de acabamento superficial;

- Avaliação do uso de adições na formulação de argamassas relacionadas a permeabilidade; 
- Avaliação de diferentes configurações de ensaio, associados a variações na potência de bomba com relação ao alcance do ensaio ao longo da profundidade do revestimento.

- Parametrização do ensaio em campo;

- Influência da espessura do revestimento na parede para determinação da permeabilidade pelo método. 


\section{REFERÊNCIAS}

ABBAS, A.; CARCASSES, M.; OLLIVIER, J.-P. Gas permeability of concrete in relation to its degree of saturation. Mater. Struct. 32, 3-8, 1999.

ACI Committee 201. Guide to durable concrete. ACI Technical Documents (2008), 49p.

AMERICAN SOCIETY FOR TESTING AND MATERIALS. Standard Test Method for Advanced Ceramic Specific Surface Area by Physical Adsorption. ASTM C 1274-00, 2006.

AMERICAN SOCIETY FOR TESTING AND MATERIALS. Standard test method for electrical indication of concrete's ability to resist chloride ion penetration. ASTM C 1202-10, 2007.

AMERICAN SOCIETY FOR TESTING AND MATERIALS. Standard Test Method for Splitting Tensile Strength of Cylindrical Concrete Specimens. ASTM C 49696, 1996.

ASSOCIAÇÃO BRASILEIRA DE NORMAS TÉCNICAS, NBR 9779. Argamassas e concreto endurecidos - determinação da absorção de água por capilaridade. Rio de Janeiro, 1995.

ASSOCIAÇÃO BRASILEIRA DE NORMAS TÉCNICAS, NBR 13278. Argamassa para Assentamento em Paredes e Revestimentos de Paredes e Tetos Determinação da Densidade de Massa e do Teor de Ar Incorporado - Método de Ensaio. Rio de Janeiro, 1995.

ASSOCIAÇÃO BRASILEIRA DE NORMAS TÉCNICAS, NBR 13749. Revestimentos de paredes e tetos em argamassas inorgânicas especificação. Rio de Janeiro, 1996.

BAÍA, L. L. M.; SABBATINI, F. H. Projeto e execução de revestimentos de argamassa. Ed. O nome da rosa, São Paulo, 2000, 88p.

BENTZ, D.P., CLIFTON, J.R., FERRARIS, C.F., GARBOCZI, E.J. Transport Properties and Durability of Concrete: Literature Review and Research Plan. NISTIR 6395, U.S. Department of Commerce, 1999.

CABRERA, J. G., CUSENS, A. R., LYNSDALE, C.J. Porosity and Permeability as Indicators of Concrete Performance. Durability of Structures, International Association for Bridge and Structural Engineering, IABSE Sysmposium, Lisbon, 1989. 
CALLISTER, W. D. Ciências e engenharia de materiais: uma introdução. 5. ed. Rio de Janeiro: Livros Técnicos e Científicos, 2002. 589 p.

CALOGOVIC, V. Gas permeability measurement of porous materials (concrete) by time-variable pressure difference method. Cement and Concrete Research, 25 [5] $1054-1062$ (1995).

CARDOSO, F. A.; AKIYOSHI, M. M.; INNOCENTINI, M. D. M.; PANDOLFELLI, V. C. Effect of curing time on the properties of CAC bonded refractory castables. J. Eur. Ceram. Soc. 24, 7 2073-2078 (2003) 2073-2078.

CARDOSO, F. A.; INNOCENTINI, M. D. M.; AKIYOSHI, M. M.; PANDOLFELLI, V. C. Effect of Curing Conditions on the Properties of Ultra-low Cement Refractory Castables. Refractories Applications and News vol. 9, n. 2, pp. 12-16, 2004.

CARDOSO, F. A. MÉTOdO DE FORMULAÇÃO DE ARGAMASSAS DE REVESTIMENTO BASEADO EM DISTRIBUIÇÃO GRANULOMÉTRICA E COMPORTAMENTO REOLÓGICO. São Paulo, 2009. 138p. Tese apresentada Escola Politécnica, Universidade de São Paulo.

CARDOSO, F.A. ; CAMPORA, F. L. ; PILEGGI, R. G. ; JOHN, V. M. Aplicabilidade de argamassas de revestimento: avaliação empírica e comportamento reológico por squeeze-flow. 3o Congresso Português de Argamassas de Construção. Lisboa, APFAC, 2010.

CASCUDO, O. O controle da corrosão de armaduras em concreto: inspeção e técnicas eletroquímicas. São Paulo: PINI, 237 p. (1997).

CASTRO, A. L. de, PANDOLFELLI, V. C. Revisão: conceitos de dispersão e empacotamento de partículas para a produção de concretos especiais aplicados na construção civil. Ver. Cerâmica. 2009, vol.55, n.333, pp. 18-32.

CLAISSE, P. A.; GANJIAN, E., ADHAM, T. A vacuum-air permeability test for insitu assessment of cover concrete. Cement and Concrete Research, 2003, 33, No. 1, 47-53.

COMITÉ EURO-INTERNATIONAL DU BÉTON . CEB - FIP model code 90. Bulletin d'Information. N. 203. 1990. Cap 1-3.

DHIR, R. K.; HEWLETT, P. C.; BYARS, E. A.; SHAABAN, I. G. A new technique for measuring the air permeability of near surface concrete. Magazine of Concrete Research, 1995, pp. 167- 1GILES, R. V.; EVETT, J. B.; LIU, C. Fluid Mechanics and Hydraulics. Ed. McGraw-Hill Book Company, New York, 1994.

DIAS, L. A.; CARASEK, H. Avaliação da permeabilidade e da absorção de água de revestimentos de argamassa pelo método do cachimbo. In: V SBTA Simpósio Brasileiro de Tecnologia de Argamassas. São Paulo: SBTA, 2003, pp. 543555. 
EBENSPERGER, L.; TORRENT, R. Medición "in situ" de la Permeabilidad al Airedel Hormigón: Status Quo. Proceeding Conpat. Valparaíso, Chile, 2009.

FIGG, J. W. Methods of measuring the air and water permeability of concrete. Mag. Concr. Res. 25(85) (1973) 213-219.

GARBOCZI, E.J., BENTZ, D.P. Percolation aspects of cement paste and concrete - properties and durability. American Concrete Institute Spring Convention, Chicago, 1999, 147-164.

GUTH, D. L.; ZIA, P. Evaluation of new air permeability test device for concrete. ACl Mater J 98 (1) (2001), pp. 44-51.

HANSEN, A. J.; OTTOSEN, N. S.; PETERSEN, C. G. Gas-permeability of concrete in situ: theory and practice. ACI SP-82 (1984) pp. 543-556.

HELENE, P.R.L. Contribuição ao estudo da corrosão em armaduras de concreto armado. São Paulo, 1993. 231p. Tese (Livre Docência). Escola Politécnica, Universidade de São Paulo.

HILSDORF, H. K. Durability of concrete - a measurable quantity? Proceedings of IABSE Symposium, Lisboa, Vol. 1, pp. 111-113, 1989.

INNOCENTINI, M. D. M; LEFEBVRE, L. P.; MELONI, R. V.; BARIL, E. Influence of sample thickness and measurement set-up on the experimental evaluation of permeability of metallic foams. Journal of Porous Materials, Volume 17, Number 4, August 2010 , pp. 491-499(9).

INNOCENTINI, M. D. M.; PANDOLFELLI, V. C. Considerações sobre a estimativa da permeabilidade em concretos refratários através das equações de Darcy e de Forchheimer. Rev. Cerâmica, vol.45, n.292-293, pp. 61-67, 1999.

INNOCENTINI, M. D. M.; PARDO, A. R. F.; PANDOLFELLI, V. C. Modified pressure-decay technique for evaluating the permeability of highly-dense refractories. Journal of the Aamerican Ceramic Society, 83 [1], pp. 220-222, 2000.

INNOCENTINI, M. D. M., PILEGGI, R. G., RAMAL JUNIOR, F. T., PANDOLFELLI, V. C. Permeability and drying behavior of PSD-designed refractory castables, Am. Ceram. Soc. Bull. 82, 7 (2003) 9401-9406.

INNOCENTINI, M. D. M.; PILEGGI , R. G.; RAMAL JUNIOR, F. T.; PARDO, A. R. F.; PANDOLFELLI, V. C.; BITTENCOURT, L. R. Relação entre permeabilidade e a velocidade de secagem em concretos refratários de alta alumina. Cerâmica [online]. 2002, vol.48, n.307, pp. 131-136.

INNOCENTINI, M. D. M.; SEPULVEDA, P.; ORTEGA, F. Permeability of Cellular Ceramics: Structure, Manufacturing, Properties and Applications. Wiley- $\mathrm{VCH}$, Weinheim - Germany (2005) 313. 
KALIFA, P.; MENNETEAU, F. D.; QUENARD, D. Spalling and Pore Pressure in HPC at High Temperatures. Cement and Concrete Research, $n^{\circ} 30$. Elsevier Science Ltd. Amsterdam, 2000.

KASSAI, Y.; MATSUI, I.; FUKUSHIMA, Y.; KAMOHARA, H. Air permeability and carbonation of blended cement mortars. ACI SP - 79,1983, pp.435 - 451.

KOLLEK, J. J. The determination of permeability of concrete by Cembureau method: a recommendation. Mater. Struct. 22 (1989) 225-230.

KROPP, J. Relations between transport characteristics and durability. In: J. Kropp and H.K. Hilsdorf, Editors, Performance Criteria for Concrete Durability, E\&F Spon, London (1995), pp. 97-137.

LOOSVELDT, H.; LAFHAJ, Z.; SKOCZYLAS, F. Experimental study of gas and liquid permeability of a mortar. Cement and Concrete Research 32 (2002), pp. 1357-1363.

MACIEL, L.; BARROS, M. S. B.; SABBATINI, F. H. Recomendações para a execução de revestimentos de argamassa para paredes de vedação internas e exteriores e tetos. São Paulo, EPUSP-PCC, 1998. (Projeto EPUSP/SENAI.)

MALKIN, A. Y. Fundamental topics in rheology: Rheology Fundamentals. Ontario: ChemTec Publishing, 1994.

MARTYS, N. S.; FERRARIS, C. F. Capillary transport in mortars and concrete. Cement and Concrete Research, 27 (5), pp. 747-760, 1997.

MEHTA, P. K.; MONTEIRO, P. J. M. Concreto - Estrutura, Propriedades e Materiais. $1^{\underline{a}}$ ed., Ed. PINI, São Paulo, Brasil, 1994, 573 p.

MONLOUIS-BONNAIRE, J. P.; VERDIER, J.; PERRIN, B. Prediction of the relative permeability to gas flow of cement based materials. Cement Concrete Res. 34,737-744, 2004.

MONTE, R.; ALMEIDA, V.; KUDO, E. K.; BARROS, M. M. S. B.; JOHN, V. M. Módulo de elasticidade dinâmico: comparação entre a velocidade da onda ultrassônica e freqüência ressonante. In: anais eletrônicos do VII Simpósio Brasileiro de Tecnologia de Argamassas (VII SBTA), Recife (2007).

MOREIRA, H. P.; FIGUEIREDO, E. P.; HELENE, P. R. L. Avaliação da influência de alguns agentes agressivos na resistência à compressão de concretos amassados com diferentes tipos de cimentos brasileiros. Boletim Técnico da Escola Politécnica da USP, São Paulo, 2001. 16p.

OLIVEIRA, I. R.; STUDART, A. R.; PILEGGI, R. G.; PANDOLFELLI, V. C. Dispersão e Empacotamento de Partículas - Princípios e Aplicações em Processamento Cerâmico, Fazendo Arte Editorial, S. Paulo (2000). 
PAGE, C. L.; SHORT, N. R.; EL TARRAS, A. Diffusion of Chloride lons in Hardened Cement Pastes. Cement and Concrete Research, Vol. 11 (3), 395-406, 1981.

PARROT, L.J.; HONG, C.Z. Some factors influencing air perrneation measurements in cover concrete. Materials and Structures, 1991, pp 403 - 408.

PAULMANN, K.; MOLIN, C. On-site test methods. In: J. Kropp and H.K. Hilsdorf, Editors, Performance Criteria for Concrete Durability, E\&F Spon, London (1995), pp. 97-137.

PICANDET, V.; KHELIDJ, A.; BELLEGOU, H. Crack effects on gas and water permeability of concretes, Cem. Concr. Res. 39 (6) (2009), pp. 537-547.

QUARCIONI, V. A.; CHOTIOLI, F. F.; ÂNGULO, S. C.; GUILGE, M. S.; CAVANI, G. R.; CASTRO, A. L. CINCOTTO, M. A. Estimativa da porosidade de argamassas de cimento e cal pelo método de cálculo de volumes. Ambiente construído, Porto Alegre. 2009, v. 9, n. 4, p. 175-187.

QUARCIONI, V. A.; CINCOTTO, M. A.; CARDOSO, F. A.; GUILGE, M. S.; INNOCENTINI, M. D. M. Aplicação do método de ensaio de permeabilidade ao ar em argamassas moldadas em laboratório. Anais eletrônicos do VII Simpósio Brasileiro de Tecnologia de Argamassas (VII SBTA), Recife (2007).

REINHARDT, H. W.; MIJNSBERGEN, J. P. G. In-situ measurement of permeability of concrete cover by overpressure. The Life of Structures. Physical Testing (Butterworth, London, 1989) pp. 243-254.

RILEM TC116-PCD. Final report: concrete durability-an approach towards performance testing. Mater. Struct. 32217 (1999), pp. 163-173.

ROMER, M. Effect of moisture and concrete composition on the Torrent permeability measurement. Mater. Struct. 38 (2005) 541-547.

SALVINI, V. R., INOCENTINNI, M. D. M., PANDOLFELLI, V. C. Correlação entre permeabilidade e resistência mecânica de filtros cerâmicos no sistema Al2O3SiC. Cerâmica, Jun 2000, vol.46, no.298, p.97-103.

SANJUAN, M.A; MUNOS-MARTIALAY, R. Modelling of the concrete air permeability evolution over time. Materials Letters 27(4-5), (1996), 269-272.

SATO, N.M.N. Análise da porosidade e de propriedades de transporte de massa em concreto. Tese de Doutorado. Escola Politécnica da Universidade de São Paulo. São Paulo, 1998. 163p.

SAVASTANO Jr, H. Desenvolvimento de tecnologia para fabricação de telhas de fibrocimento sem amianto. Projeto FAPESP PITE 01/03833-6. São Paulo. 20012004. 
SCHEIDEGGER, A.E. The Physics of Flow through Porous Media, University of Toronto Press, Toronto (1974).

SCHÖLIN, K., HILSDORF, H. K. Evaluation of the effectiveness of curing of concrete structures. ACI SP-100, Vol. 1 (1987) pp. 207-226.

SIA 262 (2003), Swiss Standard: “Concrete Construction”, part of Swiss structural codes.

STORMONT, J.C. In situ gas permeability measurements to delineate damage in rock salt. Int. J. Rock Mech. Min. Sci. Geomech. Abstr. 34: 1055-1064, 1997.

SUGIYAMA, T.; BREMNER, T.W.; HOLM, T.A. Effect of stress on gas permeability in concrete. ACI Mater. J. 935 (1996), pp. 443-450.

TAYLOR, H. F. W. Cement Chemistry. Academic Press, London, 1990.

TORRENT, R. J. A two-chamber vacuum cell for measuring the coefficient of permeability to air of the concrete cover on site, Mater Struct. 25 (1992) 358365.

TORRENT, R. J.; FRENZER G. Methods for measuring and assessing the characteristics of the concrete cover on site. Report $N^{\circ} 516$, Office Fédéral des Routes, Zürich, 1995.

TORRENT, R. J. Modelling air flow and derivation of formula to calculate kT. Materials Advanced Services Ltd., 8p. Buenos Aires, 2009.

VALÉK, J.; HUGHES, J.J.; BARTOS, P.J.M. Portable probe gas permeability: a non-destructive test for the in-situ characterisation of historic masonry. Mater Struct. 33 (2000) 194-197.

VAN BRAKEL, J.; MODRY, S.; STAVA, M. Mercury Porosimetry: State of the Art. Powder Technology 1981; 29: 1-12. 